UNIVERSIDAD DE SALAMANCA

FACULTAD DE DERECHO

DEPARTAMENTO DE DERECHO DEL TRABAJO

Y TRABAJO SOCIAL

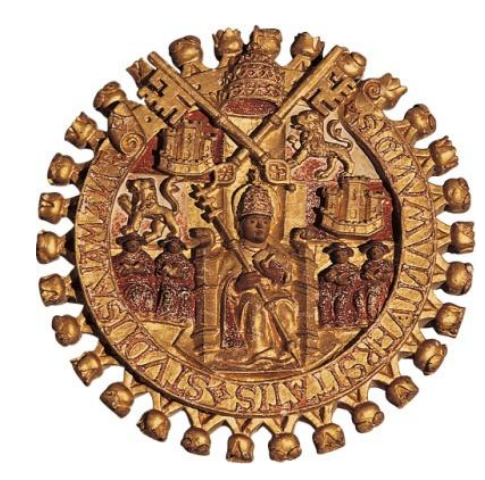

TESIS DOCTORAL

LA IGUALDAD ENTRE HOMBRES Y MUJERES

EN EL EMPLEO PÚBLICO LABORAL

GLORIA APARICIO GARCÍA-RISCO 


\author{
UNIVERSIDAD DE SALAMANCA \\ FACULTAD DE DERECHO \\ DEPARTAMENTO DE DERECHO DEL TRABAJO \\ Y TRABAJO SOCIAL
}

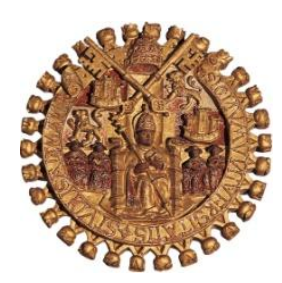

\title{
LA IGUALDAD ENTRE HOMBRES Y MUJERES EN EL EMPLEO PÚBLICO LABORAL
}

Doctoranda: Gloria Aparicio García-Risco

Tesis doctoral dirigida por el Dr. D. Enrique Cabero Morán, presentada en la Facultad de Derecho, Universidad de Salamanca.

$\mathrm{V}^{\mathrm{o}} \mathrm{B}^{\mathrm{o}}$

El Director de la Tesis

La Doctoranda

Fdo.: Enrique Cabero Morán

Fdo.: Gloria Aparicio García-Risco 


\title{
LA IGUALDAD ENTRE HOMBRES Y MUJERES EN EL EMPLEO PÚBLICO LABORAL
}

\author{
GLORIA APARICIO GARCÍA-RISCO
}

\author{
DIRECTOR
}

DR. ENRIQUE CABERO MORÁN

UNIVERSIDAD DE SALAMANCA SALAMANCA MMXIV 


\section{INDICE}

\section{LA IGUALDAD ENTRE HOMBRES Y MUJERES EN EL EMPLEO PÚBLICO LABORAL}

I- INTRODUCCIÓN.

II- GÉNESIS Y TRANSFORMACIONES DEL CONCEPTO DE IGUALDAD.

1. PERSPECTIVA HISTÓRICA Y FILOSÓFICA. ORIENTACIONES BÁSICAS.

1.1. DE LA ANTIGÜEDAD A LA EDAD MODERNA. TOMA DE CONCIENCIA.

1.2. EL PERIODO REVOLUCIONARIO. RECHAZO A LAS TRADICIONES Y PRIMERAS REIVINDICACIONES.

1.3. EL SIGLO XIX. EL ORIGEN DE LOS MOVIMIENTOS FEMINISTAS.

1.4. EL SIGLO XX. LO PRIVADO ES POLÍTICO.

2. PERSPECTIVA SOCIOLÓGICA Y CULTURAL.

2.1. LA RELACIÓN ENTRE SEXO Y GÉNERO.

2.2. LA DIVISIÓN SEXUAL DEL TRABAJO.

2.3. SITUACIÓN ACTUAL.

2.4. OTRAS DIFICULTADES.

2.5. MOVIMIENTOS SOCIALES. 
III-LA IGUALDAD COMO VALOR SUPERIOR DEL ORDENAMIENTO JURÍDICO.

IV-LA IGUALDAD COMO PRINCIPIO.

1. IGUALDAD ANTE LA LEY.

1.1. LA IGUALDAD EN LA LEY.

1.2. LA IGUALDAD EN LA APLICACIÓN DE LA LEY.

2. PROHIBICIÓN DE DISCRIMINACIÓN.

3. LA CLÁUSULA DEL ARTÍCULO 9.2 DE LA CONSTITUCIÓN ESPAÑOLA.

4. IGUALDAD DE GÉNERO.

V- LA IGUALDAD COMO DERECHO.

VI-REGULACIÓN NORMATIVA DE LA IGUALDAD ENTRE HOMBRES Y MUJERES: DESCRIPCIÓN, COMENTARIO, ANÁLISIS Y PROPUESTAS.

1. ÁMBITO INTERNACIONAL.

2. DERECHO DE LA UNIÓN EUROPEA.

2.1. DERECHO ORIGINARIO.

2.2. DERECHO DERIVADO.

2.3. DESARROLLO JURISPRUDENCIAL. 
3. LEGISLACIÓN ESPAÑOLA.

3.1. LEgislación ESTAtAl. La LEY ORGÁNiCA 3/2007 DE 22 DE MARZO PARA LA IGUALDAD EFECTIVA DE MUJERES Y HOMBRES.

3.2. LEGISLACIÓN AUTONÓMICA.

VII- DIFERENTES ASPECTOS DE LA IGUALDAD ENTRE HOMBRES Y MUJERES EN EL ÁMBITO DEL EMPLEO PÚBLICO LABORAL.

1. CUESTIONES PREVIAS: EVOLUCIÓN HISTÓRICA DEL RÉGIMEN JURÍDICO APLICABLE A LOS EMPLEADOS PÚBLICOS.

1.1. LA REFORMA ORGANIZATIVA DE LÓPEZ BALLESTEROS.

1.2. Bravo Murillo y el poder político de LA BUROCRACIA.

1.3. El estatuto de Maura.

1.4. REFORMAS BUROCRÁTICAS POSTERIORES AL ESTATUTO DE MAURA.

1.5. LA LEY DE BASES DE FUNCIONARIOS CIVILES DEL ESTADO.

1.6. LA CONSTITUCIÓN ESPAÑOLA DE 1978 Y SU PRIMER DESARROLLO NORMATIVO EN MATERIA DE FUNCIÓN PÚBLICA.

1.7. LA LEY $7 / 2007$ DE 12 DE ABRIL DEL ESTATUTO BÁSICO DEL EMPLEADO PÚBLICO. 
2. IGUALDAD EN EL ACCESO AL EMPLEO PÚBLICO.

2.1. Principios Constitucionales de acceso al EMPLeO PÚBLICO. EXTENSIÓN AL PERSONAL LABORAL DE LA ADMINISTRACIÓN PÚBLICA.

2.2. REQUisitos DE ACCESO AL EMPLEO PÚBLICO.

2.3. IGUALDAD EN LA PLANIFICACIÓN DE LOS RECURSOS HUMANOS.

2.4. CONVOCATORIAS DE LOS PROCESOS SELECTIVOS.

2.5. IGUALDAD EN LOS PROCESOS SELECTIVOS.

3. CONDICIONES DE TRABAJO. IGUALDAD DENTRO DE LA RELACIÓN LABORAL DE EMPLEO PÚBLICO.

3.1. Modalidades de CONTRATACión LABORAL DESDE LA PERSPECTIVA DE LA IGUALDAD DE GÉNERO.

3.2. IGUALDAD DE DERECHOS.

3.3. IgUaLdAD DE OBLIGACIONES. CÓdigo DE CONDUCTA.

VIII- LA NEGOCIACIÓN COLECTIVA AL SERVICIO DE LA IGUALDAD ENTRE HOMBRES Y MUJERES. MEDIDAS DE ACCIÓN POSITIVA Y PLANES DE IGUALDAD.

1. LAS MEDIDAS DE IGUALDAD: ACCIONES POSITIVAS. 
2. LOS PLANES DE IGUALDAD.

2.1. Plan De igualdad. Concepto y Fases De ELABORACIÓN.

2.2. Plan ESTRATÉGico DE IGUALDAD DE OPORTUNIDADES.

2.3. Plan DE IGUALDAD DE OPORTUNidADES ENTRE HOMBRES Y MUJERES DE CASTILLA Y LEÓN.

2.4. PlanES DE IGUALDAD EN LA ADMINISTRACIÓN LOCAL. EL PLAN DE IGUALDAD DE LA DIPUTACIÓN DE SALAMANCA.

2. OTROS INSTRUMENTOS.

IX-RETOS Y PERSPECTIVAS DE FUTURO: EL TELETRABAJO.

1. CAMBIOS TECNOLÓGICOS E IGUALDAD DE GÉNERO.

2. DEL TRABAJO A DOMICILIO AL TELETRABAJO. EVOLUCIÓN Y RÉGIMEN JURÍDICO.

3. CONCEPTO Y CARACTERÍSTICAS DEL TELETRABAJO.

3.1. ELEMENTO ESPACIAL.

3.2. ELEMENTO InStRUMENTAL. LAS TECNOLOGÍAS DE LA INFORMACIÓN Y LAS COMUNICACIONES.

3.3. ELEMENTO ORGANIZATIVO. 
4. VENTAJAS E INCONVENIENTES DEL TELETRABAJO.

4.1. CARACTERÍsticas DE LA PERSONA QUE TELETRABAja.

4.2. CARACTERÍSTICAS DEL ENTORNO LABORAL.

4.3. CARACTERÍSTICAS DEL ENTORNO FAMILIAR.

5. OTRAS CUESTIONES RELACIONADAS CON EL TELETRABAJO.

6. EJEMPLO DE PROYECTO PILOTO DE TELETRABAJO EN LA ADMINISTRACIÓN LOCAL.

$\mathrm{X}$ - CONCLUSIONES.

BIBLIOGRAFÍA

COLECCIONES Y REVISTAS

JURISPRUDENCIA 


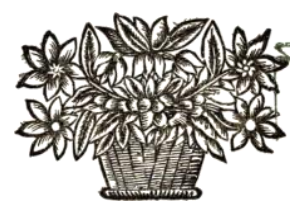




\section{I- INTRODUCCIÓN.}

El prejuicio sobre la inferioridad innata de las mujeres es uno de los más antiguos y arraigados en el mundo. A pesar de ello, no siempre la cuestión de la igualdad entre hombres y mujeres ha suscitado el mismo interés. Ha habido periodos caracterizados por ser objeto de encendidas discusiones filosóficas y otros en los que este debate se ha aletargado. Afrontar el estudio de la legislación y de las políticas públicas que se han puesto en marcha para lograr que la igualdad entre hombres y mujeres sea real y efectiva requería conocer previamente la historia de las mujeres, comprender las dificultades personales, económicas, sociales o políticas con las que tuvieron que enfrentarse para que hoy en día la mayoría podamos disfrutar de una vida propia con independencia de cuál sea nuestro sexo. Con este fin se han apuntado las reflexiones más destacadas de autoras como Cristina de Pizán, Olympe de Gouges, Mary Wollstonecraft, Simone de Beauvoir o Judith Butler, y de algunos hombres como Poullain de la Barre, Condorcet, John Stuart Mill o Pierre Bourdieu, en defensa de la emancipación femenina. La teoría feminista ha sido determinante a la hora de tomar conciencia del problema de la subordinación de las mujeres con respecto al hombre, y ha desencadenado el inicio de una de las 
corrientes sociales más reivindicativas de la historia: el movimiento feminista. Gracias a él ha sido posible que las mujeres reaccionaran solidariamente en contra de unas tradiciones y unas leyes que las anulaban como personas, al mismo tiempo que situaba los problemas derivados de la discriminación por razón de sexo dentro de la agenda política. De forma paralela, a través del análisis del concepto de género, de los mecanismos por los que se construye y cuál ha sido su influencia en la división sexual del trabajo, la Sociología también ha contribuido al esclarecimiento de las causas por las que aún hoy siguen existiendo desigualdades entre hombres y mujeres.

Este breve análisis de cuestiones históricas, filosóficas y sociológicas relacionadas con la igualdad entre hombres y mujeres se ha realizado con todas las limitaciones propias de quien se ha aproximado, fuera del campo de su especialidad, a unas disciplinas de evidente complejidad. Sin embargo, para poder entender qué es lo que nos ha llevado hasta la situación actual, por qué se han aprobado las leyes en defensa de la igualdad entre hombres y mujeres, no hay que perder de vista la perspectiva que nos ofrecen estas ciencias. En caso contrario podemos tender a infravalorar los logros alcanzados, o no percatarnos de los obstáculos que han tenido que superar mujeres de todos los tiempos para la defensa de sus derechos, de nuestros derechos. Se trata de hacer justicia a los esfuerzos de las generaciones que nos han precedido y de entender que las normas se han aprobado por motivos que 
hunden sus raíces en otros ámbitos del conocimiento conectados con el Derecho, como la Historia, la Filosofía o la Sociología.

La posición subordinada de la mujer en la sociedad, situando su existencia siempre en función de otros (del padre, del marido, de los hijos), y siempre dentro del espacio doméstico, ha empezado a cambiar de modo cualitativo sobre todo a partir de la segunda mitad del siglo Xx. La Constitución Española de 1978, con el único antecedente de la Constitución de la Segunda República, sienta las bases de un nuevo modelo jurídico y social de las relaciones entre los sexos. La mujer aparece por primera vez en la historia de nuestro constitucionalismo como sujeto de derecho en posición de igualdad con el hombre, a excepción de la sucesión en la Corona, en la que dentro del mismo grado sigue siendo preferido el varón a la mujer. El esquema argumental seguido se inicia con la referencia a los aspectos genéricos de la igualdad contenidos en el artículo 1.1 CE, el artículo 14 CE y el artículo 9.2 CE. La igualdad como valor superior del ordenamiento jurídico es el ideal al que toda sociedad aspira. Es también la lógica ética de un país que luego se plasma en las normas jurídicas que se aprueban por los poderes públicos y que sirve de guía a los jueces y tribunales en su interpretación y aplicación. Este valor se concreta en el principio de igualdad y se realiza a través del ejercicio del derecho a la igualdad. Como se verá, la jurisprudencia del Tribunal Constitucional ha contribuido a precisar estos conceptos. A través de su análisis queda reflejada la 
complementariedad entre la igualdad formal o de iure, y la igualdad material o de facto, que caracteriza al Estado social. De manera que para que todas las normas vigentes en materia de igualdad tengan relevancia práctica en la vida diaria de las personas, es necesaria una acción decidida por parte de los poderes públicos encaminada a remover todas aquellas formas de discriminación que subsistan tras su aprobación, que impidan o sigan dificultando la realización efectiva de la igualdad entre hombres y mujeres. Por tanto no basta con tomar conciencia, con comprender las causas de la discriminación, con aprobar leyes que la neutralicen. Si las desigualdades permanecen vigentes es porque hay otros motivos que escapan a nuestro conocimiento. La labor de la sociedad y de los poderes públicos es no dejar de trabajar para acabar con situaciones que atentan contra la dignidad de las personas y que, en definitiva, constituyen un peligro para la paz social.

Tras ello se pondrá de manifiesto la evolución que ha experimentado el reconocimiento jurídico de la igualdad entre hombres y mujeres en el empleo público, mediante la descripción de la normativa aprobada a nivel europeo y nacional, y la jurisprudencia del Tribunal de Justicia de la Unión Europea. Posteriormente se estudian los diferentes aspectos de la igualdad entre hombres y mujeres en el empleo público, empezando por un análisis detallado del régimen jurídico funcionarial desde el Estatuto de López Ballesteros hasta el Estatuto Básico del Empleado Público, y continuando con un examen del concepto 
amplio de acceso al empleo público (comenzando con la aprobación de la oferta de empleo público, pasando por el desarrollo de los procedimientos selectivos, hasta llegar a la toma de posesión del correspondiente puesto de trabajo y al disfrute de los derechos encaminados a conciliar la vida personal con la familiar) desde la perspectiva de la igualdad entre hombres y mujeres. De lo que se trata, en definitiva, es de abordar la implicación de las Administraciones Públicas en el desarrollo efectivo de la igualdad de mujeres y hombres a la vista de la legislación surgida recientemente, especialmente la Ley Orgánica para la Igualdad Efectiva de Hombres y Mujeres. Y no sólo como sujetos pasivos que garantizan la aplicación de dichas leyes, sino también como sujetos activos que promueven a través de la negociación colectiva medidas de igualdad, como las acciones positivas, y planes de igualdad.

Finalmente se dedica un capítulo a las posibilidades que confiere el teletrabajo para lograr un cambio en la mentalidad organizativa de la Administración en aras a facilitar, no sólo su deseada modernización, sino también una forma de conciliar trabajo y familia dentro del tiempo de trabajo. A pesar de los inconvenientes asociados a esta forma de desarrollar el trabajo, se ha dedicado un apartado a la puesta en marcha de un proyecto de estas características en la Administración local, no sólo como forma de contribuir a visibilizar el potencial que tiene esta forma de prestación de los servicios públicos para mejorar la calidad de 
los mismos, sino también como forma de consolidar un sistema de empleo público más racional y que beneficie a todos los implicados: ciudadano, Administración y empleado público.

Nos encontramos en un momento en el que el sentimiento mayoritario es que ya no hay grandes motivos de discriminación que sean preocupantes, al menos en lo que al empleo público se refiere. ¿Nos podemos dar por satisfechos con lo que se ha conseguido hasta ahora? ¿Es imposible avanzar más en este terreno? ¿Para qué seguir hablando de la igualdad cuando, por otra parte, es un tema minusvalorado como objeto de investigación, al que se achaca frecuentemente falta de rigor científico? Por mi parte, he tratado de vencer este tipo de resistencias y contribuir a la superación de las connotaciones peyorativas que suelen ir aparejadas al adjetivo feminista, que suele predicarse de aquellas personas que decidimos suscitar este tipo de debates. Y es que si no se habla de este problema es como si realmente no existiera, aunque desde mi punto de vista lo que sucede es que no se perciben, se desconocen, o no se comprenden suficientemente las desigualdades aún subsistentes entre hombres y mujeres. Por eso decidí abordar la cuestión de la igualdad o desigualdad entre hombres y mujeres en el empleo público, con ánimo didáctico por un lado, ofreciendo una visión de conjunto de las disciplinas más importantes que han afrontado su estudio, pero también con espíritu crítico hacia la situación actual, incluyendo algunas propuestas para mejorarla. Ahora bien, crealmente es posible la 
igualdad entre hombres y mujeres bajo un sistema que se basa en la competición individual por el poder y la riqueza en todos los aspectos de la vida? La transformación de este sistema social en un sistema basado en la cooperación y en la justicia parece la única solución. Como se verá, tal cooperación ha de darse tanto en el espacio público como en el privado. 



\section{II- GÉNESIS Y TRANSFORMACIONES DEL CONCEPTO DE IGUALDAD.}

En este apartado se expondrá de manera orientativa la situación de la mujer occidental a lo largo de la historia, para hacer ver que lo que puede parecer inferioridad es realmente ausencia de igualdad. Se podrá comprobar que la desigualdad, y en su caso la discriminación entre los sexos, se apoya en diferencias construidas a lo largo del tiempo por los diferentes agentes que intervienen en la sociedad: Familia, Escuela, Estado. La referencia a algunos de los textos literarios y filosóficos más importantes en la materia, se hace para evidenciar cómo se toma conciencia del problema de la desigualdad, la posterior crítica y rechazo de unas tradiciones que hacen de las mujeres seres humanos dependientes de los hombres, y finalmente la reivindicación de los mismos derechos con independencia del sexo de las personas. También se incluirán las aportaciones de disciplinas más recientes como la sociología, que ayudarán a entender el problema de una forma más racional. Todo ello con el objetivo de comprender mejor y valorar adecuadamente los logros más importantes que se han alcanzado en materia de igualdad entre hombres y mujeres en el empleo público a partir del siglo $\mathrm{XX}$.

La normativa que se estudiará en epígrafes posteriores se ha aprobado porque previamente se ha desarrollado una labor de 
pensamiento crítico, sin la que no hubiera sido posible entender el por qué de la posición de subordinación de la mujer con respecto al hombre. Junto a la elaboración de las teorías críticas que explican y deslegitiman esta situación de dependencia, ha sido fundamental el desarrollo del movimiento feminista, que paulatinamente ha reivindicado derechos para las mujeres con el fin de redefinir la sociedad para que esta pueda ser considerada más justa. La teoría crítica es el motor de los movimientos sociales que a su vez reclaman a los poderes públicos la aprobación de leyes y la puesta en marcha de políticas públicas que permitan garantizar la igualdad entre hombres y mujeres, tanto desde el punto de vista formal como material.

Sin embargo, a pesar de los avances legislativos y de las políticas públicas implementadas, se siguen reproduciendo desigualdades a través de hábitos mentales, medidas jurídicas e instituciones sociales que están profundamente arraigadas en nuestra conciencia individual y colectiva. La sociología ha contribuido a explicar cómo se perpetúan las diferencias entre los sexos, por lo que es necesario no abandonar los estudios en esta materia, seguir cuestionándonos situaciones que pueden resultar ser, sólo en apariencia, normales, y reclamar una acción decidida de toda la sociedad para cambiarlas. Únicamente así se podrá seguir avanzando en la consecución del objetivo último, que es que la igualdad entre hombres y mujeres sea real y efectiva. 


\section{PERSPECTIVA HISTÓRICA Y FILOSÓFICA. ORIENTACIONES BÁSICAS.}

\subsection{DE LA ANTIGÜEDAD A LA EDAD MODERNA. TOMA DE CONCIENCIA.}

En la Antigüedad "a las mujeres se las representa antes de describirlas o hablar de ellas, y mucho antes de que ellas mismas hablen"". Las imágenes de las mujeres en las artes o en la literatura antigua son reflejo, con pocas excepciones, de la mirada masculina. Conocer los modelos femeninos en el mundo antiguo ${ }^{2}$, el pensamiento de Aristóteles sobre el género ${ }^{3}$, o cómo el derecho romano se fundaba íntegramente en la división de los $\operatorname{sexos}^{4}$, nos ayudará a emprender posteriormente lo que Pierre Bourdieu denominó, en $L a$ dominación masculina ${ }^{5}$, una labor de “deshistoricización”. Esta labor permitirá comprender que las diferencias entre los sexos y la relación de dominación de uno sobre otro no se basan en su naturaleza inmutable, sino que son producto de una construcción social elaborada y repetida a lo largo de siglos de historia.

${ }^{1}$ Duby, Georges y Michelle Perrot. Historia de las mujeres en Occidente. Taurus, Madrid, 2003, I, pág. 22.

${ }^{2}$ Loraux, Nicole. ¿Qué es una diosa?, en Duby, 2003, I, págs. 47-87.

3 Sissa, Giulia. Filosofias del género: Platón, Aristóteles y la diferencia sexual, en Duby, 2003, I, págs. 89-134.

4 Thomas, Yan. La división de los sexos en el derecho romano, en Duby, 2003, I, págs. 136-203.

${ }^{5}$ Bourdieu, Pierre. La dominación masculina. Anagrama, Barcelona, 2000. 
Durante la Edad Media se sigue imponiendo una visión de las mujeres cuya elaboración proviene principalmente del mundo religioso $^{6}$ y de la medicina ${ }^{7}$. Salvo algunos casos, como el de Isabel de Castilla, la ausencia (o la presencia minorada) de mujeres en los libros de historia demuestra que durante este periodo las mujeres son, en buena medida, silenciadas ${ }^{8}$. No es que no hubiera mujeres destacadas, sino que éstas tuvieron enormes dificultades para vivir y sobresalir en las tareas tradicionalmente reservadas a los hombres como el saber, la escritura o el poder político 9 . No obstante, hay algunos autores que hacen justicia a las mujeres y empiezan a hablar de ellas por la relevancia de sus hechos al margen o con independencia de su relación con los hombres. Tal es el caso de Boccaccio y su obra Mujeres preclaras $^{10}$, primer tratado sobre mujeres célebres en el que se defiende la moral de cada una de las figuras femeninas elegidas. En ella se inspirará posteriormente Don Álvaro de Luna al escribir el Libro de las

\footnotetext{
${ }^{6}$ Dalarun, Jacques. La mujer a ojos de los clérigos, en Duby, 2003, II, págs. 41-71.

${ }^{7}$ Thomasset, Claude. La naturaleza de la mujer, en Duby, 2003, II, págs. 72-104.

${ }^{8}$ Régnier-Bohler, Danielle. Voces literarias, voces místicas, en Duby, 2003, II, págs. 473-546.

${ }^{9}$ Morant, Isabel. Historia de las mujeres en España. Volumen I: De la Prebistoria a la Edad Media. Cátedra, Madrid, 2005, págs. 7-16. En este volumen podemos encontrar interesantes trabajos de investigación como el de Georges Martin sobre otras figuras femeninas como la reina Berenguela de Castilla, que también tuvieron poder e influencia durante la Edad Media [Berenguela de Castilla (12141246): en el espejo de la bistoriografía de su época, págs. 569-594]. Véase, de este mismo autor, Mujeres y poderes en la España medieval. Centro de Estudios Cervantinos, Alcalá de Henares, 2011.

${ }^{10}$ Boccaccio, Giovanni. Mujeres preclaras. Cátedra, Madrid, 2010.
} 
virtuosas e claras mugeres ${ }^{11}$, considerado el ejemplo más importante de la filoginia medieval castellana ${ }^{12}$.

A finales de la Edad Media las mujeres alzan la voz para rechazar unas tradiciones que defendían la subordinación y la inferioridad de su sexo. La palabra de las mujeres contra la visión negativa del alma y del cuerpo femenino impuesta por la mayoría de los hombres se refleja en el debate literario y filosófico conocido con el nombre de querelles des femmes. Uno de los mayores exponentes de este debate es la obra de Cristina de Pizán La ciudad de las damas ${ }^{13}$, en la que reflexiona sobre la condición femenina a través de tres figuras alegóricas: Razón, Rectitud y Justicia. La igualdad en la virtud es el razonamiento seguido para refutar la inferioridad femenina, argumento que también será empleado por Cornelio Agripa en el libro titulado De la nobleza y preexcelencia del sexo femenino ${ }^{14}$ para subrayar en este caso la preeminencia del sexo femenino sobre el masculino ${ }^{15}$.

\footnotetext{
${ }^{11}$ De Luna, Álvaro. Libro de las virtuosas e claras mugeres. Cátedra, Madrid, 2009.

12 Vélez Sainz, Julio. "De amor, de honor e de donas" Mujer e ideales corteses en la Castilla de Juan II (1406-1454). Editorial Complutense, Madrid, 2013, pág. 183.

${ }^{13}$ De Pizán, Cristina. La Ciudad de las Damas. Siruela, Madrid, 2000.

${ }^{14}$ Agripa, Enrique Cornelio. De la nobleza y preexcelencia del sexo femenino. Indigo, Barcelona, 1999.

${ }^{15}$ En este texto del siglo XVI se defiende la virtud femenina y la superioridad del sexo femenino sobre el masculino basándose en los ejemplos y testimonios que se extraen de las Santas Escrituras. Se examina la excelencia de la mujer a partir de una serie de hechos, como el lugar que le corresponde en el orden de la creación, el lugar mismo en el que ésta fue creada o la materia de su creación, que ponen de relieve que más que a la mujer terrenal, lo que se ensalza es la idea divina de lo que debe ser una mujer.
} 
Si el ejercicio de la virtud igualaba a hombres y mujeres, ¿de dónde venía la subordinación del sexo femenino? En el apartado primero del Libro I de La ciudad de las damas la autora se pregunta "cuáles podrían ser las razones que llevan a tantos hombres, clérigos y laicos, a vituperar a las mujeres". Toma conciencia de sí misma, examina su propio carácter y su propia conducta, así como la de otras mujeres, con el objetivo de comprobar si los hombres están en lo cierto cuando afirman que la mujer, "mala por esencia y naturaleza, siempre se inclina hacia el vicio". Lucha contra todos los pensamientos negativos que parecen sumirla en "estado de catalepsia", según sus propias palabras, y finalmente llega a la conclusión de que la idea de inferioridad innata de las mujeres en realidad tiene su origen en su inferior educación ${ }^{16}$.

Por la defensa de argumentos como el anterior, Cristina de Pizán es considerada una de las primeras feministas de la historia. A través una metáfora, - la ciudad que construye a modo de refugio de mujeres virtuosas-, empieza a construir también una identidad femenina al margen de las opiniones negativas que tenían la mayoría de los hombres sobre ellas. Impulsa a las mujeres a desconfiar de esas opiniones y a construir sus propias verdades

\footnotetext{
16 En el apartado XXVII del Libro I, contra el argumento misógino de la incapacidad intelectual de las mujeres, Razón le dice a Cristina de Pizán que "si la costumbre fuera mandar a las niñas a la escuela y enseñarles las ciencias con método, como se hace con los niños, aprenderían y entenderían las dificultades y sutilezas de todas las artes y ciencias tan bien como ellos".
} 
basadas en su experiencia personal como fuente de saber más segura.

Esta forma de pensar basada en la experimentación continua desarrollándose en el siglo XVII y queda reflejada, emblemáticamente, en el Discurso del método ${ }^{17}$ de René Descartes. En esta obra clave del pensamiento filosófico se cuestionaban los conocimientos que no resultaban compatibles con la regla de la evidencia, según la cual no se podía admitir una cosa como verdadera si no se la conocía evidentemente como tal. Para ello era necesario juzgar las cosas por uno mismo después de haberlas examinado detenidamente, y evitar remitimos directamente a la opinión de los demás a riesgo de caer en el prejuicio, en el error. Descartes atribuye al conocimiento que se adquiere en los libros un enorme valor práctico, ya que la calidad del razonamiento depende del conocimiento; sin embargo, "las ciencias de los libros, por lo menos aquellas cuyas razones son solo probables y carecen de demostraciones, habiéndose compuesto y aumentado poco a poco con las opiniones de varias personas diferentes, no son tan próximas a la verdad como los simples razonamientos que un hombre de buen sentido puede hacer, naturalmente, acerca de las cosas que se presentan"18.

${ }^{17}$ Descartes, René. Discurso del método. Ediciones Orbis, Barcelona, 1983.

${ }^{18}$ Descartes, 1983, pág. 54. 
Este argumento servirá de apoyo para que su discípulo François Poullain de la Barre proponga deslegitimar el discurso tradicional sobre la inferioridad de la mujeres con respecto al varón. Para Poullain de la Barre, el prejuicio relacionado con la desigualdad entre los sexos es el más obstinado y ancestral, por lo que si podemos refutarlo lo podremos hacer con todos los demás. Este filósofo del siglo XVII aplica las exigencias críticas derivadas del método cartesiano, pensadas inicialmente para las ciencias teóricas, a cuestiones que tienen que ver más con la ética y la moral de una sociedad, en nuestro caso la reforma de las costumbres que subordinan la mujer al varón. El debate sobre la igualdad de los sexos se utilizó para poner a prueba la viabilidad del programa de Descartes de someter todas nuestras creencias y convicciones a la regla de la evidencia, al contraste con las ideas claras y distintas ${ }^{19}$.

La regla de la evidencia lógica se convierte así en un criterio para cuestionar aquellos comportamientos que no se fundan en la razón ni pueden ser contrastados con el sentido común. Así sucede con el trato desigual que sufren las mujeres que, tal y como argumenta Poullain de la Barre en su obra De

19 Amorós, Celia. Teoría Feminista: de la Ilustración a la Globalización. Minerva, Madrid, 2005, Tomo I, pág. 110. 
l'excellence des hommes ${ }^{20}$, no tiene un fundamento natural sino que procede de un prejuicio cultural $^{21}$.

La obra de Poullain de la Barre no solo está influenciada por el cartesianismo, sino también por el movimiento de las preciosas. Se trata de un movimiento social y cultural de la primera mitad del siglo XVII que responde al deseo de elegancia $y$ refinamiento en los modales, las costumbres, los gustos sentidos por una parte de la sociedad parisina, especialmente por las mujeres de la aristocracia y la burguesía, que llevado al extremo resultó ridículo, tal y como se refleja en la obra de Molière Las Preciosas ridículas ${ }^{22}$. Las mujeres del siglo XVII fueron promotoras de las nuevas formas de saber, cuestionaban la autoridad marital, pedían acceso al mundo intelectual, apoyaban el desarrollo de la lengua francesa... A pesar de la denostación realizada por Molière no hay que restar importancia a la aportación que el mismo haya podido hacer en la superación del prejuicio consistente en denegar el acceso a la cultura, al saber y, en definitiva, a la educación, por parte de las mujeres.

\footnotetext{
${ }^{20}$ De la Barre, Poullain. De l'excellence des hommes contre l'égalité des sexes. Jean du Puis, Paris, 1675.

${ }^{21}$ Para este autor las causas de la desigualdad entre los sexos están ligadas al fin del estado naturaleza, en el que todos los hombres eran iguales, justos y sinceros, y solamente tenían por regla y por ley el bon sens. A partir del momento en que a algunos hombres, abusando de sus fuerzas y de su ocio, se les ocurrió someter a los demás, la libertad se trocó en servidumbre. Por tanto, si en el estado naturaleza no hay desigualdad, la desigualdad no tiene origen natural, por lo que carece de base racional y por ende de legitimidad.

${ }^{22}$ Molière. Les Précieuses ridicules. Gallimard, Paris, 1998.
} 
Desde finales del siglo XVII y hasta el comienzo de la Revolución Francesa, durante el periodo conocido con el nombre de la Ilustración, la instrucción de la población se empieza a considerar como un elemento imprescindible para el progreso de los seres humanos. En España fue el padre Feijoo uno de los primeros en propiciar el debate sobre el fomento de la educación femenina. De hecho tuvo una enorme resonancia que fuese precisamente un catedrático de teología el que, desde el humanismo cristiano, defendiese en su Teatro critico universal ${ }^{23}$ la necesidad del reconocimiento de la igualdad de los sexos ${ }^{24}$. Sin embargo, y pese al desarrollo de esta corriente crítica frente al discurso dominante sobre la condición de inferioridad femenina, la consideración de la capacidad femenina no varió sustancialmente de sus presupuestos iniciales. Se deseaba una mejor y mayor educación para las mujeres, pero para servir mejor al marido y a los hijos. Se trataba de que las mujeres fueran más útiles a la Familia y al Estado, no de valorar intrínsecamente su propia capacidad intelectual.

Los contenidos educativos desarrollados en la época se sustentaban en las convicciones de Rousseau reflejadas en el capítulo V del Emilio o De la educación ${ }^{25}$, en el que las costumbres y los hábitos de las mujeres son analizados por el filósofo como si

\footnotetext{
${ }^{23}$ Feijoo, Benito. Teatro crítico universal. Joaquín Ibarra, Madrid, 1778, Tomo I.

24 Ortega López, Margarita. Siglo XVIII: La Ilustración, en Garrido González, Elisa, directora. Historia de las mujeres en España. Síntesis, Madrid, 1997, pág. 384.

${ }^{25}$ Rousseau, Jean Jacques. Emilio o De la educación. Alianza, Madrid, 2007.
} 
fueran innatos, olvidando que desde que nacemos nuestros gustos están socialmente condicionados. En el caso de las niñas la educación, según los postulados de Rousseau, las dirigiría hacia la sumisión a la opinión pública, la obediencia al marido, la castidad, y el cuidado de los demás, haciéndolas ignorantes y dependientes, para después concluir que esa dependencia forma parte de su naturaleza. Pero la naturaleza de la que habla Rousseau es fruto, en realidad, de un modelo educativo con contenidos distintos para niñas y niños, y que se traduce en una situación de desigualdad entre mujeres y hombres en la edad adulta. Aunque, según su opinión, cuando la mujer se queja de la injusta desigualdad en que le ha puesto el hombre "se equivoca, esa desigualdad no es una institución humana, o al menos no es obra del prejuicio, sino de la razón" ${ }^{26}$. Aunque de forma contradictoria, al comienzo del Discurso sobre el origen y los fundamentos de la igualdad entre los hombres ${ }^{27}$ se pregunta: “¿cómo podría meditar sobre la igualdad que la naturaleza ha puesto entre los hombres y la desigualdad que ellos han instituido (...)?”28 , por lo que en este momento reconoce que la desigualdad la han instituido los hombres ${ }^{29}$.

\footnotetext{
${ }^{26}$ Rousseau, 2007, pág. 539.

${ }^{27}$ Rousseau, Jean-Jacques. Discurso sobre el origen y los fundamentos de la desigualdad entre los hombres y otros escritos. Tecnos, Madrid, 2010.

${ }^{28}$ Rousseau, 2010, pág. 96.

${ }^{29}$ En el mismo discurso queda muy clara cuál era la actitud de Rousseau hacia las mujeres. Al dirigirse a las mujeres de la República de Ginebra señala: “¿Podría olvidar yo esa preciosa mitad de la república que constituye el placer de la otra y cuya dulzura y sabiduría mantienen aquí la paz y las buenas costumbres? Amables y virtuosas ciudadanas, el destino de vuestro sexo será siempre gobernar al nuestro. ¿Qué dicha cuando vuestro casto poder, ejercido tan solo en la unión conyugal, sólo se hace sentir para la gloria del Estado y la dicha pública" [Rousseau, 2010, pág. 107]. Este es un ejemplo de los discursos
} 
La persistencia de actitudes tradicionales de dominación masculina durante la Revolución Francesa, por la que tantas cosas cambiaron para los hombres, puso en evidencia la situación de desigualdad en la que se encontraban las mujeres. La exclusión de las mujeres del ámbito de la ciudadanía, de los derechos civiles, políticos y sociales justo en el momento en el que las democracias occidentales comenzaban a desarrollarse hace que las mujeres se revelen contra su exclusión de la igualdad y la libertad proclamada por las primeras declaraciones de derechos. Las mujeres no quieren quedar al margen de la vida política y aún sin poseer la ciudadanía se expresan públicamente sobre la Revolución. La Revolución Francesa es el momento histórico del descubrimiento de que la mujer puede ocupar un lugar en la sociedad, lo que no significa, sin embargo, una concesión automática. Reconocer que las mujeres puedan llegar a ser sujetos activos de la Revolución, en pie de igualdad con los hombres, era una hipótesis intolerable para muchos hombres. Era más tranquilizador pensar que los hombres hacen leyes civiles emancipadoras para la mujer, pues en este caso la mujer conserva la condición de objeto; objeto de una legislación

que proliferaban en la época, cuyo objeto es destacar el arte que las mujeres poseen para agradar, subyugar y finalmente dominar a los hombres, y que fueron determinantes en la construcción de una identidad femenina que no se corresponde con la defendida en la actualidad por los movimientos que luchan por la igualdad entre géneros. Para profundizar en los discursos masculinos durante este periodo remito al estudio de Crampe-Casnabet, Michelle. Las mujeres en las obras filosóficas del siglo XVIII, en Duby, 2003, III, págs. 344-384. 
progresista, pero objeto al fin y al cabo $^{30}$. La mujer civil, la que se hace oír en la ciudad, la que se considera también como un individuo libre y racional capaz de gobernarse a sí misma aparece por primera vez en este momento histórico. Un ejemplo de reivindicación del papel político de la mujer en este periodo lo encontramos en Olympe de Gouges, autora de la Declaración de los Derechos de la Mujer y la Ciudadana ${ }^{31}$, redactada en septiembre de 1791, que parte de la idea de Rousseau de que la ley debe ser expresión de la voluntad general, sólo que en la constitución de esa voluntad se debe tener en cuenta a las mujeres, ya que si "la mujer tiene el derecho de subir al cadalso; debe tener igualmente el de subir a la Tribuna (...)"32. De hecho, el activismo político de Olympe de Gouges contra las insuficiencias y las inconsecuencias de la Revolución Francesa le conducirá a la guillotina dos años después de la redacción de su declaración ${ }^{33}$. Considera que la Revolución Francesa no supone ninguna ventaja para las mujeres, ya que no se ha eliminado la tiranía sino que se ha desplazado su ejercicio $^{34}$.

\footnotetext{
${ }^{30}$ Sledziewski, Elisabeth G. Revolución Francesa. El giro, en Duby, 2003, IV, pág. 60.

31 De Gouges, Olympe. Declaración de los derechos de la mujer y de la ciudadana, en Puleo, Alicia. La Ilustración olvidada. La polémica de los sexos en el siglo XVIII. Anthropos, Madrid, 1993, pág. 153.

32 Párrafo $\mathrm{x}$ de la Declaración de los derechos de la mujer y de la ciudadana.

${ }^{33}$ En nuestro país encontramos unos años más tarde ecos de este activismo político por parte de mujeres como Mariana Pineda, aunque más como símbolo de la causa liberal que por su defensa del derecho a participar en cuestiones políticas por parte de las mujeres. Su destino fue igualmente trágico ya que fue ajusticiada en 1831.

${ }^{34}$ Sledziewski, en Duby, 2003, pág. 65.
} 
Hombres como Condorcet llegaron a la misma conclusión, es decir, que la exclusión de las mujeres de los derechos civiles es un acto de tiranía, a imagen y semejanza de la tiranía ejercida por la aristocracia en el Antiguo Régimen, “y para que no lo fuera habría que probar alguno de estos dos prejuicios: o bien que las mujeres no tienen los mismos derechos naturales, o bien que aún teniéndolos, no son capaces de ejercerlos”,35. Al excluir a las mujeres de la ciudadanía se las constituía en estamento al mismo tiempo que en ese momento histórico se estaba desmantelando una sociedad estamental. No es de extrañar que a la vista de su situación, las mujeres se designaran a sí mismas como Tercer Estado dentro del Tercer Estado. En el análisis de Condorcet publicado el 3 de julio de 1790 se plantea el tema de la exclusión de las mujeres de la ciudadanía desde un punto de vista filosófico, alejado de la militancia política de Olympe de Gouges, aunque también Condorcet fuera perseguido por su defensa pública de la causa de las mujeres. Este autor teoriza sobre la negativa a integrar a las mujeres en la comunidad cívica y considera este hecho un retraso de la conciencia. En este periodo chocan las discriminaciones que, a favor del hábito y de los prejuicios, continuaron floreciendo sin la menor perturbación ni remordimiento de quienes trabajan por convertir la igualdad de derechos en el fundamento único de las instituciones políticas ${ }^{36}$.

\footnotetext{
${ }^{35}$ De Condorcet, Nicolas. Sobre la admisión de las mujeres al derecho de ciudadanía, en Puleo, Alicia. La Ilustración olvidada. La polémica de los sexos en el siglo XVIII. Anthropos, Madrid, 1993, pág. 101.

36 Sledziewski, en Duby, 2003, pág. 63.
} 
Mary Wollstonecraft representa la recepción en Inglaterra de las ideas feministas elaboradas en la Revolución Francesa. En Vindicación de los Derechos de la Mujer ${ }^{37}$ se centra en la dimensión cultural del problema de la opresión de las mujeres, analizándolo desde el punto de vista ético. El objetivo de Wollstonecraft en este libro no es que las mujeres asuman un papel activo en política, en pie de igualdad con los hombres, sino hacer que se reconozca a las mujeres su capacidad para asumir, si así lo desean y con pleno conocimiento de causa, su responsabilidad en la sociedad. Reivindica para la mujer su derecho a decidir racionalmente dónde está su lugar, en vez de consentir servilmente que ese lugar sea el decidido por los hombres ${ }^{38}$. La escritora británica critica a aquellos pensadores, especialmente Rousseau, que consideran la naturaleza femenina inferior a la masculina justificando así su exclusión de los derechos civiles y políticos. ¿Por qué alguien como Rousseau, que había explicado el carácter socialmente construido de todas las instituciones y de todas las relaciones sociales, no se cuestiona la situación de subordinación de las mujeres? Además, Rousseau había subrayado la igualdad como uno de los rasgos del estado naturaleza, por lo que si el modelo político esbozado en El contrato socia ${ }^{39}$ pretendía restablecer esa igualdad del estado naturaleza, ¿por qué las mujeres deben estar sometidas al hombre y excluidas

\footnotetext{
37 Wollstonecraft, Mary. Vindicación de los derechos de la mujer. Cátedra, Madrid, 1994.

38 Sledziewski, en Duby, 2003, pág. 68.

${ }^{39}$ Rousseau, Jean Jacques. El contrato social. RBA, Barcelona, 2004.
} 
de la voluntad general? Esta incoherencia en los razonamientos de Rousseau es puesta en evidencia por Mary Wollstonecraft. Para ella el prejuicio de la inferioridad femenina está tan profundamente arraigado en la sociedad que "los hombres, en general, parecen emplear su razón para justificar los prejuicios que han asimilado de un modo que les resulta difícil descubrir, en lugar de deshacerse de ellos" $"$.

Mary Wollstonecraft fue muy crítica con las teorías educativas para las niñas plasmadas en el Emilio, a las que ya se ha hecho referencia. Esta valiente mujer reivindicaba la educación de las mujeres no para que fueran mejores dentro de sus papeles tradicionales, sino para que fueran mejores seres humanos, capaces de ser independientes de los hombres. Para esta autora la educación desempeña un papel fundamental como forma de disminuir las desigualdades entre mujeres y hombres y como uno de los instrumentos más significativos para el progreso social e individual. En otra de sus obras más destacadas, La educación de las hijas $^{41}$, reclama la misma educación para ambos sexos y cuestiona los prejuicios que justifican la inferioridad de las mujeres. Es destacable, por otro lado, su determinación al abordar la cuestión de la educación de las mujeres en un momento histórico en el que dicha educación no les garantizaba un futuro laboral o social.

\footnotetext{
40 Wollstonecraft, 1994, pág. 116.

41 Wollstonecraft, Mary. La Educación de las Hijas. El Desvelo Ediciones, Santander, 2010.
} 
Al igual que Cristina de Pizán, Wollstonecraft confió en su propio criterio y experiencia más que en la autoridad de pensadores influyentes como Rousseau, y defendió que las mujeres nacen como seres humanos, pero se les hace inferiores por medio de una educación deficiente. Rechaza las ideas sobre la educación de las mujeres de Rousseau y apela al Estado para reformar la educación de las jóvenes mediante la aprobación de leyes que terminen con las tradiciones de subordinación femenina. De este modo se convierte en una de las primeras personas en reclamar a un gobierno nacional la implantación de un nuevo sistema de educación para las mujeres ${ }^{42}$ orientado a que éstas consigan llevar una vida útil y gratificante con independencia de los hombres. Pondrá todo su empeño en evitar que la educación deforme a las mujeres.

Wollstonecraft da un paso más en el pensamiento feminista. Si las mujeres no nacen inferiores y si podían ser educadas para ser iguales a los hombres, ¿por qué entonces habrían de ser excluidas de la vida política y civil? A partir de este momento, desde finales del siglo XVIII, las reivindicaciones feministas se centran en los aspectos políticos y civiles de la vida de las mujeres ${ }^{43}$.

\footnotetext{
42 Anderson, Bonnie S. y Judith P. Zinsser. Historia de las mujeres. Una historia propia. Crítica, Barcelona, 1991, pág. 844.

43 Anderson y Zinsser, 1991, pág. 846.
} 
A pesar de que la Revolución Francesa animó a las feministas europeas a reclamar derechos políticos y civiles para las mujeres, el periodo de represión que siguió a la revolución trajo consigo un trágico destino para aquellas que cuestionaban las tradiciones sobre el sexo femenino. Las reivindicaciones que hacían, que consistían en rechazar gran parte de la cultura europea tradicional, las conducían en el mejor de los casos al aislamiento, por lo que las reivindicaciones se promovían a menudo en solitario, sin el respaldo todavía de un movimiento social y sin el apoyo de ningún partido político. Es preciso esperar a que surja el sentimiento de solidaridad social para que ese movimiento feminista se desate.

\subsection{El SIGLO XIX. EL ORIGEN DE LOS MOVIMIENTOS FEMINISTAS.}

El feminismo tiene una doble vertiente, como pensamiento crítico y como movimiento social. Por lo que respecta al pensamiento crítico, en un comienzo las feministas escribían como filósofas, con el ánimo de suscitar el debate sobre unas tradiciones que marginaban a la mujer y la hacían depender del varón en todos los sentidos. A finales del siglo XVIII y principios del XIX las feministas comienzan a escribir como activistas políticas y culturales, esperando influir en los gobiernos para que éstos cambiasen las leyes a favor de las mujeres ${ }^{44}$ y remover la conciencia moral de la sociedad. Olympe de Gouges y Mary Wollstonecraft dan los

${ }^{44}$ Anderson y Zinsser, 1991, pág. 850. 
primeros pasos hacia el enriquecimiento de un pensamiento que tendrá eco en los inmediatos movimientos feministas.

Los primeros movimientos feministas surgen a principios del siglo XIX. La industrialización y el capitalismo alteraron las relaciones entre los sexos, y dentro del colectivo de las mujeres también hubo diferencias entre las obreras, que se incorporaron masivamente a las fábricas como mano de obra barata, y las que integraban la burguesía, la clase social ascendente, que fueron enclaustradas en el hogar símbolo del estatus y el éxito laboral del varón. Fueron estas mujeres las que experimentaron de manera más acusada la privación de los derechos políticos, educativos y económicos que los hombres de su misma clase estaban consiguiendo, ya que, salvo excepciones, al no ganar dinero ni tener propiedades, dependían totalmente de la caridad de los varones de su familia para su subsistencia ${ }^{45}$. Fueron las mujeres de la burguesía las que se organizaron en torno a la reivindicación del derecho de sufragio, lo que explica su denominación como "sufragistas".

Al principio, las mujeres que tenían alguna actividad política se unían a otro tipo de movimientos, como por ejemplo la abolición de la esclavitud, en vez de organizarse para conseguir sus propios derechos. Las feministas norteamericanas dirían después que fue su exclusión de la Convención Mundial contra la

45 Anderson y Zinsser, 1991, pág. 855. 
Esclavitud lo que las impulsó a organizar la primera convención por los Derechos de las Mujeres, conocida como la Declaración de Seneca Falls de 19 de julio de $1848^{46}$, en el estado de Nueva York, impulsada por Elizabeth Cady Stanton y Susan B. Anthony, siendo este uno de sus textos fundacionales ${ }^{47}$.

Veinte años después de esta Declaración, John Stuart Mill publicó El sometimiento de las mujeres ${ }^{48}$, inspirado por las ideas de su esposa Harriet Taylor Mill. Como las feministas norteamericanas, Harriet comparaba a los hombres con los dueños de esclavos y a las mujeres con los esclavos ${ }^{49}$, y las soluciones propuestas para superar esta situación eran la educación superior también para las mujeres, la aprobación de leyes que les permitieran conservar sus propios ingresos y las protegieran de la violencia masculina así como divorciarse si lo deseaban, y la actividad política. Esta obra es considerada un clásico de la teoría feminista, y por tanto también del pensamiento social y político, y su éxito radica en haber logrado identificar la ideología de la naturaleza femenina, en concreto el discurso sobre la ideología diferente y complementaria de los sexos, como el enemigo principal de los derechos de las mujeres ${ }^{50}$. Los argumentos de Stuart Mill para desarticular dicha

\footnotetext{
${ }^{46}$ El texto de la Declaración de Seneca Falls se ha consultado en Rey Martínez, Fernando. El derecho fundamental a no ser discriminado por razón de sexo. McGrawHill, Madrid, 1995, págs. 121-125.

${ }^{47}$ Anderson y Zinsser, 1991, pág. 856.

${ }^{48}$ Mill, John Stuart. El sometimiento de las mujeres. Edaf, Madrid, 2005.

49 Anderson y Zinsser, 1991, pág. 857.

${ }^{50}$ De Miguel, Ana. Prólogo a la edición de El sometimiento de las mujeres. Edaf, Madrid, 2005, pág. 13.
} 
ideología y apoyar el sufragio universal se basan en los principios del utilitarismo como filosofía política.

Esta filosofía define la corrección de toda acción por su utilidad, es decir, por los resultados o consecuencias producidos por ellas. Se juzga la corrección de cualquier medida legal o política, de cualquier acción humana, según su resultado en términos de cantidad de placer o felicidad obtenida. De esta forma las leyes serán consideradas justas y buenas si contribuyen a aumentar la felicidad del mayor número de personas. Por lo que las leyes deberían reformarse, según este principio, y sustituir un régimen jurídico basado en el privilegio de unos pocos por un sistema transparente, racional y secular. Es decir, debían reformarse las leyes que reprimían los derechos de las mujeres y, a ser posible, dejar que las mujeres participaran activamente en dicha reforma mediante el reconocimiento del derecho de sufragio activo y pasivo.

Si cada individuo tiene derecho a defender su felicidad, es decir, sus intereses, y la felicidad de cada individuo, hombre o mujer cuenta igual en el cómputo global de felicidad, y dichos intereses están representados por el voto, entonces el derecho de sufragio deberá ser reconocido a todos los individuos, incluidas las mujeres. Pero la realidad fue otra, ya que durante un tiempo se consideró que los intereses de las mujeres estaban incluidos en los de sus padres o los de sus maridos, precisamente como 
consecuencia de la ideología de la naturaleza complementaria de los sexos a la que me he referido anteriormente. Este argumento trajo consigo la aparición de La demanda de la mitad de la raza bumana, las mujeres ${ }^{51}$, que también influyó de manera considerable en la redacción de El sometimiento de las mujeres de John Stuart Mill.

Para Stuart Mill, "el principio que regula las relaciones sociales vigentes entre los dos sexos (la subordinación legal de un sexo a otro) es incorrecto por sí mismo y (...) es uno de los mayores obstáculos que se oponen al desarrollo humano" ${ }^{\text {2. Lo }}$ que sucede es que dicho principio está arraigado con fuerza en los sentimientos de la mayoría de las personas. Se trata de una opinión casi universalmente aceptada como consecuencia de esos sentimientos y no de argumentos sólidos y racionales al respecto.

La primera consecuencia es que la dominación de un sexo sobre otro acaba apareciendo como algo natural y algo a lo que las mujeres consienten. Y la segunda es que los argumentos racionales para terminar con esta forma de pensar arraigada en los sentimientos, no son suficientes para acabar con el prejuicio de la inferioridad femenina.

\footnotetext{
51 Thomson, William y Anna Wheeler. La demanda de la mitad de la raza bumana, las mujeres, contra la pretensión de la otra mitad, los hombres, de mantenerlas en la esclavitud politica, y en consecuencia civil y doméstica. Comares, Granada, 2000.

${ }^{52}$ Mill, 2005, pág. 71.
} 
Según Stuart Mill, "al ser costumbre universal el sometimiento de las mujeres a los hombres, es natural que cualquier apartamiento de ella parece antinatural”, por tanto "antinatural no significa generalmente otra cosa que desacostumbrado"53. Según Stuart Mill, "lo que ahora se llama naturaleza de las mujeres es algo eminentemente artificial" ${ }^{\prime 54}$, ya que mientras la ciencia etológica no esté avanzada no es posible conocer cuáles son las diferencias naturales entre los sexos ${ }^{55}$ La ignorancia respecto a qué es lo que influye en la formación del carácter humano no permite deslindar lo que es esencial a la naturaleza de los sexos y lo que es adquirido ${ }^{56}$, en algunos casos como consecuencia de una represión forzada, es decir, fruto de leyes que prohíben expresamente el acceso de las mujeres a la política, a la educación superior, a trabajos no proletarios, etc., y en otros casos como consecuencia de un estímulo antinatural, es decir, a través de una educación que tiende a anularlas como personas autónomas.

Por lo que respecta al consentimiento de las mujeres, para este autor lo que sucede en realidad es que su proceso educativo,

\footnotetext{
${ }^{53}$ Mill, 2005, pág. 92.

${ }^{54}$ Mill, 2005, pág. 107.

55 Mill insiste en la necesidad de desarrollar las ciencias que estudian la formación del carácter humano para cerrar el paso a corrientes que basan la inferioridad femenina en los estudios que desde la fisiología y la frenología se realizaban en aquel momento y que confirmaban arbitrariamente que las mujeres no poseían la misma estructura cerebral que los hombres, lo que les impedía realizar razonamientos complejos, o trascender el interés privado en beneficio del público.

${ }^{56}$ Mill, 2005, págs. 108-110.
} 
radicalmente diferente al de los hombres y que les inculca que su naturaleza es "vivir para los demás, renunciar por completo a sí mismas y no tener más vida que la de sus afectos" ${ }^{\$ 57}$, les conduce a que sus trabajos y posiciones sociales sean también radicalmente diferentes en una etapa posterior de sus vidas.

Stuart Mill concluye de este modo que la costumbre, por universal que sea, "no debe servir de prejuicio a favor del sistema que deja a las mujeres sometidas social y políticamente a los hombres" ${ }^{\prime 58}$. La razón es insuficiente en la lucha contra el prejuicio, ya que el prejuicio no se funda en la razón; de hecho, “cuanto más incisivos y contundentes son los argumentos racionales contra el prejuicio combatido, más parece éste ganar en estabilidad", sino que se apoya en los sentimientos y en la costumbre. Por tanto, habrá que combatir el prejuicio a través de los elementos que intervienen en nuestro proceso de socialización, fundamentalmente la educación que recibimos a través de la familia y la escuela.

En este sentido, como ya ha podido comprobarse, el derecho a la educación de las mujeres era, y sigue siendo, una de las reivindicaciones fundamentales del feminismo. Sin embargo, la educación que habían recibido las mujeres hasta ese momento las

\footnotetext{
${ }^{57}$ Mill, 2005, pág. 96.

${ }^{58}$ Mill, 2005, pág. 98.
} 
aniquilaba como personas autónomas al inculcarles como fin en sus vidas ser abnegadas esposas y madres.

En España, las ideas de Emilia Pardo Bazán y de Rafael Torres Campos sobre esta cuestión son reflejo de las de John Stuart Mill. De hecho, la traducción de El sometimiento de la mujer al español y su publicación en nuestro país se lleva a cabo a partir de la iniciativa de Emilia Pardo Bazán, que decidió editar una serie de obras bajo el título La Biblioteca de la mujer ${ }^{59}$. Pardo Bazán rechaza las concepciones pedagógicas vigentes en la época, herederas de Rousseau y de otros pedagogos de finales del siglo XVIII y principios del XIX como Pestalozzi, al considerar que privan a la mujer de su propia individualidad. En la ponencia La educación del hombre y la mujer, presentada en el importante Congreso Pedagógico Hispano-Portugués-Americano de 1892, denunciaba los contenidos educativos de una enseñanza que podría denominarse “doma” más que educación, ya que ésta se basa en los valores de “obediencia, pasividad y sumisión”. Por su parte, Torres Campos, en Las profesiones de la mujer, reclama también el acceso de las mujeres a todos los niveles educativos y el derecho a desarrollar cualquier tipo de actividad profesional en aras a garantizar su dignidad como personas ${ }^{60}$. No hay que olvidar que a finales del

\footnotetext{
${ }^{59}$ El prólogo de Emilia Pardo Bazán a la primera edición española del texto de John Stuart Mill, traducido entonces como La esclavitud femenina, puede leerse en Mill, John Stuart y Harriet Taylor Mill. Ensayos sobre la igualdad sexual. Antonio Machado Libros, Madrid, 2000, págs. 265-280.

${ }^{60}$ Folguera Crespo, Pilar. Revolución y Restauración. La emergencia de los primeros ideales emancipadores (1868-1931), en Garrido, 1997, pág. 464.
} 
XIX algunas mujeres como Concepción Arenal, que también participó en el mencionado Congreso con una ponencia titulada La educación de la mujer ${ }^{61}$, soslayaron la prohibición de asistir a la universidad protegiéndose tras atuendos masculinos ${ }^{62}$. Esto pone de manifiesto que a pesar de que en España no se prohibió por ley el acceso de la mujer a la educación superior, el peso de las costumbres, las circunstancias familiares o el coste elevado de la misma, les cerraba prácticamente el acceso efectivo a la vida académica $^{63}$.

Lo cierto era que si no se actuaba, la educación que estaban recibiendo las mujeres en aquel momento les impediría el desarrollo de su propia individualidad, de sus capacidades y talentos, privándolas de autonomía. Y ello porque aunque en el siglo XIX la libertad y la igualdad son los dos valores que presiden las instituciones modernas, las relaciones entre mujeres y hombres se caracterizaban por su ausencia. Falta de libertad porque, por si acaso la educación no resulta suficiente para que las mujeres acepten de buen grado su esclavitud, las leyes de la época terminaban de lesionar su dignidad personal al impedirles dirigir su propia vida. No sólo porque las mujeres en algunos países tenían

\footnotetext{
${ }^{61}$ Jagoe, Catherine. La mujer en los discursos de género: textos y contextos en el siglo XIX. Icaria, Barcelona, 1998, pág. 197.

${ }^{62}$ Romeo Mateo, María Cruz. Destinos de mujer: esfera pública y políticos liberales, en Morant, Isabel, directora. Historia de las mujeres en España y América Latina. Volumen III: Del siglo XIX a los umbrales del siglo XX. Cátedra, Madrid, 2008, pág. 79.

${ }^{63}$ De Madariaga, Salvador. Mujeres españolas. Espasa-Calpe, Madrid, 1972, pág. 36.
} 
prohibido por ley el acceso a la educación superior, a los trabajos no proletarios y a cualquier tipo de actividad política, sino también porque dichas leyes establecen su sumisión al marido una vez casadas, tras la firma del único contrato que se les permitía firmar, el del matrimonio. La falta de libertad se traduce en desigualdad y en injusticia para las mujeres que, a pesar del surgimiento del sujeto individual como consecuencia de las transformaciones revolucionarias, seguían sin poder emanciparse de sus padres o maridos.

Por ello Stuart Mill considera de gran importancia el desarrollo de un sentimiento de solidaridad hacia las mujeres y entre las propias mujeres, ya que una de las dificultades añadidas con las que éstas se encontraban era que, la carga de probar su igualdad les correspondía a ellas mismas, no a quienes la rechazaban sistemáticamente. Stuart Mill considera que la capacidad de sentir con los demás, de que lo que les suceda nos afecte y no nos deje indiferentes, supone que la sociedad progrese y sea realmente democrática. Sin embargo, aunque las feministas desarrollaron un sentimiento de solidaridad con otras mujeres, en un principio fueron minoría, ya que ser feminista suponía apartarse de unas tradiciones aceptadas socialmente y enfrentarse por tanto al rechazo y al aislamiento social. 
No obstante, a pesar del rechazo a este movimiento ${ }^{64}$, poco a poco se toma conciencia de que la emancipación de las mujeres no sólo las beneficia a ellas, sino también a la sociedad en su conjunto. Es decir, la sociedad se moraliza con el paulatino aprendizaje e interiorización de los sentimientos de igualdad y libertad. Gana la justicia y eso debe ser suficiente.

Stuart Mill ocupó un escaño en el Parlamento inglés y como representante del interés general defendió el voto femenino. La participación de las mujeres en la sociedad a través del voto podría suponer un cambio decisivo en sus vidas. El derecho a elegir a sus representantes políticos y a ser elegidas les abría el camino hacia la aprobación de nuevas leyes que les reconocieran los mismos derechos que a los hombres, y la reforma de aquellas otras que hasta ese momento las habían limitado como personas, como sujetos autónomos.

Y es que el derecho debe deslegitimar la desigualdad en la sociedad. El derecho es ante todo regulador de las relaciones sociales y eso incluye forzosamente las relaciones de sexo, por lo que desempeña un papel crucial a la hora de desarticular los razonamientos sobre la inferioridad de las mujeres. El

\footnotetext{
${ }^{64}$ Frente a John Stuart Mill, Pierre Lerroux, Karl Marx o Charles Secrétan, que hablaban en beneficio de las mujeres, otros como Proudhon se inscriben en la tradición de Kant o Schopenhauer y se inclinan hacia la exclusión social y política del sexo femenino. Sobre esta cuestión me remito al estudio de Fraisse, Geneviève. Del destino social al destino personal. Historia filosófica de la diferencia de los sexos, en Duby, 2003, IV, págs. 71-108.
} 
ordenamiento jurídico se adapta a los cambios sociales mediante la aprobación de normas que contribuyen a la autonomía de la mujer, normas que tengan en cuenta a la mujer como sujeto de derecho, escuchando las demandas de una sociedad que reclama los mismos derechos para todos los ciudadanos y ciudadanas.

\subsection{EL SIGLO XX. LO PRIVADO ES POLÍTICO.}

Durante los años de entreguerras el feminismo europeo estuvo temporalmente inactivo y las preocupaciones se centraron básicamente en la propia supervivencia. La entrada de Gran Bretaña en la Primera Guerra Mundial en agosto de 1914 terminó de golpe con la lucha sufragista. El comportamiento de las mujeres durante la guerra inclinó a la opinión pública a favor del voto, siendo así que las inglesas mayores de treinta años obtuvieron el voto en 1918. Al final de la Primera Guerra Mundial el tema del sufragio femenino había dejado ya de ser una reivindicación radical en muchos países ${ }^{65}$. No así en España ${ }^{66}$, donde la organización colectiva de mujeres para exigir derechos políticos es un fenómeno relativamente tardío en comparación con otros países europeos o con Estados Unidos. No es hasta el año 1931, con el triunfo de los partidos republicanos, cuando se reforma la ley electoral vigente hasta entonces, reconociéndose el derecho de sufragio pasivo a las

\footnotetext{
65 Anderson y Zinsser, 1991, pág. 865.

66 Sobre el grado de implantación de las ideas emancipadoras del feminismo en nuestro país en este periodo resulta de gran interés la lectura de la obra de Posada, Adolfo. Feminismo. Librería de Fernando Fé, Madrid, 1899.
} 
mujeres a partir de los veintitrés años. Aunque la nueva ley sólo reconoce el derecho de las mujeres a ser elegidas, existía por parte del nuevo gobierno un deseo de incorporar a las mujeres en política. Sin embargo, esta incorporación estaba dificultada por el bajo nivel educativo y por el escaso número de mujeres que trabajaban fuera de sus casas. Tras la celebración de las elecciones de 28 de junio, las nuevas Cortes Constituyentes se establecieron el 14 de julio de 1931 con sólo dos mujeres entre sus miembros: Victoria Kent y Clara Campoamor. De esta última destaca su defensa del voto femenino sin ningún tipo de limitaciones, pese al riesgo que suponía que el voto se inclinase a favor de la derecha ${ }^{67}$.

Sin embargo, los derechos de ciudadanía como el derecho al voto en realidad significaron relativamente poco para la mayoría de las mujeres. En el ensayo feminista Una habitación propia ${ }^{68}$, Virginia Woolf declaraba que "la noticia de mi herencia me llegó una noche, más o menos al mismo tiempo que se aprobaba la ley que daba el voto a las mujeres (...). De las dos cosas - el voto y el dinero -, el dinero, lo confieso, me pareció infinitamente más importante" ${ }^{69}$. La mayoría de mujeres feministas contempló con frustración que las elecciones no lograban cambiar su vida de manera significativa ${ }^{70}$. En el nuevo contexto de política participativa se seguían manteniendo los papeles y funciones

\footnotetext{
${ }^{67}$ Folguera Crespo, Pilar. La II República. Entre lo privado y lo público (1931-1939), en Garrido, 1997, pág. 509.

${ }^{68}$ Woolf, Virginia. Una habitación propia. Seix Barral, Barcelona, 2011.

${ }^{69}$ Woolf, 2011, págs. 52-53.

${ }^{70}$ Anderson y Zinsser, 1991, pág. 866.
} 
tradicionales de las mujeres. Por ello, las reivindicaciones jurídicas de las mujeres sólo tienen sentido cuando, al mismo tiempo, cuestionan las relaciones de poder en su conjunto.

En la primera mitad del siglo Xx, el ensayo de Simone de Beauvoir El segundo sexo ${ }^{71}$, escrito en 1949, dota de una fundamentación filosófica elaborada y consistente a las posiciones partidarias de la emancipación femenina dentro de los parámetros ilustrados -derecho a la educación igualitaria, ciudadanía, igualdad de oportunidades de realización existencial... - y destruye los mitos sobre la feminidad en la línea de lo que ya sostuvo Mary Wollstonecraft en su obra Vindicación de los derechos de la mujer quien, en polémica con Rousseau, puso de manifiesto que "lo femenino" es producto de una construcción social totalmente $\operatorname{artificial~}^{72}$. Simone de Beauvoir supo ver cómo lo masculino se había solapado con lo que se considera genérica y universalmente humano. Consideraba que la opresión de las mujeres estaba relacionada con el hecho de estar relegadas al ámbito de la inmanencia - a la mera repetición de la vida a través del parto y la crianza de los hijos, frente a la trascendencia que se encarna en la tarea prestigiosa por excelencia para los varones que es la guerra. Por ello se trataba de incluir a las mujeres en el universo de los hombres, aunque con el paso de los años se consideró que esto no era suficiente.

${ }^{71}$ De Beauvoir, Simone. El segundo sexo. Cátedra, Madrid, 2011.

72 Amorós, 2005, Tomo I, págs. 27-30. 
En primer lugar porque incluir a las mujeres en el universo de los hombres no puede suponer identificar lo femenino con lo masculino, con las mismas actitudes, las mismas funciones sociales, los mismos talentos. Homogeneizar los sexos no contribuye a una mayor igualdad entre ellos sino a una ceguera respecto de las cualidades y virtudes específicas de cada uno. Afirmar la alteridad de las mujeres y no la asimilación a los hombres es el principio del reconocimiento de su dignidad como personas, con los mismos derechos pero respetando las diferencias entre ambos.

En segundo lugar, porque aquello que se consideraba como genéricamente humano y universal, finalmente sólo se acomodaba a determinados grupos de individuos. Aquello en que los varones hacían consistir la trascendencia y lo irreductiblemente humano eran precisamente aquellas actividades que ellos mismos consideraban más prestigiosas, como la guerra o la caza mayor, en lugar de hacerlo depender de otro hecho tan heroico como puede ser la maternidad cuando se identifica con un proyecto de vida deseado y aceptado libremente ${ }^{73}$.

La constatación de la usurpación de lo universal por parte de quienes detentan el poder es lo que se denomina patriarcado, $y$ es el descubrimiento de esta realidad la gran aportación del

${ }^{73}$ Amorós, 2005, Tomo I, págs. 31-40. 
feminismo durante la segunda mitad del siglo XX. A partir de este momento se amplía el radio de la crítica feminista a la crítica del patriarcado, así como a la crítica cultural y política de un sistema democrático que se legitima por la universalidad de sus principios, pero que al mismo tiempo sigue siendo excluyente con las mujeres, los negros y en este periodo además, con los homosexuales y transexuales. Estas contradicciones del sistema democrático propician la aparición de nuevos movimientos sociales a favor de los derechos civiles de estos colectivos de personas ${ }^{74}$.

A finales de la década de los sesenta, las mujeres constataron que seguía habiendo una contradicción entre lo que les decían que habían conseguido y la percepción concreta de su propia situación. Las feministas tenían la convicción de que las mujeres seguirían estando oprimidas hasta que no se transformaran sus condiciones de vida en la familia. Puesto que la revolución política y económica no termina con un sistema de poder que las conduce a la represión en la vida privada, este movimiento feminista centró su atención en la esfera privada bajo el lema "lo personal es político". Para ello se identificaron aspectos de la vida que hasta entonces se consideraban privados y que ponían de manifiesto las relaciones de poder que estructuran la familia y la sexualidad, al mismo tiempo que se movilizaron

\footnotetext{
74 Sobre las características del feminismo de los años setenta y sus reivindicaciones resulta de gran interés el análisis efectuado por Bock, Gisela. La mujer en la bistoria de Europa. Crítica, Barcelona, 2001, págs. 269- 279.
} 
poniéndose de manifiesto una vez más "la estrecha relación entre el análisis teórico y la práctica que caracteriza al feminismo" ${ }^{\text {75. }}$.

El conocido como movimiento de liberación de mujer aspiraba a redefinir su vida en términos de individualidad, no en relación con el hombre y la familia. En este movimiento se cuestionaba la tradición según la cual el hombre era la medida de todas las cosas, es decir, que la experiencia y percepción masculina eran el punto de referencia de toda la humanidad. El rechazo de esta tradición exigía confianza en sí mismas y fortaleza. Las mujeres debían relacionarse entre sí para conseguirlo, tenían que ser capaces de movilizar a mujeres y hombres en apoyo de sus reivindicaciones, que van desde el control de la natalidad, el reconocimiento del derecho al aborto, cuestionan la heterosexualidad misma, la lucha contra la violencia física (violación, incesto, acoso) y doméstica, así como el deseo de superar la falta de discurso común mediante el impulso de estudios feministas, integrando la perspectiva de las mujeres en aquellas disciplinas en las que antes era ignorada por completo, como la historia, por ejemplo ${ }^{76}$.

Una de las feministas más destacadas del movimiento de liberación de la mujer fue Simone de Beauvoir, aunque ella misma no se consideró feminista hasta principios de la década de los

75 Amorós, 2005, Tomo I, pág. 71.

76 Anderson y Zinsser, 1991, pág. 909-938. 
setenta. En El segundo sexo, parece identificarse con los hombres, ya que escribe objetivamente como si ella no fuese una mujer. Para De Beauvoir, reconocer públicamente que había abortado supuso su primer acto político como feminista, ya que de este modo se identificaba con otras mujeres y luchaba por mejorar la vida de todas ellas. Esto demuestra también que las experiencias personales de las mujeres tenían importantes implicaciones políticas para la sociedad.

El feminismo como teoría crítica ha conseguido hacer ver un hecho determinante, como es que las diferencias biológicas entre hombres y mujeres han servido para justificar la desigualdad entre ellos. Pero no sólo ha contribuido a clarificar este hecho y a explicar sus causas, sino también a cuestionarlo y deslegitimarlo para que las mujeres lleguen a tener una visión más reflexiva y consciente de su situación. De este modo, la teoría crítica feminista desafía el orden social establecido por el patriarcado, poniendo en tela de juicio principios, valores y actitudes aprendidos e interiorizados desde la infancia en el seno de la familia. Y es que, si las desigualdades entre hombres y mujeres se han ido reproduciendo a lo largo de la historia es porque el sistema patriarcal se manifiesta dentro y fuera de la familia. Por este motivo, uno de los fines del feminismo es "romper la implacable dinámica de refuerzo mutuo que se da entre las prácticas de la vida 
cotidiana y de las macroestructuras económicas, políticas e ideológicas" ${ }^{77}$.

El feminismo en la actualidad se encuentra ante la tarea de responder al interrogante acerca de cuáles son los mecanismos por los que a día de hoy se sigue reproduciendo la desigualdad sexual. Al final de siglo XIX surgen nuevas ciencias humanas como la sociología, que abre paso a la era de un "saber" sobre los sexos. Las aportaciones de esta disciplina a la cuestión de la igualdad entre los sexos se tratarán a continuación.

77 Amorós, 2005, Tomo I, pág. 62. 


\section{PERSPECTIVA SOCIOLÓGICA Y CULTURAL.}

El concepto de hecho social fue elaborado por Émile Durkheim en Las reglas del método sociológico ${ }^{78}$, obra clásica de la sociología que continúa vigente en la actualidad. En ella se parte de la proposición de que los hechos sociales deben ser tratados como cosas, aunque no en el sentido material del término, sino entendidos como "todo objeto de conocimiento que no es naturalmente penetrable para la inteligencia, todo aquello de lo que no podemos darnos una idea adecuada por un simple procedimiento de análisis mental, todo lo que el espíritu no puede llegar a comprender más que a condición de salir de sí mismo por vía de la observación y la experimentación, pasando progresivamente de los caracteres más exteriores y más accesibles inmediatamente a los menos visibles y más profundos"79.

Esta ciencia se revela como un medio de descifrar por qué hoy en día, a pesar de todos los avances conseguidos, sigue habiendo desigualdades en el mundo, y en concreto, por lo que ahora nos interesa, entre hombres y mujeres en el empleo público. Nuestra forma de comportarnos, y la conciencia individual que podamos tener de nuestro propio comportamiento, son insuficientes para entender los hechos sociales. Esta forma de

\footnotetext{
${ }_{78}$ Durkheim, Émile. Las reglas del método sociológico. Morata, Madrid, 1993.

${ }^{79}$ Durkheim, 1993, 19.
} 
análisis solo nos daría una impresión confusa y subjetiva del hecho social, que no permitiría averiguar las verdaderas razones que nos impulsan a obrar de una determinada manera, es decir, a actuar como mujeres o como hombres en cada uno de los contextos en los que nos relacionamos como seres sociales.

Por eso se considera que los hechos sociales son formas de actuar, pensar o sentir externas a los individuos ${ }^{80}$, con una realidad propia al margen de las vidas y percepciones de sus integrantes ${ }^{81}$. También se caracterizan porque son capaces de ejercer una influencia coercitiva ${ }^{82}$ sobre los individuos, aunque las personas no suelen ser conscientes de ese carácter condicionante de los hechos sociales.

Los que se oponen a esta manera de enfocar los estudios sociológicos sostienen que la visión de Durkheim prioriza las restricciones de la sociedad sobre las personas, olvidando que aunque los hechos sociales puedan condicionar nuestras acciones, no las determinan, puesto que como seres humanos tenemos razones para hacer lo que hacemos. De manera que los defensores de esta última posición, sostienen que los fenómenos sociales no

\footnotetext{
${ }^{80}$ Durkheim, 1993, 35.

${ }^{81}$ La sociología se ocupa del estudio de la conciencia colectiva, a diferencia de la psicología que se centra en la conciencia individual. Para Durkheim los estados de la conciencia colectiva son de otra naturaleza que los de la conciencia individual; la mentalidad de los grupos no es la de los particulares, sino que posee sus propias leyes. Es así como individuos perfectamente inofensivos en su mayoría pueden, reunidos en una muchedumbre, dejarse arrastrar a la realización de atrocidades.

${ }^{82}$ Durkheim, 1993, 26.
} 
son exactamente cosas, sino que dependen de los significados simbólicos que les asignamos.

Para el sociólogo Anthony Giddens, si queremos obtener una perspectiva sociológica es esencial "la comprensión de las formas sutiles aunque complejas en que nuestras vidas individuales reflejan los contextos de nuestra experiencia social"83. La sociología nos permite conocer de qué forma nuestro comportamiento individual está condicionado por nuestra experiencia social, sin olvidar que cada ser humano tiene su propia individualidad. Por lo que podemos decir que la sociología se centra en investigar la conexión entre lo que la sociedad hace de nosotros y lo que hacemos de nosotros mismos ${ }^{84}$.

Asimismo, conviene tener presente que los contextos sociales de nuestra vida están estructurados o siguen una pauta, es decir, que nuestra forma de ser y las relaciones que mantenemos unos con otros presentan regularidades, lo que se denomina una "estructura social" 85 , y que "todos participamos activamente en la construcción y reconstrucción de la estructura social en el curso de nuestras actividades cotidianas" $\$ 86$. De este modo, el estudio de la estructura social puede proporcionarnos información valiosa sobre

${ }^{83}$ Giddens, Anthony. Sociología. Alianza, Madrid, 2012, pág. 25.

${ }^{84}$ Giddens, 2012, pág. 28.

${ }^{85}$ Giddens, 2012, pág. 28.

${ }^{86}$ Giddens, 2012, pág. 110. 
las causas por las que se perpetúan las desigualdades entre hombres y mujeres.

A través de la perspectiva sociológica se pretende que nos demos cuenta de que cuestiones que parecen preocupar únicamente al individuo en realidad tienen que ver con asuntos más generales. La desigualdad entre hombres y mujeres en el acceso a puestos directivos en empleo público, por ejemplo, puede ser una frustración para una mujer que objetivamente está bien preparada para desempeñarlo, pero el problema rebasa el nivel individual cuando éste afecta a la mayoría de las mujeres con titulación superior en la Administración Pública, y es entonces cuando se convierte en un asunto público que expresa una tendencia social ${ }^{87}$.

La sociología contribuye al esclarecimiento de las causas por las que hoy en día se siguen reproduciendo las desigualdades entre hombres y mujeres. No basta con tomar conciencia de nuestras ideas sobre la desigualdad entre hombres y mujeres. Aunque esta labor haya sido determinante para poder avanzar y llegar a la situación actual, el análisis ideológico del pensamiento feminista debe completarse con la sociología, con esta ciencia que se centra en revelarnos la realidad que nos rodea.

${ }^{87}$ Giddens, 2012, pág. 27. 
A continuación se exponen brevemente algunas cuestiones planteadas por la sociología para explicar el conjunto de reglas que han determinado la permanencia del dominio del hombre sobre la mujer ${ }^{88}$. Esto es algo fundamental ya que, en palabras de Pierre Bourdieu, "no hay poder que no le deba una parte -y no la menorde su eficacia al desconocimiento de los mecanismos que lo fundamentan" $" 89$.

\subsection{LA RELACIÓN ENTRE SEXO Y GÉNERO.}

El sexo y el género son dos conceptos que se utilizan en sociología para explicar las desigualdades entre hombres y mujeres. La antropología feminista también se ha adentrado en el estudio de la relación entre la mujer y el hombre y del papel del género en la estructuración de las sociedades humanas, de su historia, ideología, sistema económico y organización política ${ }^{90}$.

El sexo aparece como una cuestión biológica que se asocia con las diferencias anatómicas y fisiológicas que definen el cuerpo del varón y el de la mujer, mientras que el género tiene un significado cultural, que se ocupa de las diferencias psicológicas y

\footnotetext{
${ }^{88}$ Las relaciones de poder en una interacción, como la que puede darse entre hombres y mujeres en el seno de la familia o dentro del empleo público, son estudiadas por Anthony Giddens en Las nuevas reglas del método sociológico. Crítica positiva de las sociologias comprensivas. Amorrortu, Buenos Aires, 2001, págs. 136140.

${ }^{89}$ Bourdieu, Pierre. Cuestiones de sociología. Istmo, Madrid, 2003, pág. 29.

${ }^{90} \mathrm{La}$ construcción cultural del género desde una perspectiva antropológica puede consultarse en Moore, Henrietta L. Antropología y feminismo. Cátedra, Madrid, 2009, págs. 27-45.
} 
sociales que hay entre hombres y mujeres. La aplicación del género a las personas, a los roles sociales y a los distintos ámbitos de la vida social se denomina sistema de género, y es lo que condiciona la identidad, la función y el espacio que nos corresponde en la sociedad. La relación que se establece entre sexo y género ha servido de apoyo a la sociología para explicar el origen y permanencia de las desigualdades entre hombres y mujeres.

a. Sexo igual a género.

Algunas corrientes sociológicas han defendido que el sexo es igual al género. Para ellas el mantenimiento de identidades, roles y espacios tradicionalmente masculinos y femeninos es la forma más lógica de organizar la sociedad, ya que en ella los hombres y mujeres realizarían las tareas para las que están mejor dotados desde un punto de vista biológico. Además piensan que este modelo contribuye a la estabilidad y a una mayor integración de la sociedad $^{91}$.

Como se verá posteriormente, este sistema es el responsable de una división sexual del trabajo en la que las mujeres se ocupan del cuidado de los hijos y del apoyo emocional a todos los miembros de la familia, y los maridos de proporcionar el sustento económico, lo que a su vez se traduce en la convencional atribución de espacios masculinos y femeninos. Además, las

${ }^{91}$ Giddens, 2012, pág. 649. 
funciones diferenciadas atribuidas a uno y otro sexo no reciben la misma valoración social, de manera que esta diferencia se acaba entendiendo como subordinación de la mujer con respecto al hombre.

El hecho de vincular la organización de la sociedad y la división sexual del trabajo con un fundamento biológico ha sido fuertemente criticado por el pensamiento feminista, ya que esto ha servido para que durante siglos se haya legitimado la inferioridad de la mujer con respecto al hombre, así como su exclusión del ejercicio de determinadas profesiones confinándolas al espacio doméstico privado. Además, también ha sido criticado por no tener en cuenta que a las personas se las socializa en los roles que una cultura espera de ellos ${ }^{92}$.

b. Sexo y género como conceptos independientes.

Si la equiparación entre sexo y género había dado como resultado una dependencia de la mujer al varón, los enfoques sociológicos inspirados en el pensamiento feminista de finales del siglo XIX y principios del $\mathrm{xx}$ defendieron que el género no tiene base biológica alguna. El objetivo consistía en destruir las diferencias de género erigidas por la sociedad a partir de la biología entendida erróneamente. Se trataba de equiparar social y jurídicamente la mujer al hombre y rechazar los comportamientos, las funciones y

${ }^{92}$ Giddens, 2012, pág. 650. 
los ámbitos que tradicionalmente habían desempeñado y protagonizado las mujeres. Se consideraba que si la mujer imitaba la conducta del hombre y se eliminaban de la sociedad los rasgos de la identidad tradicionalmente femenina, como la pasividad y la dependencia, entonces podría alcanzarse la igualdad. Por eso se habla de un sistema basado en la igualdad sin diferencia.

Sin embargo, esta distinción radical entre sexo (biológico) y género (cultural) no está exenta de problemas. En primer lugar, supone que lo culturalmente considerado femenino es negativo porque conlleva la dominación del hombre sobre la mujer, y en segundo lugar porque piensa que equiparando las mujeres a los hombres los problemas de desigualdad serán solucionados. Además, también implica aceptar que el sexo nos es dado, que es inmutable y que además está bien definido, lo que en la actualidad es algo muy criticable desde el punto de vista científico. Admitir que la relación entre sexo y género no es de equivalencia absoluta, pero tampoco de diferencia tajante, nos lleva a una postura intermedia que se expone a continuación.

c. La socialización del género basada en el sexo de las personas.

Decir que el género es "los significados culturales que asume el cuerpo sexuado" 93 , pone de manifiesto que la identidad de género,

${ }_{93}$ Butler, Judith. El género en disputa. El feminismo y la subversión de la identidad. Paidós, Barcelona, 2001, pág. 39. 
y por tanto los roles y los espacios en los que ésta se manifiesta, son producto de una construcción social que se apoya en el sexo de los individuos. Por tanto, aunque el género no sea consecuencia directa del sexo, ni sea tan aparentemente fijo como el sexo, su definición sí que se hace depender del sexo de las personas.

La socialización del género se lleva a cabo mediante el proceso que Janet Saltzman ha denominado sexualización o diferenciación sexual ${ }^{94}$. Como todo proceso social está sujeto a cambios, conviene no olvidar que el género, o la interpretación cultural que se hace del sexo, es algo que puede variar con el paso del tiempo.

Según la teoría de la socialización del género, mujeres y hombres son guiados desde la infancia hacia el comportamiento que se espera de ellos ${ }^{95}$; es decir, se les inculca una determinada ideología sexual.

La primera etapa del proceso de diferenciación sexual se produce de forma voluntaria. La aceptación de la ideología sexual entendida como el modelo cierto o correcto de masculinidad y feminidad, es lo que explica que las mujeres hayan asumido su

\footnotetext{
${ }^{44}$ Saltzman, Janet. Equidad y género: una teoría integrada de estabilidad y cambio. Cátedra, Madrid, 1992.

95 Para una primera aproximación a las teorías que explican el aprendizaje de la identidad de género en la infancia nos remitimos a las explicaciones de Sigmund Freud y de Nancy Chodorow que pueden consultarse en Giddens, 2012, págs. 324-327.
} 
situación de subordinación como un hecho normal. La ideología sexual sirve para justificar o legitimar derechos, responsabilidades, restricciones y recompensas diferentes y desiguales para hombres y mujeres. Además, suele ser estable y resistente a los cambios porque lo más frecuente es que se apoye en las religiones u otras creencias y valores culturales con profundas raíces históricas.

La ideología sexual se convierte con el paso del tiempo y por fuerza de la costumbre en norma sexual, que refleja lo que debería ser una mujer y que no tiene por qué coincidir con lo que es en realidad, dando lugar al estereotipo sexual, que se termina por considerar cierto y como algo que realmente forma parte de la naturaleza de cada uno de los sexos.

La teoría de la socialización del género sostiene que la ideología sexual, o el aprendizaje de determinados comportamientos en función del sexo de las personas, se lleva a cabo con la ayuda de los agentes sociales, es decir, de "grupos o contextos sociales en los que ocurren procesos significativos de socialización" "96 , como pueden ser la familia, la escuela, los grupos de compañeros, las organizaciones, el lugar de trabajo o los medios de comunicación. De manera que "la interacción social que se produce en estos contextos contribuye a que las personas

${ }^{96}$ Giddens, 2012, pág. 317. 
aprendan valores, normas y creencias que constituyen las pautas de su cultura" $" 97$.

La identidad de género así aprendida se expresa en los roles sociales y se refleja en cada uno de los ámbitos de actuación de las personas que, como ya se ha apuntado, están sujetos a profundos cambios.

En todas las sociedades hombres y mujeres realizan funciones diferentes, son educados y socializados desde la infancia para que aprendan a desempeñar estas tareas y para que acepten este orden social como normal ${ }^{98}$. De este modo hay roles $y$ espacios considerados tradicionalmente femeninos (o privados) en los que se expresan los sentimientos y el afecto, y funciones y áreas consideradas predominantemente masculinas (o públicas), en las que priman las relaciones formales e impersonales ${ }^{99}$.

Los adultos buscan mostrar las conductas definidas socialmente como específicas de un sexo, confirmando su identidad masculina o femenina y recreando continuamente definiciones sociales de su sexo, que contribuyen a la diferenciación sexual. Las explicaciones de Goffman sobre las

${ }^{97}$ Giddens, 2012, pág. 317-318.

${ }_{98} \mathrm{El}$ proceso de identificación de los roles de género en el seno de la familia puede estudiarse en la obra de Talcott Parsons y Robert F. Bales. Family, Socialization and Interaction Process. Routledge and Kegan Paul Ltd., Londres, 1956, págs. 99-104.

${ }_{99}$ Astelarra, Judith, Veinte años de politicas de igualdad. Cátedra, Madrid, 2009, págs. $11-17$. 
relaciones que se mantienen entre dos equipos que se organizan dentro de los límites físicos de una industria pueden aplicarse a las relaciones entre hombres y mujeres de manera que, cuando los hombres y las mujeres interaccionan "tienden a mantener una línea de conducta que demuestre que son lo que pretenden ser; tienden, en una palabra, a permanecer dentro de su personaje" ${ }^{\text {"100 }}$. Así por ejemplo, los hombres tienden (en este modelo descriptivo) a entrar en las relaciones con una orientación separadora, que defiende el comportamiento egoísta como natural y resta énfasis a la empatía, mientras que la actitud de las mujeres hace hincapié en la cercanía emocional. Además, la conducta de hombres y mujeres suele apoyar la puesta en escena por parte de cada uno de ellos de los rasgos que tradicionalmente se consideran típicos masculinos y femeninos, tales como demostraciones de fuerza y dominio, o de sumisión y modestia, respectivamente.

De tal forma que si a los niños y a las niñas no solo se les educa con planes de estudio que siguen líneas de género diferentes, sino que también están rodeados de adultos, en la familia, en la escuela, en la publicidad, en los libros, etc., cuyo modelo de conducta está diferenciado en función del sexo, se les acaba por modelar para que actúen según corresponde a su sexo. Si además se sanciona negativamente a la persona que se desvía de la línea de

100 Goffman, Erving. La presentación de la persona en la vida cotidiana. Amorrortu, Buenos Aires, 1997, pág. 180. 
actuación fijada, se refuerza la conducta sexual que se espera de ellos y el proceso de socialización se completa.

En la edad adulta, como consecuencia de dicha socialización, los individuos realizan elecciones que son coherentes con la definición social-sexual de su identidad de género y que contribuyen al mantenimiento de las desigualdades entre hombres y mujeres. Es decir, en la edad adulta las personas tienden a ser vistas como lo que supuestamente deben ser, dados los estereotipos sobre ellas, lo que se traduce en una división sexual del trabajo que determina una distribución desigual de oportunidades y recompensas en los distintos ámbitos de actuación de mujeres y hombres ${ }^{101}$.

Esta socialización influye negativamente en las mujeres porque siguen aceptando voluntariamente, por efecto de la misma, una posición en el trabajo o en sus relaciones personales que tiende a la subordinación con respecto al varón. Esto podría llevar a pensar que los desequilibrios que pueden aparecer en el trabajo o en otras organizaciones de tipo burocrático son consecuencia de las elecciones que tienden a hacer las mujeres, y que sirven para perpetuar su estatus de desventaja. De forma que aquellas están en desventaja no por ser mujeres per se, sino por no ejercer suficiente poder dentro de las organizaciones. Según este argumento, a medida que haya más mujeres en puestos de responsabilidad irán

101 Saltzman, 1992, pág. 81-90. 
desapareciendo estos desequilibrios, pero no se analiza qué es lo que realmente impide que haya pocas mujeres en puestos con capacidad de decisión: porque no pueden, porque no saben, porque no les interesa, porque no se las deja... Para los enfoques feministas más radicales, el desequilibrio dentro de las organizaciones no es algo que pueda resolverse mediante el ascenso de más mujeres a puestos con más poder, ya que el problema reside en que las organizaciones están esencialmente contaminadas por los valores masculinos y por las pautas de dominación que les caracterizan ${ }^{102}$. La solución para este sector es que las mujeres construyan sus propias organizaciones a partir de principios muy diferentes al de los hombres, aunque esta alternativa supone seguir segregando y claudicar en la posibilidad de un trabajo en el que podamos actuar de forma cooperativa hacia el mismo fin.

Como se verá posteriormente al hablar de la división sexual del trabajo, cuando las mujeres eligen asumir roles de trabajo no doméstico, seleccionan trabajos del sector de los servicios y de trato con las personas antes que en las fábricas y en el trato con las cosas. A través de la selección de roles definidos socialmente como femeninos, las mujeres expresan su identidad femenina y representan el rol que se espera de ellas. Si además estos roles están devaluados e infrarrepresentados en comparación con otros roles que implican un trabajo aparentemente igual, se

102 Giddens, 2012, pág. 849. 
reproduce la desigualdad y la discriminación entre hombres y mujeres.

d. El género y el sexo como construcción social.

La teoría de la socialización del género es criticada porque no tiene en cuenta la capacidad del individuo para rechazar las expectativas sociales que corresponden a cada uno de los roles sexuales y a las identidades masculina y femenina que les acompañan. Las personas no son seres mecánicos a los que se pueda programar para recibir su identidad de género ${ }^{103}$, sino que tienen razones para hacer lo que hacen.

Además, en esta teoría, las normas de comportamiento según género se apoyan sobre cuerpos biológicamente masculinos y femeninos. Esto ha llevado a algunas destacadas autoras feministas como Judith Butler a sostener que "aun cuando los sexos parezcan ser nítidamente binarios en su morfología y constitución (lo que tendrá que cuestionarse), no hay razón para suponer que también los géneros deberán seguir siendo sólo dos" $" 104$.

Si seguimos afirmando que el género es producto de una construcción social condicionada por el carácter inmutable del

103 Giddens, 2012, pág. 634-637.

104 Butler, 2001, pág. 39. 
sexo de las personas, ¿hasta qué punto el género puede ser construido socialmente si está limitado por el sexo? Por lo que, o bien ni el género ni el sexo se definen por la sociedad, o bien los dos son producto de ella. Y los estudios más avanzados van en esta última dirección, más progresista e igualitaria porque engloba a todas las personas, no sólo a hombres y mujeres. Pero para ello hay que estar dispuesto a admitir la posibilidad de que el sexo puede no estar bien definido en el momento del nacimiento y, por tanto, que el sexo de las personas puede cambiar o se puede transformar mediante las intervenciones de la tecnología y de la medicina (reconociendo la existencia de cyborgs o de personas transexuales por ejemplo). Sólo entonces podría llegarse a la conclusión de que tanto el sexo como el género son producto de una construcción social.

Esta es la línea de investigación seguida por las teorías sociológicas más recientes, que en vez de considerar el sexo como algo determinado biológicamente y el género como algo que se aprende culturalmente, señalan que ambos son producto de una construcción social. Las teorías que creen en la construcción social del sexo y del género rechazan que las diferencias de género puedan tener base biológica alguna. Para Judith Butler la expresión cultural del género no se basa en una identidad determinada biológicamente. No hay una base sexual para el género que 
determine el comportamiento de las personas ${ }^{105}$. Según esta autora, si se acepta que "quizás el sexo esté tan socialmente construido como el género", entonces "no tendría sentido definir el género como la interpretación cultural del sexo, si éste es ya de suyo una categoría dotada de género". O por lo menos no tendría sentido definirlo así exclusivamente, sino que habría que añadir que el género es el “aparato mismo de producción mediante el cual se establecen los sexos entre sî’106.

Es decir, que son las diferencias sexuales que se perciben en la sociedad las que están en el origen de las diferencias de género, de tal forma que una sociedad en la que el comportamiento masculino se asocie a la fuerza física alentará a los hombres a comportarse como tal. Para esta autora la identidad de género se crea y se personifica, se representa, en la sociedad. Lo que conlleva que la identidad de género no sea una categoría fija, sino algo que fluye y se muestra más en lo que hacen las personas, que en lo que son.

Esta postura, según la cual ni el género ni el sexo tienen fundamento biológico, resulta muy interesante desde el punto de vista teórico pero no ha sido materializada en la práctica, quizás

\footnotetext{
105 Este es el punto de partida de la teoría queer (el término queer pasó de ser un insulto a ser la forma en que gays y lesbianas se autodeterminaban en la década de los ochenta del siglo xx) que se enfrenta a la noción de identidad como algo relativamente inmóvil o asignado a las personas por los agentes socializadores, y que critica también los presupuestos heterosexuales que subyacen en gran parte del pensamiento contemporáneo.

106 Butler, 2001, pág. 40.
} 
porque la sociedad todavía no ha avanzado tanto como para aceptar este tipo de planteamientos, que alumbran la posibilidad, quizás no tan remota, de un mundo asexuado o un mundo sin género, y que pone en peligro la supervivencia de instituciones como la familia tal y como la entendemos hoy en día. Este modelo, que en realidad implica una deconstrucción de la sociedad, fue propugnado no sólo por Judith Butler, sino también por otros destacados filósofos del siglo XX como Michel Foucault $^{107}$.

e. Igualdad en la diferencia.

En la actualidad nos encontramos en un momento en el que se ha avanzado mucho en el reconocimiento jurídico de la igualdad y en el que se respetan las diferencias entre mujeres y hombres. Este modelo, que se ha definido como el modelo de la igualdad en la diferencia, reivindica una interdependencia y corresponsabilidad entre los sexos. A la vez que reclama más presencia de la mujer en la vida pública, considera necesaria una mayor participación del hombre en los asuntos domésticos y en la educación de los hijos. Reconoce el derecho del hombre a intervenir en tareas reservadas tradicionalmente a las mujeres, de manera que el hombre pueda disfrutar también de muchos de los aspectos asociados a este tipo de roles. No hay inconvenientes en que el cuidado y la socialización de las personas también puedan ser desempeñados

${ }^{107}$ Foucault, Michel. Historie de la sexualité. Gallimard, Paris, 1976. 
por los varones, pues no responden a impulsos instintivos, sino que sólo requieren de aptitudes que todos los seres humanos, con independencia de su sexo, poseen y pueden desarrollar. Al contrario, una de las ventajas derivadas de la participación de los hombres en el proceso educativo de sus hijos es que aumentará las posibilidades de invertir su proceso de socialización en roles tradicionales.

Desde un punto de vista práctico es el modelo que ofrece más soluciones a los problemas que se plantean a la mayoría de hombres y mujeres en su vida diaria. Sin embargo, no supone realmente un avance en la cuestión ya que no nos enfrenta al problema de fondo, esto es, que la desigualdad no solo se produce entre hombres y mujeres en el mundo occidental, sino entre personas con independencia de su sexo en todo el mundo.

Otro inconveniente es que siguen sin explicarse los rasgos que definen la conducta de mujeres y hombres ${ }^{108} \cdot$ ¿Cuáles son esos rasgos que diferencian a las mujeres de los hombres? ¿Son sólo rasgos de tipo psicológico o internos, o rasgos definidos por el discurso dominante, y que suele ser el masculino, en cada tiempo y lugar? Y en el supuesto de que consigamos definirlos de manera aséptica, y de que aceptemos que no son inmutables, estos rasgos

\footnotetext{
108 Fernández Villanueva, Concepción. Feminismos, masculinismos e individualismos: el futuro de la igualdad de género, en Quintero Soto, $\mathrm{M}^{\mathrm{a}}$ Luisa y Carlos Fonseca Hernández, coordinadores. Investigaciones sobre el género. Aspectos conceptuales y metodológicos. Porrúa, México D.F., 2008, págs. 30-31.
} 
que nos diferencian deben tener una misma valoración social para que pueda darse esa cooperación, lo que a día de hoy considero que todavía no se ha alcanzado. Sigue habiendo una infravaloración del trabajo doméstico y en general continúa el estigma de la supuesta falta de compromiso de las mujeres con su trabajo, así como la realidad general, con excepciones, de la escasa participación del hombre en el trabajo doméstico.

\subsection{LA DIVISIÓN SEXUAL DEL TRABAJO.}

Uno de los rasgos organizativos más importantes de toda sociedad es la división del trabajo, es decir, la asignación de tareas distintas a personas diferentes. Cuando la distribución de dichas tareas se realiza en función del sexo de cada individuo, se habla de división sexual del trabajo. Esta división es una de las causas por las que se mantienen las desigualdades entre hombres y mujeres, por eso en este apartado se explicará brevemente por qué se ha producido la división sexual del trabajo y su relación con el concepto de género.

Algunos estudios sociológicos sugieren que en sociedades hortícolas tecnológicamente más sencillas, las mujeres controlan sus propios medios de producción y los frutos de su trabajo. La horticultura se realiza en pequeñas parcelas situadas cerca de la vivienda y con herramientas como la azada que son poco pesadas, de forma que las mujeres pueden combinar fácilmente la horticultura con el cuidado de la familia. 
Desde el punto de vista antropológico también se ha estudiado la relación entre las formas de agricultura y la jerarquía de género, entendida esta última como aquellas desigualdades que pueden llegar a producirse entre hombres y mujeres como consecuencia de la atribución de roles de género diferentes. El antropólogo Marvin Harris ha explicado las variaciones en las jerarquías de género en función del significado que tienen las diferencias anatómicas entre hombres y mujeres para desarrollar ciertas tareas agrícolas importantes. En sociedades en las que el modo de producción agrícola se basa en la agricultura de la azada, las mujeres pueden utilizar este instrumento con la misma eficacia que los hombres, lo que les permite controlar su propia oferta de alimentos, involucrarse en el comercio de sus productos $\mathrm{y}$ participar con voz y con voto en los asuntos domésticos y políticos $^{109}$.

A medida que se va desarrollando la tecnología agraria, el arado, con frecuencia arrastrado por una animal, sustituyó a la azada. Si además los campos de cultivo se encontraban a una distancia considerable de la vivienda, el papel de las mujeres en el trabajo generador de recursos se acabó relegando a un segundo plano $^{110}$.

\footnotetext{
${ }^{109}$ Harris, Marvin. Introducción a la antropología general. Alianza, Madrid, 2013, pág. 522.

${ }^{110}$ Saltzman, 1992, pág. 142.
} 
Los hombres consiguieron el monopolio sobre el uso del arado tirado por un animal, por el mismo motivo por el que lograron el monopolio de las armas de caza y de guerra en las sociedades más primitivas: su mayor fuerza corporal les capacitaba para ser más eficientes que las mujeres ${ }^{111}$. Porque si bien es cierto que las diferencias en la fuerza muscular de hombres y mujeres pueden reducirse con el entrenamiento, la superioridad que siguen conservando los hombres es suficiente para establecer la diferencia entre pasar o no pasar hambre en ciertos tipos de economías ${ }^{112}$.

Al conseguir el control sobre el arado, consiguen ser dueños de los animales de tiro. Con la difusión de la rueda y la aparición de los primeros medios de transporte, los hombres adquirieron también el dominio del comercio y el intercambio de las cosechas, convirtiéndose en los primeros mercaderes. A medida que creció la importancia del comercio fue necesario llevar a cabo un registro de todas las operaciones, lo que facilitó que los hombres lograran ser los primeros contables. Por extensión, los hombres tuvieron acceso a la lectura, a la escritura y al cálculo, así que no es de extrañar que los primeros filósofos y matemáticos también fueran hombres y no mujeres ${ }^{113}$.

En las sociedades industriales, el uso de máquinas elimina en buena medida la superioridad muscular de los hombres sobre

\footnotetext{
111 Harris, 2013, pág. 516.

112 Harris, 2013, pág. 358.

113 Harris, 2013, pág. 517.
} 
las mujeres. Esto permitió que durante los primeros años de desarrollo industrial las mujeres tuvieran a su alcance nuevas oportunidades de empleo. Sin embargo, se puso en marcha la segregación sexual y se acentuó la división sexual del trabajo que ha continuado perjudicando a las mujeres desde entonces. En primer lugar, porque su incorporación al trabajo industrial se produjo para desempeñar determinados puestos de trabajo, que eran fiel reflejo de las tareas que no habían dejado de asumir en el ámbito doméstico. En segundo lugar, porque el trabajo se realizaba a cambio de un salario sumamente bajo y en lugares que carecían de las condiciones sanitarias y de seguridad adecuadas. Y en tercer lugar, porque su vuelta al mundo laboral se produjo sin que cesaran de asumir las pesadas responsabilidades del trabajo doméstico.

Por ello, tras una primera fase de explotación en las fábricas, la mayoría de las mujeres fueron recluidas en el hogar no sólo como forma de protección de los salarios masculinos, sino también para asegurar la reproducción de la clase trabajadora.

Tras la Segunda Guerra Mundial, se produce una nueva incorporación de mujeres alfabetizadas a trabajos en los que la importancia de las condiciones físicas y anatómicas es cada vez menor. La feminización de la fuerza de trabajo, la bajada de la tasa de natalidad y la reivindicación y reconocimiento de los mismos derechos a las mujeres están profundamente asociados a los 
cambios en la forma de producir y con el paso de una sociedad de producción a una sociedad de información y de servicios ${ }^{114}$.

De manera que una sociedad en la que las mujeres son capaces de ganarse la vida sin depender de otros hombres es una sociedad que progresa hacia la igualdad de género y no sólo hacia un mayor rendimiento económico.

Para algunos enfoques sociológicos inspirados en el pensamiento feminista, la división sexual del trabajo tiene su origen en el patriarcado y se expande con el capitalismo.

a. Patriarcado.

Para Celia Amorós el patriarcado aparece como "un sistema que implica, sobre todo, la adjudicación de espacios sociales según el género y la jerarquización valorativa de esos espacios", y que en las sociedades occidentales se ha concretado en la dicotomía público y privado $^{115}$. Para esta autora, la esfera pública ha estado tradicionalmente reservada a los hombres, a los que se asociaba la cultura, la libertad, la universalidad, la capacidad para producir ideas, el comportamiento razonable, y la competitividad, entre otros. Mientras que la esfera privada, generalmente reservada a las mujeres, estaría condicionada por sus sentimientos y por los

114 Harris, 2013, pág. 518.

115 Amorós, 2005, Tomo I, pág. 76. 
cuidados que proporcionan a su familia, y a las que la función reproductora ha hecho improductivas a los ojos de la sociedad.

Las sociedades son patriarcales en la medida en que los hombres tienen poder sobre las mujeres, lo que se traduce en una relación de jerarquía entre lo masculino y lo femenino. Esta teoría permite señalar que las desigualdades entre las mujeres y los hombres no tienen un origen natural sino social. De este modo, si las desigualdades entre hombres y mujeres se han ido reproduciendo a lo largo de la historia es porque el sistema patriarcal se manifiesta dentro y fuera de la familia. Por este motivo, uno de los objetivos debe ser "romper la implacable dinámica de refuerzo mutuo que se da entre las prácticas de la vida cotidiana y de las macroestructuras económicas, políticas e ideológicas" ${ }^{\prime 116}$.

Para alcanzar este objetivo, las primeras reivindicaciones del movimiento feminista se centraron principalmente en la participación de las mujeres en la esfera pública al igual que lo podían hacer los hombres (a través del reconocimiento del derecho de sufragio, el acceso a la educación superior y a determinadas profesiones hasta entonces reservadas a los hombres). Sin embargo, con el paso de los años, se ha llegado a la conclusión de que la inclusión de las mujeres en la esfera pública no es suficiente para acabar con el problema de la desigualdad

116 Amorós, 2005, Tomo I, pág. 62. 
entre hombres y mujeres, pasando a establecer también un foco de atención en las relaciones entre hombres y mujeres en la esfera $\operatorname{privada}^{117}$.

El fenómeno de la violencia de género está en estrecha relación con la necesidad de acabar con la subordinación de las mujeres en el ámbito doméstico, siendo ésta la manifestación más extrema y penosa de dicha desigualdad aún subsistente y que reclama una intervención activa por parte de los poderes públicos en este ámbito, considerado hasta hace poco, un ámbito privado.

En la actualidad se plantea la necesidad de definir los límites entre lo público y lo privado, donde la igualdad en lo privado sería una condición sine qua non para que la igualdad en lo público pudiera ser algo real y efectivo. Se trata de "conseguir dotar de universalidad lo que el sistema patriarcal ha considerado y quiere seguir considerando como valores y actividades femeninas", es decir, "de poner fin a la adjudicación de espacios, identidades y funciones sociales según el sexo" $"$.

\section{b. Capitalismo.}

Para Engels los factores materiales y económicos del capitalismo son la base de la supeditación femenina ante los hombres, porque

117 Amorós, 2005, Tomo I, pág. 77-78.

118 Amorós, 2005, Tomo I, pág. 80. 
al igual que sucede con el patriarcado, tiene sus raíces en la propiedad privada. Asimismo sostenía que el capitalismo intensifica el patriarcado, entendido como aquel sistema en el que se produce la dominación de los hombres sobre las mujeres, mediante la concentración de poder y riqueza en manos de unos pocos hombres. El capitalismo sostiene el patriarcado porque crea una enorme riqueza en comparación con épocas anteriores ${ }^{119}$.

El capitalismo busca una mano de obra barata con el fin de obtener los máximos beneficios. Esto es lo que hace que las mujeres trabajen cada vez más fuera de casa, pero en trabajos mal pagados. Algunos autores consideran que a la sociedad capitalista le interesa seguir manteniendo esta desigualdad, ya que al pagar menos a las mujeres, contribuye a mantener su dependencia respecto de los hombres, y por lo tanto estabiliza la familia y la sociedad. Las mujeres, como esposas, proporcionan servicios a sus maridos dentro de la organización familiar, realizando el trabajo no pagado del ámbito doméstico, y apoyan al capitalismo en su papel de consumidoras de esa organización ${ }^{120}$. Por su parte, el sistema patriarcal, como forma de relación entre hombre y mujer, define a las mujeres principalmente como madres, lo que ayuda a mantener la segregación con respecto a los empleos y los sueldos bajos para las mujeres, así como su compromiso con el trabajo no remunerado de la casa y la familia.

\footnotetext{
119 Giddens, 2012, pág. 651-652.

120 Saltzman, 1992, pág. 25.
} 


\subsection{TRABAJO REMUNERADO Y TRABAJO DOMÉSTICO.}

La industrialización sentó las bases para la diferenciación entre la esfera masculina (pública) y la esfera femenina (privada) ${ }^{121}$. La división sexual del trabajo dio lugar a unas relaciones de poder que siguen manteniéndose hoy en día, que son reflejo del sistema de género creado por la sociedad, y que han situado a los hombres en una posición de ventaja con respecto a las mujeres. Mientras el ámbito público adquirió valor económico, social y de prestigio, al ámbito privado sólo se le asignó un valor simbólico. Por eso, para poder hablar de discriminación, hay que medir primero las diferencias entre hombres y mujeres en términos de distribución de bienes, servicios, prestigio y poder.

Según este esquema, al hombre le corresponden aquellos roles de trabajo que generan acceso directo a los recursos materiales. De este modo, la posesión y, sobre todo, el control de los medios y del resultado de la producción, se acumulan en una minoría de personas que resulta ser masculina ${ }^{122}$. Por el contrario, cuando las mujeres producen bienes que no se dedican al consumo doméstico, normalmente las labores que desarrollan generan menos recursos que aquellas de las que se responsabilizan los hombres. Debido a que los hombres llevaban el peso general del trabajo necesario para la producción de los alimentos, las labores

121 Giddens, 2012, pág. 404.

122 Saltzman, 1992, pág. 56. 
necesarias para la crianza de los hijos y el mantenimiento de la familia y del hogar, se convierten en especialidad de las mujeres.

Lo que sucede con el trabajo doméstico es que no produce ningún acceso directo al dinero u otros bienes materiales que se puedan intercambiar por otros fuera del ámbito de la familia, lo que otorga pocas recompensas y escaso reconocimiento social en sociedades cuyas economías están estructuradas en torno a la producción y a la permuta de una plusvalía ${ }^{123}$.

Algunas autoras como Ann Oakley han puesto de manifiesto la estrecha relación que existe entre las formas de trabajo remunerado y no remunerado. Por un lado, ese trabajo doméstico no reconocido ni recompensado mantiene el resto de la economía, al proporcionar servicios gratuitos esenciales a gran parte de la población activa. Y por otro, el trabajo remunerado aporta unos ingresos que a su vez crean unas relaciones de poder desiguales, al hacer a las amas de casa dependientes de sus compañeros masculinos para su propia supervivencia económica y la de su familia ${ }^{124}$.

Este esquema se ha explicado por la teoría del intercambio, en la que el trabajo doméstico se intercambia por apoyo económico $^{125}$. Según esta teoría, para que la relación entre hombre

\footnotetext{
${ }^{123}$ Saltzman, 1992, pág. 57.

${ }^{124}$ Giddens, 2012, pág. 934-935.

125 Giddens, 2012, pág. 377.
} 
y mujer continúe a lo largo del tiempo de una manera estable, deben proporcionarse mutuamente valores aproximadamente iguales. Los hombres aportan a la familia todos o prácticamente todos los recursos materiales necesarios para la supervivencia de sus miembros, así como para la adquisición de cosas deseadas aunque no necesariamente necesitadas. Para equilibrar el intercambio, las mujeres cuidan las necesidades personales de la familia, del hogar, ofreciendo deferencia ante las exigencias de sus cónyuges, de forma que cuanto mayor es la proporción de la contribución de recursos materiales llevada a cabo por las mujeres con respecto a los hombres, menor es la obediencia de las mujeres a sus maridos.

Para los defensores de esta teoría, la mayoría de habilidades laborales no domésticas se pueden transferir a otro empresario en el marco de otra relación laboral, mientras que las habilidades domésticas pueden no ser relevantes en el seno de otra familia distinta, máxime cuando los servicios domésticos pueden ser adquiridos fuera de aquella. Por eso, en esta situación en la que la mujer no trabaja fuera de casa y el trabajo doméstico no reporta independencia económica, siempre será más costoso y más problemático para la mujer prescindir del apoyo material del hombre, lo que le otorga a este último un mayor poder en términos de recursos económicos. 
La incorporación de la mujer al mundo laboral ha hecho disminuir su dependencia del hombre, y en teoría esa dependencia debería ser menor a medida que las diferencias salariales entre ambos se acortan. Sin embargo, en la mayoría de los casos, el dominio del hombre no se elimina cuando la mujer trabaja fuera del hogar, sino que esta situación de subordinación se reproduce en un nivel superior al doméstico. El hecho de que los hombres tengan mayor acceso que las mujeres a los recursos productivos, $\mathrm{y}$ en consecuencia, disfruten de un mayor poder sobre los mismos, les dota de más autoridad a la hora de definir la realidad y la conducta apropiada para las mujeres. Si los hombres hacen uso de ese poder para seguir apoyando la división sexual del trabajo y la deferencia femenina ante los hombres, las desigualdades entre los sexos se seguirán perpetuando dentro y fuera de la familia.

El trabajo remunerado de las mujeres no se puede entender si no se tienen en cuenta sus funciones domésticas, ya que su incorporación al ámbito público se ha producido sin abandonar el privado. De igual modo, el trabajo de los hombres tampoco puede entenderse sin tener en cuenta la organización doméstica en que generalmente se apoya, haciendo posible su elevada disponibilidad para la vida profesional.

Aunque hoy en día se acepta el derecho de las mujeres a tener las mismas oportunidades de carrera que los hombres, esta idea no será real hasta que se venzan los prejuicios relacionados 
con las responsabilidades maternas y paternas con la familia. La teoría del interaccionismo simbólico se ha acercado al problema, preguntándose si la participación o no en el trabajo del hogar está relacionada con los roles de género creados por la sociedad, para llegar a la conclusión de que la distribución desigual de tareas está relacionada con el entendimiento de que hombres y mujeres deben actuar en esferas diferentes, asumiendo las responsabilidades que lleva implícita cada una de ellas, y que les correspondería según esta división. Así se espera que los hombres sean proveedores y que las mujeres se ocupen de cuidar a la familia, incluso cuando trabajen fuera de casa. Estas expectativas refuerzan los roles tradicionales de género aprendidos durante el proceso de socialización desde que nacemos. Al reproducir estos roles el género se refuerza y contribuye a seguir diferenciando entre hombres y mujeres según estos parámetros ${ }^{126}$.

Esto evidencia que las diferencias de género no son neutrales y son una forma importante de estratificación social. De hecho, algunos autores consideran el género como uno de los ejemplos más claros de estratificación ${ }^{127}$. Los hombres suelen tener más riqueza, estatus e influencia que las mujeres en ciertos aspectos de la vida social, y esto es consecuencia del género. Si pensamos en el trabajo, la mayor parte de las mujeres se encuentran en una posición subordinada dentro del mismo, por lo

${ }^{126}$ Giddens, 2012, pág. 378.
127 Giddens, 2012, pág. 495. 
que el tipo de oportunidades en el ámbito laboral y las elecciones a las que se enfrentan las personas realmente varían en función del género. Pero además, la situación material de las mujeres tiende a ser un reflejo de la de sus padres o maridos, por lo que algunos enfoques teóricos como el marxismo han explicado las desigualdades de género en función de la clase social a la que pertenecen.

Es cierto que se ha avanzado en este terreno y que en la actualidad los hombres comparten las responsabilidades domésticas con las mujeres, pero todavía queda mucho por hacer. Si la mujer trabaja igual que el hombre y gana lo mismo que él, los dos deberían participar en las tareas domésticas del mismo modo. Pero lo que no se explica es por qué cuando la mujer gana más que el hombre el peso de las tareas domésticas sigue siendo asumido en mayor medida por ellas. ¿Realmente la participación en el trabajo del hogar está relacionada con los roles de género creados por la sociedad? ${ }^{128}$

Puede suceder que aunque las mujeres desean que los hombres participen más en el hogar, no siempre están dispuestas a compartir la toma de decisiones en este ámbito. Las mujeres se siguen ocupando mayoritariamente de la coordinación y los hombres suelen ser, en la mayoría de los casos porque no se les da otra opción, meros ejecutores de las órdenes que reciben,

${ }^{128}$ Giddens, 2012, pág. 377. 
relacionadas con la manera y el momento en que deben hacerse los trabajos domésticos ${ }^{129}$.

Si no se cambia de actitud será imposible educar a las generaciones futuras en un sentido más igualitario y romper de una vez por todas con la clásica compartimentalización de tareas y ámbitos de actuación propios de mujeres y de hombres. Hasta que no se consiga igualdad en lo privado, las responsabilidades familiares se seguirán percibiendo como un obstáculo para participar en el empleo sólo cuando se trata de las mujeres. Las madres trabajadoras cargarán con la sospecha de falta de dedicación o interés profesional, ya que se asume que su prioridad es la familia. Son ellas las que interrumpen sus carreras para cuidar a la familia. En cambio, para los hombres, la familia se continuará considerando como un factor de mayor responsabilidad profesional, mientras su rol principal siga siendo proporcionar sustento económico ${ }^{130}$.

Por ello es necesario, no sólo poner en práctica políticas públicas de flexibilización laboral, sino también, cambiar las actitudes, los roles de los hombres y de las mujeres en relación con el cuidado de los hijos y con el trabajo doméstico, así como la

129 Tobío, Constanza. La familia y el empleo: prácticas y discursos de las mujeres, en Radl Philipp, Rita, directora. Cuestiones actuales de sociología del género. Centro de Investigaciones Sociológicas, Madrid, 2001, pág. 142.

130 Tobío, 2001, págs. 129-130. 
percepción que tiene la sociedad de que el cuidado y el trabajo doméstico corresponde en mayor medida a ellas.

\subsection{OTRAS DIFICULTADES.}

Las mujeres de hoy en día que poseen educación superior universitaria desean participar, en buena medida, en el trabajo asalariado como forma de realizarse desde un punto de vista personal con independencia de los hombres. Además de las dificultades derivadas de la división sexual del trabajo, las mujeres se enfrentan al hecho de que en la actualidad existe un excedente de personas con una buena educación universitaria y a una situación de crisis económica. Esto puede ser favorable para mitigar la segregación laboral, en el sentido de que los trabajos tradicionalmente masculinos no han podido absorber la enorme cantidad de hombres con estudios, por lo que muchos de ellos han ocupado empleos femeninos, que en algunos casos requerían una menor cualificación y estaban peor remunerados. Sin embargo, las mujeres se han podido ver desplazadas de un trabajo que en otra situación hubiera sido desempeñado por ellas.

Por otro lado la superpoblación también puede ser un obstáculo para el empleo femenino, ya que puede hacer disminuir sus oportunidades de empleo. Si el crecimiento de población se mantuviera constante lo más probable es que las mujeres se vieran apartadas del trabajo generador de recursos. 
No obstante, esta no es la tendencia en España, con una tasa de natalidad de las más bajas de Europa. Desde un punto de vista demográfico, la participación de la mujer en el mundo laboral ha supuesto que las mujeres decidan tener menos hijos o no tenerlos. Y esto implica tener que enfrentarse a una dificultad de carácter cultural, renunciar o postergar demasiado en el tiempo lo que convencionalmente se ha esperado de la mujer: tener hijos, mantener una relación afectiva estable, construir una familia. La cuestión es que puede ser cierto que la mayoría de las mujeres quieren formar voluntariamente una familia, pero sin renunciar al trabajo fuera de casa, sin renunciar a su espacio público. Por lo que "la cuestión no es sólo conciliar actividades en el tiempo sino conciliar culturas, reinventando nuevas formas de ser" ${ }^{\text {"131. }}$.

\subsection{MOVIMIENTOS SOCIALES.}

Los movimientos sociales feministas son los responsables de la mayor parte de los cambios sociales de los que podemos disfrutar mujeres y hombres hoy en día. A través de ellos se han generado importantes transformaciones de las estructuras políticas existentes, lo que ha permitido una mayor participación de las mujeres en aquellas cuestiones que también les afectan como ciudadanas activas de la sociedad a la que pertenecen.

\footnotetext{
131 Castells Oliván, Manuel y Marina, Subirats Martori. Mujeres y hombres ¿un amor imposible? Alianza, Madrid, 2007, pág. 26.
} 
La vida política no sólo tiene lugar dentro del marco ortodoxo de los partidos políticos, el voto y la representación en los organismos legislativos y gubernamentales. Por ello es importante proteger los movimientos sociales en general, y los feministas en particular, ya que son una de las manifestaciones más poderosas de la acción colectiva, en el sentido de que tienen gran influencia en los gobiernos para que éstos tomen decisiones que favorezcan la igualdad entre mujeres y hombres.

Siguiendo a Enrique Laraña, los movimientos sociales se definen como una forma de acción colectiva "que apela a la solidaridad para promover cambios sociales, cuya existencia en sí misma es una forma de percibir la realidad, ya que vuelve controvertido un aspecto de ésta que antes era aceptado como normativo, que implica una ruptura de los límites del sistema de normas y relaciones sociales en el que se desarrolla su acción, y que tienen capacidad para producir nuevas normas $y$ legitimaciones en la sociedad"132.

El movimiento feminista es expresión del malestar producido por determinados aspectos de la vida social, como es que las diferencias biológicas entre hombres y mujeres hayan determinado la identidad, los roles de género y el espacio que ha

132 Larraña, Enrique. La construcción de los movimientos sociales. Alianza, Madrid, 1999, págs. 126-127. 
correspondido tradicionalmente a las mujeres, y que se caracteriza por su dependencia y subordinación al varón.

La sociología ha contribuido a clarificar este hecho social explicando las causas del mismo, y el movimiento social feminista las ha deslegitimado con el propósito de transformar la sociedad y a quienes participan en él.

Como todo movimiento de cambio social, el feminismo ha contribuido a definir como injusta una situación generalmente aceptada y respaldada por la tradición cultural y la costumbre ${ }^{133}$. Presenta un aspecto de la vida social que ya está sometido a discusión pública, aunque anteriormente se hubiera aceptado como norma. De hecho, una de las dificultades añadidas del movimiento feminista es que sus reivindicaciones nunca han sido consideradas como algo natural. Por tanto, "entender el feminismo es entender que las múltiples formas en que se concreta $y$ reproduce la opresión de las mujeres nunca han sido ni evidentes ni de sentido común"134.

El feminismo y los enfoques sociológicos basados en el mismo han apoyado el movimiento feminista mostrando hechos $\mathrm{y}$ desarrollando teorías sobre las causas de la desigualdad y convenciendo a las personas para que se unan en defensa de sus

133 Amorós, 2005, Tomo I, pág. 58.

134 Amorós, 2005, Tomo I, pág. 63. 
intereses. La teoría feminista tiene entre sus fines definir adecuadamente, como conflictos y producto de unas relaciones de poder determinadas, hechos y relaciones que se consideran normales o naturales, o en todo caso, inmutables ${ }^{135}$. Para ello hay que dar un nombre al hecho que se quiere hacer visible, así como poner de manifiesto que se trata de un hecho irracional y generalizarlo. Con esto último se consigue hacer comprender que no se trata de casos aislados vinculados a los rasgos psicológicos que tradicionalmente se atribuyen en función del sexo a hombres y mujeres, sino que se trata de un fenómeno que supera los límites de la esfera privada y que con el paso de los siglos se ha ido incorporando al espacio público pasando a tener la consideración de problema social ${ }^{136}$.

En realidad estamos ante un proceso en el que se pasa de la experiencia individual a la acción colectiva y al surgimiento de la solidaridad entre mujeres. Las mujeres solas se dan cuenta de que sus problemas personales (como la exclusión del derecho de sufragio, de la educación, del trabajo, del control de su propia sexualidad y por tanto de la natalidad, etc.), eran en realidad producto de una estructura social que había que comprender y cambiar. Es la experiencia personal la que provoca que algunas mujeres se organicen, sin una ideología previa. Gracias al movimiento feminista se crean los primeros espacios para estudiar

135 Amorós, 2005, Tomo I, pág. 61.

136 Amorós, 2005, Tomo I, págs. 15-26. 
su situación, desde la propia experiencia personal, y organizarse para reivindicar derechos de los que carecían.

La institucionalización del feminismo ha tenido una clara influencia en esta cuestión. La creación del Instituto de la Mujer, la formación de lobbies o grupos de presión, o la proliferación en las universidades de centros de investigaciones feministas tiene mucho que ver con lo que se conoce con el nombre de liberación cognitiva de las mujeres, con su cambio de percepción de la realidad, lo que conduce a cuestionarla críticamente. De esta forma, para algunas autoras los principios del feminismo han pasado de ser patrimonio de unos pocos a convertirse en una forma de proceder que es de sentido común para la mayoría ${ }^{137}$.

El movimiento feminista ha contribuido a la construcción de la identidad femenina común al reclamar la aplicación de los principios democráticos de manera universal, la inclusión de las mujeres en la vida pública mediante el derecho al sufragio, al trabajo asalariado y a la educación superior. Superada esta fase, una vez conquistados estos derechos, una vez que se consolida la igualdad formal, jurídica o de iure, se constata la insuficiencia de la misma y comienza una nueva etapa de pensamiento crítico que permitirá seguir avanzando hacia una igualdad real o material. Por tanto, aunque los cambios legales han sido fundamentales, al igual que las reformas asociadas al Estado del Bienestar, tiene tanta o

137 Amorós, 2005, Tomo I, pág. 83-88. 
más importancia el trabajo dedicado a educar a las mujeres y a los hombres individualmente así como a la sociedad en la que se integran, en el sentido de la importancia de disfrutar de los mismos derechos y obligaciones.

Sin embargo, tal y como ha puesto de manifiesto Pierre Bourdieu en La dominación masculina, "la revolución simbólica que reclama el movimiento feminista no puede limitarse a una simple conversión de las conciencias y de las voluntades" ${ }^{\prime 138}$. No es posible esperar la liberación de las mujeres por el solo hecho de que tomen conciencia de su situación, es necesario verificar y explicar cómo funcionan las estructuras sociales que inclinan a las mujeres a su situación de subordinación para poder transformar las pautas de comportamiento dominador en unos casos, subordinado en otros.

138 Bourdieu, 2000, pág. 58. 



\section{III- LA IGUALDAD COMO VALOR SUPERIOR DEL ORDENAMIENTO JURÍDICO.}

En el artículo 1 apartado primero de la Constitución Española de 1978 se establece que "España se constituye en un Estado social y democrático de Derecho que propugna como valores superiores de su ordenamiento jurídico la libertad, la justicia, la igualdad y el pluralismo político". Esta es la primera vez que un texto constitucional recoge de forma expresa la palabra "valores", calificándolos como "superiores" y citando además cuáles son ${ }^{139}$.

Si analizamos la historia del constitucionalismo español ${ }^{140}$, se comprueba que las inclusiones de valores se hacen en tres textos que se pueden calificar de progresistas, mientras que se omite en todos los textos moderados ${ }^{141}$. No se encuentra referencia al concepto de valores superiores ni en la Constitución de 19 de marzo de $1812^{142}$, ni en el Estatuto Real de 10 de abril de 1834. En los artículos 1 a 4 de la Constitución de Cádiz se reconoce la libertad e independencia de la Nación española, en la que reside la soberanía, para establecer sus leyes fundamentales, leyes que debían ser "sabias y justas" para conservar y proteger "la libertad

\footnotetext{
139 Díaz Revorio, Francisco Javier. Valores superiores e interpretación constitucional. Centro de Estudios Políticos y Constitucionales, Madrid, 1997, págs. 32-33.

140 Tierno Galván, Enrique. Leyes politicas españolas fundamentales (1808-1978). Tecnos, Madrid, 1984.

${ }_{141}$ Peces Barba, Gregorio. Los valores superiores. Tecnos, Madrid, 1984, pág. 20.

${ }^{142}$ Fernández García, Antonio. La Constitución de Cádiz. (1812) y discurso preliminar a la Constitución. Castalia, Madrid, 2002.
} 
civil, la propiedad y los demás derechos legítimos de todos los individuos que la componen". En contraposición, el texto conservador del Estatuto Real no reconoce la soberanía nacional por lo que según su artículo 33, para la formación de las leyes se requiere la aprobación de los dos Estamentos que componen las Cortes Generales, el de Próceres del Reino y el de Procuradores del Reino, y además la sanción del Rey. Por tanto, se eliminan las notas progresistas de la Constitución de 1812 y con ello las referencias a la libertad civil y a la justicia de las leyes.

Tampoco aluden a los valores superiores del ordenamiento jurídico tal y como hoy los concebimos ni la Constitución de 18 de junio 1837, ni la de 23 de mayo 1845, progresista y conservadora, respectivamente. Nuevas y sucesivas revueltas violentas entre progresistas y moderados culminan en 1868 con el exilio a Francia de la reina Isabel II y la aprobación de la Constitución de 1869, resultado de la Revolución conocida con el nombre de la Gloriosa. Tanto la Constitución de la Monarquía española de 5 de junio de 1869 como el proyecto de Constitución Federal de la República española de 17 de julio de 1873, hacen una referencia a la justicia y a la libertad como fines a alcanzar con la Constitución, pero es una referencia que carece de valor normativo al situarse en un preámbulo que antecede a la Constitución. En la Constitución de 1869 se indica que "la Nación española y en su nombre las Cortes Constituyentes, elegidas por sufragio universal, deseando afianzar la justicia, la libertad y la seguridad, y proveer al bien de cuantos 
vivan en España, decretan y sancionan la siguiente Constitución (...)”. Para Díaz Revorio, el término “afianzar” es equiparable a la palabra "propugnar" que emplea la Constitución de 1978, ya que ambos revelan el deseo de realizar de forma progresiva en el tiempo los referidos valores ${ }^{143}$. Por su parte, el Título Preliminar del Proyecto de Constitución Federal de la República española señala que "toda persona encuentra asegurados en la República, sin que ningún poder tenga facultades para cohibirlos, ni ley ninguna autoridad para mermarlos, todos los derechos naturales. Entre ellos el derecho a la libertad de trabajo y la igualdad ante la ley".

Posteriormente, en la Constitución de 30 de junio de 1876 se vuelve a omitir cualquier referencia a dichos valores. Hay que esperar a la Constitución republicana de 9 de diciembre de 1931 para que, ya dentro del texto, se mencionen los valores de libertad, justicia e igualdad. En el artículo 1 al señalar que "España es una República democrática de trabajadores de toda clase, que se organiza en régimen de Libertad y de Justicia”, y en el artículo 2 cuando se reconoce que "todos los españoles son iguales ante la ley", aunque este concepto es más restringido y tiene un significado más limitado que la proclamación de la igualdad sin añadidos, que comprende también la igualdad real o promocional $1^{144}$. Por otro lado cabe indicar que en ninguno de

\footnotetext{
143 Díaz Revorio, 1997, pág. 56.

144 Díaz Revorio, 1997, pág. 59.
} 
estos textos se menciona el pluralismo político, que se incluye en el texto de 1978 como lógica reacción frente al régimen franquista.

No obstante, aunque estos textos ya se refieren a valores como la justicia, la libertad o la igualdad, la forma en que lo hace nuestra vigente Ley fundamental carece de precedentes por cuanto los califica como "valores superiores del ordenamiento jurídico"145. Llamas Cascón afirma que la Constitución de 1978 introduce una triple innovación en su texto respecto a la historia de los textos político-jurídicos de similares características en España. En primer lugar incorpora los valores superiores en el articulado del texto. En segundo lugar, vincula los valores a una forma concreta de modelo de Estado. Y en tercer lugar, la fórmula utilizada, "que propugna como valores superiores", declara la autoexigencia de un Estado que se propone como fines, elementos jurídico-morales desde su propio ordenamiento jurídico ${ }^{146}$. En este sentido, el artículo 1.1 CE representa una superación de la antítesis iusnaturalismopositivismo, y consigue integrar en el ordenamiento jurídico la moral que reflejan esos valores superiores.

Luciano Parejo Alfonso ${ }^{147}$ ha puesto de relieve la correspondencia entre los valores superiores con las notas definitorias del Estado, de tal forma que el Estado de Derecho se

145 Díaz Revorio, 1997, pág. 59.

146 Llamas Cascón, Ángel. Los valores jurídicos como ordenamiento material. Universidad Carlos III y Boletín Oficial del Estado, Madrid, 1993, pág. 215.

${ }_{147}$ Parejo Alfonso, Luciano. Estado Social y Administración Pública. Cívitas, Madrid, 1983, pág. 65. 
conecta con el valor "libertad", el Estado social con el valor "igualdad" y el Estado democrático con el valor "pluralismo político". Sin embargo, la relación entre valores superiores y los diversos tipos de Estado no es unívoca. El Estado de Derecho también se asocia al valor de la igualdad, en el sentido formal de igualdad ante la ley. Y el Estado social se vincula con la libertad, la cual adopta de este modo una dimensión menos individualista, ya que conlleva en algunos casos prestaciones estatales ${ }^{148}$. Esto evidencia, tal y como ha puesto de manifiesto Norberto Bobbio, que los valores superiores se relacionan entre sí. Para este pensador italiano "la igualdad, como valor supremo de una convivencia ordenada, feliz y civil, y por consiguiente, de una parte, como aspiración perenne de los hombres que viven en sociedad, y de otra, como tema constante de las ideologías y de las teorías políticas, queda aparejada a menudo con la libertad"149. No obstante, mientras que la libertad es una cualidad o propiedad de la persona, la igualdad se refiere a "un cierto tipo de relación entre los entes que forman parte de la categoría abstracta de la humanidad"150. Por tanto, según Bobbio, lo que caracteriza a la igualdad como valor es su indeterminación, es decir, que no significa nada sin identificar los titulares y las cosas respecto a las que son iguales ${ }^{151}$.

\footnotetext{
148 Díaz Revorio, 1997, pág. 84.

${ }^{149}$ Bobbio, Norberto. Igualdad y libertad. Paidós, Madrid, 1993, pág. 53.

150 Bobbio, 1993, pág. 55.

151 Bobbio, 1993, pág. 56.
} 
Por lo que respecta al valor superior "justicia”, algún sector de la doctrina considera que escaparía a la correlación entre valores y tipos de Estado. Para Peces Barba esto implica que "esa relación que prescinde el valor justicia, cuyo concepto es problemático, (...), sitúa los valores superiores en el plano de la totalidad", haciendo de ellos "el marco, el límite y el objetivo a alcanzar por el ordenamiento, al que tienen que acoplarse todas las demás normas y al que tienen que ajustar su actuación todos los operadores jurídicos" $" 152$.

El concepto de justicia se ha identificado con el de legalidad y también con el de igualdad, considerándose que un determinado comportamiento es justo cuando se lleva a cabo de acuerdo con lo establecido en las leyes, y respeta una relación de igualdad. De esta forma la justicia aparece como el elemento de orden, de equilibrio o de armonía de las partes de un todo, en nuestro caso, del ordenamiento jurídico en su conjunto. La instauración de una cierta igualdad entre las partes y el respeto de la legalidad son las dos condiciones para la institución y conservación de la armonía del todo, son dos condiciones necesarias y suficientes para que actúe la justicia. En todo caso, lo que hace que la igualdad sea un valor deseable, un fin a alcanzar por el ordenamiento jurídico y por la sociedad, es su justicia.

152 Peces Barba, 1984, pág. 38. 
Para Gregorio Peces Barba la justicia como valor superior no añade nada a la libertad y a la igualdad. Para este autor la justicia es el "instrumento de los jueces para incorporar a las resoluciones criterios de moralidad existentes en el ámbito cultural en el que se produce la sentencia, intereses propios e intereses generales y, también, muchas veces, intereses de sectores sociales, de grupos de presión y el reflejo de la propia mentalidad del juez, donde todos esos elementos son tamizados, interiorizados y reconvertidos a través del prisma de su personalidad" ${ }^{153}$. Se trataría de un concepto que puede ser un cheque en blanco para el Tribunal Constitucional y potenciar un judicialismo indeseable. Aunque esta visión quizás sea demasiado negativa. Hay que confiar en el juez como pieza clave para que los valores incluidos con intención utópica en la Constitución consigan dar su fruto. Además, los criterios de justicia pueden servir para dictar resoluciones judiciales alejadas de una visión demasiado estática del ordenamiento jurídico, y que, aunque puedan ser ajustadas a derecho, sean contrarias a la idea de lo que es justo para la ciudadanía. De hecho, el propio Tribunal Constitucional en la Sentencia 20/1987 de 19 de febrero, ha negado que la justicia sea un arma a favor del activismo judicial según la particular concepción que de la misma tenga el juez, pues la justicia no es un valor ajeno y contrario al ordenamiento positivo, sino uno de los valores superiores del $\operatorname{mismo}^{154}$.

\footnotetext{
153 Peces Barba, 1984, pág. 146.

${ }^{154}$ FJ 4 párrafo tercero de la STC 20/87, de 19 de febrero.
} 
Los valores superiores son la base del sistema jurídico-político y delimitan las líneas de su desarrollo. Los valores superiores como moralidad legalizada son una orientación sobre dónde debe ir el Derecho, y se concretan en el Título I de la Constitución de 1978 rubricado "De los derechos y deberes fundamentales", y especialmente en el Capítulo III "De los principios rectores de la política social y económica", que es plasmación del valor igualdad $^{155}$. La vinculación entre los principios rectores y el valor igualdad en su vertiente material se ha puesto de manifiesto por la STC 19/1987 de 17 de febrero, en la que se indica que la igualdad ante la ley del artículo 14 y la igualdad del artículo 31, son reflejo de la igualdad como valor superior consagrado en el artículo 1.1 $\mathrm{CE}^{156}$.

La inclusión de los valores superiores en una norma jurídica como es el artículo 1.1 CE implica reconocer el carácter normativo de los mismos. El aludido carácter normativo deriva de que este precepto forma parte de la Constitución, obra del poder constituyente, que es el pueblo soberano, y que ésta tiene carácter jurídico y vinculante, previendo además mecanismos de sanción para su incumplimiento ${ }^{157}$. Esta consideración de los valores como norma jurídica tiene como consecuencia que éstos vinculan no sólo a los poderes públicos, tanto de forma negativa (lo que trae

\footnotetext{
155 Peces Barba, 1984, pág. 41.

${ }^{156}$ FJ 3 de la STC 19/87, de 17 de febrero.

157 Díaz Revorio, 1997, pág. 161.
} 
como consecuencia la inconstitucionalidad de aquellos actos o normas que los contradigan), como positiva (imponiéndoles deberes de actuación positiva), sino también a los ciudadanos, a los que sólo vinculan de manera negativa, en el sentido de que han de abstenerse de actuaciones contrarias a los mismos ${ }^{158}$. Por este motivo puede afirmarse que los valores despliegan eficacia jurídica.

Sin embargo, hay autores que niegan su carácter jurídico, por ejemplo Rubio Llorente, para quien el simple enunciado de unos valores como tales carece en sí mismo de significado jurídico, aunque se haga en el cuerpo de la más alta disposición. Entiende que el significado del artículo $1.1 \mathrm{CE}$ es la determinación o especificación de finalidades a alcanzar, pero en todo caso carece de eficacia jurídica real, de manera que se trata de una norma vacía de la que no cabe derivar derechos ni deberes u obligaciones ${ }^{159}$. Para este autor la ineficacia de los valores superiores deriva de su propio contenido, lo que hace que si bien pueden configurarse como normas jurídicas, no pueden desplegar los efectos que son propios de éstas, convirtiéndose en mera retórica, incapaz de vincular a los poderes públicos ${ }^{160}$.

\footnotetext{
158 Un campo o materia en el que se manifiesta claramente la eficacia de los valores frente a ciudadanos es el de las relaciones laborales. La igualdad suele aplicarse en su manifestación como principio de no discriminación del artículo 14 CE. Así, el artículo 17 del Estatuto de los Trabajadores declara la nulidad de los pactos individuales y decisiones unilaterales del empresario que contengan discriminaciones, lo que permitiría hablar de una eficacia mediata del valor igualdad en las relaciones laborales.

159 Rubio Llorente, Francisco. Derechos fundamentales y principios constitucionales. Ariel, Barcelona, 1995, apartado tercero del prólogo a la obra que se cita.

${ }^{160}$ Díaz Revorio, 1997, pág. 165.
} 
Siguiendo a Gregorio Peces Barba, el artículo 1.1 CE positiviza los contenidos éticos que el Estado pretende alcanzar a través del ordenamiento jurídico, y que son precisamente esos valores. En este sentido los valores superiores representan los ideales que una comunidad decide erigir como sus máximos objetivos a desarrollar por el ordenamiento jurídico, son expresión de la moralidad mayoritariamente aceptada en el ámbito cultural y en el momento histórico en el que se sitúa nuestra Constitución, y son también expresión máxima de la decisión política de España como Estado social y democrático de Derecho ${ }^{161}$. Además, al tener una procedencia desde la moralidad, no se agotan en su contenido normativo, sino que también realizan una función crítica y de presión social. El fundamento de esos valores es un fundamento racional e histórico que representa el juicio del legislador constituyente ratificado en referéndum y que se convierte así en un gran acuerdo social, en un consenso básico de que esos valores superiores son el cauce para la realización de uno de los objetivos básicos del Estado: el desarrollo de la dignidad humana a través de la vida social, haciendo posible la plenitud de esa dignidad.

El hecho de que la dignidad de la persona se considere fundamento del orden político y de la paz social, permite reconducir sus características al Estado social y democrático de Derecho. Esto lleva a cuestionarnos si la enumeración de valores

161 Peces Barba, 1984, pág. 42. 
superiores que hace el artículo 1.1 CE es o no taxativa. La doctrina es prácticamente unánime al reconocer que la dignidad es un valor constitucional fundamental. El Tribunal Constitucional también ha afirmado que la dignidad es un valor constitucional esencial, cuya importancia sobrepasa a los demás conceptos del artículo 10.1 CE para equipararse más bien a los valores del artículo $1.1 \mathrm{CE}^{162}$.

La dimensión de conjunto en relación con el sistema jurídico que tienen los valores superiores, que nos proporcionan un fundamento ético-jurídico del Estado social y democrático de Derecho, los convierte en elementos que permiten identificar el sistema político expresado por la Constitución de 1978, realizando no sólo una función de integración y de homogeneización social como también una labor de distinción del sistema, diferenciándolo de los anteriores, tanto del régimen franquista como de los sistemas de las Constituciones de 1876 y de 1931. Los valores superiores son así guía para la interpretación y para el desarrollo del ordenamiento, y al mismo tiempo, límite para los mismos. Asimismo, los valores superiores deben ser también punto central en los razonamientos del Tribunal Constitucional, el contenido y la razón de fondo, la expresión de la legitimidad del sistema político y de la justicia del ordenamiento jurídico en cuanto son cauces para la afirmación de la dignidad humana y en ese sentido, de ellos se extraen las razones éticas para la obediencia al Derecho ${ }^{163}$.

\footnotetext{
162 FJ 3 de la STC 53/85, de 11 de abril.

163 Peces Barba, 1984, págs. 43-45.
} 
La inclusión constitucional de la igualdad entre los valores superiores de nuestro ordenamiento jurídico la convierte en una de las metas u objetivos básicos que nuestro sistema jurídico-político se propone alcanzar. Por eso se dice que la igualdad en su condición de valor superior constitucional tiene una dimensión trascendente, es decir, se presenta como un criterio para enjuiciar las acciones, ordenar la convivencia y establecer sus fines, que supera la esfera de la estricta positividad. La igualdad supone el contexto axiológico fundamentador o básico para la interpretación de todo el ordenamiento jurídico, el postulado-guía para orientar la hermenéutica teleológica y evolutiva de la Constitución, y el criterio para medir la legitimidad de las diversas manifestaciones del sistema de legalidad ${ }^{164}$.

Esta condición axiológica y trascendente de la igualdad se ha visto corroborada por la STC 8/1983 de 18 de febrero, según la cual la igualdad como valor superior "se proyecta con una eficacia trascendente, de modo que toda situación de desigualdad persistente a la entrada en vigor de la norma constitucional deviene incompatible con el orden de valores que la Constitución, como norma suprema, proclama"165. La norma impugnada era el artículo 94 del Reglamento de Trabajo de la Compañía Telefónica Nacional de España aprobado por Orden ministerial de 20 de

\footnotetext{
164 Pérez Luño, Antonio Enrique. Dimensiones de la igualdad. Dykinson, Madrid, 2007, págs. 84-85.

${ }^{165}$ FJ 3 de la STC 8/83, de 18 de febrero.
} 
junio de 1947, el cual contenía una cláusula de celibato, esto es, suspendía el contrato de trabajo para el personal femenino por causa de matrimonio ${ }^{166}$. El Tribunal la declaró inconstitucional por discriminatoria, pues no hacía derivar idéntica consecuencia en relación con el personal masculino de la misma empresa que contrajera matrimonio ${ }^{167}$. Después de la entrada en vigor de la Constitución y al amparo del artículo $14 \mathrm{CE}$, del artículo 32.1 CE por el que "el hombre y la mujer tienen derecho a contraer matrimonio con plena igualdad jurídica” y del artículo 35.1 CE según el cual "todos los españoles tienen el deber de trabajar y el derecho al trabajo, a la libre elección de profesión u oficio, a la promoción a través del trabajo y a una remuneración suficiente para satisfacer sus necesidades y las de su familia, sin que en ningún caso pueda hacerse discriminación por razón de sexo”, el mencionado artículo 94 del Reglamento de Trabajo fue derogado.

Esta eficacia derogatoria de la Constitución se extiende a "todas aquellas disposiciones que no son susceptibles de reconducir por vías interpretativas al marco constitucional"168. El Tribunal señala que no está aplicando retroactivamente la Constitución, sino simplemente entendiendo derogada por ésta la situación de excedencia forzosa en caso de matrimonio, eliminando así en el conjunto de los factores y condiciones del

166 Artículo 94 de la Reglamentación de Trabajo de la Compañía Telefónica Nacional "el personal femenino que contraiga matrimonio quedará en situación de excedencia forzosa en tanto no se constituya en cabeza de familia (...)".

${ }^{167}$ Rey Martínez, 1995, pág. 12.

${ }^{168}$ FJ 3 de la STC 8/83, de 18 de febrero. 
empleo, una discriminación basada en el sexo o en el estado civil, o en ambas circunstancias conjuntamente ${ }^{169}$.

A pesar de esto, para Díaz Revorio lo cierto es que sí que hay un cierto grado de aplicación retroactiva de la Constitución ${ }^{170}$ desde el momento que el propio Tribunal admite que la excedencia sobreviene ilegítima con efectos ex tunc por la fuerza derogatoria de la norma constitucional ${ }^{171}$, y considera que el derecho a reingresar en el servicio activo habría prescrito ${ }^{172}$ si tenemos en cuenta los plazos de prescripción que para las acciones derivadas del contrato de trabajo fija el Texto Refundido de la Ley del Estatuto de los Trabajadores ${ }^{173}$.

Por lo que respecta a los plazos de prescripción reviste especial importancia la lectura de la STC 7/1983 de 14 de febrero. En el voto particular formulado a la sentencia de esta fecha se intenta aclarar la cuestión de las relaciones entre la igualdad jurídica reconocida por el artículo 14 CE y el instituto de la prescripción extintiva. Existe en este caso un problema constitucional concerniente al plazo de prescripción de la acción para hacer

\footnotetext{
169 FJ 4 de la STC 8/83, de 18 de febrero “(...) ningún efecto retroactivo se asigna a la norma constitucional, cuando, como aquí acontece, la relación jurídica se mantiene, aunque, como es obvio, no con el contenido que es propio de la situación de activo, pero sí en situación de suspensión, entendida como una de las vicisitudes posibles de la relación laboral y dominada por la idea de temporalidad (...)".

${ }^{170}$ Díaz Revorio, 1997, pág. 404.

${ }^{171} \mathrm{FJ} 5$ de la STC 8/83, de 18 de febrero.

${ }^{172} \mathrm{FJ} 5$ de la STC 8/83, de 18 de febrero.

${ }^{173}$ Artículo 59.1 del Real Decreto Legislativo 1/1995, de 24 de marzo.
} 
efectivo el derecho fundamental ${ }^{174}$ contenido en el artículo $14 \mathrm{CE}$, consistente en no ser discriminado por razón de sexo. Los derechos fundamentales son permanentes e imprescriptibles, lo que no es ningún obstáculo para que puedan quedar sujetas a prescripción las acciones nacidas para defenderlos frente a concretas lesiones. Esta prescripción de la acción en modo alguno puede extinguir el derecho fundamental de que se trate, ya que el ciudadano lo podrá ejercer y hacer valer en relación con cualquier otra lesión futura. La cuestión del plazo de prescripción y del dies a quo del cómputo de la prescripción no ha sido del todo pacífica. Para el ponente de la sentencia Francisco Tomás y Valiente, el plazo de prescripción es el establecido en el derecho que regula la relación jurídica de base en la cual la lesión concreta se produce, lo que significa en este caso la aplicación de los plazos de prescripción de las acciones derivadas de un contrato de trabajo a derechos que tienen su asiento en la Constitución. Sin embargo, Luis Díez Picazo formula un voto particular y afirma que esto no es posible ya que los plazos de prescripción del derecho especial no constituyen un derecho común de la prescripción. Asimismo disiente de la sentencia en lo que se refiere al momento inicial del arranque del cómputo de la prescripción, que la sentencia sitúa en el momento de la promulgación de la Constitución. En primer lugar porque la concreción de este derecho fundamental a la igualdad requiere una compleja labor interpretativa, de tal forma

\footnotetext{
${ }^{174}$ Como puede verse esta Sentencia se refiere ya a la igualdad como un derecho fundamental, aspecto este al que se hará referencia en el capítulo $\mathrm{V}$ de este trabajo.
} 
que el plazo de prescripción sólo debería empezar a contarse a partir del momento en que los titulares del mismo tengan conciencia de serlo, y sólo una vez que la lesión del derecho haya desaparecido.

Una vez destacada la importancia de la igualdad como valor superior del ordenamiento jurídico, como ideal que España pretende alcanzar al constituirse como Estado social; una vez que se comprende que este fue el primer peldaño en la normativa reciente de nuestro país para avanzar en la relación de igualdad entre hombres y mujeres, se analizan a continuación aquellos aspectos de la igualdad, como principio y como derecho fundamental, que permitirán tener una visión genérica de las tres vertientes de este concepto. 




\section{IV- $\quad$ LA IGUALDAD COMO PRINCIPIO.}

El valor de la igualdad se concreta a través del principio de igualdad. Para Robert Alexy los principios y valores están estrechamente vinculados entre sí porque, por ejemplo, la progresiva satisfacción de los principios tiene su equivalente en la realización gradual de los valores. Sin embargo existe una diferencia importante entre ellos, ya que según este autor, los principios son mandatos de optimización, y en cuanto tales pertenecen al ámbito deontológico, al ámbito del deber ser. En cambio, los valores se adscriben al nivel axiológico, se ubican en la esfera de lo bueno ${ }^{175}$. El principal rasgo distintivo de los principios con relación a los valores reside en su mayor índice de concreción, de especificación respecto a las situaciones a las que pueden ser aplicados y a las consecuencias jurídicas de su aplicación, pero sin ser todavía normas analíticas ${ }^{176}$. Sin embargo, no podemos negar el carácter normativo de los valores el cual, como ya se ha indicado, deriva de su inclusión en el artículo 1.1 de la Norma Suprema de nuestro ordenamiento jurídico.

Para autores como Francisco Javier Díaz Revorio, la diferencia entre valores y principios constitucionales no puede realizarse de forma nítida o tajante, de manera que no se trata de conceptos que

175 Alexy, Robert. Teoría de los derechos fundamentales. Centro de Estudios Políticos y Constitucionales, Madrid, 2007, pág. 126.

176 Pérez Luño, 2007, pág. 87. 
por su naturaleza difieran entre sí. Seguramente, la distinción de la que deriven más efectos concretos es la que reside en la calificación de los valores como superiores, sin que el calificativo de superiores implique una superioridad jerárquica de los mismos, sino que se pretende señalar cuáles son los valores fundamentales para el conjunto del ordenamiento jurídico ${ }^{177}$.

La igualdad como principio ha sido acogida en la Constitución Española de 1978 en sus dos vertientes fundamentales. Primero como la igualdad formal, jurídica o de iure, regulada en el artículo $14 \mathrm{CE}$, que se proyecta en el sistema desde el punto de vista subjetivo como garantía general de un trato igual y no discriminatorio de las personas por parte de los poderes públicos. Y segundo como igualdad material, de hecho o de facto, atribuyendo a los poderes públicos en el artículo 9.2 CE la tarea de "promover la condiciones para que la libertad y la igualdad del individuo y de los grupos en los que se integra sean reales y efectivas; remover los obstáculos que impidan o dificulten su plenitud y facilitar la participación de todos los ciudadanos en la vida política, económica, cultural y social", lo que supone la búsqueda de la igualdad efectiva en la vida social a través de la mejora en las condiciones de vida de los más desfavorecidos, y que tiene por tanto un alcance colectivo.

177 Díaz Revorio, 1997, pág. 258. 
La aplicación práctica del principio de igualdad en la ley plantea importantes problemas, puesto que este principio no dice lo que es igual, sino que sólo determina que lo igual debe ser tratado igual; también lo contrario, que lo que no es igual debe ser tratado desigualmente ${ }^{178}$.

Esto permite distinguir la igualdad del concepto de identidad. Mientras que la identidad se identifica con la interdicción de la diferencia, la igualdad permite hacer diferencias en el tratamiento legal de las personas en función de su situación. A partir de esta concepción, no toda desigualdad de trato en la regulación de una materia es desigualdad en la ley, sino sólo la que no se apoye en criterios razonables y objetivos $^{179}$.

Desde un punto de vista lógico, la igualdad se desglosa en tres caracteres básicos. En primer lugar, se trata de una noción que exige partir, constitutivamente, de una pluralidad de personas, objetos y situaciones; alude siempre a dos o más entes entre los que se manifiesta la condición de ser iguales. En segundo lugar, el concepto de igualdad implica una dimensión relacional. No existe igualdad donde no se establece un determinado nexo entre varios entes, de manera que en un supuesto de entes aislados e incomunicados no cabe establecer juicios de igualdad. En tercer

\footnotetext{
178 Rodríguez Piñero, Miguel y M ${ }^{a}$ Fernanda Fernández López. Igualdad y discriminación. Tecnos, Madrid, 1986, pág. 46.

${ }^{179}$ Balaguer Callejón, $\mathrm{M}^{\mathrm{a}}$ Luisa. Igualdad y Constitución Española. Tecnos, Madrid, 2010, pág. 46-47.
} 
lugar se hace explícita en la comparación entre los entes de los que se predica. Se precisa contar con un elemento que haga posible la comparación, un tertium comparationis. La determinación de este término de comparación es básica para calificar a dos o más entes como iguales, siendo necesario identificar qué entes y qué aspectos de los mismos van a considerarse relevantes a efectos de la igualdad ${ }^{180}$. Además, la exigencia de un término de comparación, también permite distinguir la igualdad del concepto de equidad, con el que en ocasiones se le identifica. Para $\mathrm{M}^{\mathrm{a}}$ Luisa Balaguer Callejón, "la equidad lo que pretende, no es la aplicación de una norma a un supuesto de hecho, sino, de alguna manera, eludir su aplicación, prevista para la generalidad de los casos, ante la eventual injusticia que pueda producir en un caso concreto (...)"181. Por tanto la equidad es un criterio de justicia material que se aplica en un determinado procedimiento y que consigue que éste pueda ser considerado justo.

Estos presupuestos lógicos del concepto de igualdad poseen incuestionable relevancia para precisar y clarificar la dimensión formal de la igualdad, que es la que más directamente opera en el seno de las relaciones jurídicas y que analizamos a continuación.

\footnotetext{
180 Pérez Luño, 2007, pág. 18.

181 Balaguer Callejón, 2010, págs. 39-40.
} 
1. IGUALDAD ANTE LALEY.

\subsection{LA IGUALDAD EN LA LEY.}

La regla general de la igualdad ante la ley contenida en el artículo $14 \mathrm{CE}$ contempla en primer lugar la "igualdad en el trato dado por la ley o igualdad en la ley". Desde esta perspectiva la igualdad no podía tratar de modo desigual a unos u otros individuos sin aportar un fundamento objetivo y razonable que descartara toda discriminación. Ahora bien, qué es objetivo y qué es razonable. Para Norberto Bobbio, la única respuesta que puede darse a estos interrogantes es que entre las personas se dan diferencias que son relevantes o no relevantes, distinción que no coincide con lo que entendemos por diferencias objetivas y no objetivas. Es cierto que entre hombres y mujeres hay diferencias objetivas, pero no tienen por qué ser relevantes, ya que "la relevancia o irrelevancia se establece por la elección del valor y, por lo tanto, está históricamente condicionada" ${ }^{\prime 182}$. Así por ejemplo, las diferencias consideradas relevantes entre hombres y mujeres durante la Revolución Francesa para excluirlas del derecho de ciudadanía, no son consideradas relevantes en la actualidad aunque siga habiendo diferencias objetivas entre ambos. Por tanto, según este autor, el principio de igualdad en la ley tiene un significado histórico que no hay que olvidar cuando se estudia hoy en día.

182 Bobbio, 1993, pág. 74. 
La igualdad en la ley constituye un límite para el ejercicio del poder legislativo. El Tribunal Constitucional ha aceptado desde un primer momento la vinculación del legislador al principio de igualdad y el funcionamiento de este principio como límite a la acción legislativa $^{183}$. La STC 22/1981 de 2 de julio afirma que la igualdad jurídica reconocida en el artículo $14 \mathrm{CE}$ vincula y tiene como destinatario no sólo a la Administración y al Poder Judicial, sino también al Legislador como se deduce de los artículos 9 y 53 de la misma ${ }^{184}$.

Por otra parte hay que añadir que el límite en el ejercicio de la potestad normativa se despliega también en relación con todos aquellos interlocutores sociales a los que les está reconocida la facultad de crear normas ${ }^{185}$. En este sentido, la STC 31/1984 de 7 de marzo sienta la obligación de respetar el principio de igualdad en el contenido de las normas de los convenios colectivos, en los mismos términos que lo hace para las normas de origen estatal. La cuestión se centraba en la fijación del salario mínimo interprofesional y el Tribunal Constitucional estimó que el sistema normal de fijación del mínimo salarial y, en general, del contenido de la relación laboral, corresponde a la autonomía de trabajadores y empresarios mediante el ejercicio del derecho a la negociación colectiva que proclama el artículo 37.1 CE, y que a nivel

\footnotetext{
183 Rodríguez Piñero y Fernández López, 1986, pág. 39.

${ }^{184} \mathrm{FJ} 3$ segundo párrafo de la STC 22/81, de 2 de julio.

185 Rodríguez Piñero y Fernández López, 1986, pág. 40.
} 
legislativo, según lo previsto también en el artículo 35.2 CE, se desarrolla en el Estatuto de los Trabajadores. Un Estado social y democrático de derecho ha de complementar aquel sistema de determinación del mínimo salarial estableciendo unos techos salariales mínimos que den efectividad al mandato constitucional contenido en el artículo 35.1 CE. Mediante esta intervención estatal se atiende a un interés social que sin embargo, no disminuye el papel de las partes sociales en la consecución de otros mínimos salariales por encima de los indisponibles del mínimo interprofesional. Tanto la regulación mínima estatal como la que se deja a la responsabilidad de la autonomía colectiva de las partes ha de operarse respetando el principio de igualdad de remuneraciones con exclusión de todo trato discriminatorio que implique violación de este principio $^{186}$.

La noción de igualdad ante la ley aparece como la exigencia de que todos los ciudadanos se hallen sometidos a las mismas normas y tribunales. Implica el reconocimiento de que la ley tiene que ser la misma para todos, sin que exista ningún tipo o estamento de personas dispensadas de su cumplimiento, o sujetos a potestad legislativa jurisdiccional distinta de la del resto de ciudadanos. El principio de igualdad ante la ley se identifica, en este plano, con los requisitos de generalidad y abstracción de la norma jurídica, esto es, con la exigencia de una tipificación en términos impersonales y universales de los supuestos que han de servir de base para la

${ }^{186}$ FJ 9 de la STC 31/84, de 7 de marzo. 
atribución de determinadas consecuencias jurídicas. Esta idea de igualdad ante la ley entendida como generalidad de la norma se halla estrechamente vinculada a los principios de legalidad y de seguridad jurídica, que se verían directamente conculcados de admitirse normas ad personam ${ }^{187}$.

El principio de igualdad se traduce, según la STC 83/1984 de 24 de julio, en la "obligación del legislador de no establecer distinciones artificiosas o arbitrarias entre situaciones de hecho cuyas diferencias reales, si existen, carecen de relevancia desde el punto de vista de la razón discernible de la norma, o de no anudar consecuencias jurídicas arbitrarias o irrazonables a los supuestos de hecho legítimamente diferenciados"188. De ahí que aunque la ley singular no esté constitucionalmente prohibida, sólo será compatible con el principio de igualdad cuando la singularidad de la situación resulte inmediatamente de los hechos, de manera que el supuesto de la norma venga dado por ellos y sólo quepa al legislador establecer las consecuencias jurídicas necesarias para alcanzar el fin que se persigue, pues el principio de igualdad excluye la creación arbitraria de supuestos de hecho, que sólo resultan singulares en razón de esa arbitrariedad. Así lo establece la STC 166/1986 de 19 de diciembre ${ }^{189}$.

\footnotetext{
187 Pérez Luño, 2007, pág. 23.

${ }^{188}$ FJ 3 de la STC 83/84, de 24 de julio.

${ }^{189}$ FJ 11 letra A segundo párrafo de la STC 166/86, de 19 de diciembre.
} 
Lo que el artículo $14 \mathrm{CE}$ no incluye es que una misma situación pueda ser tratada de forma distinta en atención a la norma que en cada caso resulta aplicable, no constituyendo este hecho una vulneración del derecho a la igualdad del artículo 14 $\mathrm{CE}^{190}$. Si bien es cierto que el artículo $14 \mathrm{CE}$ ampara la igualdad ante la Ley, ello no impide que a través de cambios normativos se ofrezca un tratamiento desigual a lo largo del tiempo; "el principio de igualdad ante la ley no exige que todas las situaciones, con independencia del tiempo en que se originaron o en que se produjeron sus efectos, deban recibir un tratamiento igual por parte de la Ley, puesto que con ello se incidiría en el círculo de competencias atribuido constitucionalmente al legislador $\mathrm{y}$, en definitiva, en la natural y necesaria evolución del ordenamiento jurídico" ${ }^{\prime 191}$. Esto evidencia las observaciones de Bobbio sobre el carácter históricamente condicionado del concepto de igualdad.

Por último, el artículo $14 \mathrm{CE}$ no ampara la falta de distinción entre supuestos desiguales, esto es, lo que se denomina "discriminación por indiferenciación" o el hipotético derecho a imponer o exigir diferencias de trato ${ }^{192}$; ni tampoco "un imposible derecho a la igualdad en la ilegalidad, de manera que en ningún caso aquél a quien se aplica la Ley pueda considerar violado el

190 Corte Heredero, Nieves. Breviario de Jurisprudencia Constitucional en Materia Laboral: El Derecho a la Igualdad (art. 14 CE), y la Garantía de Indemnidad (art. 24.1 CE). Aranzadi, Cizur Menor, 2011, págs. 30-31.

${ }^{191}$ FJ 9 último párrafo de la STC 119/87, de 9 de julio.

${ }^{192} \mathrm{FJ} 2$ de la STC 88/01, de 2 de abril. 
citado principio constitucional por el hecho de que la Ley no se aplique a otros que asimismo la han incumplido"193.

\subsection{LA IGUALDAD EN LA APLICACIÓN DE LA LEY.}

La regla general de la igualdad ante la ley contenida en el artículo $14 \mathrm{CE}$ es asimismo "igualdad en la aplicación de la ley", lo que impone que un mismo órgano jurisdiccional no puede modificar arbitrariamente el sentido de sus decisiones en casos sustancialmente iguales. Así se establece una protección frente a las divergencias arbitrarias de trato en resoluciones judiciales, frente a las desigualdades de trato en la aplicación de la ley por un mismo órgano judicial cuando puedan calificarse de arbitrarias, irrazonables o que obedecen a un propósito discriminatorio. De este modo, la igualdad ante la ley entraña la garantía funcional de regularidad en los procedimientos de aplicación de las normas, lo que implica que los ciudadanos se hallarán sujetos a unos mismos procedimientos, que su posición en el desarrollo de los procedimientos será la misma y que los órganos jurisdiccionales aplicarán las normas según pautas de coherencia o regularidad. Y es que, el principio de igualdad en la aplicación de la ley protegido por el artículo $14 \mathrm{CE}$ y conectado al principio de interdicción de la arbitrariedad de los poderes públicos que consagra el artículo 9.3 de la propia Constitución, significa, en relación con el ejercicio de la potestad jurisdiccional, que un mismo juez o tribunal no puede

${ }^{193}$ FJ 4 de la STC 21/92, de 14 de febrero. 
modificar el sentido de las decisiones adoptadas con anterioridad en casos sustancialmente idénticos. Por tanto, lo que prohíbe el derecho a la igualdad en la aplicación de la Ley es el cambio arbitrario de criterios generales en la interpretación y aplicación de las normas jurídicas, llevado a cabo por una resolución judicial que responde de manera particular y aislada al concreto supuesto planteado, en contradicción injustificada con dichos criterios generales $^{194}$.

Sin embargo, el principio de igualdad no protege frente al cambio de criterio del mismo órgano judicial, siempre que tal cambio esté suficientemente motivado y justificado. $\mathrm{Y}$ es que sobre los órganos judiciales no pesa la exigencia de resolver siempre en los mismos términos sobre supuestos que se pretenden iguales, pues cada caso, para el mismo juzgador, puede merecer una consideración diversa, ya por las peculiaridades que a su juicio muestra, ya porque el entendimiento judicial de la norma aplicable variase a lo largo del tiempo, ya porque parezca necesario corregir errores en su aplicación ${ }^{195}$. La Sentencia del Tribunal Constitucional 30/1987 de 11 de marzo pone de manifiesto que lo que el principio de igualdad garantiza no es que quienes acudan a los Tribunales vayan a obtener una "resolución igual a las que se hayan adoptado o puedan adoptarse en el futuro por el mismo órgano judicial sino, más estrictamente, la razonable confianza -

${ }^{194}$ FJ 2 de la STC 108/88, de 8 de junio.

195 Pérez Royo, Javier. Curso de Derecho Constitucional. Marcial Pons, Madrid, 1994, pág. 245. 
enlazada con la seguridad jurídica que la Constitución consagra (artículo 9.3 CE)- de que la propia pretensión merecerá del juzgador la misma respuesta obtenida por otros en casos iguales"196.

Aquí se pone de manifiesto la conexión entre el principio de igualdad con la justicia como valor superior del ordenamiento jurídico. Las investigaciones de John Rawls en su obra Teoría de la justicia $^{197}$, ponen de manifiesto que en la justicia procesal perfecta "lo esencial es que existe una norma independiente para decidir el resultado que es justo y un procedimiento que garantiza que se llegará a él", sin embargo, sólo hay una mera probabilidad subjetiva de que el procedimiento de la justicia procesal perfecta garantice resultados justos de procedimiento. Es decir que, "si bien existe un criterio independiente para el resultado correcto, no hay ningún procedimiento factible que conduzca a él con seguridad"198. Por lo tanto, si se quiere que la igualdad sea justa, hay que asegurar no sólo que los procedimientos sean justos e imparciales, sino también las instituciones que los establecen y aplican a cada caso concreto.

Distinto es el problema de la igualdad en la aplicación de la ley cuando ésta no se refiere a un único órgano, sino a órganos

\footnotetext{
${ }^{196}$ FJ 2 tercer párrafo de la STC 30/87, de 11 de marzo.

${ }^{197}$ Rawls, John. Teoría de la justicia. Fondo de Cultura Económica, México D.F., 2010.

198 Rawls, 2010, pág. 90.
} 
plurales. Para tales casos, tal y como subraya la STC 49/1982 de 14 de julio, "la institución que realiza el principio de igualdad y a través de la que se busca la uniformidad es la jurisprudencia, encomendada a órganos jurisdiccionales de superior rango, porque el principio de igualdad en la aplicación de la ley tiene necesariamente que cohonestarse con el principio de independencia de los órganos encargados de la aplicación de la ley cuando éstos son órganos jurisdiccionales" ${ }^{, 199}$. Esta sentencia advierte además que "la igualdad a que el artículo 14 se refiere, que es la igualdad jurídica ante la ley, no comporta necesariamente una igualdad material o igualdad económica real y efectiva"200. Significa que a iguales supuestos de hecho se apliquen iguales consecuencias jurídicas. En efecto, tal y como establece la STC 26/1987 de 27 de febrero dictada en el recurso de inconstitucionalidad promovido por el Gobierno vasco contra determinados preceptos de la Ley Orgánica 11/1983 de 25 de agosto de Reforma Universitaria, un trato diferente no es discriminatorio si no hay igualdad en los supuestos de hecho, ya que no puede darse violación del principio de igualdad entre quienes se hallan en situaciones diferentes ${ }^{201}$. El principio de igualdad consagrado en el artículo 14 de la Constitución no impide al legislador valorar situaciones diferentes para regularlas de distinta manera, siempre que entre aquellas diferencias y esta distinción se dé una relación razonable que

\footnotetext{
${ }^{199}$ FJ 2 tercer párrafo de la STC 49/82, de 14 de julio.

${ }^{200}$ FJ 2 segundo párrafo de la STC 49/82, de 14 de julio.

${ }^{201}$ FJ 12 apartado 4) segundo párrafo de la STC 26/87, de 27 de febrero.
} 
explique o justifique el trato desigual ${ }^{202}$. Quiere decirse que en tal supuesto es el recurrente el que tiene que correr con la carga de la prueba suministrando el tertium comparationis, ya que es sabido que para efectuar el juicio de igualdad y razonar acerca de la posible vulneración del derecho a la igualdad hace falta que se aporte un adecuado término de comparación, sin cuya concurrencia no es posible llevar a cabo aquella comparación ${ }^{203}$.

En consecuencia, para introducir elementos de diferenciación tiene que existir una suficiente justificación de tal diferencia, que aparezca al mismo tiempo como fundada y razonable, de acuerdo con criterios y juicios de valor generalmente aceptados. Además, también es necesario para que sea constitucionalmente admisible la diferencia de trato, que las consecuencias jurídicas que se deriven de tal distinción sean proporcionadas a la finalidad perseguida, $y$ que no se vulnere ni el principio de seguridad jurídica ni los derechos y libertades del Capítulo II del Título I de la CE que vinculan a todos los poderes públicos. En este sentido la STC 75/1983 de 3 de agosto señala que "sólo resulta posible al legislador establecer para los ciudadanos un trato diferenciado cuando tenga que resolver situaciones diferenciadas fácticamente con mayor o suficiente intensidad que requieren en su solución por su mismo contenido una decisión distinta, pero a tal fin resulta indispensable que exista una justificación objetiva y razonable, de

\footnotetext{
${ }^{202}$ FJ 14 párrafo noveno de la STC 26/87, de 27 de febrero. ${ }^{203}$ FJ 3 párrafo tercero de la STC 14/85, de 1 de febrero.
} 
acuerdo con criterios y juicios de valor generalmente aceptados, cuya exigencia deba aplicarse en relación con la finalidad y efectos de la medida considerada, debiendo estar presente por ello una razonable relación de proporcionalidad entre los medios empleados y la finalidad perseguida, y dejando en definitiva al legislador con carácter general la apreciación de situaciones distintas que sea procedente diferenciar y tratar desigualmente, siempre que su acuerdo no vaya contra los derechos y libertades protegidos en los artículos 53.1 y 9.3 de la Constitución ni sea irrazonable"204. Más recientemente, la STC 214/2006 de 3 de julio, insiste en que "el principio de igualdad no sólo exige que la diferencia de trato resulte objetivamente justificada, sino también que supere un juicio de proporcionalidad en sede constitucional sobre la relación existente entre la medida adoptada, el resultado producido y la finalidad pretendida ${ }^{, 205}$. Por tanto, para alcanzar los fines previstos en la norma, es preciso que el legislador seleccione los medios que sean más moderados y que causen el menor perjuicio posible a la esfera de los intereses privados y los demás derechos individuales de los ciudadanos ${ }^{206}$.

\footnotetext{
${ }^{204}$ FJ 2 primer párrafo de la STC 75/83, de 3 de agosto.

${ }^{205}$ FJ 2 primer párrafo de la STC 214/06, de 3 de julio.

206 Redondo García, Ana M ${ }^{\mathrm{a}}$. Igualdad en la Ley y juicio de constitucionalidad, en Pérez Tremps, Pablo, coordinador. La Reforma del Tribunal Constitucional. Actas del $V$ Congreso de la Asociación de Constitucionalistas de España. Tirant lo Blanch, Valencia, 2007, pág. 453.
} 



\section{PROHIBICIÓN DE DISCRIMINACIÓN.}

La virtualidad del artículo $14 \mathrm{CE}$ no se agota en la cláusula general de igualdad con la que se inicia su contenido, sino que a continuación el precepto constitucional se refiere a la prohibición de una serie de razones o motivos concretos de discriminación como son el "nacimiento, raza, sexo, religión, opinión o cualquier otra condición o circunstancia personal o social". Esto supone, una vez que el precepto ha sancionado la igualdad ante la ley, el reconocimiento de la eficacia general del derecho constitucional a la no discriminación en las relaciones entre particulares y en particular, en las relaciones que se establecen en el marco del trabajo asalariado ${ }^{207}$.

Por lo tanto, la segunda parte del precepto va más allá de la mera declaración de objetividad de las leyes y de la prohibición de arbitrariedad en su aplicación, y pasa a realizar una crítica a determinadas situaciones sociales que son injustas y que reclaman una tutela antidiscriminatoria para corregirlas, lo que hace que en último término el artículo $14 \mathrm{CE}$ se conecte con el artículo 9.2 CE. Según esto, los poderes públicos no sólo tendrían la responsabilidad de no aprobar leyes discriminatorias, o de suprimir

\footnotetext{
207 Palomeque López, Manuel Carlos. El derecho constitucional de igualdad y no discriminación y su contenido esencial en el sistema de relaciones de trabajo y de protección social, en Palomeque López, Manuel Carlos, director. Igualdad efectiva de mujeres y hombres. Ratio Legis, 2011, pág. 26.
} 
las discriminaciones legales existentes, sino también la de adoptar las medidas adecuadas para evitar que otras personas discriminen, incluso si esa discriminación se produce en el ámbito privado. De tal forma que la tutela antidiscriminatoria no se reduce a poner fin a la discriminación producto de la actividad legislativa, sino que abarca también "formas de discriminación social, producto de actuaciones privadas, que el Estado no puede tolerar de forma pasiva si no quiere convertirse él mismo en cómplice de dicha discriminación"208.

Con el término discriminación se han calificado en el contexto internacional una serie de situaciones y de actos cuya existencia en sí misma se ha considerado que estaba en contra de la propia dignidad humana, que significaba una violación de los derechos del hombre, habiéndose elaborado una serie importante de instrumentos internacionales ${ }^{209}$ de lucha contra la discriminación, de los que puede considerarse herencia directa nuestro artículo 14 $\mathrm{CE}^{210}$. El término discriminación adquiere un significado peyorativo que hace referencia a un trato desigual injustificado de los seres humanos, y que tiene su origen en aspectos culturales o tradicionales de una sociedad, como puede ser la que afecta a la relación entre hombres y mujeres, y que hasta hace un siglo, no habían sido objeto de preocupación por parte de los poderes

\footnotetext{
${ }^{208}$ Rodríguez Piñero y Fernández López, 1986, págs. 158-159.

${ }^{209}$ Convenio 111 de la Organización Internacional del Trabajo, la Convención sobre la eliminación de todas las formas de discriminación contra la mujer.

${ }^{210}$ Rodríguez Piñero y Fernández López, 1986, pág. 82.
} 
públicos. Es decir que "no son nuevas las situaciones discriminatorias, la novedad consiste en considerarlas «discriminatorias»y en tratar de reaccionar frente a ellas",211.

La STC 214/2006 de 3 de julio ha señalado que la referencia expresa a los motivos o razones de discriminación del artículo 14 CE, "no implica el establecimiento de una lista cerrada de supuestos de discriminación, pero sí representa una explícita interdicción de determinadas diferencias históricamente muy arraigadas y que han situado, tanto por la acción de los poderes públicos como por la práctica social, a sectores de la población en posiciones no sólo desventajosas sino contrarias a la dignidad de la persona que reconoce el artículo 10.1 CE (...),212. Esta jurisprudencia, sentada por vez primera por la STC 128/1987 de 16 de julio ${ }^{213}$, supone el abandono del enfoque exclusivamente formal de la igualdad, y la conexión del problema de la discriminación con situaciones históricas de marginación de determinados colectivos.

En relación con el sexo, la prohibición constitucional de discriminación impide su consideración como criterio de diferenciación en el acceso al empleo entendido en sentido amplio, es decir, no sólo en el momento de la contratación, sino también dentro de la relación jurídica laboral y las condiciones de trabajo

\footnotetext{
211 Rodríguez Piñero y Fernández López, 1986, pág. 84.

212 FJ 2 segundo párrafo de la STC 214/06, de 3 de julio.

${ }^{213}$ FJ 5 de la STC $128 / 87$, de 16 de julio.
} 
que ésta lleve aparejadas. Además, tal prohibición impide los tratamientos peyorativos que se apoyan en la pura y simple constatación del sexo de la víctima (discriminaciones directas), como aquellos otros que se fundan en determinadas circunstancias como el embarazo, la maternidad y la lactancia, o la supuesta inferioridad física de las mujeres, y que bajo la apariencia de tratamientos formalmente neutros o no discriminatorios encubren consecuencias perjudiciales para la mujeres y para toda la sociedad (discriminaciones indirectas) $^{214}$.

La discriminación en función del sexo de las personas resulta inaceptable desde el punto de vista de su dignidad como seres humanos. Primero porque supone un perjuicio y una desventaja no deseada por ellos, y segundo por las consecuencias negativas que lleva aparejada. El resultado social que se deriva de diferencias de trato discriminatorias presupone una marginalización y una cierta exclusión social de los individuos afectados que pone en riesgo la estabilidad y la paz social. Por eso tiene tanta trascendencia no sólo la supresión de actos o medidas discriminatorias, sino también la lucha contra las desigualdades de hecho entre individuos o grupos sociales, sobre la base de uno de los criterios de discriminación prohibidos por el artículo $14 \mathrm{CE}$, desigualdades que además pueden permanecer tras la desaparición del las prácticas discriminatorias formales. Los mecanismos desarrollados con este fin por los poderes públicos se tratarán en

${ }^{214}$ Palomeque López, 2011, págs. 28-31. 
epígrafes posteriores, analizándose a continuación el fundamento constitucional de dicha actuación. 



\section{LA CLÁUSULA DEL ARTÍCULO 9.2 DE LA CONSTITUCIÓN ESPAÑOLA.}

En nuestro ordenamiento constitucional el principio de igualdad no es solamente un principio limitador de la actividad de los poderes públicos, sino también un principio promotor de dicha actividad. El mandato que el artículo 9.2 CE dirige a los poderes públicos para promocionar y eliminar obstáculos a la libertad y la igualdad, se convierte en el elemento complementario del principio de igualdad y no discriminación contenido en el artículo $14 \mathrm{CE}$. No basta con garantizar que no se producirá entre los ciudadanos trato desigual alguno, no es suficiente con eliminar las normas discriminatorias del ordenamiento jurídico, sino que hay que actuar para erradicar las causas que se encuentran en el origen de las discriminaciones y compensar sus efectos regenerando la sociedad en que vivimos. La realidad social aparece así como uno de los criterios interpretativos de las normas que puede ser capaz de llevar a cabo esa transformación. Por eso la labor de los jueces es decisiva, y así se ha puesto de manifiesto en la abundante jurisprudencia constitucional sobre uno de los motivos de discriminación vetados por el artículo $14 \mathrm{CE}$ : el generado por la pertenencia a uno u otro sexo.

La STC 39/1986 de 31 de marzo, ha señalado que "el artículo 9.2 de la $\mathrm{CE}$ es un precepto que compromete la acción de los 
poderes públicos a fin de que pueda alcanzarse la igualdad sustancial entre los individuos, con independencia de su situación social" ${ }^{215}$. El principio de igualdad sustancial exige tomar en consideración las diferencias que caracterizan a cada grupo humano respecto de los demás y ello con el último interés de dotar a todos ellos de iguales oportunidades ${ }^{216}$. Se trata de asegurar a todos los individuos que estén incluidos en alguno de los colectivos a que se refiere el artículo $14 \mathrm{CE}$, condiciones que les equiparen en origen a los demás, de forma que tengan las mismas posibilidades de desarrollo personal y social.

La STC 269/1994 de 3 de octubre señala que "la discriminación, tal como es prohibida por el artículo 14 de la Constitución, impide la adopción de tratamientos globalmente entorpecedores de la igualdad de trato o de oportunidades de ciertos grupos de sujetos, teniendo dicho tratamiento su origen en la concurrencia en aquéllos de una serie de factores diferenciadores que expresamente el legislador considera prohibidos, por vulnerar la dignidad humana",217. Por tanto, la prohibición de discriminación del artículo $14 \mathrm{CE}$ parte de la constatación de la existencia en la sociedad de grupos o colectivos de personas sistemática y tradicionalmente marginados. La prohibición de discriminación

\footnotetext{
${ }^{215}$ FJ 4 letra C) sexto párrafo de la STC 39/86, de 31 de marzo.

${ }^{216}$ García-Perrote Escartin, Ignacio y Jesús R. Mercader Uguina. La Ley de Igualdad: Consecuencias prácticas en las relaciones laborales y en la empresa. La parte general de la Ley Orgánica para la igualdad efectiva de mujeres y hombres: la extensión material de la tutela por razón de sexo. Lex Nova, Valladolid, 2007, pág. 23.

${ }^{217}$ FJ 4 de la STC 269/94, de 3 de octubre.
} 
respecto de tales colectivos implica una violación más cualificada de la igualdad, que debe ser corregida y eliminada exigiendo, incluso, un trato desigual compensador o acción positiva para lograr que la igualdad de los colectivos marginados sea real y efectiva $^{218}$.

De todo lo expuesto hasta ahora se deduce que la vertiente formal y material del principio de igualdad no son compartimentos estancos, sino que el artículo $14 \mathrm{CE}$ y el artículo 9.2 CE, así como la igualdad como valor superior del ordenamiento jurídico, están conectados entre sí, poniéndose de manifiesto las relaciones entre valores y principios, el carácter fundamentador, orientador y crítico de aquellos, y la tarea concretizadora de éstos ${ }^{219}$.

\footnotetext{
218 Sánchez Trigueros, Carmen. Comentarios a la Ley Orgánica 3/2007 de 22 de marzo para la Igualdad Efectiva de Mujeres y Hombres. Aranzadi, Cizur Menor, 2008, pág. 47.

${ }^{219}$ Pérez Luño, 2007, pág. 89.
} 



\section{IGUALDAD DE GÉNERO.}

Un paso más se ha dado gracias a la Ley Orgánica 3/2007 de 22 de marzo para la Igualdad efectiva de Mujeres y Hombres (LOIMH), la cual supone un importante avance en el principio de igualdad material que, como ya se ha puesto de manifiesto, busca la igualdad real y efectiva. Ya no se trata de tener en cuenta exclusivamente el sexo y las situaciones biológicas que al mismo van unidas, básicamente embarazo, maternidad y lactancia. Junto al sexo, como diferencia biológica inmutable entre hombres y mujeres, la realización efectiva de la igualdad debe tener en cuenta que existen muchas otras diferencias entre hombres y mujeres cuyas bases son sociales, culturales e históricas y que, aunque pueden variar en el tiempo, no derivan exclusivamente del sexo. Así resulta de la lectura de la STC 240/1999 de 20 de diciembre.

La configuración desigual de los sexos en torno a la distribución de las funciones productivas y reproductivas, ha dado lugar a una distribución del poder también desigual, común a casi todas las sociedades y cuya consecuencia más visible es la inferioridad y dependencia de las mujeres con respecto a los hombres. La perspectiva de género implica la aceptación de una concepción de la igualdad como situación objetiva en la que hombres y mujeres puedan desarrollar sus capacidades personales y decidir sobre su destino vital sin las limitaciones impuestas por 
los roles tradicionales ${ }^{220}$. Para ello, desde el punto de vista normativo, se han ido aprobado una serie de leyes con el objetivo de nivelar progresivamente la posición jurídica de mujeres y hombres. Uno de los aspectos más significativos es la introducción del principio del mainstreaming o transversalidad de género, según el cual el tratamiento de las políticas de la mujer no puede ser sectorial y tiene que integrarse en el conjunto de políticas públicas y aplicarse a todos los procesos de toma de decisiones, como se verá posteriormente.

Se considera que este es el paso previo para que las mujeres puedan ir asumiendo posiciones de poder y alcanzar una mayor presencia en el ámbito público, sin olvidar la necesidad del compromiso de los hombres dentro del espacio doméstico.

220 Sánchez Trigueros, 2008, págs. 50-51. 




\section{V- LA IGUALDAD COMO DERECHO.}

Por último, la igualdad se manifiesta en nuestra Constitución como un derecho fundamental.

Para Norberto Bobbio, "el elenco de derechos fundamentales varía de una época a otra, de un pueblo a otro, y por ello no se puede hacer una relación de una vez para siempre: se puede solamente decir que son fundamentales los derechos que en una determinada Constitución están atribuidos a todos los ciudadanos indistintamente, aquéllos, en una palabra, respecto de los cuales todos los ciudadanos son iguales". La igualdad acompaña a todos los derechos fundamentales, ya que éstos, para ser considerados realmente como tales, exigen que la titularidad del derecho sea universal. Sin olvidar que el derecho debe estar constitucionalmente reconocido, y que la Constitución deberá tener supremacía normativa y carácter vinculante inmediato ${ }^{221}$.

En un principio, por la ubicación sistemática del derecho a la igualdad fuera de la Sección $1^{\mathrm{a}}$ del Capítulo II Título I CE, se consideró que no tenía naturaleza de derecho fundamental. Sin embargo, en el artículo 53.1 CE se establece que los poderes públicos están vinculados por los derechos y libertades

221 Tomás y Valiente, Francisco. Códigos y Constituciones (1808-1978). Alianza, Madrid, 1989, pág. 154. 
reconocidos en dicho Capítulo II, lo que comprende también el derecho de igualdad, y además "cualquier ciudadano podrá recabar la tutela de las libertades y derechos reconocidos en el artículo 14 y la Sección $1^{\mathrm{a}}$ del Capítulo II ante los Tribunales ordinarios por un procedimiento basado en los principios de preferencia y sumariedad y, en su caso, a través del recurso de amparo ante el Tribunal Constitucional ${ }^{, 222}$, ampliándose expresamente al artículo $14 \mathrm{CE}$ la protección jurisdiccional mediante el recurso de amparo.

Cuando hablamos de igualdad, a diferencia de otros derechos fundamentales que aparecen perfectamente acotados en su definición e incluso en su extensión como tales derechos fundamentales, hemos de tener en cuenta que este derecho contiene importantes elementos de interrelación con otros derechos fundamentales. En este sentido se ha considerado que es instrumental de otros derechos ${ }^{223}$. Así por ejemplo, la STC 30/1991 de 14 de febrero contempla el artículo 14 CE en conexión con los derechos reconocidos en el artículo 39.1 CE en el que "los poderes públicos aseguran la protección social, económica y jurídica de la familia” y en el artículo 41 CE según el cual "los poderes públicos mantendrán un régimen público de Seguridad Social para todos los ciudadanos, que garantice la asistencia y prestaciones sociales suficientes ante situaciones de necesidad, especialmente en caso de desempleo "224. Esta sentencia

\footnotetext{
222 Artículo 53.2 CE.

223 Balaguer Callejón, 2010, pág. 57.

${ }^{224}$ FJ 3 de la STC 30/91, de 14 de febrero.
} 
se refiere a la doctrina del Pleno del Tribunal Constitucional según la cual la regulación de las pensiones de viudedad en el artículo 160 de la Ley General de la Seguridad Social ${ }^{225}$ no vulnera lo dispuesto en el artículo 14 de la Constitución. En el mencionado precepto se reconoce el derecho a la pensión de viudedad solamente al cónyuge superviviente, por lo que es posible denegar dicha pensión en el caso de ausencia de relación jurídica matrimonial, y ello porque "el matrimonio y la convivencia matrimonial no son situaciones equivalentes, siendo posible por ello que el legislador, dentro de su amplísima libertad de decisión, deduzca razonablemente consecuencias de la diferente situación de partida" ${ }^{, 226}$. El matrimonio es una institución social garantizada por la Constitución, y el derecho del hombre y la mujer a contraerlo es un derecho constitucionalmente previsto en el artículo $32 \mathrm{CE}$ cuyo régimen jurídico corresponde a la ley por mandato constitucional. Nada de ello ocurre con la unión de hecho. Por tanto, tales diferencias constitucionales entre matrimonio y unión de hecho pueden ser legítimamente tomadas en consideración por el legislador a la hora de regular las pensiones de viudedad ${ }^{227}$. Sin embargo, es cierto que el legislador podría extender a las uniones estables de hecho los beneficios de la pensión de viudedad, pero el no hacerlo así, no lesiona el artículo $14 \mathrm{CE}^{228}$.

\footnotetext{
225 Actualmente artículo 174 del Real Decreto Legislativo 1/1994 de 20 de junio por el que se aprueba el Texto Refundido de la Ley General de la Seguridad Social.

${ }^{226}$ FJ 3 párrafo primero de la STC 184/90, de 15 de noviembre.

${ }^{227}$ FJ 3 párrafo tercero de la STC 184/90, de 15 de noviembre.

${ }^{228}$ FJ 3 párrafo sexto de la STC 184/90, de 15 de noviembre.
} 
El voto particular de Vicente Gimeno Sendra en la mencionada STC 30/1991 de 14 de febrero es un ejemplo de cómo las resoluciones judiciales pueden ser el reflejo de una realidad social que cada vez es más frecuente, teniendo en cuenta que el número de matrimonios cada vez es menor. El magistrado pone de manifiesto que el matrimonio o vínculo legal no puede justificar la diferencia de trato porque dicho negocio jurídico no es la causa de la pensión. $\mathrm{Y}$ es que, la pensión de viudedad no tiene por estricta finalidad atender una situación de necesidad, sino más bien "compensar frente a un daño, cual es la falta o minoración de unos ingresos de los que participaba el cónyuge supérstite". Además, sólo si las prestaciones de Seguridad Social se configurasen como elementos naturalmente integradores del régimen de matrimonio el legislador podría legítimamente excluir de tales prestaciones a los ciudadanos no casados. Así lo establece también la Sentencia del Tribunal Constitucional 31/1991 de 14 de febrero.

De este modo, en un primer momento, la igualdad se consideró no tanto un derecho autónomo como un derechopuente, e instrumental a otros derechos como el ejercicio de la libertad sindical, el de representación política, o el de acceso a la función pública ${ }^{229}$. De esta consideración de la igualdad ha extraído el Tribunal Constitucional importantes consecuencias.

${ }^{229}$ Balaguer Callejón, 2010, pág. 58. 
Por ejemplo, según la STC 76/1983 de 5 de agosto 230 , "la igualdad reconocida en el artículo 14 no constituye un derecho subjetivo autónomo existente por sí mismo, pues su contenido viene establecido siempre respecto de relaciones jurídicas concretas. De ahí que pueda ser objeto de amparo en la medida que se cuestione si tal derecho ha sido vulnerado en una concreta relación jurídica y, en cambio no pueda ser objeto de una regulación o desarrollo normativo con carácter general",231, lo que justificaría la exclusión del artículo 14 en el artículo 81.1 de la CE, en el que se establece que "son leyes orgánicas las relativas al desarrollo de los derechos fundamentales y de las libertades públicas (...)”.

A partir de la STC 49/1982 de 14 de julio, el Tribunal Constitucional admite la configuración de la igualdad como un derecho fundamental. Uno de los argumentos empleados es que “el artículo $14 \mathrm{CE}$ al establecer el principio general de que los españoles son iguales ante la ley, establece un derecho subjetivo a obtener un trato igual, impone una obligación a los poderes públicos de llevar a cabo ese trato igual y, al mismo tiempo, limita el poder legislativo y los poderes de los órganos encargados de la aplicación de las normas jurídicas"232. No obstante, el reconocimiento de la igualdad como derecho fundamental se hace

\footnotetext{
${ }^{230}$ Esta sentencia fue dictada en relación con la impugnación del doble carácter, orgánico y armonizador, del Proyecto de Ley Orgánica de Armonización del Proceso Autonómico (LOAPA), así como en relación con la legitimidad del legislador estatal para dictar normas que, referidas al ámbito competencial de las Comunidades Autónomas, interpretan, integran o alteran el texto constitucional. ${ }^{231} \mathrm{FJ} 2$ letra a) tercer párrafo último inciso de la STC 76/83, de 5 de agosto. ${ }^{232}$ FJ 2 segundo párrafo de la STC 49/82, de 14 de julio.
} 
partir de su propia significación como principio general de igualdad ante la ley, en lugar de derivarlo de su incidencia en las situaciones subjetivas de no discriminación que expresamente se enuncian en el artículo 14 CE. Más precisa es la STC 75/1983 de 3 de agosto $^{233}$ donde se sostiene que "el artículo 14 de la Constitución configura el principio de igualdad ante la ley como un derecho subjetivo de los ciudadanos, evitando los privilegios y las desigualdades discriminatorias entre aquellos, siempre que se encuentren dentro de las propias situaciones de hecho a las que deben corresponder un tratamiento jurídico igual, pues en tales supuestos la norma debe ser idéntica para todos",234.

Las sentencias más recientes del Tribunal Constitucional relacionadas con la igualdad han tendido a no descartar su significado de auténtico derecho fundamental. Así sucede por ejemplo con la STC 142/1985 de 23 de octubre ${ }^{235}$ y la STC $39 / 1986$ de 31 de marzo 236 .

\footnotetext{
${ }^{233}$ Esta misma sentencia también destaca por el voto disidente formulado entre otros por Francisco Tomás y Valiente, en el que se recogen la pluralidad de significados normativos que encierra el artículo $14 \mathrm{CE}$, esto es, un principio general del derecho, un derecho subjetivo de los ciudadanos que les permite recabar de los Tribunales la tutela y protección para que la igualdad menoscabada sea restituida, y una limitación del poder legislativo, que impide que el legislador pueda dictar normas jurídicas introduciendo desigualdades. ${ }^{234}$ FJ 2 de la STC 75/83, de 3 de agosto.

235 FJ 1 de la STC 142/85, de 23 de octubre, se refiere a la igualdad como derecho fundamental consagrado en el artículo $14 \mathrm{CE}$.

${ }^{236}$ FJ 6 primer párrafo de la STC 39/86, de 31 de marzo.
} 
Existen por tanto una diversidad de criterios jurisprudenciales y doctrinales sobre el alcance de la igualdad en el artículo $14 \mathrm{CE}$ por lo que es conveniente establecer las siguientes conclusiones:

La condición de derecho fundamental de la igualdad formal sancionada en el artículo 14 CE se comprueba por su inclusión en el Capítulo II "Derechos y libertades", del Título I "De los derechos y deberes" fundamentales de la Norma Suprema del ordenamiento jurídico español, así como por su garantía reforzada dispuesta en el artículo 53.2 CE para la tutela de las libertades y derechos reconocidos en el artículo 14 y la Sección $1^{\text {a }}$ del Capítulo II, a través de un procedimiento basado en los principios de preferencia y sumariedad ante los tribunales ordinarios y, en su caso, a través del recurso de amparo ante el Tribunal Constitucional. No siendo relevante para objetar su carácter de derecho fundamental autónomo el hecho de que no aparezca incluido en la Sección $1^{\text {a }}$ "De los derechos fundamentales y de las libertades públicas” del Capítulo II Título I de la CE, ya que de prevalecer esta interpretación restrictiva de los derechos fundamentales, se negaría tal condición a un importante grupo de derechos y libertades reconocidos en el texto constitucional.

Por otro lado, el sistema de reconocimiento de la igualdad empleado en la CE no supedita el ejercicio del derecho a la igualdad enunciado en el artículo 14 a su relación con otros derechos fundamentales. Que la valoración del derecho a la 
igualdad no pueda ser realizada en abstracto, sino referida a situaciones fácticas o relaciones jurídicas concretas no entraña un rasgo peculiar de la igualdad, sino una condición común al ejercicio y tutela de cualquier derecho fundamental.

La Constitución ha considerado la igualdad, además de derecho, principio inspirador del ordenamiento y valor constitucional. Esta regulación confiere a la igualdad una especial consideración, no sólo en el sistema de fuentes, sino también porque orienta además de al legislador, a los operadores jurídicos, que han de conducirse en todo momento sin producir un trato discriminatorio en la interpretación y en la aplicación de la ley. Si la igualdad inspira y condiciona la creación de la ley, también representa por ello un modelo de sistema jurídico. Lo que permite a través de ella considerar un determinado modelo de Estado ${ }^{237}$.

En realidad, el establecimiento de un derecho de igualdad como derecho fundamental directamente aplicable, produce una transformación en el sistema de fuentes del derecho, que reduce de manera importante el valor de la ley, fundamentalmente en la tradicional consideración jerárquica de la ley ${ }^{238}$.

\footnotetext{
237 Balaguer Callejón, 2010, pág. 60.

238 Balaguer Callejón, 2010, pág. 61.
} 


VI- REGULACIÓN NORMATIVA DE LA IGUALDAD

ENTRE HOMBRES Y MUJERES: DESCRIPCIÓN, COMENTARIO, ANÁLISIS Y PROPUESTAS.

\section{AMBITO INTERNACIONAL.}

La igualdad entre mujeres y hombres es un principio jurídico universal reconocido en diversos textos internacionales sobre derechos humanos, entre los que destaca la Convención sobre la eliminación de todas las formas de discriminación contra la mujer aprobada por la Asamblea General de Naciones Unidas en diciembre de 1979 y ratificada por España en 1983. En este mismo ámbito son significativos los avances introducidos por conferencias mundiales monográficas como la de Nairobi en 1985 y Pekín en septiembre de 1995. En esta última, se consideró como objetivo estratégico fomentar una armonización de responsabilidades laborales y familiares entre hombres y mujeres. Además se invitó a los gobiernos a integrar la perspectiva de género en todas las políticas y los programas para analizar así sus consecuencias para las mujeres y los hombres antes de tomar decisiones. Posteriormente, del 5 al 9 de junio de 2000, se llevó a cabo un periodo extraordinario de sesiones de la Asamblea General a fin de hacer una evaluación quinquenal conocida como Beijing +5 , cuyo tema fue "La mujer en el año 2000: igualdad entre los géneros, desarrollo y paz en el siglo XXI”. 
La normativa internacional más significativa sobre igualdad la encontramos en la Declaración Universal de Derechos Humanos $^{239}$ que en su artículo 7 establece que "todos son iguales ante la ley y tienen, sin distinción, derecho a igual protección contra toda discriminación que infrinja esta Declaración y contra toda provocación a tal discriminación"; el Pacto Internacional de Derechos Económicos, Sociales y Culturales ${ }^{240}$ que reconoce el deber de asegurar a las mujeres condiciones de trabajo no inferiores a las de los hombres, con salario igual por trabajo igual $^{241}$; el Pacto Internacional de Derechos Civiles y Políticos ${ }^{242}$ que garantiza a hombres y mujeres la igualdad en el goce de todos los derechos civiles y políticos ${ }^{243}$, entre otros se refiere a la igualdad de derechos y de responsabilidades de ambos esposos en cuanto al matrimonio, durante el matrimonio y en caso de disolución del mismo ${ }^{244}$, o también el acceso, en condiciones de igualdad, a las funciones públicas ${ }^{245}$; y la Convención sobre la eliminación de

\footnotetext{
239 Adoptada y proclamada por la Asamblea General de Naciones Unidas en su Resolución 217 A (III) de 10 de diciembre de 1948.

240 Adoptado y abierto a la firma, ratificación y adhesión por la Asamblea General de Naciones Unidas en su Resolución 2200 A (XXI) de 16 de diciembre de 1966.

${ }^{241}$ Artículo 7 a) i. del Pacto Internacional de Derechos Económicos, Sociales y Culturales.

242 Adoptado y abierto a la firma, ratificación y adhesión por la Asamblea General de Naciones Unidas en su resolución 2200 A (XXI) de 16 de diciembre de 1966.

243 Artículo 3 del Pacto Internacional de Derechos Civiles y Políticos.

244 Artículo 23.4 del Pacto Internacional de Derechos Civiles y Políticos.

245 Artículo 25 c) del Pacto Internacional de Derechos Civiles y Políticos.
} 
todas las formas de discriminación contra la mujer ${ }^{246}$, que consagra su artículo 11 a las medidas apropiadas para eliminar la discriminación contra la mujer en la esfera del empleo.

246 Adoptada y abierta a la firma y ratificación, o adhesión, por la Asamblea General de Naciones Unidas en su resolución 34/180 de 18 de diciembre de 1979. 



\section{DERECHO DE LA UNIÓN EUROPEA.}

La Unión Europea ha impulsado de manera especial el desarrollo del principio de igualdad entre hombres y mujeres en el ámbito laboral. Desde el núcleo histórico originario de afirmación de la prohibición de discriminación por razón de nacionalidad y de la igualdad entre hombre y mujer en materia de retribución, la UE cuenta hoy con un amplio elenco de normas jurídicas y de acciones políticas que comprenden muy diferentes dimensiones de la igualdad y de la lucha contra las discriminaciones ${ }^{247}$. En este epígrafe se hará referencia a la evolución que ha experimentado la normativa, tanto en el derecho originario como en el derivado, y la jurisprudencia comunitaria en materia de igualdad.

\subsection{DERECHO ORIGINARIO.}

a. La igualdad formal como igualdad de trato $y$ no discriminación.

En una primera etapa, que corresponde al periodo comprendido entre la segunda mitad de la década de los 50 y el final de los años 70, el régimen de promoción de la igualdad de entre hombres y mujeres se desarrolla sobre la base del principio de igualdad

${ }^{247}$ Mercader Uguina, Jesús Rafael. Esquemas de derecho social de la Unión Europea. Tirant lo Blanch, Valencia, 2010, pág. 31. 
formal, es decir, sobre la base del principio de igualdad de trato. Este principio supone la adopción de medidas legislativas de promoción de la igualdad entre hombres y mujeres, y la prohibición de cualquier tipo de discriminación entre ambos.

El Tratado Constitutivo de la Comunidad Económica Europea, suscrito en Roma el 25 de marzo de 1957, se centra en la creación de un mercado común y en cuestiones afines de carácter social. Con relación a estas últimas, su Título III refleja el contenido de la política social de las Comunidades Europeas. Concretamente, en el artículo 117 se indica que el progreso social, y en particular las condiciones de vida y laborales de los trabajadores, se concibe como un efecto secundario del crecimiento económico. Por tanto, no puede afirmarse que la igualdad entre hombres y mujeres fuera uno de los principios fundadores de las Comunidades Europeas. Además, aunque el Tratado de las Comunidades Europeas consagraba el Título III a la política social, no otorgaba competencias a las instituciones comunitarias para elaborar y desarrollar una política de este tipo. Únicamente el artículo 118 atribuía a la Comisión Europea la tarea de promover una colaboración estrecha entre los Estados miembros en el ámbito de lo social. Es en la cumbre de Paris de 1972 donde se toma la decisión de desarrollar una política social y como consecuencia el Consejo adopta la Resolución de 21 de enero de 1974, relativa a un Programa de Acción Social ${ }^{248}$. Se inicia

${ }^{248}$ DOUE C no 013 de 12 de febrero de 1974, págs.1-4. 
así una activa política social comunitaria, entre cuyos objetivos prioritarios está la implantación efectiva del principio de igualdad de trato por razón de sexo.

De este modo, no fue la preocupación por la igualdad entre hombres y mujeres lo que llevó a los redactores del Tratado a incluir dentro del mismo el artículo 119. El objetivo inicial del reconocimiento del derecho a la no discriminación por razón de sexo en el ámbito comunitario es de carácter puramente económico, es decir, se encuentran ausentes de él connotaciones de tipo social. Esto explica por qué el artículo 119 del Tratado de Roma reduce su aplicación a cuestiones retributivas ${ }^{249}$. En este precepto 119 TCEE existe un trasfondo liberal que tiene como único objetivo garantizar la corrección y la transparencia en el funcionamiento del mercado común europeo, evitando el dumping social y la competencia a la baja entre los trabajadores ${ }^{250}$.

De cara a la consecución de este objetivo y tras el impulso que supone para la política social comunitaria la mencionada Resolución del Consejo de 21 de enero de 1974, se aprobaron tres

\footnotetext{
${ }^{249}$ El Convenio relativo a la igualdad de remuneración entre la mano de obra masculina y la mano de obra femenina por un trabajo de igual valor, adoptado por la Conferencia General de la Organización Internacional del Trabajo el 29 de junio de 1951 y en vigor desde el 23 de mayo de 1953, fue tenido en cuenta a la hora de redactar el artículo 119 del Tratado de Roma. No obstante, el alcance de la igualdad de retribución en esta disposición es más limitado que el estipulado en el referido Convenio.

250 Pérez del Río, Teresa. Mujer e Igualdad: estudio en materia social y laboral. Tomo I. La evolución de la normativa y la jurisprudencia comunitarias y la jurisprudencia constitucional 1994-1998. Instituto Andaluz de la Mujer, Sevilla, 1999, pág. 7.
} 
Directivas. La primera de ellas, la Directiva 75/117/CEE adoptada el 10 de febrero de $1975^{251}$, que perfila el contenido del artículo 119 al introducir la igualdad de retribución por un trabajo de igual valor, y obliga a que los sistemas de clasificación profesional para la determinación de las retribuciones se basen en criterios comunes a dichos trabajadores. La segunda es la Directiva 76/207/CEE de 9 de febrero de $1976^{252}$, que extiende la aplicación del principio de igualdad de trato al acceso al empleo, a la formación y a la promoción profesionales, y a las condiciones de trabajo, procediendo a una regulación detallada de dicho principio en el conjunto de las relaciones de trabajo. Debe notarse que por primera vez dicho principio pierde toda conexión inmediata con la preocupación por salvaguardar las condiciones de competencia económica, prevaleciendo los objetivos sociales. En último término, la Directiva 79/7/CEE adoptada el 19 de diciembre de 1978, que establece la aplicación progresiva del principio de igualdad de trato en materia de seguridad social ${ }^{253}$.

Si estas Directivas contribuyen a la efectiva aplicación del principio de igualdad de trato entre hombres y mujeres, también lo hará, como se verá posteriormente, la labor desarrollada por el Tribunal de Justicia de las Comunidades Europeas, actualmente Tribunal de Justicia de la Unión Europea, sobre todo a partir de la sentencia dictada en el caso $n^{\circ}$ 43/75 de 8 de abril de 1976 entre

${ }^{251}$ DOUE L no 045 de 19 de febrero de 1975, págs. 19-20.

252 DOUE L no 39 de 14 de febrero de 1976, págs. 40-42.

${ }^{253}$ DOUE L no 006 de 10 de enero de 1979, págs. 0024-0025. 
Gabrielle Defrenne contra la sociedad anónima belga Sabena, conocido como caso Defrenne $\mathrm{II}^{254}$.

b. La igualdad material como igualdad de oportunidades.

A finales de la década de los 70, el régimen de promoción de la igualdad entre hombres y mujeres se caracteriza porque se desarrolla y consolida la legislación relativa a la igualdad de trato. Además, con el objetivo superar la brecha que separa la igualdad formal de la igualdad material y hacer efectivo el principio de igualdad de oportunidades, se empiezan a adoptar, de forma complementaria, las medidas de acción positiva. En el epígrafe VIII de este trabajo se analizarán las medidas de acción positiva como uno de los instrumentos que, al amparo de la negociación colectiva, pueden adoptarse para la consecución de la igualdad real a que se refiere la Ley Orgánica 3/2007 de 22 de marzo para la Igualdad Efectiva de Mujeres y Hombres ${ }^{255}$, sin perjuicio de que, como se verá posteriormente, se haga una referencia a la jurisprudencia del Tribunal de Justicia de la Unión Europea que ha inspirado tanto nuestra doctrina como la normativa nacional.

\footnotetext{
254 Mora Ruiz, Manuela. Formación y objeto del Derecho antidiscriminatorio de género: perspectiva sistemática de la igualdad desde el Derecho público. Atelier. Barcelona, 2010, pág. 41.

${ }^{255}$ Boletín Oficial del Estado núm. 71 de 23 de marzo de 2007.
} 
c. Desarrollo y consolidación de la legislación relativa a la igualdad de trato.

El Acta Única Europea da un nuevo impulso a la política social añadiendo al Tratado de Roma un artículo 118 A que exigía a los Estados miembros el compromiso de mejorar la protección de la seguridad y la salud de los trabajadores, y se fija el objetivo de la armonización de las condiciones existentes en este ámbito. Para que se pueda hablar en un futuro de un ordenamiento jurídico europeo unitario, es necesario que previamente se haya llevado a cabo un proceso de aproximación de legislaciones, de armonización normativa. Con este fin, el mencionado artículo 118 A incorpora al Derecho comunitario la técnica de la norma mínima, en virtud de la cual, las Directivas comunitarias no deberán limitarse a indicar la dirección hacia la que debe encaminarse el proceso de armonización, sino que además deberán establecer un punto de partida mínimo para empezar a caminar ${ }^{256}$.

El Consejo Europeo de Estrasburgo de 9 de diciembre de 1989 adoptó la Carta Comunitaria de derechos sociales fundamentales de los trabajadores. Esta Carta enuncia una serie de derechos cuya puesta en marcha por los Estados miembros o por

256 Cruz Villalón, Jesús. La igualdad de trato en el Derecho Comunitario Laboral. Aranzadi, Cizur Menor, 1997, pág. 23. 
la Comunidad Europea dependerá en cada caso de la aplicación del principio de subsidiariedad ${ }^{257}$.

El paso siguiente se da con el Tratado de la Unión Europea firmado en Maastricht el 7 de febrero de 1992. En relación con el principio de igualdad las novedades más importantes se incluyen en el Protocolo sobre la política social, conocido como Protocolo 14, texto que no pudo formar parte del Tratado propiamente dicho al no ser aceptado por el Reino Unido. Este Protocolo sigue la técnica de la norma mínima, estableciendo un común denominador normativo para todos los Estados, sin olvidar tener en cuenta las condiciones y regulaciones técnicas existentes en cada uno de aquéllos. Además, este Protocolo consagra la validez de las acciones positivas ya previstas en la Directiva 76/207/CEE y en la Recomendación 84/635/CEE del Consejo de 13 de diciembre de 1984. Las acciones positivas se habían incorporado ya en la Directiva 76/207/CEE aunque la expresión no figure en el texto de la misma. Así, el artículo 2 párrafo 4 la Directiva se refiere a las medidas encaminadas a promover la igualdad de oportunidades entre hombres y mujeres, en particular para corregir las desigualdades de hecho que afectan a las oportunidades de las mujeres. Posteriormente, la Recomendación 84/635/CEE del Consejo de 13 de diciembre de $1984^{258}$ relativa a la promoción de acciones positivas en favor de la

\footnotetext{
${ }^{257}$ Druesne, Gérard. Droit et politiques de la Communauté et de l'Union européennes. Presses Universitaires de France, París, 1998, pág. 463.

${ }^{258}$ DOUE L no 331 de 19 de diciembre de 1984, págs. 34-35.
} 
mujer, insiste en la necesidad de emprender acciones tendentes a compensar los efectos perjudiciales que para las mujeres en activo resultan de actitudes, comportamientos y estructuras de la sociedad. En esta etapa se apuesta por combatir la discriminación y trabajar por la igualdad sobre la base del reconocimiento de las diferencias que existen entre hombres y mujeres. Se admite la necesidad de otorgar un trato especial a las mujeres con el fin de alcanzar la igualdad material, compensando las desigualdades que limitan las oportunidades de las mujeres a través de medidas de acción positiva.

Por lo que respecta al concreto desarrollo y consolidación de la legislación relativa a la igualdad de trato, se aprueban dos Directivas que reconocen las especificidades de las mujeres como trabajadoras. La Directiva 86/378/CEE de 24 de julio de $1986^{259}$ relativa a la aplicación del principio de igualdad de trato entre hombres y mujeres en los regímenes profesionales de la seguridad social y la Directiva 86/613/CEE de 11 de diciembre de $1986^{260}$, que extiende la aplicación del principio de igualdad de trato a los hombres y mujeres que ejercen una actividad autónoma, incluidas las actividades agrarias. En el mismo orden de cosas, el 19 de octubre de 1992 se adopta la Directiva 92/85/CEE ${ }^{261}$ con la que se pretende mejorar el nivel de seguridad e higiene en el trabajo de

\footnotetext{
${ }^{259}$ Modificada como consecuencia del caso Barber por la Directiva 96/97/CE del Consejo de 20 de diciembre de 1996 y publicada en Diario Oficial de la Unión Europea L no 46 de 17 de febrero de 1997, págs. 20-24.

${ }^{260}$ DOUE L no 359 de 19 de diciembre de 1986, págs. 56-58.

${ }^{261}$ DOUE L no 348 de 28 de noviembre de 1992, págs. 1-8.
} 
las trabajadoras embarazadas, que hayan dado a luz recientemente o en periodo de lactancia.

d. La igualdad de género.

En la primera mitad de la década de los noventa, la Unión Europea responde a los compromisos asumidos en la Cuarta Conferencia Mundial sobre la Mujer celebrada en el año 1995 en Pekín ${ }^{262}$, integrando la perspectiva de género como eje transversal de sus actuaciones. El método de trabajo consiste en que los gobiernos y otros agentes deben fomentar la incorporación de una perspectiva de género en todas las políticas y programas de modo que antes de la adopción de una decisión, se realice un análisis de sus posibles efectos para uno y otro sexo. Esta estrategia se completará con la adopción de medidas positivas específicas a favor de las mujeres. No obstante, por sí solas, las acciones positivas tampoco son capaces de eliminar las desigualdades, por lo que conviene integrar el principio de igualdad de trato y el principio de igualdad de oportunidades con el principio de igualdad de género, reconociéndose así su carácter complementario y acumulativo.

Poco después de la celebración de la Conferencia, la Comisión declara su compromiso formal con el principio de mainstreaming o transversalidad de género en la Comunicación

${ }^{262}$ A/CONF. 177/20/Rev. 1 
titulada "Integrar la igualdad de oportunidades entre hombres y mujeres en el conjunto de políticas y acciones comunitarias", adoptada el 21 de febrero de $1996^{263}$. En ella se hace hincapié en la necesidad de diseñar todas las acciones y políticas generales teniendo en cuenta sus posibles efectos sobre las situaciones de los hombres y de las mujeres. Esta Comunicación apuesta asimismo por la adopción complementaria de medidas de acción positiva.

Esta doble estrategia también ha sido incorporada por el Tratado de Ámsterdam. Prueba de ello son las previsiones del párrafo 2 del artículo 3, que obliga a eliminar en todas las actividades de la Comunidad las desigualdades entre el hombre y la mujer. Por lo que se refiere a las medidas de acción positiva, el párrafo 4 del artículo 141 del Tratado de Ámsterdam (antiguo artículo 119 TCEE), las define como ventajas concretas destinadas a facilitar al sexo menos representado el ejercicio de actividades profesionales o a evitar o compensar desventajas en sus carreras profesionales. Pero no sólo eso, el Tratado de Ámsterdam amplía la atención a la desigualdad, tratando de erradicar la discriminación en una variedad de ámbitos adicionales al género. En tal sentido, su artículo 13 establece el procedimiento para adoptar medidas adecuadas contra la discriminación por motivos de sexo, de origen racial o étnico, religión o convicciones, discapacidad, edad u orientación sexual. Esta disposición refleja el reconocimiento de la

${ }^{263} \operatorname{COM}(96) 67$ final. 
necesidad de desarrollar un enfoque coherente e integrado en materia de lucha contra la discriminación ${ }^{264}$.

El Libro verde "Igualdad y no discriminación en la Unión Europea ampliada", de fecha 28 de mayo de $2004^{265}$, insiste en este enfoque precisando que la igualdad de trato y el respeto a la diversidad redundan en beneficio de toda la sociedad. Posteriormente el Consejo adopta la Directiva 2000/43/CE del Consejo de 29 de junio de $2000^{266}$, relativa a la aplicación del principio de igualdad de trato de las personas independientemente de su origen racial o étnico; la Directiva 2000/78/CE del Consejo de 27 de noviembre de $2000^{267}$ relativa al establecimiento de un marco general para la igualdad de trato en el empleo y la ocupación; y mucho más recientemente la Directiva 2004/113/CE del Consejo de 13 de diciembre de $2004^{268}$ por la que se aplica el principio de igualdad de trato entre hombres y mujeres al acceso a bienes y servicios y su suministro. Se da paso así a una nueva fase en la que se habla de lucha contra la discriminación múltiple y de igualdad para todos, con las críticas que esto ha suscitado puesto que cada una de las categorías de posibles discriminaciones tiene una dinámica diferente y puede requerir acciones legislativas

\footnotetext{
264 Mora Ruiz, 2010, pág. 47.

265 COM (2004) 379 final.

266 DOUE L no 180 de 19 de julio de 2000, págs. 0022-0026.

267 DOUE L n ${ }^{\circ} 303$ de 2 de diciembre de 2000, págs. 0016-0022.

268 DOUE L no 373 de 21 de diciembre de 2004, págs. 0037-0043.
} 
distintas, y además con el riesgo de que la igualdad entre hombres y mujeres quede diluida en esa igualdad para todos ${ }^{269}$.

e. El Tratado de Lisboa.

- Modificaciones introducidas en el Tratado de la Unión Europea.

La igualdad entre hombres y mujeres es un valor y un principio fundamental del Derecho Comunitario en virtud del artículo 2 y del artículo 3 apartado 3 párrafo segundo del Tratado de la Unión Europea modificado por el Tratado de Lisboa ${ }^{270}$. Así, el artículo 2 señala que "la Unión Europea se fundamenta en los valores de respeto de la dignidad humana, libertad, democracia, igualdad, Estado de Derecho y respeto de los derechos humanos, incluidos los derechos de las personas pertenecientes a las minorías. Estos valores son comunes a los Estados miembros en una sociedad caracterizada por el pluralismo, la no discriminación, la tolerancia, la justicia, la solidaridad y la igualdad entre mujeres y hombres". En el artículo 3.1 del TUE se establecen entre los fines de la Unión, promover la paz y los valores indicados anteriormente. Para ello, en el apartado tercero del mismo precepto se pone de manifiesto que "la Unión combatirá la exclusión social y la

\footnotetext{
269 Mora Ruiz, 2010, pág. 49.

270 Versión consolidada del Tratado de la Unión Europea publicada en el DOUE de 26 de octubre de 2012 (C326), e instrumento de ratificación del Tratado de Lisboa por España publicado en el BOE núm. 286 de 27 de noviembre de 2009.
} 
discriminación y fomentará la justicia y la protección sociales, la igualdad entre mujeres y hombres, la solidaridad entre las generaciones y la protección de los derechos del niño”.

El artículo 6 TUE indica que "la Unión reconoce los derechos, libertades y principios enunciados en la Carta de Derechos Fundamentales de la Unión Europea de 7 de diciembre de 2000, tal como fue adaptada el 12 de diciembre de 2007 en Estrasburgo, la cual tendrá el mismo valor jurídico que los Tratados". La Carta de los Derechos Fundamentales de la Unión Europea se refiere en su Título II a la Igualdad, en concreto el artículo 20 dispone que todas las personas son iguales ante la ley, en el artículo 21 se prohíbe toda discriminación, en particular la discriminación por razón de sexo u orientación sexual, y el artículo 23 señala que se debe garantizar la igualdad entre mujeres y hombres en todos los ámbitos, inclusive en materia de empleo, trabajo y retribución. Por otro lado señala expresamente que el principio de igualdad no impide el mantenimiento o la adopción de medidas que supongan ventajas concretas en favor del sexo menos representado.

Por lo que atañe a la igualdad ante la Ley, el nuevo artículo 9 del TUE ubicado en el Título II del mismo relativo a las Disposiciones sobre los principios democráticos, señala que "la Unión respetará en todas sus actividades el principio de la igualdad de sus ciudadanos". 
- Tratado de Funcionamiento de la Unión Europea.

El Tratado constitutivo de la Comunidad Europea queda modificado del siguiente modo. En primer lugar, el título del Tratado se sustituye por "Tratado de Funcionamiento de la Unión Europea". En todo el Tratado las palabras "la Comunidad o la Comunidad Europea" se sustituyen por "la Unión", y las palabras de "las Comunidades Europeas o de la CEE" se sustituyen por “de la Unión Europea”, y los adjetivos "comunitario, comunitaria, comunitarios y comunitarias" se sustituyen por "de la Unión”.

Dicho esto, en el artículo 5 recoge un principio fundamental en relación con los últimos avances llevados a cabo en materia de igualdad como es el de transversalidad. Según este precepto "en la definición y ejecución de sus políticas y acciones, la Unión tratará de luchar contra toda discriminación por razón de sexo, raza u origen étnico, religión o convicciones, discapacidad, edad u orientación sexual".

Por lo que atañe a la política social, la denominación del título XI "Política social, de educación, de formación profesional y de juventud" se sustituye por la de "Política social" y se enumera como IX. El artículo 157.1 TFUE (anterior artículo 141.1 TCE conforme al Tratado de Ámsterdam), establece una configuración rotunda, clara e incondicionada del derecho a la no discriminación por razón de sexo al establecer que "cada Estado miembro 
garantizará la aplicación del principio de igualdad de retribución entre trabajadores y trabajadoras para un mismo trabajo o para un trabajo de igual valor". Sin embargo, la discriminación indirecta sigue sin encontrar reflejo expreso en este precepto y la referencia que se hace a la legalidad de las medidas de acción positiva, no constituye propiamente un reconocimiento, que estaba ya sobradamente admitido, sino más bien la reproducción en el ámbito del derecho originario de las limitaciones jurisprudenciales a su ejercicio ${ }^{271}$.

\subsection{DERECHO DERIVADO.}

El artículo 249.1 TFUE señala que para ejercer las competencias de la Unión, las Instituciones adoptarán reglamentos, directivas, decisiones, recomendaciones y dictámenes.

Como ya se ha indicado en el epígrafe anterior, existen varias Directivas europeas que contienen disposiciones cuya finalidad es la aplicación del principio de igualdad de trato entre hombres y mujeres. Entre ellas podemos destacar la Directiva 75/117/CEE del Consejo de 10 de febrero de 1975 sobre la aplicación del principio de igualdad de retribución entre los trabajadores masculinos y femeninos; la Directiva 76/207/CEE del Consejo de 9 de febrero de 1976, relativa a la aplicación del principio de

\footnotetext{
271 Ballester Pastor, María Amparo. La transposición del principio antidiscriminatorio comunitario al ordenamiento jurídico laboral español. Tirant lo Blanch, Valencia, 2010, pág. 36.
} 
igualdad de trato entre hombres y mujeres en lo que se refiere al acceso al empleo, a la formación y a la promoción profesionales, y a las condiciones de trabajo; la Directiva 86/378/CEE del Consejo de 24 de julio de 1986, relativa al principio de igualdad de trato entre hombres y mujeres en los regímenes profesionales de seguridad social; la Directiva 97/80/CE del Consejo de 15 de diciembre de 1997, relativa a la carga de la prueba en los casos de discriminación por razón de sexo.

Ahora bien, dado que en dichas Directivas se han hecho modificaciones, se ha procedido a refundir en un único texto las principales disposiciones existentes en esta materia. El resultado ha sido la aprobación de la Directiva 2006/54/CE del Parlamento Europeo y del Consejo de 5 de julio de 2006 relativa a la aplicación del principio de igualdad de oportunidades e igualdad de trato entre hombres y mujeres en asuntos de empleo y ocupación ${ }^{272}$. Según el artículo 34 de esta Directiva, con efecto a partir del 15 de agosto de 2009, las Directivas 75/117/CEE, 76/207/CEE, 86/378/CEE y 97/80/CE quedarán derogadas ${ }^{273}$.

La Directiva 2006/54/CE tiene por objeto garantizar la aplicación efectiva del principio de igualdad de trato y de oportunidades entre hombres y mujeres en el acceso al empleo, incluida la formación y la promoción profesional, en las

\footnotetext{
272 Directiva 2006/54/CE del Parlamento Europeo y del Consejo de 5 de julio de 2006 publicada en el DOUE L 204 de 26 de julio de 2006, págs. 0023-0035.

273 Anexo I Parte A de la Directiva 2006/54/CE.
} 
condiciones de trabajo y en los regímenes profesionales de la seguridad social ${ }^{274}$. Por lo que respecta a la igualdad de trato en el acceso al empleo, se prohíbe toda discriminación directa ${ }^{275}$ o indirecta $^{276}$ por razón de sexo en los sectores público o privado relacionada con las condiciones de acceso al empleo, con el acceso a todos los tipos y niveles de orientación y formación profesional, con las condiciones de empleo y de trabajo, y con la afiliación y la participación en una organización profesional. No obstante, los Estados miembros podrán disponer que una diferencia de trato basada en una característica relacionada con el sexo no supondrá una discriminación, cuando dicha característica constituya un requisito profesional esencial y determinante y, siempre y cuando, su objetivo sea legítimo y el requisito proporcionado ${ }^{277}$.

También es muy destacable que esta Directiva reconozca el derecho de la mujer, una vez finalizado el permiso de maternidad - o paternidad en el caso de que los Estados miembros hayan reconocido este derecho a sus ciudadanos, a reintegrarse a su puesto de trabajo o a uno equivalente, en términos y condiciones

\footnotetext{
274 Artículo 1 Directiva 2006/54/CE.

${ }^{275}$ El artículo 2.1 a) de la Directiva 2006/54/CE define la discriminación directa como "la situación en que una persona sea, haya sido o pudiera ser tratada por razón de sexo de manera menos favorable que otra en situación comparable".

276 El artículo 2.1 b) de la Directiva 2006/54/CE define la discriminación indirecta como "la situación en que una disposición, criterio o práctica aparentemente neutros sitúan a personas de un sexo determinado en desventaja particular con respecto a personas del otro sexo, salvo que dicha disposición, criterio o práctica pueda justificarse objetivamente con una finalidad legítima y que los medios para alcanzar dicha finalidad sean adecuados y necesarios".

277 Artículo 14. 2 Directiva 2006/54/CE.
} 
que no le resulten menos favorables, y a beneficiarse de cualquier mejora en las condiciones de trabajo a la que hubiera podido tener derecho durante su ausencia ${ }^{278}$. Asimismo se protegerá a los trabajadores del despido motivado por el ejercicio de estos $\operatorname{derechos}^{279}$.

Para que la aplicación del principio de igualdad de trato sea más eficaz, los Estados miembros velarán por la existencia de los procedimientos judiciales o administrativos adecuados para el cumplimiento de las obligaciones que impone la Directiva 2006/54/CE, y porque aquellas asociaciones que tengan un interés legítimo en velar por el cumplimiento de lo dispuesto en dicha Directiva, puedan iniciar en nombre o en apoyo del demandante, y con su autorización, cualquier procedimiento administrativo establecido para exigir el cumplimiento del principio de igualdad de trato y de oportunidades entre mujeres y hombres ${ }^{280}$. También son importantes para garantizar el respeto efectivo del principio de igualdad de trato, la adopción de normas sobre carga de la prueba. De este modo, cuando una persona que se considere perjudicada por la no aplicación, por lo que a ella se refiere, del principio de igualdad de trato y presente, ante un órgano jurisdiccional u otro órgano competente, hechos que permitan presumir la existencia de discriminación directa o indirecta, corresponderá a la parte demandada demostrar que no ha habido vulneración del principio

\footnotetext{
278 Artículo 15 Directiva 2006/54/CE.

279 Artículo 16 Directiva 2006/54/CE.

280 Artículo 17.2 Directiva 2006/54/CE.
} 
de igualdad de trato $^{281}$, salvo en los procedimientos en los que la instrucción de los hechos corresponda a los órganos jurisdiccionales o al órgano competente ${ }^{282}$. Además, los Estados miembros están facultados para introducir, en todas las fases de los procedimientos, un régimen probatorio que resulte más favorable a la parte demandante ${ }^{283}$.

Con el objetivo de impulsar la aplicación efectiva del principio de igualdad de trato, la Directiva 2006/54/CE también ha previsto que los Estados miembros fomenten el diálogo entre los interlocutores $\operatorname{sociales}^{284}, \quad y$ con la organizaciones no gubernamentales $^{285}$. Y es que, la igualdad de trato de hombres y mujeres en asuntos de empleo y ocupación no puede limitarse a únicamente a medidas de carácter legislativo. La Unión Europea y los Estados miembros deben seguir fomentando, a través del diálogo, el proceso de toma de conciencia del problema de la desigualdad.

Finalmente, los Estados miembros deben establecer sanciones efectivas, proporcionadas y disuasorias en caso de incumplimiento de las disposiciones de la Directiva ${ }^{286}$.

\footnotetext{
281 Artículo 19.1 Directiva 2006/54/CE. 282 Artículo 19.3 Directiva 2006/54/CE.

283 Artículo 19.2 Directiva 2006/54/CE.

284 Artículo 21 Directiva 2006/54/CE.

285 Artículo 22 Directiva 2006/54/CE.

286 Artículo 25 Directiva 2006/54/CE.
} 
Recientemente la protección otorgada a la discriminación por razones de género en derecho comunitario se ha extendido a vertientes extralaborales ${ }^{287}$ como así se refleja en la Directiva del Consejo 2004/113/CE de 13 de diciembre de 2004, por la que se aplica el principio de igualdad de trato entre hombres y mujeres al acceso a bienes y servicios y su suministro ${ }^{288}$.

Otros motivos de discriminación en el empleo prohibidos por las Directivas europeas son la 2000/43/CE del Consejo de 29 de julio $^{289}$, cuyo objetivo es la interdicción de la discriminación por origen racial o étnico, y la Directiva 2000/78/CE del Consejo de 27 de noviembre ${ }^{290}$ contra la discriminación en el empleo por religión o convicciones, discapacidad, edad y orientación sexual. El ámbito personal de ambas directivas son todas las personas, tanto en el sector público como en el privado.

\subsection{DESARROLLO JURISPRUDENCIAL.}

El Tribunal de Justicia de las Comunidades Europeas, que ha pasado a denominarse tras el Tratado de Lisboa, Tribunal de Justicia de la Unión Europea, se ha configurado como una de las principales Instituciones en el desarrollo del principio de igualdad entre hombres y mujeres en el sistema jurídico comunitario. La

\footnotetext{
287 Ballester Pastor, 2010, pág. 33.

288 DOUE L no 373 de 21 de diciembre de 2004, págs. 0037-0043.

${ }^{289}$ DOUE L no 180 de 19 de julio de 2000, págs. 0022-0026.

${ }^{290}$ DOUE L no 303 de 2 de diciembre de 2000, págs. 0016-0022.
} 
evolución de la acción comunitaria en esta materia no puede comprenderse sin el análisis conjunto del desarrollo del Derecho Comunitario y de la jurisprudencia del Tribunal de Justicia. Los pronunciamientos del Tribunal han desarrollado un análisis jurídico que, partiendo de la igualdad formal, se ha orientado hacia el objetivo de lograr una igualdad real en las sociedades de los Estados miembros. Esta perspectiva ha inspirado las sucesivas reformas que se han materializado en el ámbito de la igualdad entre hombres y mujeres, tanto en los tratados constitutivos como en las Directivas sobre el tema ${ }^{291}$.

La labor jurisprudencial del Tribunal de Justicia de la Unión Europea en materia de igualdad entre mujeres y hombres, comenzó con la primera de las tres sentencias que se ocuparían del caso Defrenne ${ }^{292}$, sentencia del TJUE de 25 de mayo de 1970, entre Gabrielle Defrenne, azafata de la compañía aérea Sabena, contra el Estado belga. En este caso el órgano judicial comunitario se ocupó de la interpretación del antiguo artículo 119 TCEE referido a la igualdad de retribución. Posteriormente, en el asunto Defrenne $\mathrm{II}^{293}$, el Tribunal de Justicia ha defendido que las previsiones en materia de igualdad entre hombres y mujeres tienen una doble finalidad. Por un lado presentan un objetivo económico, el de salvaguardar la competencia en el mercado intracomunitario, y por otro, una finalidad social, ya que el sistema comunitario no

\footnotetext{
${ }^{291}$ Mora Ruiz, 2010, pág. 54.

292 STJUE de 25 de mayo de 1970, C-80/70.

${ }^{293}$ STJUE de 8 de abril de 1976, C-43/75.
} 
se limita a una unión económica sino que persigue también el progreso social y la mejora de las condiciones de vida y empleo en las sociedades de los estados miembros. La reforma operada por el Tratado de Ámsterdam en 1997 resulta un buen ejemplo de la incidencia de esta jurisprudencia en el desarrollo del principio de igualdad entre sexos en el sistema comunitario. Este texto incluyó el principio de igualdad entre hombres y mujeres como uno de los objetivos de la Comunidad ${ }^{294}$; estableció como un mandato general la transversalidad de género ${ }^{295}$; y reconoció expresamente la competencia de esta organización para acciones de eliminación de diferentes causas de discriminación entre las que se incluye el sexo $^{296}$. En la Sentencia Defrenne III $^{297}$, el Tribunal va más allá y reconoce la igualdad entre sexos como un Derecho Humano Fundamental $^{298}$.

El Tribunal a través de su jurisprudencia ha tratado de salvar los estrictos límites de la igualdad formal en busca de unos pronunciamientos que incidieran en el objetivo de la igualdad material. Algunos de los pronunciamientos más destacados se mencionan a continuación.

\footnotetext{
294 Artículo 2 TCE.

295 Artículo 3.2 TCE.

296 Artículo 13 TCE.

297 STJUE de 15 de junio de 1978, C-149/77.

298 Mora Ruiz, 2010, pág. 57.
} 
a. Sobre la aplicación directa del principio de igualdad entre hombres y mujeres.

La capacidad de aplicación directa del derecho originario en materia de igualdad entre sexos se va a reconocer por primera vez en la Sentencia Defrenne II. En este texto el Tribunal consideró que el artículo 119 TCEE (después 141 TCE y actual 157 TFUE) es una norma clara y precisa que se impone no sólo a la acción de las autoridades públicas sino que se extiende igualmente a todos los convenios que tienen como fin regular de manera colectiva el trabajo asalariado, así como a los contratos entre particulares. Se reconoce por tanto la eficacia directa horizontal plena del derecho a la no discriminación retributiva configurado en el artículo 119 TCEE. El punto de inflexión en este asunto se produce con ocasión de la sentencia dictada en el caso Barber ${ }^{299}$. En ella el Tribunal de Justicia sigue el mismo criterio de aplicación directa del antiguo artículo 119 TCEE con la importante matización de que dicha aplicación directa tenía prioridad frente a la aplicación de lo establecido en las Directivas en su desarrollo. Esta interpretación suponía que el artículo 119 TCEE tenía un contenido sustantivo pleno, que prevalecía frente a lo establecido en las Directivas de desarrollo. Sin embargo, las instituciones comunitarias reaccionaron en contra de este pronunciamiento jurisprudencial a través de la aprobación del denominado Protocolo Barber, incorporado al Tratado de Maastricht y 
aprobado por todos los estados entonces integrantes de la Unión Europea, con el fin de evitar los efectos económicos perjudiciales derivados de una eventual retroactividad de la doctrina sentada por el Tribunal. Por tanto, el protocolo Barber significa que se detiene temporalmente el avance interpretativo social de la jurisprudencia comunitaria en torno al concepto retributivo para devolverle su sentido netamente economicista, no desde el punto de vista material sino desde la perspectiva estrictamente temporal ${ }^{300}$. Es decir, que el efecto directo sólo podía considerarse desde la fecha de la sentencia Barber, el 17 de mayo de 1990, y ello por razones de seguridad jurídica.

b. Sobre la tutela judicial efectiva de la igualdad entre hombres y mujeres.

En relación con la tutela judicial efectiva, la sentencia dictada en el caso Margueritte Johnston ${ }^{301}$ consagra expresamente el derecho a acudir a la vía jurisdiccional para la protección frente a la discriminación por razón de sexo. En este caso el TJUE se pronuncia sobre la prohibición del acceso de la mujer a determinadas profesiones consideradas peligrosas para ella como una medida aparentemente dirigida a su protección. A causa de la situación de violencia terrorista reinante en el momento de los hechos en Irlanda del Norte, las autoridades británicas

\footnotetext{
300 Ballester Pastor, 2010, págs. 27-28.

301 STJUE de 15 de mayo de 1986, C- 224/84.
} 
competentes decidieron dotar de armas de fuego en el ejercicio normal de sus funciones a las fuerzas de policía que operaban en ese territorio, cuando generalmente tales fuerzas no van armadas. Adoptada tal medida la autoridad competente decidió no renovar los contratos de las mujeres que formaban parte de dichas fuerzas una vez expiraran, decisión cuya motivación era prevenir los riesgos de atentado de que podían ser víctimas las mujeres y la posibilidad consiguiente para los terroristas de apropiarse de las armas. La señora Johnston afectada por dicha medida recurrió ante el juez nacional, que sometió diversas cuestiones prejudiciales al TJUE al efecto de obtener una interpretación sobre la Directiva 76/207/CEE. El TJUE consideró que tal diferencia de trato entre hombres y mujeres era discriminatoria ${ }^{302}$.

c. Sobre la discriminación indirecta.

Uno de los conceptos primordiales del desarrollo jurisprudencial del Tribunal de Justicia en materia de igualdad entre hombres y mujeres aparece en la Sentencia Defrenne II al señalar que la prohibición de discriminación comprende tanto la discriminación directa como la indirecta. En los supuestos de discriminación indirecta el Tribunal se enfrenta a contextos aparentemente neutros en cuanto al sexo, pero que encubren situaciones discriminatorias que proceden de una determinada posición

302 Jimena Quesada, Luis. La Europa social y democrática de Derecho. Dykinson, Madrid, 1997, págs. 212-213. 
personal y social. En estos casos el Tribunal valora no sólo la letra de una norma o la apariencia de una práctica sino sus resultados respecto a la consecución de una igualdad real. Este proceso lleva al Tribunal a analizar datos extrajurídicos de la realidad cotidiana de las mujeres en todo el territorio comunitario y a tomarlos en consideración en sus razonamientos ${ }^{303}$. Como consecuencia el Tribunal ha desarrollado los conceptos de trabajo de igual valor y la técnica de la inversión de la carga de la prueba.

El tema de la valoración de los puestos de trabajo y sus consecuencias en la inferior retribución de las categorías feminizadas ha sido analizado por el TJUE en los casos Danfoss ${ }^{304}$ y Dato $^{305}$. El Tribunal analiza factores concretos como la responsabilidad, la formación o la disponibilidad para el puesto de trabajo, así como los criterios genéricos utilizados para justificar la diferencia retributiva. Tales factores pueden ser causa de diferencia retributiva sólo si resulta esencial para el trabajo que se realiza, y deberá ponerse en conexión con los factores concurrentes en las categorías ocupadas mayoritariamente por mujeres para garantizar que también las condiciones en que se desarrolla su actividad son adecuadamente valoradas desde la perspectiva retributiva.

Por tanto, el valor de un trabajo concreto se determina por su contenido. El problema es cómo ha de ser establecido ese

\footnotetext{
303 Mora Ruiz, 2010, pág. 60.

304 STJUE de 17 de octubre de 1989, C-109/88.

${ }^{305}$ STJUE de 1 de julio de 1986, C-237/85.
} 
contenido. Los sistemas de clasificación profesional o de evaluación del desempeño son un medio para facilitar esta apreciación. Estos sistemas deben basarse en criterios iguales para hombres y mujeres y deben ser diseñados de tal forma que eliminen toda diferencia basada en el sexo ${ }^{306}$. Para determinar si el trabajo es de igual valor, el Tribunal en el caso Cerámicas Royal Copenhaguen $^{307}$ ha señalado que debe comprobarse si habida cuenta de un conjunto de factores, como la naturaleza del trabajo, las condiciones de formación y las condiciones laborales, puede considerarse que dichos trabajadores se encuentran en una situación comparable. Esta comprobación se basa en el mecanismo de inversión de la carga de la prueba, y es que, si bien para determinar el trabajo de igual valor se utilizan fundamentalmente datos estadísticos, la prueba estadística no es suficiente por sí misma para demostrar la existencia de discriminación, pero puede ser suficiente para desencadenar el mecanismo judicial de la inversión de la carga de la prueba, que impone al empleador la obligación de probar que la disparidad comprobada no deriva de una discriminación fundada en el sexo $^{308}$. Sin embargo, a partir del caso Cadman $^{309}$ el TJUE consideró que la antigüedad era un factor en principio justificado, aunque genera efectos adversos en el colectivo femenino. El TJUE abordó directamente el requisito de la antigüedad como

306 Cruz Villalón, 1997, pág. 143.

307 STJUE de 26 de junio de 2006, C-381/99.

308 Cruz Villalón, 1997, págs. 90-91.

309 STJUE de 3 de octubre de 2006, C-17/05. 
susceptible de implicar tratos discriminatorios indirectos por razón de sexo, dado el mayor nivel de rotación de la mano de obra femenina, y concluyó en su validez comunitaria. Para ello partió de la validez a priori de dicho criterio de selección. El Tribunal elimina la aplicación de la modificación de la carga de la prueba y presumió la validez del criterio de la antigüedad, transfiriendo a la víctima de una discriminación estadística de esta naturaleza la obligación de probar su carácter injustificado ${ }^{310}$. En consecuencia introducía un factor exceptuado de la aplicación de la modificación de la carga de la prueba, que podría abrir camino a otros factores.

d. Sobre las medidas de acción positiva.

El Derecho de la Unión Europea reconoce, de forma general, la posibilidad de desarrollar medidas nacionales de acción positiva que favorezcan a un sexo infrarrepresentado en un sector determinado. Tanto el derecho originario como el derivado contienen referencias expresas a las acciones positivas, sin embargo, ha sido el Tribunal de Justicia quién ha definido los principales parámetros con los que poder juzgar la compatibilidad de la acción positiva con el derecho comunitario. El problema radica en que la acción positiva enfrenta al Tribunal a un escenario en el que prima el componente social de la igualdad de sexos y su reconocimiento como un Derecho Humano Fundamental,

310 Ballester Pastor, 2010, pág. 37. 
necesitando de una actuación jurídica no sólo de protección sino también de promoción ${ }^{311}$.

La sentencia del TJUE dictada en el caso Kalanke ${ }^{312}$ desató una gran polémica. En el fondo del asunto se discutía la introducción de un modelo de promoción preferente de las mujeres, como es el sistema de cuotas, en un sector de la administración pública en el que estaban infrarrepresentadas. En concreto la ley de Bremen de 1990 sobre igualdad de trato entre hombres y mujeres en el sector público preveía que se diera preferencia a la mujer cuando éstas no cubren la mitad de los puestos de un servicio. El caso se originó con la denuncia presentada por un funcionario, Eckhardt Kalanke, que fue relegado en la promoción de su empleo en el Ayuntamiento de Bremen frente a una mujer con el mismo currículo. El consistorio, tras reconocer que ambos candidatos cumplían los mismos requisitos para la obtención del puesto, otorgó prioridad a la candidata con apoyo en la normativa de Bremen sobre cuotas femeninas.

En su fallo, el TJUE determinó que la legislación de Bremen era contraria al principio comunitario de igualdad de oportunidades entre hombres y mujeres en el acceso al empleo (artículo 119 del Tratado de Roma y artículo 2.3 de la Directiva

311 Mora Ruiz, 2010, pág. 62.

312 STJUE de 17 de octubre de 1995, C-450/93. 
76/207/CEE, actuales artículo 157 TFUE, artículo 23 de la Carta de Derechos Fundamentales y artículo 3 de la Directiva 2006/54/CE). El Tribunal considera que se ha vulnerado el principio de proporcionalidad entre los medios y los fines elegidos para la promoción de la igualdad real. En primer lugar porque la norma nacional garantiza la preferencia absoluta e incondicional de las mujeres en la promoción profesional, lo cual va más allá de una medida de fomento de la igualdad de trato y supone una discriminación de los hombres con respecto a las mujeres. Y en segundo lugar, porque la medida nacional no incide en la igualdad de oportunidades sino en la igualdad de resultados, imponiendo un resultado final que no resulta acorde con la normativa comunitaria. Ello se debe a que, cuando se trata del acceso a la función pública, mientras no se produzca discriminación en el acceso a la educación y a la formación no debiera producirse tampoco en el acceso al posterior puesto de trabajo. Nuestra Norma Jurídica Fundamental también ofrece cobertura jurídica al fallo del TJUE en los artículos 23 y $103.3 \mathrm{CE}$ de los que se desprende que el principio de igualdad en el acceso a la función pública equivale al principio de mérito y capacidad, lo cual no resulta del todo compatible con el sistema de cuotas concebido de este modo.

Sin embargo, en la STJUE dictada en el Asunto Marschall ${ }^{313}$, el pronunciamiento del Tribunal se matiza. Se parte del mismo presupuesto según el cual la acción positiva es una excepción al

${ }^{313}$ STJUE de 11 de noviembre de 1997, C-409/95. 
principio de igualdad y, como tal, debe interpretarse de forma restrictiva. Es decir, parece que hay una contraposición entre igualdad formal y la igualdad material, entre igualdad de trato e igualdad de oportunidades. La principal diferencia con el caso Kalanke es que en el asunto Marschall la norma nacional contiene una cláusula de apertura. Según esta cláusula, no sería contraria al derecho comunitario la legislación nacional que obliga a conceder preferencia en la promoción a las candidatas femeninas sobre los hombres, cuando tengan igual capacitación, desde el punto de vista de aptitud, competencia y prestaciones profesionales, siempre que en el nivel del puesto de trabajo de que se trate las mujeres estén representadas en menor número, y la candidatura femenina no tenga motivos personales que inclinen la balanza a su favor. Esta cláusula evita que la preferencia por un sexo pueda considerarse como absoluta e incondicional y permite afirmar su compatibilidad con el principio de proporcionalidad.

El Tratado de Ámsterdam da paso a un nuevo contexto normativo en el que se desarrolla la interpretación del Tribunal de Justicia en materia de igualdad. Con el reconocimiento del principio de transversalidad, la obligación de tener en cuenta la igualdad de sexos se extiende a todo el ámbito laboral y en todos los sectores de competencia comunitaria. Después de Marschall, la siguiente sentencia referida a las acciones positivas es dictada en el asunto Badeck ${ }^{314}$. En este caso se produce un cambio notable, y es

314 STJUE de 28 de marzo de 2000, C-158/97. 
que por primera vez se considera que la igualdad formal y la igualdad material son complementarias. La igualdad material se puede alcanzar a través de medidas que por su objeto tienen carácter discriminatorio, pero que encuentran su justificación en la necesidad de corregir situaciones de dificultad real de algunos grupos de población que no se podrían afrontar garantizando el respeto del principio general de no discriminación. El Tribunal admite en este caso que la acción positiva no sólo quedaba circunscrita a la igualdad de oportunidades sino que también podía actuar en el punto de llegada y articular una preferencia efectiva en la contratación o promoción del sexo infrarrepresentado. Ahora bien, siempre y cuando dicha preferencia no fuera absoluta e incondicional, y de que exista una metodología del análisis del caso a caso en el que tendrá que darse una valoración ponderada de todos los candidatos, y en la que se permite optar por una solución diferente a la propuesta por la preferencia general ${ }^{315}$.

Por tanto, el Tribunal admite las medidas de acción positiva en materia de contratación laboral y promoción profesional siempre y cuando se respete el principio de proporcionalidad entre los objetivos perseguidos y los fines utilizados. Es decir, que los méritos alegados por quienes acceden a una determinada plaza sean equivalentes, se haya incluido una cláusula de apertura y un procedimiento que garantice que se tendrán en cuenta todas las circunstancias de las personas que concurren al puesto ofertado.

315 Mora Ruiz, 2010, pág. 68. 
También el Tribunal Europeo de Derechos Humanos acepta las diferencias de trato legislativo siempre y cuando no se sobrepasen ciertos límites. Así, según la Sentencia de 12 de enero de 2006, Caso Mizzi contra Malta, una diferencia de trato es discriminatoria si no tiene una justificación objetiva y razonable, esto es, si no persigue un fin legítimo o si no existe una relación razonable de proporcionalidad entre los medios empleados y el fin que se pretende conseguir ${ }^{316}$. La apreciación de esa relación razonable corresponderá, en primer término al legislador y, en su caso, al Tribunal Constitucional.

e. Sobre la protección de la maternidad.

Las sentencias comunitarias han dado el visto bueno a determinados beneficios en favor de la mujer por el hecho físico de la maternidad. En lo que se refiere al permiso por maternidad, el TJUE ha sentado su doctrina en la sentencia pronunciada en el caso Ulrich Hoffmann ${ }^{317}$. En este asunto se dilucidaba si la ley alemana relativa a la protección de la madre era contraria al derecho comunitario en la medida en que tras la expiración del forzoso periodo de convalecencia de la madre, únicamente concedía un permiso a la misma hasta que el niño tuviese seis meses. Este permiso no podían disfrutarlo alternativamente los

316 Considerando 132 de la STEDH de 12 de enero de 2006.

317 STJUE de 12 de julio de 1984, C-184/83. 
hombres que también ejercieran una actividad remunerada, ni siquiera en el caso de conformidad de ambos padres. El demandante, tras el periodo de convalecencia obligatoria de su esposa, obtuvo de su empleador un permiso no remunerado hasta que el niño cumplió seis meses, mientras que la madre volvió a su trabajo como institutriz. El demandante denunciaba discriminación por razón de sexo en cuanto a la percepción de la prestación por maternidad que le fue denegada por las autoridades alemanas competentes. El TJUE declaró la normativa alemana conforme a Derecho comunitario, en concreto a la Directiva 76/207/CEE, pero sin establecer una solución final europea, pronunciándose a favor del margen de apreciación nacional. Según el Tribunal de Luxemburgo, la Directiva no impone a los Estados miembros la obligación de permitir alternativamente el otorgamiento de tal permiso al padre, incluso en caso de decisión conforme de los padres. En virtud del mencionado margen nacional, la legislación social española en la materia difiere de la alemana, permitiéndose al hombre que disfrute del permiso de maternidad social, tras el periodo forzoso de convalecencia de la mujer por maternidad biológica ${ }^{318}$. Muy próximo al caso anterior, el TJUE vuelve a examinar la legislación social alemana sin ofrecer una solución final europea, haciendo prevalecer nuevamente el margen de apreciación estatal. Pero, en este caso, el asunto Rita Grau-Hupka ${ }^{319}$, parece contradecirse si lo comparamos con el

\footnotetext{
318 Jimena Quesada, 1997, pág. 211.

319 STJUE de 13 de diciembre de 1994, C-297/93.
} 
precedente. El TJUE estimó que la reducción de la pensión de jubilación de una persona al no computar en su cálculo los periodos dedicados a la educación de un hijo era conforme al artículo 119 del TCEE y a la Directiva 79/7/CEE del Consejo relativa a la aplicación progresiva del principio de igualdad de trato entre hombres y mujeres en materia de Seguridad Social ${ }^{320}$. Si tenemos en cuenta el asunto Hoffmann, observaremos que lo que parecía una medida en favor de la mujer se torna discriminatoria, pues si sólo ella puede disfrutar de ese permiso de maternidad remunerado para la educación de los hijos, normalmente será la mujer quien disfrute de tal permiso, lo que al tiempo redunda en esa reducción de la pensión de jubilación.

$\overline{320}$ DOUE L n ${ }^{\circ} 006$ de 10 de enero de 1979, p. 0024-0025 

3. LEGISLACIÓN ESPAÑOLA.

3.1. LEgISLACIÓN ESTATAL. LA LEY ORGÁNICA 3/2007 DE 22 DE MARZO PARA LA IGUALDAD EFECTIVA DE MUJERES Y HOMBRES.

Siguiendo el principio de jerarquía normativa nos referimos a la Constitución Española, a la Norma Suprema de nuestro ordenamiento jurídico, que en su artículo 14 establece que "los españoles son iguales ante la Ley, sin que pueda prevalecer discriminación alguna por razón de raza, sexo, religión, opinión o cualquier otra condición o circunstancia personal social", correspondiendo a los poderes públicos, en cumplimiento de lo dispuesto en el artículo 9.2 CE, "promover las condiciones para que la libertad y la igualdad del individuo y de los grupos en que se integra sean reales y efectivas".

Con la Ley 39/1999 de 5 de noviembre de conciliación de la vida familiar y laboral de las personas trabajadoras ${ }^{321}$ se completa la transposición de las directrices marcadas por la normativa internacional y por las Directivas del Consejo 92/85/CEE y 96/34/CE, superando los niveles mínimos de protección previstos en las mismas. Esta Ley introduce importantes cambios legislativos en el ámbito laboral. Por lo que respecta al empleo público, se da

${ }^{321}$ Boletín Oficial del Estado núm. 266 de 6 de noviembre de 1999. 
una nueva redacción al artículo 29.4 y al artículo 30.3 de la Ley 30/1984 de 2 de agosto, de Medidas para la Reforma de la Función Pública en relación con la excedencia por cuidado de familiares, y el permiso por maternidad y paternidad, mecanismos dirigidos a hacer posible una mejor compatibilización de ambas esferas de la existencia de las personas. La política de conciliación de esta ley no ha estado dirigida a suplir las carencias existentes en materia de servicios e infraestructuras de apoyo para el cuidado de niños y personas dependientes, sino más bien, en la creación de una larga lista de permisos, reducciones de jornada y excedencias que si bien no están previstos de forma exclusiva para las mujeres, a excepción de riesgo durante el embarazo y el periodo de descanso obligatorio postparto, en la práctica son solicitados casi de forma exclusiva por las mujeres ya que estas siguen asumiendo el grueso de las responsabilidades familiares, por lo que se contribuye al mantenimiento del rol tradicionalmente subordinado de las mujeres más que a liberarlas de él. Los permisos, reducciones de jornada y excedencias deben contemplarse como una posibilidad más de conciliación para ambos sexos, pero no la única.

No obstante, ambos preceptos han sido derogados por la Ley 7/2007 de 12 de abril del Estatuto Básico del Empleado Público, regulándose en el artículo 49 de esta Ley los permisos por motivos de conciliación de la vida personal, familiar y laboral y por razón de violencia de género, y en el artículo 89 las modalidades de 
excedencia, entre las que se incluyen la excedencia por cuidado de familiares y por razón de violencia de género. También son muy destacables las reformas llevadas a cabo en el texto refundido de la Ley del Estatuto de los Trabajadores, aprobado por el Real Decreto Legislativo 1/1995 de 24 de marzo, y que resulta de aplicación al personal laboral de la Administración Pública en virtud de lo dispuesto por el artículo 7 la Ley 7/2007 de 12 de abril.

La Ley 53/2002 de 30 de diciembre de Medidas Fiscales, Administrativas y del Orden Social ${ }^{322}$ introduce en su artículo 58 modificaciones en la Ley 30/1984 de 2 de agosto. Concretamente se modifica el artículo 30 de la misma, pudiendo destacar como novedad la posibilidad de que los permisos por maternidad puedan disfrutarse en régimen de jornada completa o a tiempo parcial, a solicitud de los funcionarios y siempre que lo permitan las necesidades del servicio. No obstante los apartados 3 y 5 de este precepto han sido derogados por la Ley 7/2007 de 12 de abril, por lo que habrá de estarse a lo que disponga esta ley en relación con los permisos por maternidad.

Con objeto de evitar consecuencias negativas no intencionales que favorezcan situaciones de discriminación, se aprueba la Ley 30/2003 de 13 de octubre sobre medidas para incorporar la valoración del impacto de género en las disposiciones normativas

322 Boletín Oficial del Estado núm. 313 de 31 de diciembre de 2002. 
que elabore el Gobierno ${ }^{323}$. Esta ley modifica los artículos 22.2 y 24.1 b) de la Ley 50/1997 de 27 de noviembre del Gobierno, para impedir que decisiones políticas que en principio parecen no sexistas, puedan tener un diferente impacto en las mujeres y en los hombres, a pesar de que dicha consecuencia ni estuviera prevista ni se deseara.

Posteriormente se aprueba la Ley Orgánica 1/2004 de 28 de diciembre de medidas de protección integral contra la violencia de género $^{324}$, la cual pone de manifiesto en su Exposición de Motivos que la violencia de género no es un problema que afecte al ámbito privado, sino que se manifiesta como el símbolo más brutal de la desigualdad aún existente en nuestra sociedad. Por ello los poderes públicos no pueden permanecer ajenos a este tipo de violencia y en cumplimiento del mandato del artículo 9.2 CE se dicta esta ley, que pretende atender a las recomendaciones de los organismos internacionales en el sentido de proporcionar una respuesta global a la violencia que se ejerce sobre las mujeres.

Recientemente, los avances más importantes se han dado con la Ley Orgánica 3/2007 de 22 de marzo para la Igualdad Efectiva de Mujeres y Hombres $^{325}$, la cual incorpora al ordenamiento jurídico español dos directivas en materia de igualdad de trato, la 2002/73/CE de reforma de la Directiva 76/207/CEE relativa a la

\footnotetext{
323 Boletín Oficial del Estado núm. 246 de 14 de octubre de 2003.

324 Boletín Oficial del Estado núm. 313 de 29 de diciembre de 2004.

325 Boletín Oficial del Estado núm. 71 de 23 de marzo de 2007.
} 
aplicación de la igualdad de trato entre hombres y mujeres en lo que se refiere al acceso al empleo, a la formación y a la promoción profesionales, y a las condiciones de trabajo; y la Directiva 2004/113/CE sobre aplicación del principio de igualdad de trato entre mujeres y hombres en el acceso a bienes y servicios y su suministro $^{326}$.

La LOIMH es mucho más prolija en lo referente a los derechos de los trabajadores por cuenta ajena que en sus referencias a los empleados públicos. Dentro del Título V Capítulo III de la LOIMH se establecen una serie de medidas de Igualdad en el empleo, si bien sólo para la Administración General del Estado y para los organismos públicos vinculados o dependientes de ella. Para los trabajadores de esta Administración se hace simplemente una referencia de carácter abierto y no exhaustivo a estos derechos que consiste en que, junto a la mención expresa de los derechos de los empleados públicos a las excedencias, reducciones de jornada y permisos, habla en general de establecer "otros beneficios" ligados a la protección de la maternidad o a facilitar la conciliación de la vida personal, familiar y laboral ${ }^{327}$. Se regulan, entre otros, la licencia por riesgo durante el embarazo y la plenitud de los derechos económicos de la funcionaria durante toda la duración de la licencia ${ }^{328}$, el derecho a disfrutar del periodo de vacaciones en fecha distinta, en el caso de que éste coincida con

\footnotetext{
${ }^{326}$ DOUE L 373 de 21 de diciembre de 2004, págs. 0037-0043.

${ }^{327} \mathrm{El}$ artículo 56 LOIMH.

328 Artículo 58 LOIMH.
} 
una incapacidad temporal derivada del embarazo, parto o lactancia natural, con el permiso de maternidad o con su ampliación por lactancia, y ello aunque haya terminado el año natural al que correspondan $^{329}$.

También mencionamos la Ley 9/2009 de 6 de octubre de ampliación de la duración del permiso de paternidad en los casos de nacimiento, adopción o acogida ${ }^{330}$, el Real Decreto 297/2009 de 6 de marzo sobre titularidad compartida en las explotaciones $\operatorname{agrarias}^{331}$, y el Real Decreto 298/2009 de 6 de marzo por el que se modifica el Real Decreto 39/1997 de 17 de enero por el que se aprueba el Reglamento de Servicios de Prevención, en relación con la aplicación de medidas para promover la mejora de la seguridad y de la salud en el trabajo de la trabajadora embarazada, que haya dado a luz o en periodo de lactancia ${ }^{332}$.

\footnotetext{
329 Artículo 60 LOIMH.

330 Boletín Oficial del Estado núm. 242 de 7 de octubre de 2009.

331 Boletín Oficial del Estado núm. 73 de 26 de marzo de 2009. En el artículo 30 apartado $1^{\circ}$ de la LOIMH se establece que con el fin de hacer efectiva la igualdad entre mujeres y hombres en el sector agrario se desarrollará la figura jurídica de la titularidad compartida para que se reconozcan plenamente los derechos de las mujeres en el sector agrario, la correspondiente protección de la Seguridad Social, así como el reconocimiento de su trabajo. También la disposición final cuarta de la Ley 45/2007 de 13 de diciembre para el desarrollo sostenible del medio rural se refiere a la cotitularidad de bienes, derechos y obligaciones en el sector agrario y la correspondiente protección de la Seguridad Social. En este sentido se ha aprobado el Real Decreto 297/2009 de 6 de marzo sobre titularidad compartida de las explotaciones agrarias, el cual opera en el campo de la regulación meramente administrativa de las explotaciones agrarias. 332 Boletín Oficial del Estado núm. 57 de 7 de marzo de 2009.
} 
En último lugar hacemos referencia a dos acuerdos por los que se adoptaron, con anterioridad a la aprobación de la LOIMH, un conjunto importante de medidas para avanzar en la igualdad. En primer lugar la Orden 525/2005 de 7 de marzo ${ }^{333}$ da publicidad al Acuerdo del Consejo de Ministros por el que se adoptan medidas para favorecer la igualdad entre hombres y mujeres en ámbitos como el empleo, empresa, conciliación de la vida laboral y familiar, investigación, solidaridad, deporte, otras medidas para la igualdad, lucha contra la violencia de género y seguimiento. Más recientemente, la Orden 720/2007, de 21 de marzo, por la que se da publicidad al Acuerdo del Consejo de Ministros por el que se toma conocimiento del Balance 2006 sobre el desarrollo de las medidas para favorecer la igualdad entre hombres y mujeres aprobadas por el Consejo de Ministros de 4 de marzo de 2005, aprueba la incorporación de nuevas medidas para su implementación durante $2007^{334}$.

En segundo lugar, la Orden 526/2005 de 7 de marzo ${ }^{335}$ por la que se dispone la publicación del Acuerdo del Consejo de Ministros de 4 de marzo de 2005 por el que se aprueba el Plan para la Igualdad de género en la Administración General del Estado, se contemplan una serie de medidas para promover la igualdad de género en el empleo público, para favorecer la promoción profesional de las empleadas públicas, para la

\footnotetext{
333 Boletín Oficial del Estado núm. 57 de 8 de marzo de 2005.

334 Boletín Oficial del Estado núm. 74 de 27 de marzo de 2007.

335 Boletín Oficial del Estado núm. 57 de 8 de marzo de 2005.
} 
conciliación de la vida personal, familiar y laboral de las personas que trabajan en la Administración General del Estado, medidas contra la violencia de género, para promover la igualdad de género en la Administración General del Estado, y finalmente, medidas de estudio y evaluación de la trayectoria profesional por sexo de los empleados públicos, y medidas dirigidas al sistema estadístico y de información relacionado con las políticas de género.

Ya hemos comprobado que existe un amplio marco jurídico internacional, europeo y nacional en el que enmarcar la configuración de la igualdad como un valor, un principio y un derecho de contenido concreto y eficaz que debe implementarse de una manera efectiva, más allá de la formulación meramente teórica.

El pleno reconocimiento de la igualdad formal ante la ley, aun habiendo comportado un paso decisivo, ha resultado insuficiente para alcanzar la plena igualdad entre hombres y mujeres. Por ello resulta necesaria una acción normativa dirigida a combatir todas las manifestaciones aún subsistentes de discriminación, directa o indirecta, por razón de sexo y a promover la igualdad real entre mujeres y hombres, con remoción de los obstáculos y estereotipos sociales que impiden alcanzarla.

En esta tarea, la labor de los poderes públicos y de las Administraciones Públicas es fundamental. Ésta últimas, haciendo 
uso de su potestad reglamentaria y de planificación, ponen en marcha políticas de carácter preventivo y promocional, participando así de forma activa en la consolidación de las exigencias de la igualdad entre mujeres y hombres. Esto las convierte, con apoyo directo en los artículos 9.2 y 103.1 de la Constitución Española de 1978, en sujetos cualificados de la igualdad de género.

El ordenamiento jurídico español ha refrendado este planteamiento, y así, la Ley Orgánica 3/2007 de 22 de marzo para la igualdad efectiva de mujeres y hombres (LOIMH), incluye esta dimensión promocional o activa de los poderes públicos entre sus líneas esenciales. Siguiendo la Exposición de motivos de la LOIMH, la mayor novedad de esta Ley radica en la prevención de las conductas discriminatorias y en la previsión de políticas activas para hacer efectivo el principio de igualdad. Para ello se aplica el principio de igualdad transversalmente, es decir, sobre los diversos ámbitos del ordenamiento de la realidad social, cultural y artística en que pueda generarse o perpetuarse la desigualdad.

La Ley se ocupa en su articulado de la proyección general del principio de igualdad en los diferentes ámbitos normativos y concreta en sus disposiciones adicionales la correspondiente modificación de las muy diversas leyes que resultan afectadas. 


\subsection{LEGISLACIÓN AUTONÓMICA.}

La Ley Orgánica 14/2007 de 30 de noviembre de reforma del Estatuto de Autonomía de Castilla y León ${ }^{336}$, norma institucional básica del ordenamiento de esta Comunidad Autónoma ${ }^{337}$, hace referencia a la igualdad en varios de sus preceptos. Dentro del Título II "Derechos y principios rectores", en el Capítulo II titulado "Derechos de los castellanos y leoneses" encontramos el artículo 14 en el que se prohíbe cualquier discriminación de género u orientación sexual tanto directa como indirecta. Además se resalta la labor de los poderes públicos, que en cumplimiento de lo dispuesto en el artículo 8.2 del Estatuto de Autonomía, el cual reitera el mandato del artículo 9.2 de la Constitución española, "garantizarán la transversalidad del principio de igualdad de género en todas sus políticas, promoviendo acciones positivas para lograr la igualdad de oportunidades entre mujeres y hombres, sobre todo en los ámbitos educativo, económico, laboral, en la vida pública, en el medio rural, en relación con la salud y con los colectivos de mujeres en situación de necesidad especial, particularmente las víctimas de violencia de género".

Así, nos referimos a las medidas de acción positiva reguladas en la Ley $1 / 2003$ de 3 de marzo de Igualdad de

\footnotetext{
336 Boletín Oficial del Estado núm. 288 de 1 de diciembre de 2007.

337 Artículo 147.1 Constitución Española de 1978.
} 
oportunidades entre mujeres y hombres en Castilla y León ${ }^{338}$, en el Título II de la misma rubricado "Estrategias de promoción de la igualdad de oportunidades entre mujeres y hombres", y más concretamente a las medidas de acción positiva para la conciliación de la vida laboral y familiar, entre las que destacamos el hecho de incentivar que las bajas, permisos o excedencias por motivos de nacimiento de hijos o cuidado de familiares sean solicitados por el padre para facilitar la vida profesional de la mujer, la promoción de la incorporación de los hombres a las tareas domésticas y responsabilidades familiares, así como valorar y hacer visible el trabajo realizado en el ámbito familiar ${ }^{339}$.

Por otro lado, dentro de los principios rectores de las políticas públicas de Castilla y León, se hace referencia a la protección integral de las distintas modalidades de familia, garantizándose la igualdad de trato entre las mismas, y favoreciendo la conciliación de la vida personal, familiar y laboral $^{340}$. En este sentido destaca la aprobación de la Ley 1/2007 de 7 de marzo de Medidas de Apoyo a las Familias de la Comunidad $^{341}$, entre cuyos principios informadores resaltamos el reconocimiento del valor social de la maternidad y la paternidad ${ }^{342}$,

\footnotetext{
338 Boletín Oficial del Estado núm. 71 de 24 de marzo de 2003, modificada por la Ley 7/2007 de 22 de octubre en relación con la personación de la Administración Autonómica en los procedimientos penales sobre violencia contra las mujeres.

339 Artículo 16 de la Ley 1/2003 de 3 de marzo.

340 Artículo 16.13 del Estatuto de Autonomía de Castilla y León.

${ }^{341}$ Boletín Oficial del Estado núm. 76 de 29 de marzo de 2007.

342 Artículo 3.8 Ley 1/2007 de 7 de marzo.
} 
la promoción de la corresponsabilidad social de los padres en relación con los hijos ${ }^{343}$, y el fomento de la conciliación de la vida personal, familiar y laboral de los responsables familiares ${ }^{344}$. Así por ejemplo, con el fin de facilitar la corresponsabilidad parental se convocarán subvenciones dirigidas a fomentar el uso del permiso de paternidad ${ }^{345}$, y dentro de las medidas para facilitar la conciliación se ha previsto la apertura de centros de Educación Infantil y/o Primaria durante los días laborables no lectivos y vacaciones escolares ${ }^{346}$.

343 Artículo 3.9 Ley 1/2007 de 7 de marzo.

344 Artículo 3.11 Ley $1 / 2007$ de 7 de marzo.

345 Artículo 10 Ley $1 / 2007$ de 7 de marzo.

346 Artículo 5.2 Ley 1/2007 de 7 de marzo. 


VII- DIFERENTES ASPECTOS DE LA IGUALDAD

ENTRE HOMBRES Y MUJERES EN EL ÁMBITO

DEL EMPLEO PÚBLICO LABORAL.

1. CUESTIONES PREVIAS: EVOLUCIÓN HISTÓRICA DEL RÉGIMEN JURÍDICO APLICABLE A LOS EMPLEADOS PÚBLICOS.

El propósito de este epígrafe es estudiar, desde la perspectiva de la igualdad entre hombres y mujeres, la evolución del régimen jurídico de los empleados públicos ${ }^{347}$ desde el siglo XIX hasta nuestros días. Se parte del siglo XIX porque es en este periodo cuando se sitúa el origen del Derecho Administrativo ${ }^{348}$, que en la

${ }^{347}$ Lalinde Abadía, Jesús. Los medios personales de gestión del poder público en la bistoria de España. Escuela Nacional de Administración Pública, Madrid, 1971, pág. 16. El personal que presta sus servicios en la Administración Pública ha recibido diferentes denominaciones a lo largo del tiempo. Según Lalinde Abadía, algunos de los términos históricos más importantes para referirnos al elemento humano que sirve de soporte al poder público y a sus órganos son los de "oficiales", "empleados", "agentes de la Administración" y "funcionarios públicos" o "funcionarios". El término "empleado" precede cronológicamente al de "funcionario", aunque ambos se han ido alternando a lo largo del tiempo. Como se verá posteriormente, tras la aprobación del Estatuto Básico del Empleado Público, se produce una vuelta del término “empleado público" para hacer referencia al conjunto de trabajadores que prestan sus servicios en la Administración, tanto funcionarios como laborales.

348 Santamaría Pastor, Juan Alfonso. Sobre la génesis del Derecho Administrativo Español en el s. XIX (1812-1845). Instituto García Oviedo, Sevilla, 1973, pág. 27. Siguiendo a Santamaría Pastor, el Decreto de las Cortes de Cádiz de 24 de septiembre de 1810 [Colección de los Decretos y Órdenes de las Cortes Generales y Extraordinarias. Imprenta Mayor de Sevilla, Sevilla, 1820, Tomo I, págs. 1-3] al 
actualidad se define como el derecho propio y específico de las Administraciones Públicas en cuanto personas ${ }^{349}$, por lo que tiende a cubrir todas las posibles zonas en las que se mueven las Administraciones Públicas, incluida la relación laboral de empleo público. Se hará una breve descripción de los principales hitos en la regulación normativa de los empleados públicos, sin olvidar el contexto social y político en el que cada una de las principales reformas ha tenido lugar. Asimismo, de forma paralela, se reflejarán las causas y las consecuencias de la aparición del personal laboral en la Administración, cuya presencia en el ámbito administrativo se consolida con el Estado social como una necesidad de adaptar los recursos humanos a los nuevos fines perseguidos por el mismo. Además, es el Estado social el que propicia el reconocimiento del derecho a la igualdad entre hombres y mujeres en el empleo público. Y aunque esto pueda parecer algo evidente en el seno de la Administración del siglo XXI, se pondrá en evidencia que encontrar muestras de su vigencia en la legislación anterior a la Constitución Española de 1978 es una quimera.

indicar que "no conviniendo queden reunidos el poder legislativo, el ejecutivo y el judicario (sic)" implantó por primera vez en la historia de España el principio de división de poderes, momento a partir del cual comienza a desarrollarse el Derecho administrativo español.

349 García de Enterría, Eduardo y Ramón Fernández, Tomás. Curso de Derecho Administrativo I. Aranzadi, Cizur Menor, 2011, pág. 48. 


\subsection{LA REFORMA ORGANIZATIVA DE LÓPEZ BALLESTEROS.}

El derecho español de función pública se inspira en el modelo de carrera francés, por el que el funcionario ingresa, una vez superado un proceso selectivo basado en los principios de mérito y capacidad, en un cuerpo o escala especializado. A cada cuerpo o escala se le asigna una serie de puestos de trabajo que el funcionario podrá ir desempeñando a lo largo de su vida profesional. Sin embargo, para poder acceder a otro cuerpo o escala, tendrá que estar en posesión del título académico correspondiente y superar un nuevo proceso selectivo, por lo que se define como un sistema cerrado. Sobre esta base se construye el régimen jurídico del funcionario, como un régimen de derecho público en el que las condiciones de empleo no se establecen en un contrato o en un convenio colectivo, sino por normas objetivas que los poderes públicos pueden modificar unilateralmente. Por ello se dice que el funcionario no tiene con la Administración una relación contractual sino estatutaria, que se rige, desde su nombramiento hasta la extinción del vínculo profesional, por un estatuto público que fija sus derechos, deberes y responsabilidades ${ }^{350}$.

350 Sánchez Morón, Miguel. Derecho de la Función Pública. Tecnos, Madrid, 1997, págs. 20-29. 
El modelo de carrera francés se refleja en la Real orden de 19 de agosto de 1825 "para que no sean admitidos en los empleos de Real Hacienda los individuos que no tengan las circunstancias que se previenen; ni sean ascendidos los que ya lo estén, sin los requisitos que se señalan" ${ }^{351}$, en el Real decreto de 7 de febrero de 1827 “clasificando a los Empleados de la Real Hacienda" 352 y en el Real decreto de 3 de abril de 1828 "dictando reglas sobre percepción de sueldo los empleados activos, cesantes, jubilados, trasladados, suspensos, etc." ${ }^{353}$.

La reforma llevada a cabo por el que fue Ministro de Hacienda, Luis López Ballesteros y Varela, corresponde al segundo periodo absolutista del reinado de Fernando VII. Durante este tiempo se mantuvieron formalmente los principios fundamentales del antiguo régimen, sin embargo, la estructura sobre la que se apoyaban había experimentado una profunda transformación liberal. Esta situación reclamaba la reforma que impulsó López Ballesteros quien, sin alterar el planteamiento político del antiguo régimen, incide sobre la burocracia como forma de organización de la que se sirve el monarca para actuar sobre la sociedad civil, y lo hace con el objetivo de que aquélla sea

\footnotetext{
351 Decretos del Rey nuestro Señor Don Fernando VII. Imprenta Real, Madrid, Tomo X, 1826, págs. 252-260.

352 Decretos del Rey nuestro Señor Don Fernando VII. Tomo XIII, Apéndice a los Tomos XII y XIII de los Reales Decretos, 1828, págs. 513-517.

353 Colección Legislativa de España. Imprenta de la Revista de Legislación, Madrid, Tomo I, 1828, págs. 154-157.
} 
lo más eficaz posible ${ }^{354}$. La Administración aparece así como un instrumento para ejecutar las decisiones del monarca. Esta concepción personal de López Ballesteros sobre la burocracia ${ }^{355}$ repercute en la reforma a la que vamos a hacer referencia, así como en la falta de previsión de disposiciones relacionadas con el tema central de nuestro estudio.

La organización de la carrera administrativa establecida por López Ballesteros, marca un hito en la historia de la función pública española ${ }^{356}$. Primero porque, aunque su ámbito de aplicación estaba limitado a la carrera y a las retribuciones de los funcionarios de la Secretaría de Hacienda, se considera, debido a la importancia cuantitativa del Ministerio de Hacienda en aquel momento, la primera reglamentación general moderna de los funcionarios públicos. Y segundo, porque por primera vez se clasifica de una manera uniforme las distintas categorías de empleados $^{357}$, y se señala las edades y las condiciones exigidas para el ingreso y ascenso en cada una de ellas. Se observa que, si bien no se hace referencia al sexo de los candidatos como criterio a

\footnotetext{
354 Nieto García, Alejandro. Estudios históricos sobre Administración y Derecho Administrativo. Instituto Nacional de Administración Pública, Madrid, 1986, págs. 299-300.

355 Nieto García, 1986, págs. 296-297. Según este autor, las reformas burocráticas suelen ser el resultado de la decisión de un ministro y de sus propias concepciones personales sobre la burocracia, de forma que el pensamiento burocrático es la base de toda reforma funcionarial.

356 Jiménez Asensio, Rafael. Políticas de selección en la Función Pública española (18081978). Instituto Nacional de Administración Pública, Madrid, 1989, pág. 55.

357 Meritorios (art. 6), escribientes (art. 7), oficiales (art. 8), gefes (sic) (art. 9), visitadores (art. 11).
} 
tener en cuenta para su selección, cada una de las categorías está definida en masculino, por lo que en principio podríamos pensar que el acceso estaba vedado a las mujeres. Por tanto, aunque esta legislación no se pueda considerar un avance en materia de igualdad entre hombres y mujeres, sí que lo es desde una perspectiva genérica de la igualdad, ya que, a partir de este momento, se procura que todos los funcionarios tengan una formación técnica adecuada al ingresar al servicio de la Administración, con lo que los méritos empiezan a sustituir a la arbitrariedad anterior, "haciendo cesar el error en que muchos se hallan de que en (sic) obteniendo el nombramiento para cualquier destino ya se tiene toda aptitud necesaria para servirlo, o que basta contar muchos años de servicio para ser un buen empleado"358.

Según Alejandro Nieto, esta reforma supone "dotar a cada empleado de una categoría personal, relativamente independiente del cargo que ocupa", de forma que "ya no va a ocupar el cargo de oficial sino a ser oficial, con la consecuencia de que su sueldo, y su vida administrativa en general, van a depender de su categoría personal o subjetiva y no del cargo objetivo"359. Además, López Ballesteros clarificó los ingresos de los empleados, imponiendo una uniformidad presupuestaria y "arreglando" el sueldo que éstos podían disfrutar, estableciendo en el Real decreto de 3 de abril de

\footnotetext{
${ }^{358}$ Encontramos tan atinada observación al comienzo de la Real orden de 19 de agosto de 1825, en lo que hoy podríamos denominar su exposición de motivos. 359 Nieto García, Alejandro. La retribución de los funcionarios en España. Revista de Occidente, Madrid, 1967, pág. 91.
} 
1828 los requisitos para determinar, de acuerdo con las funciones, años de servicio y nombramientos, el sueldo de los empleados de activo servicio en propiedad, jubilados, cesantes y suspensos, y $\operatorname{procesados}^{360}$.

En este momento no se plantean cuestiones de igualdad entre hombres y mujeres. La única referencia que hemos encontrado a la presencia femenina en el empleo público durante este periodo está en el texto del Estatuto de funcionarios de López Ballesteros, aprobado por Real decreto de 7 de febrero de 1827. En el artículo 9 se refiere a la categoría de "Subalternos de Real Hacienda" 361 , en la que se incluía a las "porteras y a las maestras de labores de las fábricas de tabacos, sales salitres, azufre y pólvora", es decir, aquellas clases que sólo prestaban un servicio material, y cuyo nombramiento no era efectuado por el Rey sino por "las Direcciones y Autoridades superiores de las Rentas en que sirvan" ${ }^{362}$. Sobre esta cuestión se incidirá posteriormente, por lo que baste decir dos cosas en este momento. Primero, que aquí se encuentra el germen de las relaciones laborales en la Administración Pública, y segundo, que la incorporación de la mujer en el empleo público sólo se permitía, expresamente, en las clases inferiores, que no realizaban ninguna actividad intelectual, y que además estaban excluidas de las ventajas del régimen funcionarial.

\footnotetext{
360 Nieto García, 1967, pág. 94.

361 Artículo 8 del Real decreto de 7 de febrero de 1827.

362 Artículo 10 del Real decreto de 7 de febrero de 1827.
} 


\subsection{Bravo Murillo Y EL PODER POLÍtico DE LA BUROCRACIA.}

Unos años más tarde se aprueba el Real Decreto de 18 de junio de $1852^{363}$, por el que se fijan las "bases que han de observarse para el ingreso y ascenso en todos los empleos de la Administración activa del Estado", el llamado Estatuto de Bravo Murillo, considerado el primer estatuto general de la función pública española, que en este caso englobaba ya a todos los empleos de la Administración activa del Estado y no sólo a los de la Real Hacienda. En él se pone de manifiesto el interés de llevar a cabo la clasificación de los empleados de una manera "terminante y clara", de evitar que los destinos en la Administración sean "patrimonio del favor", y de fijar las "reglas para el abono de sueldos". El Estatuto de Bravo Murillo se considera un intento de resolver uno de los principales problemas del funcionario, como era la falta de estabilidad y de independencia con respecto a los regímenes políticos ${ }^{364}$. Se trata de una reforma que pretende no sólo alcanzar una mayor eficacia del aparato funcionarial, sino también reorganizarlo para hacer de él un poder capaz de influir en el juego político del país ${ }^{365}$.

\footnotetext{
363 Colección Legislativa de España, Tomo LVI, 1852, págs. 173-182.

364 Carrasco Canals, Carlos. La burocracia en la España del siglo XIX. Instituto de Estudios de Administración Local, Madrid, 1975, págs. 235-240.

365 Nieto García, 1986, pág. 313.
} 
Sin embargo, tras su aprobación, los principales inconvenientes de la función pública siguieron sin resolverse. Así por ejemplo, no se reconoció la inamovilidad de los funcionarios ni, en consecuencia, se acabó con el sistema de las cesantías ${ }^{366}$, que se caracterizaba por la provisión de los puestos de trabajo en función de la vinculación política al sistema vigente en cada momento, ya sea el liberalismo o el absolutismo ${ }^{367}$. El origen inmediato de este sistema lo encontramos en el siglo XVIII, en el que los empleos públicos eran considerados como algo material, con valor económico y por tanto susceptible de enajenación, que pertenecían en propiedad a una persona, de tal forma que incluso podían pertenecer a una mujer. Esta concepción patrimonial de los empleos públicos desemboca en el sistema de cesantías. Lo que sucede es que en el siglo XIX el propietario ya no es un particular, sino el monarca o el gobierno, que reparte los empleos para premiar a quienes les han ayudado a subir al poder, y les hayan

\footnotetext{
366 Sánchez Morón, 1997, pág. 42.

${ }^{367}$ Ya en el Decreto de las Cortes de Cádiz de 11 de agosto de 1812 [Colección de los Decretos y Órdenes de las Cortes Generales y Extraordinarias. Imprenta Mayor de Sevilla, Sevilla, 1820, Tomo III, págs. 48-50] se declaraba que "cesarán inmediatamente en el egercicio (sic) de sus funciones todos los empleados que haya nombrado el Gobierno intruso", así como aquellos que "han servido al Gobierno intruso, aunque no hayan sido nombrados por él". En el artículo 171 quinta de la Constitución de Cádiz [La Constitución de Cádiz (1812) y discurso preliminar a la Constitución. Castalia, Madrid, 2002], se atribuía al Rey la provisión de "todos los empleos civiles y militares". Este privilegio soberano de nombrar a sus empleados venía acompañado de la facultad de cesarlos, apareciendo así la figura del cesante, con la que originariamente se hacía referencia a los funcionarios nombrados por el gobierno de José Bonaparte que fueron proscritos de toda propuesta para el desempeño de empleos públicos durante el periodo liberal. El restablecimiento del absolutismo por Fernando VII no impidió la continuidad de estas prácticas, la única diferencia era el sistema al que se debía fidelidad por parte de los funcionarios.
} 
demostrado la suficiente lealtad, por eso se dice que "la burocracia durante el siglo XIX es un patrimonio político, la concesión de empleos es un premio y la amenaza de la cesantía es un estímulo a la fidelidad"368.

Como reacción al sistema de las cesantías comienza a desarrollarse el fenómeno del corporativismo, por el que algunos grupos de funcionarios especializados fueron consiguiendo un estatuto especial, beneficiándose de la inamovilidad y quedando exentos de la posibilidad de ser cesados. Surgen así los primeros cuerpos de funcionarios que aportaron objetividad $y$ profesionalidad a la Administración. Además, comienza el acceso al empleo en las Administraciones Públicas de obreros y clases subalternas, los cuales tienen intereses que no tienen por qué coincidir con los de la Administración, poniéndose de relieve el elemento patrimonial de la relación, esto es, la realización de un trabajo a cambio de un salario, surgiendo de forma paralela la necesidad de hacer valer sus derechos a través del movimiento sindical $^{369}$. De este modo, a medida que el sector público crece y las tareas encomendadas al personal a su servicio se apartan del clásico núcleo de las funciones de soberanía, la aplicación del Derecho del trabajo junto al Derecho administrativo comienza a tener razón de ser.

\footnotetext{
368 Nieto García, 1986, pág. 304.

369 López Gómez, José Manuel. La relación laboral especial de empleo público. Estudio de su régimen jurídico tras el Estatuto Básico del Empleado Público. Aranzadi, Cizur Menor, 2009, págs. 29-31.
} 
En este sentido y como ya apuntábamos en el epígrafe anterior al hablar del artículo 9 del Real decreto de 7 de febrero de 1827, en el que se vislumbraba la distinción entre funcionarios y laborales, en el Estatuto de Bravo Murillo esa distinción se produce ya de una forma evidente, puesto que excluye expresamente a las clases subalternas del régimen funcionarial ${ }^{370}$. Esto a su vez propicia el nacimiento de las primeras normas del derecho obrero, el antecedente del Derecho del trabajo y, de forma paralela, comienza la construcción jurídica del contrato de trabajo $^{371}$. Así por ejemplo destacamos la Real Orden de 26 de marzo de $1884^{372}$, que estableció la obligación de descansar los domingos y festivos de los trabajadores de las obras públicas que se hicieran por administración, veinte años antes de que dicha prohibición se estableciera con carácter general para todos los trabajadores mediante la Ley de 3 de marzo de $1904^{373}$, lo que según José Manuel López Gómez sitúa el origen del Derecho del trabajo en las relaciones laborales con las Administraciones Públicas $^{374}$.

\footnotetext{
${ }^{370}$ En el artículo 1 último inciso del Estatuto de Bravo Murillo se establece que "los subalternos no tienen el carácter de empleados públicos para los efectos de este decreto (...)".

371 Palomeque López, Manuel Carlos. La construcción jurídica del contrato de trabajo, en Rojas Rivero, Gloria, coordinadora. Origenes del contrato de trabajo y nacimiento del Sistema de Protección Social. Bomarzo, Albacete, 2012, págs. 35-45. Sobre el proceso histórico de formación del Derecho del Trabajo véase Palomeque López, Manuel Carlos. Derecho del Trabajo. Editorial Universitaria Ramón Areces, Madrid, 2013, págs. 41-100.

372 Colección Legislativa de España, Tomo CXXXII, 1884, pág. 260.

373 Colección Legislativa de España, Tomo XVII, 1904, págs. 490-491.

${ }^{374}$ López Gómez, 2009, pág. 35.
} 
Sin embargo, la trascendencia del Estatuto de Bravo Murillo fue más teórica que práctica. El Decreto se incumple, primero por la circunstancia de ser un Decreto y no una Ley, que garantizase tanto la seguridad en el empleo de los funcionarios, como una base racional en su ascenso y selección, y segundo por la situación política del momento. Bravo Murillo pretendió suplantar la fuerza del Parlamento y la del Ejército con una nueva potencia, la Administración ${ }^{375}$. Esto, lógicamente, representaba un peligro para todos aquellos que no estaban de acuerdo con Bravo Murillo, por lo que su reforma va a ser rechazada por los demás poderes, que se coaligaron en contra. Esta reforma, al igual que la de López Ballesteros, no es fruto de presiones económicas sino que es el resultado de la obra personal de un administrador ${ }^{376}$.

No obstante, a pesar de su inaplicación, el sistema establecido por el Estatuto de Bravo Murillo permanece en la mente de los responsables de la función pública y consigue inspirar, impulsar las reformas posteriores, hasta el punto de que autores como Carrasco Canals consideran que "todas las previsiones contenidas en 1852 se realizan en 1918”,377.

En esta situación, como las necesidades que podríamos considerar "básicas" del empleo público no estaban aún realmente

\footnotetext{
375 Nieto García, 1986, pág. 309.

376 Nieto García, 1967, pág. 129.

377 Carrasco Canals, 1975, pág. 242.
} 
satisfechas, no encontramos el menor rastro de previsiones normativas relacionadas con la igualdad entre hombres y mujeres en el empleo público. La única referencia a la mujer es la que se hace a la Reina ${ }^{378}$, a la que se somete la aprobación del Decreto. Lo que evidencia, tal y como ha puesto de manifiesto Lalinde Abadía, que, en general, durante este periodo, "el poder público se apoya exclusivamente en los hombres como medios personales de gestión, aunque la dirección suprema del país pueda estar en manos de una mujer en calidad de reina, regente, etc." ${ }^{379}$.

\subsection{El ESTATUTO De MAURA.}

El siguiente gran paso en la evolución normativa de la función pública española se da con la aprobación de la Ley de Bases de 22 de julio de $1918^{380}$ acerca de la condición de los funcionarios de la Administración civil del Estado y su Reglamento de 7 de septiembre, que contienen el denominado Estatuto de Maura, y que supuso tanto el fin del sistema de cesantías $^{381}$ como el desarrollo del modelo corporativo. Por ello, aunque se mejora la independencia y objetividad de la Administración, se multiplican no sólo los cuerpos especiales para acceder a las ventajas y

\footnotetext{
378 El Estatuto se refiere a la reina Isabel II como "Señora", la cual llegó a serlo gracias a la abolición de la Ley Sálica mediante la aprobación por Fernando VII de la Pragmática Sanción.

379 Lalinde Abadía, 1971, pág. 80.

${ }^{380}$ Colección Legislativa de España, Tomo LVII, 1918, págs. 451-462.

${ }^{381}$ No obstante, esta afirmación no puede ser tajante, ya que tras la lectura de la Base $5^{a}$ del Estatuto se observa que sí que es posible que "por conveniencia del servicio" pueda acordarse discrecionalmente la cesantía.
} 
privilegios funcionariales, sino también las normas reguladoras de los mismos, sin que el Estatuto de Maura consiga integrarlas de manera coherente y uniforme.

Uno de los mayores logros de la reforma burocrática de 1918 fue poner de manifiesto el poder de la burocracia para organizarse y reclamar sus derechos. Los funcionarios, al igual que el resto de la sociedad de principios de siglo $\mathrm{XX}$, estaban descontentos con la situación de crisis económica y política que vivía el país en aquel momento. Fruto de las reformas anteriores, comenzaron a organizarse para reclamar derechos que hasta entonces les estaban vedados. Es decir que, al tomar conciencia de su poder de influir en política, decidieron utilizarlo en su propio beneficio, y no en el del monarca o del gobierno de turno. A las reivindicaciones de los funcionarios se respondió con el Estatuto de Maura, que les contentó con ventajas materiales, es decir, con un aumento de sus retribuciones, pero se cortó de raíz esa nueva fuerza social que representaba una burocracia organizada mediante la limitación de su derecho de asociación ${ }^{382}$. Esto reforzó el corporativismo, ya que reclamar y alcanzar derechos generales resultaba prácticamente imposible. Las tensiones entre

\footnotetext{
382 La Base 10 del Estatuto se refiere a las asociaciones de funcionarios y exige para su formación y subsistencia la aprobación expresa del Ministro competente. De esta forma, la pertenencia a una asociación que no goce del consentimiento ministerial constituía una desobediencia grave.
} 
Administración y funcionarios estaban servidas ${ }^{383}$, y el mayor perjudicado fue el ciudadano.

Por otro lado, el personal al servicio del sector público regido por el Derecho del trabajo adquirió más importancia cuantitativa a medida que aumentaba la intervención de los poderes públicos en el sector de la producción de los bienes y servicios. Posteriormente, la creación del Cuerpo General de Subalterno rompió la tradicional incompatibilidad entre el trabajo no intelectual y la relación de servicios funcionarial ${ }^{384}$, empezando en este momento la inevitable confusión entre dos regímenes jurídicos distintos, el Derecho administrativo y el Derecho del trabajo.

En este contexto, en el Estatuto de Maura no sólo no encontramos ninguna previsión sobre la igualdad entre hombres y mujeres sino lo que es peor, las referencias a la mujer son para limitar injustificadamente su ingreso en el servicio civil del Estado. En concreto, en la Base $2^{a}$ del Estatuto de Maura, se establece que "la mujer podrá servir al Estado en todas las clases de la categoría de Auxiliar", es decir, en la categoría más baja de las dos existentes $^{385}$. Sin embargo, para acceder a la categoría superior, la

\footnotetext{
383 Nieto García, 1986, págs. 313-320.

384 Godino Reyes, Martín. El contrato de trabajo en la Administración Pública. Civitas, Madrid, 1996, pág. 75.

385 En la Base $1^{\text {a }}$ del Estatuto de Maura se establece que en la Administración civil del Estado existen únicamente dos escalas, la escala técnica y la escala
} 
Base $2^{a}$ continúa diciendo que "los Reglamentos determinarán las funciones a que puede ser admitida y aquéllas que por su especial índole no se lo permitan", de forma que el ingreso en el servicio técnico se dejaba al arbitrio de cada Reglamento, sin que se estableciera ningún criterio objetivo sobre lo que debía entenderse por "especial índole" de las funciones que sólo podían desempeñar los hombres. Con esta disposición se restringía el acceso de las mujeres al empleo público y su promoción dentro del mismo, lo cual hoy nos resulta inconcebible.

La situación no mejora con la derogación formal del Estatuto de Maura a través de la Disposición final del Real decreto de 20 de enero de $1925^{386}$, que en el párrafo tercero de su Exposición de motivos continua prohibiendo a las mujeres el desempeño de puestos de trabajo que "llevan aparejada una función directiva o el ejercicio de una autoridad francamente incompatible con las limitaciones que imponen al sexo femenino la organización social y hasta la misma naturaleza" ${ }^{\text {387 }}$. Por tanto, a comienzos del siglo XX, nos encontramos con una marginación de la mujer en el empleo público que se debe, no a un capricho del legislador, sino a la organización social y a la naturaleza de la mujer. Este reconocimiento legal de las causas de dicha

auxiliar. Los funcionarios auxiliares constituyen una única categoría distinguiéndose los auxiliares de primera clase, de segunda y de tercera.

386 Colección Legislativa de España, Tomo I, 1925, págs. 99-108.

387 González Antón, Ricardo. Estatutos bistóricos de los funcionarios de la Administración Civil del Estado (1828-1963). Ministerio de Administraciones Públicas, Madrid, 1996, pág. 37. 
marginación puede considerarse, siendo muy generosos, como un avance respecto de la situación anterior, en la que la discriminación de la mujer en el empleo público no sólo no se cuestionaba, sino que era algo aceptado tácitamente, que no requería ningún comentario al respecto, ninguna justificación por peregrina que ésta pueda parecernos a día de hoy.

\subsection{REFORMAS BUROCRÁTICAS POSTERIORES AL ESTATUTO DE MAURA.}

Ya hemos visto cómo a lo largo del siglo XIX la Administración había sido un instrumento al servicio de los intereses del gobierno, y los funcionarios eran, en su mayoría, fieles al sistema que los había nombrado. Los esfuerzos de Bravo Murillo para potenciar la Administración fueron sofocados por el resto de poderes que se vieron amenazados por esa nueva fuerza que podía representar un funcionariado organizado. Sin embargo, los empleados públicos fueron conscientes de que, como el resto de trabajadores, tenían derechos y debían reclamarlos. Por tanto, una vez lograda la inamovilidad y superada la amenaza constante de las cesantías, comenzaron a reclamar mejoras en sus condiciones de trabajo. Con el Estatuto de Maura se aplacó en cierto modo la furia reivindicativa de los funcionarios. Se les contentó con subidas salariales y paralelamente se les limitó el derecho de asociación. De este modo, los funcionarios tuvieron que renunciar a ejercer todo tipo de influencia fuera de sus despachos, concentrando sus 
esfuerzos reformadores en el interior de la organización, creando un reducto inaccesible al poder político. Sin embargo, a la Administración le cuesta reformarse a sí misma, ya sea por las reticencias a cambiar situaciones que por el transcurso del tiempo están plenamente consolidadas y cuya transformación es fuente de numerosos conflictos internos, ya sea por lo complicado de los procedimientos para llevarlas a cabo, o simplemente porque siempre suele haber otra cosa más urgente que hacer que resolver los problemas de fondo de la Administración. Por ello, parece que toda reforma que parte desde la política supone tener que enfrentarse a los empleados públicos, de los que depende para la ejecución de su programa de gobierno. Esta situación se repite tanto con la Dictadura de Primo de Rivera como durante la Segunda República, cuya política funcionarial ningún resultado positivo consiguió aportar a la función pública española, ni a la igualdad entre hombres y mujeres dentro de la misma.

La reforma burocrática desarrollada durante la dictadura de Primo de Rivera, y que en 1923 sustituyó al régimen parlamentario anterior, no pretendía llegar al fondo de los problemas que aquejaban a la Administración, ni tampoco transformar su organización. Sólo se ocupaba de corregir sus defectos más llamativos para perfeccionar su funcionamiento. Sus reformas se tradujeron en medidas aisladas que ponían de manifiesto su desconocimiento de la realidad social sobre la que operaban. Así por ejemplo, al comprobar que la Administración funcionaba mal 
porque los empleados desatendían sus cargos, se aprobó la Real orden de 17 de septiembre de $1923^{388}$ en la que se declaraban cesantes los empleados de todas las dependencias oficiales que por viciosa costumbre, por incumplimiento de su deber y por censurable tolerancia de sus jefes, no asistan habitualmente a las oficinas o centros de que dependen ${ }^{389}$. Se trata de reformas que carecían de sistemática y que no tenían en cuenta el momento histórico en el que debían ser aplicadas.

Por lo que respecta al avance del Derecho del trabajo dentro de la Administración Pública, en este periodo se otorgó a la Administración la condición de empresario. Durante la dictadura de Primo de Rivera, el Real decreto-ley de 23 de agosto de $1923^{390}$ por el que se aprobó el Código de Trabajo, consideraba como empresario al Estado, Diputaciones y Ayuntamientos ${ }^{391}$. Esta tendencia continuó durante la II República que, en la Ley relativa al contrato trabajo de 21 de noviembre de $1931^{392}$, establecía en su artículo quinto párrafo tercero que el Estado, las Diputaciones y los Ayuntamientos quedan equiparados a los patronos respecto de las obras y servicios que se ejecuten directamente por administración ${ }^{393}$. A pesar de esta equiparación, el artículo 8 de

388 Colección Legislativa de España, Tomo LXXXI, Volumen III, 1923, págs. 371373.

${ }^{389}$ Nieto García, 1986, pág. 321.

390 Colección Legislativa de España, Tomo IV, 1926, pág. 593.

${ }^{391}$ En su Título II se regula el contrato de trabajo en relación a las obras y servicios públicos.

392 Colección Legislativa de España, Tomo V, 1931, págs. 244-261.

${ }^{393}$ López Gómez, 2009, págs. 35-36. 
esta norma, introduce la dualidad de regímenes jurídicos en la Administración Pública al establecer que "los funcionarios públicos se regirán por su legislación especial”. Por lo que si bien dicha norma reconocía la aplicación del Derecho del trabajo a toda persona que prestara un servicio o ejecutara una obra para un patrono a cambio de una remuneración, cualquiera que fuera el tipo de actividad del trabajador, no incluía la relación de trabajo que vinculaba a los funcionarios públicos con la Administración. Durante este periodo, la aplicación de las normas laborales no depende de que el empresario sea o no una Administración Pública, a la que como se ha puesto de manifiesto se reconoce la aptitud para serlo, sino de que el trabajador tenga o no la condición de funcionario público. Esta complicada situación se ha mantenido hasta nuestros días ${ }^{394}$, a pesar de los intentos del Estatuto Básico del Empleado Público por clarificarla a través de un proceso de equiparación de regímenes jurídicos, en el que la negociación colectiva sigue desempeñando un papel decisivo ${ }^{395}$.

Durante la Segunda República la Administración se caracteriza por su independencia respecto del poder político. Como ya se ha puesto de manifiesto al hablar de la igualdad como valor superior del ordenamiento jurídico, la Constitución Republicana de 1931 es la única que se opone expresamente a la

\footnotetext{
394 Godino Reyes, 1996, págs. 77-79.

395 Fernández Domínguez, Juan José y Susana Rodríguez Escanciano. La Negociación Colectiva de los Funcionarios Públicos. Centro de Estudios de Derecho, Economía y Ciencias Sociales, Barcelona, 1996, págs. 67-73.
} 
discriminación, declarando que todos los españoles sin distinción de sexo son admisibles a los empleos y cargos públicos. Sin embargo, su derogación impide que sus previsiones se materialicen en una ley que regule las condiciones de empleo público, lo que provoca un retroceso de la cuestión a la situación anterior en la que, en general, la carrera en la Administración estaba reservada casi exclusivamente a los hombres.

La guerra civil de 1936-1939 transformó el panorama administrativo. Se volvió al sistema de las cesantías, apartándose de la Administración a aquellos funcionarios que no comulgaban con el nuevo régimen. La situación de la función pública se caracterizó nuevamente por la confusión entre administración y política, perdiéndose los avances realizados en relación con la objetividad de la Administración. Los empleos públicos, aún mal remunerados, se consideraban un botín de los vencedores que los repartieron en procesos de selección fraudulentos, en virtud de las lealtades políticas. Además, se produjo una desviación del sistema corporativo, que degeneró en una lucha entre los múltiples cuerpos funcionariales existentes para obtener mejoras comparativas sin tener en cuenta ni las necesidades de la Administración ni tampoco las de los ciudadanos ${ }^{396}$. Por otra parte, los nuevos candidatos para ingresar en la función pública, en lugar de una formación científica o de una competencia profesional, sólo podían ofrecer una experiencia bélica. Sólo el tiempo podía

396 Sánchez Morón, 1997, págs. 44-45. 
curar esta carencia de formación. Veinte años después, la burocracia y los gobiernos se fueron rejuveneciendo, los nuevos burócratas y políticos no habían participado en la guerra civil y su formación y competencia era mucho más elevada. Se trata de individuos que no esgrimen por título una ideología o un servicio político previo sino una determinada competencia técnica ${ }^{397}$.

El periodo comprendido entre 1939 y 1965 se caracteriza por la ausencia de una política unitaria que contemple de manera uniforme el régimen jurídico del personal al servicio de la Administración. Por supuesto, en este contexto político y social no se produce ningún avance en materia de igualdad entre hombres y mujeres en el empleo público, considerado siempre como una cuestión de menor importancia.

\subsection{LA LEY DE BASES DE FUNCIONARIOS CIVILES DEL ESTADO.}

La evolución que se produce en el empleo público durante el siglo $\mathrm{XX}$, sobre todo a partir de la segunda mitad, es consecuencia de la implantación del Estado social. En primer lugar, las funciones tradicionales de regulación y policía, que llevan aparejado el ejercicio de autoridad inherente a los poderes públicos, se complementan con la actividad de producción de bienes y de prestación de servicios públicos. Esto supone un extraordinario desarrollo del aparato administrativo, aumentando de forma

397 Nieto García, 1986, pág. 339. 
considerable los efectivos de personal y apareciendo la Administración funcional, integrada por nuevos colectivos de empleados, cada vez más heterogéneos y que se someten a un ordenamiento más flexible como es el Derecho del trabajo. Por tanto, se acentúa la diversificación de regímenes aplicables a los empleados públicos. Pero además, como es lógico, el propio Derecho administrativo evoluciona de ser un régimen de privilegios del poder público a un sistema de garantías para el ciudadano frente a las arbitrariedades y prerrogativas de aquél, entre las que destacan la actuación de acuerdo con el procedimiento legalmente establecido, imprescindible para un funcionamiento objetivo del conjunto del sistema. Asimismo, el Derecho administrativo se impregna del contenido del Derecho del trabajo y se hace más democrático, es decir, se hace compatible con el reconocimiento y respeto de las libertades públicas del funcionario, aunque este reconocimiento haya sido gradual y se haya producido en fechas recientes ${ }^{398}$.

La Exposición de motivos de la Ley 109/1963, de 20 de julio, de Bases de Funcionarios Civiles del Estado ${ }^{399}$, señala en su apartado I punto segundo que "la eficacia de la Administración radica fundamentalmente en la calidad de quienes la sirven y en el acertado régimen de personal que tenga establecido", por lo que concluye en el apartado II punto sexto que es aconsejable "la

\footnotetext{
398 Sánchez Morón, 1997, pág. 36.

${ }^{399}$ Boletín Oficial del Estado núm. 175 de 23 de julio de 1963.
} 
promulgación de una nueva Ley de Funcionarios que, superando la excesiva diversidad de normas aplicables", es decir, superando los excesos del corporativismo, “implante los modernos principios de organización de personal, responda a las exigencias de nuestra Administración $y$, al mismo tiempo, garantice, justa $y$ equitativamente los derechos de quienes la sirven". En definitiva, esta Ley trata de avanzar hacia el sistema de empleo ${ }^{400}$. Para ello desarrolla una política de personal coordinada a través de la Comisión Superior de Personal, unifica la regulación de las incompatibilidades y de las situaciones administrativas, crea los cuerpos generales en un intento de reducir el entramado de cuerpos especiales, y adecua los recursos humanos a las funciones administrativas, y no la estructura de la organización a las aspiraciones y presiones de los funcionarios ${ }^{401}$. Además introduce el principio de proporcionalidad interna en los sueldos de la Administración como un presupuesto indeclinable para su buen funcionamiento, y trata de acabar con las visibles desigualdades retributivas existentes en aquel momento, sentando el criterio de que los funcionarios sólo podrán ser remunerados por los conceptos que se determinen en la ley.

\footnotetext{
400 Recordemos que mientras el sistema de carrera se funda en la existencia de categorías personales jerarquizadas a las que se accede por antigüedad o por méritos o por ambos factores, de manera que el funcionario va ascendiendo gradualmente hasta alcanzar, en su caso, la cúspide de su profesión dentro de la Administración, por otro lado en el sistema de empleo la carrera se identifica con el desempeño sucesivo de puestos de trabajo, de forma que los puestos de trabajo mejor retribuidos se asignarían a los mejores, con independencia de su antigüedad o posición en el escalafón

401 Sánchez Morón, 1997, pág. 45-47.
} 
Por lo que respecta al régimen laboral, tanto la Ley 109/1963 como el Decreto 315/1964 de 7 de febrero por el que se aprueba la Ley articulada de Funcionarios Civiles del Estado ${ }^{402}$, admiten la existencia de un sistema de empleo público dual, funcionarial y laboral. La Base I de la Ley, en la disposición general quinta señala que "los trabajadores contratados por la Administración civil se regirán por el Derecho laboral”, y el artículo 7 del Decreto dispone que, "son trabajadores al servicio de la Administración civil los contratados por ésta con dicho carácter, de acuerdo con la legislación laboral, que les será plenamente aplicable", concepto amplio limitado únicamente por la necesidad de autorización reglamentaria. Por otro lado, al referirse al personal funcionario, el artículo 1 del Decreto afirma que son aquellas personas incorporadas a la Administración "por una relación de servicios profesionales y retribuidos, regulada por el Derecho administrativo", añadiendo el artículo 4 que "figuran en las correspondientes plantillas y perciben sueldos o asignaciones fijas con cargo a las consignaciones de personal de los Presupuestos Generales del Estado”. De este modo se avanza en la instauración de un sistema de clasificación de puestos de trabajo con la supresión de grados y categorías personales que caracteriza al sistema de función pública cerrado al que nos referíamos al inicio de nuestra exposición.

402 Boletín Oficial del Estado núm. 40 de 15 de febrero de 1964. 
En relación con las previsiones sobre la igualdad entre hombres y mujeres en al acceso al empleo público, el artículo 30.2 del Decreto establece que "la mujer puede participar en las pruebas selectivas para el ingreso en la Administración pública, conforme a la Ley 56/1961 de 22 de julio”. En el artículo tercero de esta Ley sobre derechos políticos profesionales y de trabajo de la mujer $^{403}$, se reconoce que la mujer puede participar en las mismas condiciones que un hombre en cualquier sistema de los establecidos por la ley para la provisión de las plazas de cualquier Administración pública, exceptuándose, entre otras, la carrera militar o la Administración de Justicia en los cargos más altos, como el de Magistrado, Juez y Fiscal, a excepción de la jurisdicción de menores y laboral. Estas limitaciones son las que derivan de la "condición femenina", sin que se defina dicha condición en ningún artículo de la parte dispositiva.

Por otra parte, una vez que la mujer ha accedido al empleo público, la Base VII apartado seis de la Ley, al regular los derechos de los funcionarios, contempla las licencias aplicables "a la condición y situaciones de la mujer”. El artículo 71. 2 del Decreto concreta un poco más y se refiere expresamente a la concesión de licencias "en caso de embarazo, por el plazo que reglamentariamente se determine". También llama la atención ver cómo dentro de las situaciones administrativas del funcionario, la excedencia voluntaria se podía reconocer a "la mujer funcionario,

403 Boletín Oficial del Estado núm. 175 de 24 de julio de 1961. 
por causa de matrimonio". Así lo establece el artículo 45.1 letra b) del Decreto. Hoy en día este supuesto podría quedar perfectamente englobado en la excedencia por interés particular, por lo que reconocerlo como un supuesto específico refleja la falta de empatía con las aspiraciones profesionales de la mujer, que una vez casada, y por el peso de una tradición social muy arraigada, abandona su carrera administrativa.

\subsection{LA CONSTITUCIÓN ESPAÑOLA DE 1978 Y SU PRIMER DESARROLLO NORMATIVO EN MATERIA DE FUNCIÓN PÚBLICA.}

La Constitución Española de 1978 supone iniciar un proceso de democratización de la Administración Pública. La aprobación de la Constitución plantea el reto de establecer un régimen democrático de relaciones laborales y de adaptar el sistema de función pública al nuevo régimen político, pero mientras que el primero se desarrolla con rapidez, encontrando su máxima expresión en la aprobación del Estatuto de los Trabajadores, la reforma de la función pública se presenta más compleja ${ }^{404}$. Ello se debe a que los factores que la impulsan también lo son. Así por ejemplo, la nueva organización territorial del Estado, basada en el principio de descentralización administrativa ${ }^{405}$, trae como consecuencia una

\footnotetext{
404 López Gómez, 2009, pág. 37.

405 En el artículo 137 CE se establece que "el Estado se organiza territorialmente en provincias, municipios y las Comunidades Autónomas que
} 
diversidad de Administraciones y entidades de derecho público, cada una con su potestad de auto organización para poder configurar su propia política de personal. Además, como resultado de la progresiva implantación del Estado del Bienestar, la Administración creada inicialmente como una organización burocrática para ejercicio de potestades públicas en aplicación de las leyes y reglamentos, ha dado paso a una Administración prestadora de un sinfín de servicios públicos a los ciudadanos, que en tiempos recientes y siguiendo la teoría del new public management, se han pasado a denominar clientes, a imagen y semejanza de lo que sucede en el sector privado, y que reclaman de la Administración una mayor eficacia, eficiencia y economía en su actuación. Además es imprescindible que este cambio en la gestión administrativa contribuya no solo a la eficacia en la actuación sino que al mismo tiempo sea respetuosa con la igualdad entre hombres y mujeres.

Esta variedad de Administraciones y de organismos, así como la multiplicación de los servicios públicos que presta cada uno de ellos, ha contribuido no sólo al incremento de personal que trabaja en el seno de la Administración, sino también a la diversidad del mismo y a la heterogeneidad actual de los regímenes de empleo público. La diversidad se manifiesta en la tendencia por parte de las Administraciones Públicas a contratar personal

se constituyan. Todas estas entidades gozan de autonomía para la gestión de sus respectivos intereses". 
conforme a la legislación laboral, y la heterogeneidad, en el régimen jurídico aplicable a este tipo de personal, que no es exactamente el mismo que el previsto para el personal funcionario de la Administración. Esto es así porque la Constitución Española de 1978 no sienta las bases para implantar un régimen jurídico unitario para el personal laboral y funcionario. Ambos colectivos se apoyan en dos preceptos distintos de la Norma Suprema de nuestro ordenamiento jurídico. El personal laboral entronca en el artículo $35 \mathrm{CE}$ y el personal funcionario en el artículo $103 \mathrm{CE}$, contemplándose la existencia de dos estatutos diferentes, para trabajadores y funcionarios respectivamente. A pesar de ello, la influencia del Derecho administrativo en la regulación de las condiciones de trabajo del personal laboral al servicio de la Administración, así como del Derecho del trabajo en la regulación de las condiciones de empleo de los funcionarios públicos, ha sido inevitable. Pensemos por ejemplo, en el reconocimiento a los funcionarios del derecho a la libertad sindical ${ }^{406}$. Esto supone la ruptura con uno de los puntos de partida de la concepción tradicional del funcionario público, según la cual el empleado de la Administración Pública se identifica totalmente con ella, negándose toda posibilidad de contraposición de intereses entre ellos. La libertad sindical lleva implícita la premisa de que entre empleado y empleador público existen intereses diferentes, que pueden ser contradictorios y que ambos son dignos de

406 Palomeque López, 2013, págs. 327-328. 
protección $^{407}$. Por tanto, con la entrada en vigor de la Constitución de 1978, se inicia un nuevo periodo para la función pública española en la que el reconocimiento de los derechos sociales de los funcionarios, sienta las bases para que la preocupación por la igualdad entre hombres y mujeres en el empleo público adquiriera progresivamente mayor importancia. Por tanto, la Constitución Española ha traído consigo un cambio trascendental de la situación de la mujer en la Administración Pública.

El siguiente avance se produce con la Ley 30/1984 de 2 de agosto de Medidas para la Reforma de la Función Pública ${ }^{408}$ que configura un modelo de función pública estructurado en torno al sistema de puestos de trabajo. El acceso a la función pública se sigue produciendo en función de la pertenencia a un determinado cuerpo o escala, mientras que la carrera del funcionario se articula a través de la sucesiva ocupación de puestos de trabajo. Esta Ley contribuye a racionalizar la función pública, refundiendo un importante número de cuerpos especiales no justificados por razones funcionales, y estableciendo como regla general la adscripción indistinta de los puestos de trabajo con independencia de su cuerpo o escala, salvo que la naturaleza de las funciones a desempeñar impongan lo contrario ${ }^{409}$. El diseño se completa con la adquisición de un determinado grado personal por el

\footnotetext{
407 López Gómez, 2009, pág. 39.

408 Boletín Oficial del Estado núm. 185 de 3 de agosto de 1984.

409 Sánchez Morón, 1997, pág. 49.
} 
desempeño de puestos de trabajo determinados durante un periodo de tiempo.

Este periodo se caracteriza por la coexistencia, sin optar por un tipo u otro, de personal laboral y funcionarial. A diferencia del Decreto 315/1964 de 7 de febrero, la Ley 30/84 de 2 de agosto, admitió sin tasa la contratación de personal laboral en la Administración. Las previsiones del artículo 15.1 de esta Ley facilitaron el crecimiento del personal laboral en el seno de las Administraciones Públicas, con lo que la aplicación del Derecho del trabajo también fue en aumento. La búsqueda de una mayor flexibilidad en la gestión administrativa propició la creación de organizaciones públicas con formas societarias, lo que trajo como resultado el fenómeno conocido con el nombre de huida del derecho administrativo, y un aumento del empleo precario en la Administración, como consecuencia de las contrataciones laborales temporales y de personal funcionario interino. Además, como ya se ha indicado, la descentralización territorial también contribuyó al exceso de personal, lo que a su vez incrementó el gasto público, que se corrigió bajando sus retribuciones ${ }^{410}$. Este proceso expansivo es frenado por la Sentencia del Tribunal Constitucional 99/1987 de 11 de junio, que declara inconstitucional el último inciso del artículo 15.1 de la Ley 30/1984. Este precepto confería al ejecutivo la facultad de especificar los puestos de trabajo que, en atención a la naturaleza

410 Sánchez Morón, 1997, págs. 50-51. 
de su contenido, se reservaban a funcionarios públicos, salvados los cuales la Administración podía optar por escoger la prestación de servicios públicos por funcionarios o por laborales. Y es que, "habiendo optado la Constitución por un régimen estatutario, con carácter general, para los servidores públicos habrá de ser la Ley, no el Ministerio de la Presidencia, la que determine en qué casos y con qué condiciones pueden reconocerse otras posibles vías para el acceso al servicio de la Administración Pública" "411. De donde se deduce primero, que para el Tribunal Constitucional la contratación de empleados públicos conforme a Derecho del trabajo no es contraria a la Constitución, y segundo, que deberá respetarse el principio de reserva de Ley establecido por el artículo 103.3 CE en materia de función pública. Como consecuencia de esta Sentencia se aprueba la Ley 23/1988 de 28 de julio de Modificación de la Ley de Medidas para la Reforma de la Función Pública $^{412}$, que introduce la doctrina del Tribunal Constitucional en dicha Ley al admitir que determinados puestos de trabajo podrán ser desempeñados por personal laboral. Sin embargo, conviene precisar que no se trata de puestos reservados a estos trabajadores sino que será la Ley la que permita su desempeño ya por funcionarios ya por personal laboral, es decir, que la adscripción de tales puestos al personal laboral no es obligatoria sino potestativa. Se invierte por tanto la tendencia de laboralización de la Administración Pública ${ }^{413}$.

\footnotetext{
${ }^{411}$ FJ 3 letra c) de la STC 99/1987, de 11 de junio.

412 Boletín Oficial del Estado núm. 181 de 29 de julio de 1988.

${ }^{413}$ López Gómez, 2009, págs. 41-45.
} 
La Ley 30/84 es un reflejo del proceso de democratización de la función pública al que hacíamos referencia con anterioridad. En ella encontramos algunos avances en materia de igualdad entre hombres y mujeres en el empleo público. Así por ejemplo se incluye en el artículo 19 el principio de acceso al empleo público de acuerdo con los principios constitucionales de igualdad, mérito y capacidad, y en el artículo 32 se indica que "a partir de la entrada en vigor de esta Ley, a efectos de Seguridad Social, no podrá haber discriminación alguna por razón de sexo" y se reconocen los mismos derechos pasivos a la mujer que al varón. Por tanto, se va avanzando en el reconocimiento de la igualdad entre hombres y mujeres en el empleo público.

Un paso más es dado por la Ley 3/1989 de 3 de marzo, por la que se amplía a dieciséis semanas el permiso por maternidad y se establecen medidas para favorecer la igualdad de trato de la mujer en el trabajo ${ }^{414}$, que modifica tanto el Estatuto de los Trabajadores como la Ley de Medidas para la Reforma de la Función Pública.

Otras leyes destacadas en esta segunda mitad del siglo XX en lo que a la regulación de la función pública se refiere, son la Ley 53/1984 de 26 de diciembre de Incompatibilidades del personal al

\footnotetext{
${ }^{414}$ Boletín Oficial del Estado núm. 57 de 8 de marzo de 1989.
} 
servicio de las Administraciones Públicas ${ }^{415}$ y la Ley 9/1987 de 12 de junio de Órganos de Representación, Determinación de las Condiciones de Trabajo y Participación del personal al servicio de las Administraciones Públicas ${ }^{416}$, que regula el sistema de representación de los funcionarios públicos. Con ambas leyes se avanza tanto en el establecimiento de un orden retributivo justo y un sistema de incompatibilidades de la Función Pública, que implique la dedicación exclusiva a la misma y elimine el riesgo de que la Administración se vea sometida a grupos de presión e intereses particulares, como en el ejercicio del derecho de sindicación de los funcionarios públicos, que les corresponde al igual que al resto de trabajadores. Hoy en día también se reconoce la negociación colectiva entre la Administración y los funcionarios, que contribuye a aproximar el régimen de la función pública al del Derecho del trabajo, sin llegar a una fusión, puesto que el personal laboral que presta sus servicios en una Administración Pública no sólo no puede acceder a su empleo por la mera voluntad de una autoridad administrativa, sino que han de participar en un proceso de selección, y su derecho a la negociación colectiva encuentra ciertos límites, como los derivados de los incrementos del gasto público que se establecen en los presupuestos de las distintas Administraciones Públicas. Además, la negociación colectiva es un instrumento fundamental para avanzar en la igualdad entre hombres y mujeres en el empleo público. Como se verá

\footnotetext{
415 Boletín Oficial del Estado núm. 4 de 4 de enero de 1985.

416 Boletín Oficial del Estado núm. 144 de 17 de junio de 1987.
} 
posteriormente, gracias a ella se ha conseguido aproximar los derechos de funcionarios y laborales en esta materia.

\subsection{LA LEY 7/2007 DE 12 DE ABRIL DEL ESTATUTO BÁSICO DEL EMPLEADO PÚBLICO.}

La aprobación de la Ley 7/2007 de 12 de abril del Estatuto Básico del Empleado Público ${ }^{417}$, en adelante EBEP, supone "un paso importante y necesario en un proceso de reforma, previsiblemente largo y complejo, que debe adaptar la articulación y la gestión del empleo público en España a las necesidades de nuestro tiempo (...) "418. Por tanto, esta Ley, además de desarrollar el mandato constitucional del artículo 103.3 CE - que establece que "la ley regulará el estatuto de los funcionarios públicos (...)"-, así como las previsiones del artículo 149.1 18 CE - que atribuye al Estado la competencia exclusiva sobre "las bases del régimen jurídico de las Administraciones públicas y del régimen estatutario de sus funcionarios (...)"-, da un paso más en la regulación normativa del personal al servicio de las Administraciones Públicas, sin constituir, no obstante, el régimen jurídico definitivo del empleo público. El Estatuto Básico del Empleado Público, “partiendo del principio constitucional de que el régimen general del empleo público en nuestro país es el funcionarial, reconoce e integra la evidencia del papel creciente que en el conjunto de

\footnotetext{
417 Boletín Oficial del Estado núm. 89 de 13 de abril de 2007.

418 Apartado tercero de la Exposición de Motivos EBEP.
} 
Administraciones Públicas viene desempeñando la contratación de personal conforme a la legislación laboral para el desempeño de determinadas tareas" ${ }^{\text {419 }}$, exceptuándose aquellas que impliquen la participación directa o indirecta en el ejercicio de las potestades públicas o en la salvaguardia de los intereses generales del Estado y de las Administraciones Públicas ${ }^{420}$. Los demás criterios a tener en cuenta a la hora de determinar qué puestos de trabajo pueden ser desempeñados por personal laboral serán fijados por las Leyes de la Función Pública que se dicten en desarrollo del EBEP ${ }^{421}$.

La Ley 7/2007 es la primera norma jurídica que afronta la regulación conjunta de funcionarios y contratados laborales. Actualmente, el sistema español de empleo público se caracteriza por la coexistencia de dos tipos de personal, el funcionario y el laboral, cada uno de ellos sujeto a un régimen jurídico distinto, el Derecho administrativo y el Derecho laboral. Dualidad de regímenes que excluye la unión absoluta de funcionarios y laborales, pero que acepta la aproximación entre ambos. Esto permite hablar de empleados públicos como una categoría que incluye todas las relaciones de servicios que se entablan en el seno de las Administraciones Públicas ${ }^{422}$. El EBEP vuelve a introducir

\footnotetext{
419 Apartado segundo de la Exposición de Motivos EBEP.

420 Artículo 9.2 EBEP.

421 Artículo 11.2 EBEP.

422 Cardenal Carro, Miguel. El Estatuto Básico del Empleado Público: reformas en las relaciones de servicios en las Administraciones Públicas, en Sempere Navarro, Antonio V. y Miguel Cardenal Carro, directores. El personal laboral al servicio de las Corporaciones Locales. El Consultor de los Ayuntamientos, Madrid, 2010, págs. 5354.
} 
en nuestro ordenamiento jurídico el concepto de empleado público, que comprende todo el personal que desempeñe "funciones retribuidas en las Administraciones Públicas al servicio de los intereses generales"423. De esta definición se deduce que el legislador se ha inclinado por un concepto amplio del empleo público que incluye no sólo a los funcionarios de carrera, sino también a los funcionarios interinos, al personal laboral y al personal eventual. El personal laboral se define como aquel que en virtud de contrato de trabajo formalizado por escrito, en cualquiera de las modalidades de contratación previstas en la legislación laboral, presta servicios retribuidos por las Administraciones Públicas ${ }^{424}$.

El EBEP trata de racionalizar el régimen jurídico aplicable a todo el personal que presta sus servicios en la Administración Pública. Para ello el EBEP sistematiza ${ }^{425}$ la dispersa legislación básica del Estado en materia de función pública, y desarrolla una labor de adaptación, de modernización ${ }^{426}$ de la Administración a las transformaciones que ha experimentado la sociedad en los

\footnotetext{
${ }^{423}$ Artículo 8.1 EBEP.

424 Art. 11.1 EBEP.

${ }^{425}$ La Disposición derogatoria del EBEP da fe de la extensión de contenidos reducidos a un único texto legal.

426 Por lo que atañe a la labor de modernización desarrollada por el EBEP, esa preocupación por las nuevas formas de organización y de gestión de la Administración se refleja en la regulación de aspectos de la función pública como la carrera profesional, la evaluación del desempeño, la estructuración del empleo público y la figura de los directivos. Es en el desarrollo de estos aspectos donde se podrán implantarse políticas públicas que garanticen la igualdad de género en la Administración.
} 
últimos veinte años. El EBEP avanza en la regulación conjunta de las condiciones de trabajo de las personas que prestan servicios retribuidos dentro del ámbito de organización de las Administraciones Públicas $^{427}$. Esta Ley descarta tanto la opción que persigue la unificación de los regímenes en el modelo funcionarial, puesto que para determinadas funciones o tareas resulta más adecuado recurrir a la contratación laboral en busca de una mayor flexibilidad, como la opción laboralizadora, ya que tropieza con los límites constitucionales ${ }^{428}$.

El objeto de esta Ley es determinar las normas aplicables al personal laboral al servicio de las Administraciones Públicas ${ }^{429}$. El artículo 7 EBEP señala que "el personal laboral al servicio de las Administraciones Públicas se rige, además de por la legislación laboral y por las demás normas convencionalmente aplicables, por los preceptos de este Estatuto que así lo dispongan”, y aquellos que no lo dispongan se aplicarán al personal laboral "en lo que proceda" ${ }^{430}$. En algunos casos el EBEP regula de forma unitaria algunos de los aspectos más trascendentales de las relaciones de empleo de ambos colectivos, estableciendo un régimen básico común en materia de derechos individuales y derechos individuales

427 López Gómez, 2009, pág. 46.

428 López Gómez, 2009, pág. 47.

${ }^{429}$ Artículo 1.2 EBEP.

430 Artículo 2.1 EBEP. 
ejercidos colectivamente ${ }^{431}$, el Código de conducta $^{432}$ y los principios relativos al régimen de $\operatorname{acceso}^{433}$ y el régimen disciplinario $^{434}$. Sin embargo, el EBEP mantiene la dualidad reguladora en lo que no es susceptible de integración. Por lo que, sin acabar con la dualidad de regímenes profundiza en el proceso de aproximación entre ambos tipos de empleados públicos. Los dos regímenes interactúan y se integran entre sí, siendo la negociación colectiva uno de los motores dicha integración.

Inspirado por la Ley Orgánica 3/2007 de 22 de marzo para la Igualdad efectiva de Mujeres y Hombres, el EBEP establece como fundamento de actuación de las Administraciones Públicas "la igualdad de trato entre mujeres y hombres" ${ }^{435}$, así como la "igualdad, mérito y capacidad en el acceso y la promoción profesional"436. Los avances introducidos por el EBEP en materia de igualdad entre hombres y mujeres en el empleo público, especialmente en el empleo público laboral, serán estudiados a continuación.

431 Artículos 14 y 15 EBEP, dentro del Capítulo I "Derechos de los empleados públicos" del Título III del EBEP "Derechos y deberes. Código de conducta de los empleados públicos".

432 Artículos 52, 53 y 54 EBEP.

433 Artículo 55 EBEP.

434 Artículo 93.1 EBEP.

435 Artículo 3.1 d) EBEP.

436 Artículo 3.1 b) EBEP. 

2. IGUALDAD EN EL ACCESO AL EMPLEO PÚBLICO.

Tal y como se ha hecho referencia al comienzo de este estudio, la mayor parte de las discriminaciones tienen su origen en los prejuicios existentes sobre la manera de comportarse en el trabajo hombres y mujeres. En este epígrafe el objetivo es, partiendo de un concepto amplio de acceso al empleo público, analizar cada uno de los elementos y las posibles conductas discriminatorias ligadas a los mismos, de manera que esos elementos se convierten en instrumentos a disposición de las Administraciones Públicas para hacer efectivo el principio de igualdad real entre hombres y mujeres en el empleo público, y más concretamente en el empleo público laboral. Ya que, tal y como dispone el artículo 51 LOIMH, las Administraciones Públicas deberán "remover los obstáculos que impliquen la pervivencia de cualquier tipo de discriminación con el fin de ofrecer condiciones de igualdad efectiva entre mujeres y hombres en el acceso al empleo público y en el desarrollo de la carrera profesional".

Se parte de un concepto amplio de acceso al empleo, de forma que desde los requisitos establecidos en la relación de puestos de trabajo para poder desempeñar un puesto determinado, hasta la publicación de la oferta de empleo público, pasando por la aprobación de las bases de la convocatoria y el proceso selectivo 
propiamente dicho, todo estos pasos van a estar inspirados en el principio de igualdad y no discriminación.

Como se verá a continuación, aunque la actuación discriminatoria puede aparecer desde el mismo momento de definir el puesto de trabajo a cubrir, por ejemplo exigiendo requisitos no necesarios para el desempeño de las funciones propias del mismo, es posible toparse con ésta en el anuncio de la convocatoria o en el tipo de procedimiento selectivo empleado y su desarrollo, que pueden adolecer de falta de objetividad al emplear pruebas, exámenes o preguntas que favorecen a un grupo y perjudican a otro y que provocan la segregación de las mujeres en el empleo público.

Además, el artículo 1.3 d) EBEP consagra la igualdad de trato entre mujeres y hombres como fundamento de actuación de las Administraciones Públicas, y deberá garantizarse también en la formación y en la promoción profesional.

2.1. PRincipios CONSTITUCiOnALES DE ACCESO AL EMPLEO PÚBLICO. EXTENSIÓN AL PERSONAL LABORAL DE LA ADMINISTRACIÓN PÚBLICA.

El principio de igualdad del artículo 14 de la CE se concreta en relación con el acceso a los cargos y a la función pública, en los artículos 23 y 103 de la CE. El artículo 23.2 CE señala que los 
ciudadanos "tienen derecho a acceder en condiciones de igualdad a las funciones y cargos públicos, con los requisitos que señalen las leyes", y el artículo 103.3 CE que "la ley regulará el estatuto de los funcionarios públicos, el acceso a la función pública de acuerdo con los principios de mérito y capacidad, las peculiaridades del ejercicio de su derecho a sindicación, el sistema de incompatibilidades y las garantías para la imparcialidad en el ejercicio de sus funciones". Se pretende acabar así con la discriminación por razón de género cuando se trata de desempeñar actividades que por ser públicas han de estar abiertas a cualquier ciudadano que cumpla los requisitos exigidos por la Ley ${ }^{437}$.

El tenor literal empleado por los artículos 23.2 CE y 103.3 CE puede inducir a confusión y de hecho provocó un debate doctrinal, hoy superado, en torno a la cuestión de si el acceso al empleo público respetando los principios de igualdad mérito y capacidad se refieren a todos los empleos públicos o únicamente a las funciones y cargos públicos.

El legislador ha reconocido en el artículo 19.1 LMRFP que "las Administraciones Públicas seleccionan su personal ya sea funcionario, ya laboral, de acuerdo con su oferta de empleo público, mediante convocatoria pública y a través del sistema de concurso, oposición o concurso-oposición libre en los que se

437 Tamames Gómez, Laura y Ramón. Introducción a la Constitución Española. Alianza, Madrid, 2003, pág. 73. 
garanticen en todo caso los principios constitucionales de igualdad, mérito y capacidad, así como el de publicidad". Este precepto ha sido derogado por la Disposición derogatoria única letra b) EBEP. No obstante, el EBEP también reconoce la aplicación de los principios rectores de acceso al empleo público sin hacer distinciones en función del vínculo jurídico que une al empleado público con la Administración. Según el artículo 55 EBEP las Administraciones públicas seleccionarán su personal funcionario y laboral mediante procedimientos en los que se garanticen los principios constitucionales de igualdad, mérito y capacidad. El contenido de estos principios reviste una gran importancia no sólo desde la perspectiva de la configuración del derecho al acceso al empleo público, sino desde la finalidad de la ley porque, en última instancia, lo que tratan de garantizar es el principio de igualdad en los procesos de selección del personal funcionario y laboral al servicio de la Administración Pública ${ }^{438}$.

La doctrina también está de acuerdo con la extensión de los principios constitucionales de acceso al empleo público al personal laboral. $\mathrm{Y}$ es que, si los principios de igualdad, mérito y capacidad tienen por finalidad evitar que el ingreso en la Administración Pública tenga lugar a través del nepotismo familiar o político, negar la extensión de dichos principios constitucionales al personal laboral implicaría abrir las vías para la quiebra de la

\footnotetext{
438 Goñi Sein, José Luis. Ámbito subjetivo de aplicación del estatuto. XIX Congreso Nacional de Derecho del Trabajo y de la Seguridad Social. El Estatuto Básico del Empleado Público. Laborum, Murcia, 2008, pág. 177.
} 
imparcialidad administrativa, contraviniendo el espíritu de la Constitución $^{439}$. Para algunos autores como Sala Franco, la extensión de estos principios al personal laboral encontraría su fundamento en el artículo 9.3 CE en el que se prohíbe la arbitrariedad de los poderes públicos ${ }^{440}$.

La jurisprudencia del Tribunal Constitucional y del Tribunal Supremo también consideran aplicables los principios constitucionales de acceso al empleo público al personal laboral de las Administraciones Públicas, no obstante el primero de ellos lo justifica en los principios recogidos en el artículo 103.1 CE y el segundo se apoya directamente en los artículos 23.2 y $103.3 \mathrm{CE}^{441}$. El Tribunal Constitucional señala que mientras que en el ámbito de las relaciones entre particulares el principio de autonomía de la voluntad deja un margen en el que la decisión unilateral del empresario en ejercicio de sus poderes de organización de la empresa puede libremente seleccionar a su personal, respetando los mínimos legales o convencionales, es decir, sin más limitación que la que se deriva del principio de no discriminación al que aluden los artículos 4.2 c) y 17 del TRET, la Administración Pública se encuentra sujeta a la Ley y al Derecho (art. 103.1 CE) con una interdicción expresa de la arbitrariedad (art. 9.3 CE) ${ }^{442}$.

\footnotetext{
${ }^{439}$ López Gómez, 2009, pág. 107.

440 Sala Franco, Tomás. Incidencia de la legislación laboral en el marco de la función pública. Instituto Nacional de Administración Pública, Madrid, 1989, pág. 26.

${ }^{441}$ Ramos Moragues, Francisco. El personal laboral de las Administraciones Públicas. La Ley, Madrid, 2011, pág. 125.

${ }^{442}$ FJ 1 párrafo segundo de la STC 161/91, de 18 de julio.
} 
Para el Tribunal Constitucional el derecho fundamental reconocido en el artículo 23.2 CE no se aplica en los supuestos de contratación de personal laboral por parte de las Administraciones Públicas, de manera que los posibles tratos discriminatorios sólo podrían conculcar el principio general de igualdad establecido en el artículo 14 de la Constitución del que el artículo 23.2 no es sino una concreción específica en relación con el ámbito de los cargos y funciones públicos ${ }^{443}$.

A diferencia de la jurisprudencia Constitucional, el Tribunal Supremo sí ha reconocido la aplicación directa de los artículos 14, 23.2 y 103.3 CE a la selección de personal laboral ${ }^{444}$. El Tribunal Supremo señala que las Administraciones Públicas deben someterse a la legislación laboral cuando, actuando como empresarios, celebren o queden vinculadas con sus trabajadores por medio del contrato de trabajo, sin embargo, ciertas cuestiones como el acceso a la condición de empleado público, tienen una regulación específica sin que sean de aplicación las soluciones previstas en el Derecho laboral. En esta jurisprudencia se constata nuevamente la dualidad de regímenes jurídicos aplicables al personal laboral al servicio de la Administración Pública. La Administración Pública cuando recurre a la contratación laboral no es libre para elegir al empleado, no siendo aplicable el artículo

\footnotetext{
${ }^{443}$ FJ 2 primer párrafo de la STC 281/93, de 27 de septiembre. ${ }^{444}$ FJ 3 primer párrafo de la STS de 20 de enero de 1998.
} 
$38 \mathrm{CE}$, lo que garantiza una mayor objetividad en la selección de personal y menos riesgos de discriminación por razón de sexo.

\subsection{REQUISITOS DE ACCESO AL EMPLEO PÚBLICO.}

Una vez aclarado el hecho de que los principios constitucionales de acceso al empleo público se aplican a todos los ciudadanos, hombres y mujeres, tanto en los procesos de selección de personal funcionario como de personal laboral, el paso siguiente es analizar los requisitos necesarios para el acceso.

Con fundamento en el artículo 23.2 CE, el artículo 55.1 del EBEP establece que "todos los ciudadanos tienen derecho al acceso al empleo público de acuerdo con los principios constitucionales de igualdad, mérito y capacidad, y de acuerdo con lo previsto en el presente Estatuto y en el resto del ordenamiento jurídico”. El alcance de esta previsión debe ser objeto de especificación, en el sentido de que este derecho nace del cumplimiento de las normas legales o reglamentarias que disciplinan en cada caso el acceso al cargo o a la función en concreto $^{445}$. Por tanto, la exigencia que deriva del artículo $23.2 \mathrm{CE}$ es la de que las reglas de procedimiento para el acceso a los cargos y funciones públicas $y$, entre tales reglas, las convocatorias de concursos y oposiciones, se establezcan en términos generales y abstractos y no mediante referencias individualizadas y concretas,

${ }^{445}$ Goñi Sein, 2008, pág. 175. 
pues tales referencias son incompatibles con la igualdad ${ }^{446}$. Y ello porque del artículo 23.2 CE "no nace derecho alguno a la ocupación de cargos o al desempeño de funciones determinadas, $\mathrm{y}$ ni siquiera el derecho a proponerse como candidato para los unos y las otras" ${ }^{\prime 47}$. Lo que garantiza el artículo 23.2 CE es el derecho de los ciudadanos a acceder a la función pública en condiciones de igualdad, con los requisitos que señalen las leyes.

En concreto, el artículo 56 EBEP atribuye la titularidad del derecho de acceso al empleo público a quienes reúnan los requisitos establecidos en el mismo, requisitos de índole subjetivo en tanto que son exigibles a la persona que pretende acceder al empleo público, y aplicables en los procesos de selección tanto de personal funcionario como laboral contratado al servicio de la Administración Pública. El artículo 56.1 EBEP enumera los requisitos para poder participar en los procesos selectivos para el acceso al empleo público y la adquisición de la relación de servicio, y que son la posesión de la nacionalidad española sin perjuicio de lo dispuesto en el artículo 57 EBEP para los nacionales de otros Estados miembros de la Unión Europea; tener la capacidad funcional para el desempeño de las tareas asignadas a cada puesto de trabajo; haber cumplido dieciséis años de edad y no exceder de la edad máxima de jubilación ${ }^{448}$; no haber sido separado mediante

\footnotetext{
${ }^{446}$ FJ 4 segundo párrafo último inciso de la STC 50/86, de 23 de abril.

${ }^{447}$ FJ 4 segundo párrafo de la STC 50/86, de 23 de abril.

${ }^{448}$ La STC 75/83, de 3 de agosto, fue dictada en relación con el establecimiento de una edad máxima para el acceso al cargo de Interventor en los municipios de
} 
expediente disciplinario del servicio de cualquiera de las Administraciones Públicas, ni hallarse inhabilitado por resolución judicial para empleos o cargos públicos; así como estar en posesión de la titulación exigida.

Además, pueden existir otros requisitos provenientes de otras normas al margen del EBEP. Así se desprende de la lectura del artículo 56.3 EBEP según el cual “podrá exigirse el cumplimiento de otros requisitos específicos que guarden relación objetiva y proporcionada con las funciones asumidas y las tareas a desempeñar. En todo caso, habrán de establecerse de manera abstracta y general". Por consiguiente, bajo los límites mencionados nada impide que se pueda exigir la acreditación de experiencia profesional o determinadas condiciones físicas, lo que, como se verá posteriormente, puede suponer un riesgo para la igualdad.

régimen especial de Barcelona y Madrid. En el FJ 3 se hace constar "que la edad no es de las circunstancias enunciadas normativamente en el artículo 14", sin embargo la intención del artículo 14 CE no es la de establecer una lista cerrada de causas de discriminación "pues en la fórmula del indicado precepto se alude a cualquier otra condición o circunstancia personal o social, carácter de circunstancia personal que debe predicarse de la edad; de modo que la edad, dentro de los límites que la ley establece para el acceso y la permanencia en la función pública, es una de las circunstancias comprendidas en el artículo 14 y en el artículo 23.2 desde la perspectiva excluyente de tratos discriminatorios". Continúa diciendo la Sentencia que "en cuanto la edad es en sí un elemento diferenciador, será legítima una decisión legislativa que, atendiendo a ese elemento diferenciador y a las características del puesto de que se trate, fije objetivamente límites de edad que suponga, para los que la hayan rebasado, la imposibilidad de acceder a estos puestos". 


\subsection{IGUALDAD EN LA PLANIFICACIÓN DE LOS RECURSOS HUMANOS.}

La planificación de los recursos humanos en las Administraciones Públicas es un instrumento imprescindible para lograr una prestación de los servicios públicos de manera eficaz, así como para el establecimiento de estrategias que permitan aprovechar los recursos humanos disponibles de manera efectiva. Así se deduce del artículo 1.3 f) EBEP, que consagra como uno de los fundamentos de actuación de la Administración Pública la "eficacia en la planificación y gestión de los recursos humanos". La planificación es también un requisito previo a la selección de personal al servicio de las Administraciones Públicas. En este epígrafe se trata de reflejar la importancia de la planificación a la hora de valorar qué medidas son más adecuadas para lograr la igualdad efectiva entre mujeres y hombres en el empleo público.

\section{a. La Relación de Puestos de Trabajo.}

Aunque la estructuración de los puestos de trabajo se ha llevado a cabo tradicionalmente a través de la Relación de Puestos de Trabajo, en adelante RPT, el artículo 74 EBEP deja abierta la posibilidad de determinar "otros instrumentos organizativos similares" siempre que comprendan, "al menos, la denominación de los puestos, los grupos de clasificación profesional, los cuerpos 
o escalas, en su caso, a que estén adscritos, los sistemas de provisión y las retribuciones complementarias".

La RPT es el instrumento técnico de ordenación del personal de acuerdo con las necesidades de los servicios y con expresión de los requisitos exigidos para su desempeño. En función de ellas se definen las plantillas de las Administraciones Públicas y se determinan las ofertas públicas de empleo ${ }^{449}$. A diferencia de la RPT, la plantilla es un instrumento de carácter más bien financiero o presupuestario de ordenación del gasto que constituye una enumeración de todas las plazas que están dotadas en el Presupuesto y que debe incluir tanto a los funcionarios como al personal laboral. Por tanto, dada la finalidad y conexión presupuestaria de la plantilla ${ }^{450}$ no es posible la creación de puestos de trabajo que no estén amparados en la misma ${ }^{451}$. La secuencia sería la siguiente: un puesto de trabajo, una plaza en la plantilla, y la dotación presupuestaria de la misma. Sin estos tres requisitos no se puede explicar la selección del todo el personal al servicio de las Administraciones Públicas, lo que como ya sabemos incluye al personal laboral.

\footnotetext{
${ }^{449}$ FJ 3 segundo párrafo de la STS de 8 de mayo de 1998 (RJ/1998/4586).

${ }^{450} \mathrm{FJ} 2$ cuarto párrafo de la STS de 20 de julio de 1990 (RJ/1990/6141). Según esta sentencia la aprobación anual de la plantilla es necesario que vaya unida a la correspondiente prevención del gasto contenida en el Presupuesto anual.

${ }^{451}$ FJ 2 segundo y tercer párrafo de la STSJ de Castilla y León 523/06 de 14 de marzo.
} 
Seguidamente se analizará el contenido de la RPT y su incidencia en la igualdad de trato entre hombres y mujeres en el empleo público.

- Denominación del puesto de trabajo.

A diferencia del artículo 15 LMRFP, el artículo 74 EBEP no incluye como contenido de la RPT las características esenciales del puesto de trabajo, ni tampoco los requisitos exigidos para su desempeño. Sin embargo, no prohíbe que se haga referencia a las mismas, ya que el contenido relacionado en el artículo 74 EBEP es mínimo tal y como se deduce de las palabras "al menos”. Además, el artículo 15 LMRFP no contradice lo dispuesto en el EBEP, por lo que entendemos que continúa vigente en base a la Disposición Final cuarta $\mathrm{EBEP}^{452}$.

La jurisprudencia del Tribunal Supremo sí que se ha referido a la obligatoriedad de incluir las características esenciales de los puestos de trabajo en la RPT enlazando dos conceptos distintos, pero indefectiblemente unidos, como son la descripción del puesto y su valoración económica.

El análisis y descripción de los puestos de trabajo consiste en determinar "qué hacen" los trabajadores, es decir, las tareas,

\footnotetext{
452 Jiménez Asensio, Rafael. La estructura del empleo público en el Estatuto Básico del Empleado Público, en Ortega Álvarez, Luis, director. Estatuto Básico del Empleado Público. El Consultor de los Ayuntamientos (La Ley), 2007, págs. 549-551.
} 
funciones o actividades que ejecutan en el desempeño del puesto, “cómo lo hacen”, es decir, los recursos, métodos y procedimientos empleados, y "para qué" lo hacen, es decir, el objetivo o propósito de cada una de las funciones. Por otro lado, la valoración exige no sólo la identificación del puesto, es decir, la denominación del mismo, sino también las responsabilidades que éste conlleva, su posición dentro del organigrama general, las condiciones físicas del trabajo, y los requerimientos y habilidades para realizar de forma satisfactoria todas las funciones del puesto de trabajo ${ }^{453}$. Por tanto, la descripción de los puestos de trabajo se identificaría con las características esenciales de los mismos, es decir, con "aquellas tareas que constituyen el núcleo definitorio del puesto de trabajo", y que son las que justifican la valoración del puesto de trabajo, es decir, la exigencia de una serie de requisitos para desempeñarlo como pueden ser "una determinada titulación académica y una formación específica”. Además deberá vigilarse que no se exijan titulaciones que no sean realmente necesarias para desempeñar el puesto de trabajo. Queda clara la conexión entre descripción y valoración del puesto, y por ende con las retribuciones que le corresponden.

De todo esto se deduce que "las características de la persona que va a ocupar un puesto de trabajo no deben dotar de contenido

453 Martín Jiménez, Rodrigo. Clasificación y valoración de puestos de trabajo, en Sempere Navarro, Antonio V. y Miguel Cardenal Carro, directores y Francisco Javier Hierro Hierro, coordinador. El personal laboral al servicio de las Corporaciones Locales. El Consultor de los Ayuntamientos (La Ley), Madrid, 2010, pág. 188. 
al mismo"454. Esta última observación es trascendental para asegurar que la descripción de los puestos de trabajo se haga en base a requisitos o criterios que guarden relación con la prestación a desarrollar, con las funciones propias del puesto de trabajo, y no con el sexo y por tanto con la mayor o menor consideración social que puedan merecer determinadas aptitudes o capacidades de los candidatos $^{455}$.

Por ello considero que la simple denominación del puesto de trabajo, la identificación del mismo por su nombre, no bastaría para garantizar la igualdad de trato entre hombres y mujeres, por mucho que se evite la utilización de denominaciones sexistas y que encontremos disposiciones como el artículo 14.11 LOIMH que incidan en la necesidad de utilizar un lenguaje neutro, sino que además sería necesaria la clara determinación de las funciones que corresponden al puesto de trabajo en cuestión. De esta forma, puesto que la Administración tiene la obligación de ofrecer unas condiciones de igualdad efectiva entre mujeres y hombres en el acceso al empleo público, debería incluir en el contenido de la RPT las características esenciales de los puestos de trabajo aunque no formen parte del contenido mínimo de aquélla según el artículo 74 EBEP. Sólo así podrá garantizar una descripción, una

\footnotetext{
${ }^{454}$ FJ 1 cuarto párrafo de la STS de 15 de junio de 2005 (RJ/2005/6256).

455 López-Romero González, $\mathrm{M}^{a}$ Piedad. El largo camino hacia la igualdad en la clasificación y promoción profesionales, en Sanguineti Raymond, Wilfredo, director y $\mathrm{M}^{\mathrm{a}}$ Luisa Martín Hernández, coordinadora. Propuestas para la igualdad de género en la negociación colectiva. Estudio a partir de la negociación colectiva en Castilla y León. Bomarzo, Albacete, 2011, pág. 67.
} 
valoración y una retribución de los puestos de trabajo que sea respetuosa con la igualdad de género.

- Grupo de clasificación profesional.

Si continuamos analizando el contenido mínimo de la RPT al que se refiere el artículo 74 EBEP, nos encontramos con los grupos de clasificación profesional. La clasificación profesional define las aptitudes de los trabajadores para desempeñar adecuadamente las funciones que definen las características esenciales del puesto de trabajo. Además, la clasificación profesional dispone de manera ordenada las tareas a desarrollar, lo que permite encuadrar de manera objetiva a los empleados públicos en el grupo profesional más adecuado atendiendo a las funciones que lleva a cabo, lo que a su vez es una garantía de igualdad de trato entre hombres y mujeres.

Por lo que respecta a la clasificación profesional del personal laboral al servicio de la Administración Pública, el artículo 77 EBEP remite de nuevo a la legislación laboral, conectando directamente con el Estatuto de los Trabajadores. Esta materia es objeto de negociación colectiva tal y como consta en el artículo 37 EBEP y en el artículo 22.1 TRET, que señala que "mediante negociación colectiva (...), se establecerá el sistema de clasificación profesional de los trabajadores, por medio grupos profesionales". La Ley 3/2012 de 6 de julio de medidas urgentes para la reforma 
del mercado laboral ${ }^{456}$, modifica el artículo 22 TRLET de manera que la categoría profesional desaparece y el grupo profesional pasa a ser la única referencia en materia de clasificación profesional. El apartado segundo define el grupo profesional como aquel "que agrupe unitariamente las aptitudes profesionales, titulaciones y contenido general de la prestación", y que "podrá incluir distintas tareas, funciones, especialidades profesionales o responsabilidades asignadas al trabajador". El apartado tercero añade, sin que sea ninguna novedad de la Ley 3/2012 de 6 de julio, que "la definición de los grupos profesionales se ajustará a criterios y sistemas que tengan como objeto garantizar la ausencia de discriminación directa e indirecta entre mujeres y hombres", lo cual implica que hay que tener en cuenta los criterios judiciales sobre neutralidad en la valoración de los trabajos a fin de evitar la creación o el mantenimiento de profesiones o grupos feminizados, y con ello situaciones de discriminación indirecta.

En relación con dichos criterios judiciales destacamos la Sentencia del Tribunal de Justicia de la Unión Europea de 1 de julio de 1986, caso Rummler ${ }^{457}$, en la que se valora la posibilidad de clasificar los puestos de trabajo en atención a la fuerza física, y por tanto, incluyendo un elemento relacionado con el sexo de las personas que a priori puede ser considerado discriminatorio. En esta sentencia la Sra. Gisela Rummler demandó a su empresa para

\footnotetext{
456 Boletín Oficial del Estado núm. 162 de 7 de julio de 2012.

457 STJUE de 1 de julio de 1986, C-237/85.
} 
obtener una clasificación en una categoría más elevada en la escala de retribuciones. El sistema de clasificación de la empresa se basaba, entre otros, en los criterios del esfuerzo, la carga muscular, y el carácter pesado del trabajo. Según la Comisión el carácter no discriminatorio debería buscarse no en cada criterio por separado, sino en el sistema de clasificación profesional en su conjunto. Ya que, un sistema no es necesariamente discriminatorio únicamente por el hecho de que uno de sus criterios se refiera a cualidades que poseen más fácilmente los hombres, siempre que se tengan en cuenta, en la medida en que la naturaleza de las tareas que deban realizarse lo permita, otros criterios con relación a los cuales los trabajadores femeninos puedan presentar especiales aptitudes, y se consiga excluir así, en su conjunto, cualquier discriminación por razón de sexo. En consecuencia, la valoración de los puestos de trabajo sobre la base de la fuerza física no constituye una discriminación si objetivamente se mide la fuerza porque el trabajo así lo exige y con la condición de que, mediante la consideración de otros criterios, consiga excluir en su conjunto cualquier discriminación por razón de sexo ${ }^{458}$.

Por este motivo sí sería discriminatorio un sistema de clasificación basado en la fuerza cuando ésta no sea necesaria para ejecutar dicho trabajo, o cuando dicho sistema de clasificación excluya a las mujeres de un empleo por el mero hecho de que son, por término medio, más pequeñas y menos fuertes que la media de

${ }^{458}$ STJUE de 1 de julio de 1986, C-237/85. 
los hombres, cuando para dicho empleo se aceptan hombres con características físicas similares ${ }^{459}$.

Una vez conseguido que el sistema de clasificación de puestos de trabajo sea neutro, el paso siguiente es preguntarnos si el hecho de que un trabajador y una trabajadora estén clasificados en la misma categoría profesional basta por sí solo para concluir que los dos trabajadores afectados realizan un mismo trabajo o un trabajo de igual valor. La respuesta es negativa puesto que esta circunstancia sólo constituye un indicio, entre otros, de que se cumple este criterio $^{460}$.

El Tribunal de Justicia de la Unión Europea ha declarado en varias ocasiones que para apreciar si unos trabajadores realizan un mismo trabajo o un trabajo al que se pueda atribuir un mismo valor, debe comprobarse si, habida cuenta de un conjunto de factores como la naturaleza del trabajo, las condiciones de formación y las condiciones laborales, puede considerarse que dichos trabajadores se encuentran en una situación comparable ${ }^{461}$. Para determinar si dos trabajos tienen el mismo valor el órgano jurisdiccional nacional tendrá en cuenta otros factores como por ejemplo si se trata de un trabajo con máquinas y exige fuerza física, si es un trabajo manual para el que se precisa sobre todo habilidad manual, si son relevantes los periodos de descanso retribuidos y a

\footnotetext{
${ }^{459}$ STJUE de 1 de febrero de 2005, C-203/03.

${ }^{460}$ STJUE de 26 de junio de 2001, C-381/99.

461 STJUE de 31 de mayo de 1995, C-400/93.
} 
la libertad de organización del trabajo, así como la nocividad de éste, etc. ${ }^{462}$

Por tanto, la valoración como proceso de carácter objetivo, debe valorar el puesto, la función dentro del organigrama y no la persona que lo ocupa. Sin embargo no es tarea sencilla diferenciar el puesto de la persona que ha de ocuparlo, porque los puestos tienden a ser considerados como algo material sobre lo que se tiene un poder de posesión desde el momento del nombramiento. Además el puesto de trabajo determina en gran medida el comportamiento que se espera de una persona al desempeñarlo ${ }^{463}$.

En la jurisprudencia del Tribunal Constitucional destaca la sentencia número 58/94 de 28 de febrero que se centra en el problema de fondo ¿cómo medir el valor del trabajo? El principio de no discriminación se aplica no sólo a los trabajos iguales, sino también a los trabajos de igual valor. En esta sentencia se examina si la distinta valoración del trabajo a desarrollar en las categorías predominantemente masculinas y en las categorías feminizadas puede ser explicada por razones ajenas a la consideración del sexo de los trabajadores y basadas exclusivamente en el mayor valor del trabajo ${ }^{464}$. "El solo enunciado de tareas diversas es un argumento descriptivo que, aunque imprescindible como paso previo, no prejuzga en absoluto la razón por la que unas tareas, las

\footnotetext{
462 STJUE de 31 de mayo de 1995, C-400/93.

463 Martín Jiménez, 2010, pág. 186.

${ }^{464}$ FJ 4 primer párrafo de la STC 58/94, de 28 de febrero.
} 
desempeñadas mayoritariamente por hombres, han sido más valoradas que otras, las desempeñadas mayoritariamente por mujeres, a efectos salariales"465. En los supuestos en los que existan categorías predominantemente ocupadas por trabajadores de uno u otro sexo, desigualmente retribuidas y no exista transparencia en la determinación de los criterios retributivos, el parámetro de igualdad no es la identidad de tareas, sino la igualdad de valor del trabajo, en la que ha de garantizarse y exigirse criterios neutros de valoración, que no supongan la excesiva valoración de características o aptitudes propias de uno de los sexos frente a las del otro. Esto excluía la posibilidad de tener en cuenta como criterio de valoración el mayor esfuerzo físico, salvo en casos excepcionales cuando el esfuerzo físico constituya un factor absolutamente determinante para el desarrollo de las tareas o bien que se trate de un elemento esencial de ésta, siendo preciso, aun en estos casos, que se combine con otros rasgos tipificadores neutros ${ }^{466}$.

Si conseguimos que la clasificación de puestos de trabajo sea neutra, y si somos capaces de establecer un sistema de valoración compatible con el principio de igualdad entre hombres y mujeres, estaremos poniendo freno a la segregación laboral y a situaciones como la contemplada en la Sentencia del Tribunal Supremo de 4 de mayo de 2000. Esta sentencia califica como discriminación

\footnotetext{
465 FJ 5 último párrafo de la STC 58/94 de 28 de febrero. ${ }^{466}$ FJ 6 primer párrafo de la STC 58/94 de 28 de febrero.
} 
indirecta la conducta empresarial de no contratar mujeres para determinada categoría profesional de la empresa. Pese al compromiso empresarial de remediar tal situación mediante la contratación de determinada proporción de mujeres, la situación no se remedió. Además la empresa requería la posesión de un determinado título profesional, el cual excedía las previsiones del Convenio colectivo - que ni siquiera exigía, por innecesaria, ninguna titulación para el trabajo en cuestión, y que pese a afectar igual a varones que mujeres perjudicaba mucho más a éstas, ya que por razones socio-económicas no solían estar en posesión de tal titulación ${ }^{467}$.

Por lo que respecta a la segmentación laboral, el contenido analizado de la RPT refleja, entre otras cosas, las disponibilidades y necesidades de personal ${ }^{468}$. Esto permitirá tener un conocimiento del número de efectivos, así como de sus perfiles profesionales y niveles de cualificación. Así sabremos no sólo si el personal disponible es suficiente para hacer frente a los servicios públicos que se prestan, o si por el contrario es necesario acudir a la incorporación de personal externo de nuevo ingreso a través de oferta de empleo público, sino también y por lo que ahora nos interesa, tendremos conocimiento de en qué sectores hay segregación ocupacional y si es adecuado la adopción de medidas para corregirlas. En este sentido, la Disposición adicional décimo

\footnotetext{
${ }^{467}$ FJ 6 cuarto párrafo de la STS de 4 de mayo de 2000 (RJ/2000/4266). 468 Artículo 69.2 a) EBEP.
} 
primera de la LOIMH ha añadido el apartado 4 en el artículo 17 TRET, que permite que a través de la negociación colectiva se puedan establecer medidas de acción positiva en las condiciones de clasificación profesional, de forma que en igualdad de condiciones de idoneidad, tengan preferencia las personas del sexo menos representado para favorecer su acceso en el grupo, categoría profesional o puesto de trabajo de que se trate. Por tanto, se trata de medidas de acción positiva de carácter neutro, es decir, que pueden beneficiar a las personas, hombres o mujeres, del sexo menos representado. Otras medidas que pueden incluirse en los convenios colectivos con la misma finalidad pueden ser las bonificaciones a la contratación estable de mujeres desempleadas en sectores en los que existe un menor índice de empleo femenino, medidas estas últimas de derecho del trabajo aplicables al personal laboral de la Administración cuando el acceso al empleo se produzca excepcionalmente mediante oferta genérica al servicio público de empleo.

Al hablar de segregación ocupacional nos referimos al hecho de que las mujeres desarrollan oficios que reproducen en el ámbito profesional las tareas que realizan en el hogar, es decir, trabajos como el de limpiadoras, cocineras, auxiliares de enfermería, etc., ocupaciones que son por lo general peor remuneradas porque son poco cualificadas ${ }^{469}$. Dentro de la segregación ocupacional

${ }^{469}$ Sanguineti Raymond, Wilfredo. Mecanismos legales de lucha contra la discriminación de la mujer en el trabajo: una revisión crítica, en Martínez Gallego, Eva Ma y Justo 
tenemos que distinguir la que se produce en sentido vertical y la que se produce en sentido horizontal. Normalmente, en los puestos de responsabilidad son más numerosos los hombres que las mujeres. Asimismo, en algunos puestos de baja cualificación profesional se produce mayor representación de mujeres que de varones, es lo que se denomina segregación vertical. En relación con la segregación horizontal, si se analizan las distintas áreas existentes en la Administración también podremos encontrar diferencias entre hombres y mujeres. Existen sectores tradicionalmente femeninos, como el de administración, y otros masculinos, como el informático.

El objetivo a alcanzar a través de la determinación del contenido de la RPT sería evitar la segregación ocupacional, ya que una de las manifestaciones de la desigualdad en el trabajo es la distribución del empleo por ocupaciones. Es preciso diseñar las relaciones de puestos de trabajo y las plantillas de manera que se combatan las políticas sistemáticas de contratación de las mujeres para determinados puestos de trabajo o funciones que reproducen su rol social subordinado respecto del varón, que son objeto de una valoración inferior o tienen asignadas funciones de una menor responsabilidad, políticas que contribuyen a perpetuar una posición inferior de las mujeres dentro de la sociedad con respecto a los hombres. En la Administración Pública la segregación es

Reguero Celada, coordinadores. Mujer y Empleo. Una estrategia para la igualdad. Comares, Granada, 2004, págs. 38-39. 
menos frecuente, pero no inexistente. No hay más que pensar en el personal de limpieza de la misma, desempeñado mayoritaria sino exclusivamente por mujeres, o los peones de vías y obras, como ejemplo de puestos ocupados por hombres.

Por todo ello es imprescindible que la ordenación de los recursos humanos de la Administración se lleve a cabo a través de instrumentos que respondan, no sólo a los principios de eficacia, eficiencia y sostenibilidad, sino también al principio de igualdad de género.

- Sistemas de provisión de puestos de trabajo.

Antes de acudir a la selección de personal externo, la Administración puede aprovechar los recursos humanos de los que dispone mediante convocatorias de provisión de puestos de trabajo vacantes. Se trata de satisfacer las necesidades de personal con los efectivos de personal existentes a través de convocatorias adoptadas desde la perspectiva de la igualdad de género. Es decir, velando porque tengan un resultado equilibrado desde el punto de vista de los sexos y sin menoscabo de los avances logrados en materia de conciliación de la vida personal y familiar de los empleados, promoviéndolas de manera preferente en aquellos ámbitos en los que haya menor representación de uno de los sexos. Por tanto, desde una perspectiva neutra de la igualdad de género. 
El artículo 83 EBEP señala que "la provisión de puestos y movilidad del personal laboral se realizará de conformidad con lo que establezcan los convenios colectivos que sean de aplicación y, en su defecto por el sistema de provisión de puestos y movilidad del personal funcionario de carrera". Por lo que si el convenio colectivo no establece otra cosa, la provisión de los puestos de trabajo en la Administración Pública se llevará a cabo por los procedimientos de concurso y libre designación con convocatoria pública y respetando los principios de igualdad, mérito y $\operatorname{capacidad}^{470}$.

El concurso "consistirá en la valoración de los méritos y capacidades y, en su caso, aptitudes de los candidatos por los

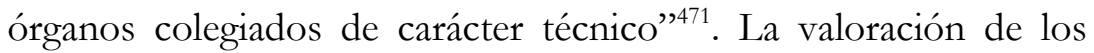
méritos es una materia objeto de negociación colectiva $^{472}$, y suele tener en cuenta el grado personal consolidado, el trabajo desarrollado, los cursos de formación que estén directamente relacionados con el puesto de trabajo convocado - lo que en la mayoría de los casos excluye, erróneamente, la posibilidad de valorar los cursos relacionados con la igualdad efectiva entre hombres y mujeres en el empleo público -, y por último, la antigüedad. Una Administración Pública realmente interesada en la igualdad de oportunidades entre hombres y mujeres en el acceso y

\footnotetext{
470 Artículo 78 EBEP.

471 Artículo 79 EBEP.

472 Artículo 37.1 c) EBEP.
} 
en el desempeño del servicio público tendría que introducir criterios de valoración relacionados con la esfera personal de los empleados públicos y que al mismo tiempo permitan al trabajador un desempeño más eficaz de su puesto de trabajo. Por ejemplo, incluir el cuidado de hijos menores y de familiares dependientes como criterio de valoración en los concursos de méritos, siempre que se acredite que el puesto de trabajo al que se opta permitiría una mejor atención a aquellas personas. Así ha sucedido en la Administración General del Estado a través de la modificación llevada a cabo por el Real Decreto 255/2006, de 3 de marzo ${ }^{473}$ en el artículo 44.2 del Real Decreto 364/1995, de 10 de marzo.

Por lo que respecta a la libre designación con convocatoria pública "consiste en la apreciación discrecional por el órgano competente de la idoneidad de los candidatos en relación con los requisitos exigidos para el desempeño del puesto" ${ }^{474}$. La mayor parte de los nombramientos de las personas titulares de los órganos directivos, o de los consejos de administración de las empresas de capital público, se efectúan mediante el sistema de libre designación sin que la igualdad de oportunidades haya dado los resultados esperados, y sin que el simple paso del tiempo haya conseguido la presencia equilibrada de las mujeres en estos puestos de trabajo que implican una mayor dedicación y responsabilidad. La discrecionalidad en este tipo de nombramientos no puede dar

\footnotetext{
473 Boletín Oficial del Estado núm. 54 de 4 de marzo de 2006.

${ }^{474}$ Artículo 80 EBEP.
} 
lugar a arbitrariedades que además supongan una vulneración del principio de no discriminación en el acceso al empleo. Para ello la decisión discrecional debe estar motivada "con referencia al cumplimiento por parte del candidato elegido de los requisitos y especificaciones exigidos en la convocatoria"475. Pero esta motivación no es suficiente a la vista de la situación actual.

La nueva jurisprudencia del Tribunal Supremo en relación con la libre designación exige que la motivación incluya no sólo la referencia al cumplimiento por parte del candidato elegido de los requisitos establecidos en la convocatoria, sino también los concretos criterios de interés general elegidos como prioritarios para decidir el nombramiento, y las cualidades o condiciones personales y profesionales que han sido consideradas en la persona nombrada para apreciar que aquellos criterios de interés general concurren en ella en mayor medida que en el resto de los solicitantes $^{476}$. Esto garantizará mayor objetividad en este tipo de nombramientos lo que en teoría redunda en beneficio de la igualdad entre hombres y mujeres en el acceso al empleo público.

En este punto es inevitable hacer referencia a las cuotas como medida para paliar el problema de la falta de presencia femenina en puestos directivos públicos. El EBEP no ha regulado

\footnotetext{
475 Artículo 56.2 del Real Decreto 364/1995 de 10 de marzo por el que se aprueba el Reglamento General de Ingreso del Personal al Servicio de la Administración General del Estado (BOE núm. 85, de 10 de abril). ${ }^{476}$ FJ 5 de la STS de 30 de septiembre de 2009 (RJ/2009/7357).
} 
expresamente estas cuotas en el sistema de libre designación. Sin embargo, al establecerse acciones positivas en las actividades de formación de contenido directivo, tal y como se refleja en el artículo 60.2 LOIMH, el legislador sí que ha reparado en la mayor dificultad de la mujer para proyectar su carrera hasta cotas elevadas, $\mathrm{y}$ ha tratado de encontrar una vía alternativa para paliar la falta de regulación expresa de esas cuotas para puestos de trabajo directivos en la Administración ${ }^{477}$. Según dicho precepto, con el fin de facilitar el acceso de las empleadas públicas a puestos directivos en la Administración General del Estado y en los organismos públicos vinculados o dependientes de ella, "en las convocatorias de los correspondientes cursos de formación se reservará al menos un $40 \%$ de las plazas para su adjudicación a aquellas que reúnan los requisitos establecidos".

- Retribuciones complementarias.

En cuanto a las retribuciones complementarias, la RPT incluye el complemento específico asignado al puesto de trabajo. La Administración determina su cuantía respetando los límites previstos en la Ley de Presupuestos Generales del Estado en cuanto a su incremento anual, y teniendo en cuenta los factores a que se refiere el artículo 24 EBEP, como la especial dificultad

477 Puñet Gómez, Pilar. Las medidas para la promoción de la igualdad efectiva en la función pública, en Sala Franco, Tomás, coordinador. Comentarios a la Ley Orgánica 3/2007 de 22 de marzo para la Igualdad Efectiva de Mujeres y Hombres. La Ley, Madrid, 2008, págs. 198-199. 
técnica, responsabilidad, dedicación, incompatibilidad exigible para el desempeño de determinados puestos de trabajo o las condiciones en que se desarrolla el trabajo. Se trata de factores objetivos que retribuyen las características del puesto de trabajo y que en principio no deberían dar lugar a discriminaciones salariales.

Más inconvenientes presentan otros conceptos retributivos que no figuran en la RPT, como la productividad, que remuneran el especial rendimiento, la actividad y dedicación extraordinaria y el interés o iniciativa con que se desempeñen los puestos de trabajo. La productividad se determinará con arreglo a circunstancias objetivas relacionadas con el tipo de puesto de trabajo y el desempeño del mismo, lo que supone una garantía para el principio de igualdad retributiva entre hombres y mujeres. Sin embargo hay un elevado riesgo de que en la valoración de la productividad se tengan en cuenta otros aspectos como la disponibilidad horaria, o la presencia en el puesto de trabajo, que difícilmente podrán beneficiar a aquellas personas que hayan optado, por ejemplo, por la reducción de jornada para poder conciliar trabajo y familia. Por lo tanto, basar el complemento de productividad en las posibilidades de extensión de la jornada de trabajo, supone que las mujeres que asumen la responsabilidad de la familia en mayor medida que los hombres, tienen más dificultad para acceder a dichos complementos. 
b. La Oferta de Empleo Público.

Antes de todo proceso selectivo es necesario que la Administración tenga aprobada la oferta de empleo público u otro instrumento similar de gestión de provisión de las necesidades de personal. La oferta de empleo tiene que ser elaborada sin tener en cuenta estereotipos que reproduzcan las diferencias de valoración entre el trabajo de las personas de uno y otro sexo, ya que esto último encubre normalmente la intención de contratar a un trabajador varón en vez de una mujer.

La Administración debe dar ejemplo e introducir, a través de la negociación colectiva, criterios para la elaboración de las ofertas de empleo que eviten el riesgo de que puedan ser utilizadas como instrumento al servicio de políticas discriminatorias. Las ofertas de empleo se harán con abstracción total de la condición del sexo, atendiendo solamente a la capacidad profesional exigida. Deben apartarse de cualquier estereotipo u orientación sexista, y favorecer el acceso de la mujer a los puestos de trabajo. La jurisprudencia comunitaria ha apoyado esta teoría en la Sentencia del Tribunal de Justicia de la Unión Europea de 22 de abril de 1997, caso Nils Draehmpaehl ${ }^{478}$, que declara discriminatoria la conducta empresarial por la que se publica una oferta de empleo para una, se decía expresamente, colaboradora ${ }^{479}$.

\footnotetext{
478 STJUE de 22 de abril de 1997, C-18/95.

${ }^{479}$ Galiana Moreno, Jesús $\mathrm{M}^{\mathrm{a}}$ y Cámara Botía, Alberto. Igualdad y no discriminación en las relaciones laborales: las decisiones discriminatorias del empresario, en Sempere
} 
Asimismo, en la formulación y difusión de las ofertas de empleo público deberá utilizarse un lenguaje genérico, o hacerse referencia a los dos sexos, evitando realizar ofertas referidas a uno de los sexos, y garantizar la difusión de las ofertas a través de canales que posibiliten que la información llegue por igual a todos los ciudadanos.

Tras la entrada en vigor de la LOIMH lo único que justifica que una oferta de empleo público o privado vaya implícita o explícitamente dirigida a un sexo en concreto es la naturaleza de la prestación laboral o las condiciones específicas en las que se va a desarrollar. Así se deduce del artículo 5 LOIMH según el cual no constituirá discriminación en el acceso al empleo "una diferencia de trato basada en una característica relacionada con el sexo cuando, debido a la naturaleza de las actividades profesionales concretas o al contexto en el que se lleven a cabo, dicha característica constituya un requisito profesional esencial y determinante, siempre y cuando el objetivo sea legítimo y el requisito proporcionado".

Esta idea se ratifica cuando la propia LOIMH introduce un artículo 22 bis en la Ley 56/2003 de 16 de diciembre de Empleo ${ }^{480}$,

Navarro, Antonio V. director y Rodrigo Martín Jiménez, coordinador. El modelo social en la Constitución española de 1978. Ministerio de Trabajo y Asuntos Sociales, Madrid, 2003, pág. 338-339.

480 Boletín Oficial del Estado núm. 301 de 17 de diciembre de 2003. 
en base al cual se "considerarán discriminatorias las ofertas referidas a uno de los sexos, salvo que se trate de un requisito profesional esencial y determinante de la actividad a desarrollar"481, añadiendo este precepto que "en todo caso se considerará discriminatoria la oferta referida a uno de los sexos basada en exigencias del puesto de trabajo relacionadas con el esfuerzo físico".

\subsection{CONVOCATORIAS DE LOS PROCESOS SELECTIVOS.}

Los procedimientos de selección del personal al servicio de las Administraciones Públicas deben guiarse por las bases de la convocatoria, que serán aprobadas por el órgano competente y publicadas en los boletines oficiales que corresponda ${ }^{482}$.

Las Bases de la convocatoria "vinculan a la Administración y a los Tribunales o Comisiones Permanentes de Selección que han de juzgar las pruebas selectivas y a quienes participen en las mismas" $" 483$. Son las normas por las que se rige el proceso selectivo, por lo tanto su contenido es de obligado cumplimiento. Esto puede servir para que aquellas previsiones relacionadas con la consecución de la igualdad entre hombres y mujeres en el empleo

\footnotetext{
${ }^{481}$ Fabregat Monfort, Gemma. La discriminación de género en el acceso al mercado de trabajo. La posibilidad de una nueva tutela a la luz de la Ley Orgánica 3/2007 de 22 de marzo para la igualdad efectiva de mujeres y hombres. Tirant lo Blanch, Valencia, 2008, págs. 91-93.

482 Artículo 55.2 a) EBEP.

483 Artículo 15.4 del Real Decreto 364/1995 de 10 de marzo.
} 
público, previsiones que como algunas de las incluidas en la LOIMH sólo tienen un carácter programático, pasen a ser obligatorias a través de su inclusión en las bases de la convocatoria, de tal manera que su incumplimiento pueda viciar de nulidad el procedimiento selectivo. Esta sería una buena forma de conseguir que la igualdad sea real y efectiva, objetivo último perseguido por la LOIMH.

Para asegurar que en las bases de la convocatoria no se establece ningún requisito susceptible de generar discriminaciones directas o indirectas por razón de género, el artículo 55 LOIMH exige, salvo en casos de urgencia, que la aprobación de convocatorias de pruebas selectivas para el acceso al empleo público en la Administración General del Estado se acompañe de un informe de impacto de género. Este informe será elaborado con el asesoramiento de las Unidades de $\operatorname{Igualdad}^{484}$, y aunque el mismo no tiene carácter vinculante al faltar toda previsión expresa en este sentido ${ }^{485}$, si resulta desfavorable puede servir de base para que prospere la impugnación de las bases de la convocatoria por las personas que pudieran verse afectadas.

Las bases deberán contener al menos la determinación de la naturaleza y características de las plazas o puestos de trabajo convocados, el sistema selectivo elegido, el tipo de pruebas a

\footnotetext{
${ }^{484}$ Artículo 77 c) LOIMH.

485 Artículo 83.1 de la Ley 30/1992 de 26 de noviembre de Régimen Jurídico de las Administraciones públicas y del Procedimiento Administrativo Común.
} 
superar y los programas que las rigen, la composición y el número de miembros de los Tribunales, los sistemas de calificación de los ejercicios y los requisitos de los aspirantes. Este contenido deberá definirse con respeto a la igualdad de oportunidades entre hombres y mujeres.

Puesto que todas estas cuestiones han sido tratadas o lo serán en apartados posteriores, en este momento sólo nos referiremos a los programas incluidos en las bases que han de regir los procedimientos selectivos. Así por ejemplo, el artículo 61.1 LOIMH ha considerado conveniente que todas las pruebas de acceso al empleo público de la Administración General del Estado “contemplarán el estudio y la aplicación del principio de igualdad entre mujeres y hombres en los diversos ámbitos de la función pública”, para lo cual tendrán que incluirse los temas correspondientes en las oposiciones o concursos oposiciones que se celebren. En el resto de Administraciones Públicas no se contempla la obligatoriedad de esta medida, aunque sería conveniente dotarla de efectividad aunque sólo fuera porque la igualdad de trato entre hombres y mujeres es reconocida como fundamento de actuación de las Administraciones Públicas.

Asimismo, según el artículo 56 LOIMH, como medida de igualdad aplicable en la Administración General del Estado, en las bases de los concursos para la provisión de puestos de trabajo se computará, a los efectos de valoración del trabajo desarrollado y 
de los correspondientes méritos, el tiempo que las personas candidatas hayan permanecido en situación administrativa de excedencia, reducción de jornada, o hayan disfrutado de permisos, suspensiones, y licencias con el fin de facilitar la conciliación de la vida personal, familiar y laboral.

\subsection{IGUALDAD EN LOS PROCESOS SELECTIVOS.}

a. Perspectiva orgánica o funcional: Los órganos de selección. El principio de composición equilibrada.

Los procedimientos selectivos de personal funcionario y laboral en la Administración se rigen por una serie de principios entre los que podemos destacar en este momento la "imparcialidad y profesionalidad de los miembros de los órganos de selección" ${ }^{486}$, así como la "independencia y discrecionalidad técnica en la actuación de los órganos de selección"487.

Desde el enfoque de la promoción de la igualdad entre hombres y mujeres, en el artículo 60.1 EBEP se establece que la composición de los órganos de selección “tenderá a la paridad entre mujer y hombre”. Asimismo, el artículo 79.1 EBEP señala que la composición de los órganos colegiados encargados de la valoración de méritos en los concursos de provisión de puestos de

486 Artículo 55.2 c) EBEP.

${ }^{487}$ Artículo 55.2 d) EBEP. 
trabajo "se adecuará al criterio de paridad entre mujer y hombre". Estos preceptos evidencian la voluntad del legislador de dar cumplimiento al artículo 51 letra d) de la LOIMH, en el que se establece como criterio de actuación obligatorio para todas las Administraciones Públicas ${ }^{488}$ la promoción de "la presencia equilibrada de mujeres y hombres en los órganos de selección y valoración", de forma que según la Disposición adicional primera de la $\mathrm{LOIMH}^{489}$, "las personas de cada sexo no superen el sesenta por ciento ni sean menos del cuarenta por ciento".

Sin embargo, la utilización en el EBEP del término "tenderá" expresa más un deseo que una obligación, sin que quepa descartar que cuando no se ha respetado el indicado criterio y tampoco se han dado razones fundadas y objetivas para ello, habiendo posibilidades para alcanzar una composición equilibrada, se pueda anular un proceso selectivo ${ }^{490}$. Entiendo que esto sólo podría ser así en el caso de la Administración General del Estado, para la que tanto el nombramiento de los miembros de tribunales u órganos de selección del personal a su servicio, como en el nombramiento de sus representantes en las comisiones de valoración de méritos para la provisión de puestos de trabajo, tiene que responder al

488 Según la Disposición final primera apartado segundo de la LOIMH este precepto tiene carácter básico.

489 Según la Disposición final primera apartado primero de la LOIMH esta disposición regula las condiciones básicas que garantizan la igualdad de todos los españoles en el ejercicio de los derechos y el cumplimiento de los deberes constitucionales de acuerdo con el artículo 149.1.1 ${ }^{\mathrm{a}} \mathrm{CE}$.

490 Goñi Sein, José Luis. XIX Congreso Nacional de Derecho del Trabajo y de la Seguridad Social. El Estatuto Básico del Empleado Público. Laborum, Murcia, 2008, pág. 185. 
principio de presencia equilibrada de mujeres y hombres, salvo que existan, como ya se indicado, razones fundadas y objetivas debidamente motivadas que lo impidan ${ }^{491}$. Por el contrario, para el resto de Administraciones, la expresión "tenderá" exige hacer un esfuerzo en aras a lograr la paridad o una situación de relativo equilibrio, pero la inexistencia de tal paridad o equilibrio no vicia de nulidad el proceso selectivo ${ }^{492}$. Y es que, según Sánchez Morón, el artículo 60.1 EBEP configura este principio a modo de directriz, que no de norma imperativa, por lo que nos encontramos ante una situación en la que formalmente se reconoce este principio, pero no se le dota de efectividad, que realmente es lo que se pretendía con la LOIMH. El gobierno aprobó la legislación, ahora es necesario ponerla en práctica para que la igualdad sea real y efectiva, como reza el título de la mencionada Ley.

En el artículo 61.1 último párrafo EBEP se establece que "los órganos de selección velarán por el cumplimiento del principio de igualdad de oportunidades entre sexos". Para ello es imprescindible que actúen de forma objetiva, y aunque la composición equilibrada o paritaria de los órganos de selección no es un requisito ineludible para el funcionamiento con arreglo a criterios objetivos de las instancias encargadas de la selección de

491 Artículo 53 de la LOIMH.

492 Aunque se habla de paridad o equilibrio como términos sinónimos, la paridad supone garantizar la presencia de mujeres y hombres en un mismo número, es decir, el 50\% de participación de ambos sexos, mientras que el equilibrio se define como aquella situación en la que, en el conjunto a que se refiera, ya sea en el ámbito público, el privado o en el de la participación política, las personas de cada sexo no superen el $60 \%$ ni sean menos del $40 \%$. 
personal, esto permite garantizar que al menos la mitad de los componentes no actúa guiados por prejuicios o valoraciones estereotipadas sobre el trabajo de las mujeres ${ }^{493}$.

Por ello es muy importante incidir sobre las instancias que adoptan las decisiones en materia de selección de personal, buscando asegurar que las adoptarán de manera no parcial respecto de los aspirantes de un sexo ${ }^{494}$. Todo ello sin olvidar que este principio debería aplicarse sin merma de los principios de cualificación técnica y especialización de los órganos de selección.

En este sentido el Convenio Colectivo para el personal laboral de la Diputación de Salamanca publicado en el Boletín Oficial de la Provincia no 99 de 25 de mayo de 2005, no se hace referencia al principio de composición equilibrada, no se incluyen previsiones en cuanto a la composición paritaria de los órganos de selección, por lo que sería conveniente corregir esta carencia.

b. Perspectiva sustantiva: Los sistemas de selección.

El establecimiento de procesos selectivos objetivos es un instrumento clave para garantizar el acceso al empleo público en

\footnotetext{
${ }^{493}$ Sanguineti Raymond, Wilfredo. La negociación colectiva sobre acceso al empleo de la mujer: el lento avance de la igualdad, en Sanguineti Raymond, Wilfredo, director y $\mathrm{M}^{\mathrm{a}}$ Luisa Martín Hernández, coordinadora. Propuestas para la igualdad de género en la negociación colectiva. Estudio a partir de la negociación colectiva en Castilla y León. Bomarzo, Albacete, 2011, págs. 45-46.

${ }^{494}$ Sanguineti Raymond, 2011, pág. 43.
} 
condiciones de igualdad. En la Administración Pública, la selección de todo el personal, ya sea funcionario ya sea laboral, se hace de acuerdo con criterios objetivos y en base a los principios de igualdad, mérito y capacidad. Por tanto, en la contratación de personal laboral que presta servicios en la Administración Pública ha habido un filtro al principio de libertad de empresa que preside las relaciones laborales en el ámbito privado, regulado en el artículo 38 de la Constitución Española, que permite contratar a voluntad del empresario y que, en ocasiones, puede ser utilizado para llevar a cabo una selección del personal con arreglo a criterios sexistas que perjudican a las mujeres. No obstante, aunque el empresario no está obligado a tratar por igual a todos los trabajadores, su actuación está limitada por el mandato constitucional de prohibición de discriminación ${ }^{495}$.

En la Administración Pública "los procesos selectivos tendrán carácter abierto y garantizarán la libre concurrencia"496 y se regirán, además de por los principios de igualdad, mérito y capacidad, por los principios rectores a que se refiere el artículo 55.2 EBEP, entre otros, la "adecuación entre el contenido de los procesos selectivos y las funciones o tareas a desarrollar”497, así como la "agilidad, sin perjuicio de la objetividad, en los procesos de selección" ${ }^{498}$.

\footnotetext{
495 Galiana Moreno, y Cámara Botía, 2003, pag. 349.

496 Artículo 61.1 EBEP.

497 Artículo 55.2 e) EBEP.

498 Artículo 55.2 d) EBEP.
} 
Los sistemas selectivos establecidos en la Administración, además de ser los mismos para todos los empleados públicos, son idénticos independientemente de cuál sea el sexo de las personas candidatas, ya que en caso contrario nos encontraríamos con un supuesto de discriminación directa por razón de sexo. Así lo ha sido considerado por la jurisprudencia comunitaria ${ }^{499}$.

El EBEP regula tres clases de sistemas selectivos, la oposición, el concurso-oposición y el concurso. Sin embargo, establece una distinción entre funcionarios y laborales. Mientras que para el personal funcionario "sólo en virtud de ley podrá aplicarse, con carácter excepcional, el sistema de concurso que consistirá únicamente en la valoración de méritos" ${ }^{\text {"50 }}$, para el personal laboral la utilización del concurso de valoración de méritos no está sujeta a dichas limitaciones ${ }^{501}$. Es decir, ni tiene carácter excepcional, ni está sujeto a reserva de ley. Esto influye de manera negativa en la consecución de la igualdad en el acceso al empleo público, no sólo entre funcionarios y laborales, sino también entre hombres y mujeres, porque aunque la oposición ha sido tachada de excesivamente memorística, es más equitativa que el sistema de concurso, cuyo principal inconveniente sigue siendo el determinar la equivalencia entre los méritos que a su vez

\footnotetext{
${ }^{499}$ STJUE de 30 de junio de 1988, C-318/86.

500 Artículo 61.6 EBEP.

${ }^{501}$ Artículo 61.7 EBEP.
} 
garantice una ponderación neutral y objetiva de las condiciones de cada aspirante.

Los procedimientos de selección deberán asegurar que el acceso al empleo público se produzca en condiciones de igualdad, por lo que resulta fundamental "la conexión entre el tipo de pruebas a superar y la adecuación al desempeño de las tareas de los puestos de trabajo convocados, incluyendo, en su caso, las pruebas prácticas que sean precisas" 502 . El EBEP precisa que "las pruebas podrán consistir en la comprobación de los conocimientos y la capacidad analítica de los aspirantes, expresados de forma oral o escrita, en la realización de ejercicios que demuestren la posesión de habilidades y destrezas, en la comprobación del dominio de lenguas extranjeras $y$, en su caso, la realización de pruebas físicas"503. Además "para asegurar la objetividad y la racionalidad de los procesos selectivos, las pruebas podrán completarse con la superación de cursos, de periodos de prácticas, con la exposición curricular por los candidatos, con pruebas psicotécnicas o con la realización de entrevistas" ${ } 504$.

\footnotetext{
502 Artículo 61.2 EBEP.

503 Artículo 61.2 EBEP.

${ }^{504}$ Artículo 61.5 EBEP.
} 

3. CONDICIONES DE TRABAJO. IGUALDAD DENTRO DE LA RELACIÓN LABORAL DE EMPLEO PÚBLICO.

El artículo 11.1 EBEP establece que cuando la Administración Pública contrata a personal laboral utilizará cualquiera de las modalidades de contratación previstas en la legislación laboral. Por tanto hay que distinguir entre modalidades de contratación establecidas en los artículos 11 a 14 TRLET, y las establecidas en el artículo 15 TRLET. Este último precepto distingue, en función de la duración del contrato, el contrato indefinido y el de duración determinada. En cambio, el EBEP establece que en función de la duración del contrato éste podrá ser fijo, indefinido o temporal.

Siguiendo a Sempere Navarro, la contratación laboral en las Administraciones Públicas exige hacer una diferenciación, diferenciación que no se lleva a cabo en el ámbito empresarial privado, entre el contrato fijo y el indefinido no fijo de plantilla, este último denominado en el EBEP simplemente como indefinido. Esta diferenciación, que tiene su origen en la jurisprudencia y que ha sido asumida por el EBEP, es desconocida por el Estatuto de los Trabajadores, en el que de forma indistinta se habla de fijo o indefinido para designar el mismo tipo de contrato laboral. En el ámbito de las Administraciones Públicas, el contrato fijo es aquel que responde a una necesidad permanente de prestación de servicios a la que se ha dado una respuesta mediante 
un proceso de selección basado en los principios de igualdad, mérito y capacidad en el acceso al empleo público. Por tanto, la diferencia entre trabajador fijo y trabajador indefinido radica en la propia titularidad de la plaza ocupada. Y es que, mientras la plaza desempeñada por personal laboral fijo no puede ser considerada vacante a efectos de proceder a su provisión definitiva, la plaza desempeñada por personal laboral indefinido está llamada a ser ocupada por el procedimiento legalmente establecido, siendo la propia Administración la que está obligada a hacer todo lo necesario para que eso sea así. Y ello porque a la tipificación como contrato indefinido se llega por la utilización fraudulenta de la contratación temporal, y porque nunca una contratación temporal irregular podrá convertirse en fija automáticamente. El carácter indefinido del contrato implica que éste no está sometido directa o indirectamente a un término. Pero esto no supone que el trabajador consolide, sin superar los procedimientos de selección, una condición de fijeza en la plantilla con adscripción definitiva del puesto de trabajo ${ }^{505}$.

En primer lugar, nos referiremos muy brevemente a las modalidades de contratación laboral desde la perspectiva de la igualdad de género, principalmente al contrato de trabajo a tiempo

\footnotetext{
505 Sempere Navarro, Antonio V. El personal laboral de las Administraciones Locales y la unificación de doctrina, en Sempere Navarro, Antonio V. y Miguel Cardenal Carro, directores. El personal laboral de las Corporaciones Locales. El Consultor de los Ayuntamientos, Madrid, 2010, pág. 1424.
} 
parcial, consagrando el epígrafe IX al estudio del contrato de trabajo a distancia.

En segundo lugar, analizaremos los derechos y deberes que corresponden a los empleados públicos, con especial referencia al personal laboral cualquiera que sea la modalidad contractual empleada, y siempre haciendo hincapié en la perspectiva de género ya que, de conformidad con el artículo 14 i) EBEP, todos los empleados públicos tienen derecho a no ser discriminados por razón de género.

\subsection{MODALidAdeS DE CONTRATACIÓN LABORAL DESDE LA PERSPECTIVA DE LA IGUALDAD DE GÉNERO.}

No todas las modalidades contractuales son igual de beneficiosas para el personal laboral de la Administración Pública. Si pensamos en los contratos formativos, el artículo 11.3 TRLET, apartado tercero redactado por la Ley $35 / 10$ de 17 de septiembre de medidas urgentes para la reforma del mercado de trabajo ${ }^{506}$, permite que en la negociación colectiva se fijen los criterios y procedimientos tendentes a conseguir una presencia equilibrada de hombres y mujeres vinculados a la empresa mediante contratos formativos. La negociación colectiva desempeña un papel fundamental en la realización efectiva del principio de igualdad entre hombres y mujeres en el empleo público. El legislador es 
consciente de ello, por lo que se introducen previsiones normativas de este tipo, que si bien no tienen carácter vinculante, hacen visible la necesidad de que hombres y mujeres tengan las mismas oportunidades de acceder al mercado de trabajo y de permanecer en el mismo por tiempo indefinido. Así se deduce de este mismo precepto, en el que se añade que, también a través de la negociación colectiva, "podrán establecerse compromisos de conversión de los contratos formativos en contratos por tiempo indefinido". Todo ello con el objetivo de revertir la tasa de temporalidad en empleo, y particularmente en el empleo femenino.

Por otra parte, también tiene importantes repercusiones para la igualdad entre hombres y mujeres en el empleo público, la determinación de la duración de la jornada de trabajo. Así por ejemplo, cuando el contrato de trabajo sea a tiempo parcial, es decir, cuando se haya acordado la prestación de servicios durante un número de horas al día, a la semana, al mes o al año, inferior a la jornada de trabajo de un trabajador a tiempo completo comparable, esto repercutirá en la determinación de los periodos de cotización y de cálculo de la base reguladora de las prestaciones de Seguridad Social, incluida la protección por desempleo. Lo que sucede es que en el contrato a tiempo parcial se computan exclusivamente las horas trabajadas, y en el contrato a tiempo completo, los periodos de tiempo en los que el contrato de trabajo estuvo vigente. Por tanto, en el contrato de trabajo a tiempo de parcial será necesario un mayor periodo de carencia dificultándose 
el acceso a las prestaciones de la Seguridad Social (como las pensiones de jubilación por ejemplo) para este tipo de trabajadores, lo que supone una infracción del mandato de igualdad y prohibición de discriminación indirecta por razón de sexo. Así se ha pronunciado el Tribunal Constitucional en la Sentencia número 61/2013 de 14 de marzo, por la que se declara inconstitucional y nula la regla segunda del apartado 1 de la disposición adicional séptima de la Ley General de la Seguridad Social, texto refundido aprobado por Real Decreto legislativo 1/1994 de 20 de junio. Y ello porque "las diferencias de trato en cuanto al cómputo de los periodos de carencia que siguen experimentando los trabajadores a tiempo parcial respecto a los trabajadores a jornada completa se encuentran desprovistas de una justificación razonable que guarde la debida proporcionalidad entre la medida adoptada, el resultado producido y la finalidad pretendida" ${ }^{907}$.

Si tenemos en cuenta que son las mujeres las que normalmente, bien por deseo propio, bien por las características propias del puesto de trabajo, firman este tipo de contratos, el resultado es que ellas son las que más perjudicadas resultan por este tipo de previsiones normativas.

${ }^{507}$ En este sentido merece ser destacada también la STJUE de 22 de noviembre de 2012, el asunto Ebal Moreno (C-385/11). 


\subsection{IGUALDAD DE DERECHOS.}

a. Derecho a la jornada de trabajo, permisos y vacaciones, y derecho a la adopción de medidas que favorezcan la conciliación de la vida personal, familiar y laboral.

En el Título III del EBEP se regulan los "Derechos y deberes. Código de conducta de los empleados públicos”. Dentro de este Título, el Capítulo V se refiere al "Derecho a la jornada de trabajo, permisos y vacaciones", y el artículo 51 EBEP señala que "para el régimen de jornada de trabajo, permisos y vacaciones del personal laboral se estará a lo dispuesto en este Capítulo y en la legislación laboral correspondiente”. Por otro lado, en el mismo Título III, el Capítulo I contempla los "Derechos de los empleados públicos", entre los que encontramos en artículo 14 letra m) EBEP el derecho "a las vacaciones, descansos, permisos y licencias", y en la letra j) el derecho "a la adopción de medidas que favorezcan la conciliación de la vida personal, familiar y laboral”.

En este apartado se estudiará el derecho a la jornada de trabajo, permisos y vacaciones del personal laboral de la Administración Pública desde la perspectiva del derecho a la adopción de medidas que favorezcan la conciliación de la vida personal, familiar y laboral, teniendo presente que el régimen jurídico aplicable se determina en el artículo 51 EBEP, es decir, se estará a lo dispuesto en el Estatuto Básico del Empleado Público y 
en el Texto Refundido de la Ley del Estatuto de los Trabajadores, sin que de la dicción de este precepto se desprenda relación de jerarquía entre ambas normas.

- Jornada de trabajo. Supuestos de reducción.

En el artículo 47 EBEP no se define la jornada de trabajo, limitándose a indicar que "las Administraciones Públicas establecerán la jornada general y las especiales de trabajo", pudiendo ser a tiempo completo o a tiempo parcial.

El tiempo de trabajo es el rasgo de la relación laboral que más directamente se vincula a la cuestión de la conciliación. Sin embargo, la conciliación en su vertiente normativa ha estado unida al tiempo no trabajado, es decir, a las reducciones, permisos, suspensiones, y excedencias ${ }^{508}$. Veamos cada una de estas posibilidades de conciliación vinculadas al tiempo que se deja de trabajar.

En el artículo 48 EBEP se regulan los permisos de los funcionarios públicos que, como se acaba de apuntar, también son aplicables al personal laboral que presta servicios en la Administración. Cabe destacar que el Real Decreto-ley 20/2012, de 13 de julio, de medidas para garantizar la estabilidad

\footnotetext{
508 Sala Franco, Tomás y $\mathrm{M}^{\mathrm{a}}$ Amparo Ballester Pastor. Reducción y adaptación de jornada por conciliación. Tirant lo Blanch, Valencia, 2009, pág. 12.
} 
presupuestaria y de fomento de la competitividad ${ }^{509}$, ha suprimido el primer párrafo de este precepto, que permitía a las Administraciones Públicas establecer, a través de la negociación colectiva, otros permisos o mejorar los reconocidos por el artículo 48 EBEP. Esto ha supuesto una merma de algunos derechos que, si bien no estaban directamente relacionados con la conciliación de la vida personal y familiar, en muchas ocasiones sí que eran utilizados con esta finalidad, piénsese por ejemplo en la reducción del número de días por asuntos particulares.

Por lo que respecta al permiso por lactancia, no se produce una disminución de las retribuciones y la regulación es similar en el caso de los funcionarios y los laborales. En ambos casos existen tres posibilidades: el derecho a una hora de ausencia del trabajo que podrá dividir en dos fracciones; la posibilidad de sustituir la ausencia por lactancia de una hora, por la reducción de la jornada normal en media hora al inicio y al final de la jornada o, en una hora al inicio o al final de la jornada con la misma finalidad; o bien, solicitar la sustitución del tiempo de lactancia por un permiso retribuido que acumule en jornadas completas el tiempo de lactancia correspondiente.

Según el artículo 48.1 f) EBEP, de las tres posibilidades descritas anteriormente, sólo el derecho a la reducción de la jornada normal por lactancia "podrá ser ejercido indistintamente

${ }^{509}$ Boletín Oficial del Estado núm. 168 de 14 de julio de 2012. 
por uno u otro de los progenitores, en el caso de que ambos trabajen". Y ello porque el tercer supuesto sólo se contempla expresamente para la "funcionaria" que así lo solicite. No obstante, la sentencia del Juzgado Central de lo Contenciosoadministrativo de 4 de abril de 2013, amparándose en dos sentencias precedentes del Tribunal Superior de Justicia de Madrid, de 7 de febrero de 2012 y 16 de enero de 2012, considera que los funcionarios tienen derecho a disfrutar del periodo de lactancia de forma compartida, en particular se refiere a la posibilidad de que se comparta el periodo de lactancia cuando se haya optado por sustituirlo por la prolongación de la licencia por razón de maternidad. El Juez considera que frente a lo establecido en el artículo 49 a) EBEP, que establece la incompatibilidad de la concesión de determinados derechos a los dos progenitores cuando ambos trabajen, el artículo 48.1 f) EBEP no establece ninguna incompatibilidad, por lo que el derecho corresponde como titulares indistintos a ambos progenitores en los tres supuestos mencionados.

En el texto del Estatuto de los Trabajadores de 1980, se consideraba como titular del permiso a la mujer trabajadora, lo que llevó a plantear que la privación del mismo al padre por su condición de varón podría vulnerar lo dispuesto en el artículo 35.1 CE puesto que es posible que el padre se encargue de la nutrición del niño mediante lactancia artificial. La Ley 3/1989 de 3 de marzo introdujo una importante modificación en el artículo 37.4 al 
permitir que este permiso pudiera ser disfrutado indistintamente por el padre o por la madre en el caso de que ambos trabajen. De forma que si la madre no trabajaba el padre no tendría derecho a disfrutar del permiso. El hecho de que la titularidad del permiso se reconociera exclusivamente a la madre no fue considerado discriminatorio por el Tribunal Constitucional. En la STC 109/1993, de 25 de marzo, el Tribunal razona que la justificación de que el permiso se otorgase a la madre trabajadora sin mencionar al padre no tiene su origen en la diferencia de sexo, sino en un hecho objetivo y razonable como es la peculiar incidencia que el hecho de la maternidad y la lactancia tiene respecto de la situación laboral de la mujer, en cuanto se trata de compensar las desventajas reales que para la conservación de su empleo soporta la mujer a diferencia del hombre ${ }^{510}$. Aunque este argumento bien podría emplearse para extender la titularidad del permiso al hombre. Ya que si realmente se quieren compensar esas desventajas, la atribución de la titularidad del permiso en cuestión al hombre supondría reconocer que la crianza de los hijos no sólo corresponde a la madre sino también al padre, que también tendría la obligación de ausentarse del trabajo para responsabilizarse de la lactancia en el caso de que se lleve a cabo de forma artificial.

La jurisprudencia del Tribunal de Justicia de la Unión Europea de 30 de septiembre de 2010, caso Roca Álvarez ${ }^{511}$, ha

\footnotetext{
${ }^{510}$ FJ 6 párrafo primero de la STC 109/93, de 25 de marzo. 511 STJUE de 30 de septiembre de 2010, C-104/09.
} 
contribuido a disipar las dudas inherentes a la esta regla obsoleta según la cual la mujer era la titular originaria del derecho y el hombre sólo podía acceder a ella por derivación.

En nuestro ordenamiento jurídico esta jurisprudencia se ha recogido a través de la Disposición Final $1^{\text {a }}$ de la Ley 3/2012, de 6 de julio, que da nueva redacción al art. 37.4 TRLET, según la cual, “este permiso constituye un derecho individual de los trabajadores, hombres o mujeres, pero sólo podrá ser ejercido por uno de los progenitores en caso de que ambos trabajen". La novedad radica en el reconocimiento de la titularidad del derecho a ambos progenitores, pero se establecen dos limitaciones. Primero que ambos progenitores trabajen y segundo que sólo puede ser ejercitado por uno de ellos. Esto es un avance desde el punto de vista de los trabajadores autónomos, hombres o mujeres, que gracias a esta previsión pueden ver cómo, en el caso de que el otro progenitor sea asalariado, pueda disfrutar de este permiso. Sin embargo, si el único asalariado es el hombre y la mujer no desempeña ninguna actividad retribuida o no es una trabajadora por cuenta ajena, este permiso no podría ser ejercido por aquél aunque sea titular de este derecho a título individual. Lo que sucede es que la titularidad viene dada por el hecho de trabajar, no por la condición de progenitor ${ }^{512}$. Esta situación es lamentable, ya que si realmente tanto la madre como el padre pueden y deben

512 Sempere Navarro, Antonio V. Comentarios al Estatuto de los Trabajadores. Aranzadi, Cizur Menor, 2013, pág. 481. 
asumir la alimentación y el tiempo de cuidado del hijo, y que no se trata de proteger la condición biológica de la mujer o las particulares relaciones entre la madre y el hijo, debería desaparecer el requisito de que ambos progenitores trabajen. El disfrute de este permiso por los padres aunque la progenitora no trabaje realizaría una inestimable labor de educación al empresario y a la sociedad sobre la función social de la maternidad y la paternidad. En relación con esta cuestión, el artículo 14.7 LOIMH establece como uno de los criterios generales de actuación de los poderes públicos "la asunción por la sociedad de los efectos derivados del embarazo, parto y lactancia".

La jurisprudencia reciente no apunta en este sentido deseado. Así por ejemplo, la Sentencia del Tribunal Superior de Justicia de Castilla y León número 523/2012 de 12 de julio, mantiene que una cosa es que ambos progenitores tengan derecho indistintamente al disfrute del permiso de lactancia y otra muy distinta es que mantenga ese derecho en caso de que no trabajen, que es lo que sucede cuando la madre se encuentra en situación de excedencia. Por lo que no procede el disfrute del permiso de lactancia por el padre en periodo coincidente con la situación de excedencia de la madre, al ser presupuesto ineludible y necesario para la concesión del citado permiso que ambos progenitores trabajen $^{513}$.

${ }^{513}$ FJ 4 párrafo segundo de la STSJ de Castilla y León, 523/2012, de 12 de julio. 
Existe además otra diferencia, y está en la edad del menor que da derecho al permiso. Mientras que el artículo 48.1 f) EBEP reconoce el derecho por lactancia de un hijo menor de 12 meses, el artículo 37.4 TRLET es más restrictivo puesto que sólo alcanza a los trabajadores que tengan un hijo menor de 9 meses. Sin embargo, entendemos que en el caso del personal laboral de la Administración Pública el derecho se amplía hasta el momento en que el menor cumpla 12 meses en aplicación del artículo 51 EBEP $^{514}$.

En segundo lugar nos referimos a la reducción de jornada por razones de guarda legal. En este caso el empleado público puede tener a su cargo el cuidado directo de un menor de doce años, de una persona mayor que requiera especial dedicación, o de una persona con discapacidad que no desempeñe actividad retribuida. Se trata de un derecho a reducir jornada con una reducción proporcional de las retribuciones. Como ya se ha indicado anteriormente, el artículo 48.1 h) EBEP sólo se refiere a los funcionarios, sin embargo, este derecho también se aplica a los trabajadores laborales de la Administración en virtud de lo establecido en el artículo 51 EBEP.

\footnotetext{
${ }^{514}$ Núñez-Cortés Contreras, Pilar. Igualdad y conciliación de vida personal y laboral en la empresa y administraciones públicas (tras las modificaciones introducidas por la Ley 3/2007 para la Igualdad Efectiva de Mujeres y Hombres y la Ley 7/2007 del Estatuto Básico del Empleado Público). Dykinson, Madrid, 2008, pág. 224.
} 
La regulación del Estatuto de los Trabajadores es más restrictiva, así el artículo 37. 5 TRLET modificado por la Disposición adicional décimo primera de la LOIMH establece que "quien por razones de guarda legal tenga a su cuidado directo algún menor de ocho años o una persona con discapacidad física, psíquica o sensorial, que no desempeñe una actividad retribuida, tendrá derecho a una reducción de jornada de trabajo diaria con la disminución proporcional del salario entre, al menos, un octavo y un máximo de la mitad de duración de aquella”. Por tanto, difieren tanto la edad del menor, que para los funcionarios es de doce años y para el personal laboral es de ocho años, como la reducción del salario, que en el caso de los empleados públicos es proporcional y en el caso de los trabajadores por cuenta ajena, también es proporcional, pero dentro de un mínimo y un máximo.

El artículo 37.5 TRLET también ha sido modificado por la Disposición Final $1^{\text {a }}$ de la Ley 3/2012 de 6 de julio, ya que adjetiva la jornada como diaria, con el fin de evitar la acumulación y el disfrute continuado de esta reducción, de manera que en la práctica se dificulta su ejercicio. Con esta última modificación se acoge la interpretación restrictiva del Tribunal Supremo según la cual la jornada de trabajo abarca tan sólo parámetros diarios ${ }^{515}$. Para algunos autores como Sala Franco, pese a esta interpretación estricta aplicada por el Tribunal Supremo, no es posible concluir que en el ordenamiento español el concepto de jornada sea

515 STS 13 de junio de 2008 (RJ/2008/4227). 
exclusivamente diario, ya que ello sería contrario al sentido de jornada otorgado en otros preceptos de la normativa laboral, como por ejemplo con relación al trabajo a tiempo parcial en el artículo 12 TRLET. Para este autor, la reducción de jornada del artículo 37.5 TRLET se refiere no sólo a la jornada diaria, sino también a la semanal, mensual o incluso anual, siempre y cuando no afecte a la determinación del horario, ya que esto último supondría una alteración cualitativa de la organización del tiempo de trabajo ${ }^{516}$.

También es posible de manera excepcional reducir la jornada sin reducción de salario por razón de enfermedad muy grave de un familiar de primer grado. Este derecho se reconoce expresamente a los funcionarios en el artículo 48.1 i) EBEP y de manera indirecta para los laborales en el artículo 51 EBEP.

Por último un derecho exclusivo de los trabajadores por cuenta ajena, que no se regula en el Estatuto Básico del Empleado Público, pero del que sí podría beneficiarse el personal laboral de la Administración Pública, es el de adaptación de la duración y distribución de la jornada de trabajo para hacer efectivo el derecho a la conciliación de la vida personal, familiar y laboral, "en los términos que se establezca en la negociación colectiva o en el acuerdo a que se llegue con el empresario respetando, en su caso, lo establecido en aquella”. Así lo permite el artículo 34.8 del

516 Sala Franco, y Ballester Pastor, 2009, págs. 18-20. 
TRLET, apartado 8 introducido por la LOIMH. Además la Ley 3/2012 de 6 de julio ha añadido un último párrafo en este precepto según el cual, "se promoverá la utilización de la jornada continuada, el horario flexible u otros modos de organización del tiempo de trabajo y de los descansos que permitan la mayor compatibilidad entre el derecho a la conciliación de la vida personal, familiar y laboral de los trabajadores y la mejora de la productividad en las empresas". Entendemos que en este precepto tendrían cabida aquellas reducciones de jornada, que en realidad son una forma de adaptación de jornada, que superen el concepto estricto de "diaria" del artículo 37.5 TRLET, y que implicarían una alteración cualitativa de la organización del tiempo de trabajo.

- Permisos.

El artículo 49 EBEP se refiere a los permisos por motivos de conciliación de la vida personal, familiar y laboral y por razón de violencia de género, que serán de aplicación al personal laboral en virtud de lo dispuesto en el artículo 51 EBEP. La legislación laboral regula estos permisos en los artículos 48.4 y 48 bis del Estatuto de los Trabajadores que se consideran como supuestos de suspensión con reserva de puesto de trabajo.

Tanto el permiso por parto del artículo 49 a) EBEP como la suspensión por maternidad del artículo 48.4 TRLET tendrán una duración de dieciséis semanas ininterrumpidas, ampliables tanto en 
el supuesto de discapacidad del hijo como en el de parto múltiple, en dos semanas más por cada hijo, a partir del segundo. En ambos casos la titular originaria del derecho es la madre, lo que no obsta su disfrute por el padre en determinados supuestos. Es coincidente para ambos estatutos, funcionarial y laboral, la posibilidad de que la madre al inicio del periodo de descanso por maternidad opte por ceder al padre parte de su disfrute, siempre que se respete que ésta descanse al menos las seis semanas inmediatamente posteriores al parto. El disfrute puede ser simultáneo o sucesivo siempre que no se supere la duración máxima del permiso. Y además, el otro progenitor podrá seguir disfrutando del permiso de maternidad inicialmente cedido aún en el caso de que en el momento previsto para la reincorporación de la madre al trabajo, ésta se encuentre en situación de incapacidad temporal.

En el caso de fallecimiento de la madre, tanto la legislación laboral como el EBEP permiten que el otro progenitor disfrute de la totalidad o en su caso, de la parte que reste del permiso. Además, el Estatuto de los Trabajadores precisa que en este supuesto de fallecimiento de la madre, el padre podrá disfrutar de la totalidad del permiso incluso si la madre no trabajaba, no descontándose la parte que la madre hubiera podido disfrutar con anterioridad al parto. Asimismo, se regula el supuesto de fallecimiento del hijo, indicándose que no se reducirá el periodo de suspensión salvo que una vez finalizadas las seis semanas de descanso obligatorio la madre solicitara reincorporarse al puesto 
de trabajo ${ }^{517}$. Estas previsiones podrían ser también de aplicación al personal laboral al servicio de la Administración Pública en virtud de lo dispuesto en el artículo 51 EBEP.

Los padres trabajadores por cuenta ajena gozan de una mejora más y es que en el caso de que la madre no tuviera derecho a suspender su actividad profesional con derecho a prestaciones, el otro progenitor tendrá derecho a suspender su contrato de trabajo por el periodo de tiempo que hubiera correspondido a la madre, lo que será compatible con el derecho regulado en el artículo 48 bis TRLET relativo a la suspensión del contrato de trabajo por paternidad $^{518}$. Esta previsión afecta positivamente a las trabajadoras autónomas.

En los casos de parto prematuro y en aquéllos en que, por cualquier otra causa, el neonato deba permanecer hospitalizado a continuación del parto, el permiso por parto se amplía en tantos días como el neonato se encuentre hospitalizado, con un máximo de trece semanas adicionales. Este permiso en los casos de parto prematuro es un permiso de carácter específico que se suma al del parto. Primero se disfruta el permiso por nacimiento de hijo prematuro u hospitalizado y, a partir del alta hospitalaria, se disfrutará el permiso por parto. De este permiso disfrutarán los funcionarios y personal laboral al servicio de la Administración por

517 Artículo 48.4 primer párrafo TRLET.

518 Artículo 48.4 tercer párrafo TRLET. 
aplicación del artículo 51 EBEP. Sin embargo, en el caso de los trabajadores por cuenta ajena la única opción viable es la interrupción del periodo de suspensión por maternidad a instancias de la madre, sin sustituirse por otro permiso distinto. Cuando la madre opte por la interrupción de la suspensión, ésta empezará a computarse a partir de la fecha de alta hospitalaria, excluyendo de dicho cómputo las seis semanas posteriores al parto, de suspensión obligatoria del contrato de la madre ${ }^{519}$. Sólo en el supuesto específico de partos prematuros con falta de peso y aquellos otros en que el neonato precise hospitalización a continuación del parto por un periodo superior a siete días, el periodo de suspensión se ampliará en tantos días como el recién nacido se encuentre hospitalizado, con un máximo de trece semanas adicionales ${ }^{520}$.

Tanto funcionarios como laborales también podrán disfrutar del permiso por adopción o acogimiento, o suspensión por adopción o acogimiento en el caso de trabajadores laborales que no presten servicio en una Administración Pública. En ambos supuestos el permiso tendrá una duración de dieciséis semanas sin interrupción, ampliables en dos semanas más en el caso de discapacidad del menor adoptado o acogido y por cada hijo, a partir del segundo, en la adopción o acogimiento múltiple. El cómputo del plazo se efectuará a elección del empleado, a partir de

519 Artículo 48.4 cuarto párrafo TRLET.

520 Núñez-Cortés Contreras, 2008, págs. 228-229. 
la decisión administrativa o judicial de acogimiento o a partir de la resolución judicial por la que se constituya la adopción sin que en ningún caso un mismo menor pueda dar derecho a varios periodos de disfrute de este permiso ${ }^{521}$. Tanto en el régimen funcionarial como el laboral, si ambos progenitores trabajan, el permiso o suspensión se distribuirá a opción de los interesados, quienes podrán disfrutarlo de forma simultánea o sucesiva, siempre por periodos no interrumpidos ${ }^{522}$. En los casos de disfrute simultáneo su suma no podrá exceder de las dieciséis semanas ${ }^{523}$.

Este permiso o suspensión, al igual que el permiso por parto o suspensión por maternidad, podrá disfrutarse a jornada completa o a tiempo parcial, cuando las necesidades del servicio lo permitan ${ }^{524}$.

La principal diferencia entre funcionarios y trabajadores por cuenta ajena es que en la nueva redacción dada al artículo 48.4 TRLET por la LOIMH se incluye expresamente el acogimiento provisional $^{525}$, que no se menciona en el EBEP. Además en el caso de los empleados públicos, mejorando con esto lo previsto para los trabajadores laborales en el TRLET, y en el supuesto de adopción o acogimiento internacional para la que sea necesario efectuar un desplazamiento previo de los progenitores al país de

\footnotetext{
${ }^{521}$ Artículo 48.4 sexto párrafo TRLET y artículo 49 b) segundo párrafo EBEP. 522 Artículo 48.4 séptimo párrafo TRLET y artículo 49 b) tercer párrafo EBEP. 523 Artículo 48.4 octavo párrafo TRLET y artículo 49 b) cuarto párrafo EBEP. ${ }^{524}$ Artículo 48.4 décimo párrafo TRLET y artículo 49 a) cuarto párrafo y b) quinto párrafo EBEP. 525 Artículo 45.1 d) TRLET.
} 
origen del adoptado o acogido, se tendrá derecho a un permiso adicional de hasta dos meses de duración, percibiendo durante este periodo exclusivamente las retribuciones básicas ${ }^{526}$.

Una de las novedades más importantes es la consagración de un derecho específico de los padres para atender al cuidado del hijo recién nacido. Este derecho es independiente del permiso por maternidad, que como ya hemos apuntado, el padre puede asumir bien porque se lo ceda la madre o bien por fallecimiento de ésta. En el caso de los funcionarios y de personal laboral al servicio de la Administración Pública, el permiso tendrá una duración de quince días. La Disposición Transitoria sexta EBEP se refiere a la ampliación progresiva de este permiso por las Administraciones Públicas hasta alcanzar el objetivo de las cuatro semanas de duración a los seis años de la entrada en vigor del estatuto, objetivo que no se ha cumplido bajo la excusa de la actual crisis económica.

En el caso de trabajadores con contrato laboral tienen dos derechos distintos. Por un lado el permiso retribuido de dos días naturales por nacimiento de hijo, por lo que se trata de un permiso que sólo se ejerce en caso de parto según se desprende de la lectura del artículo 37.3 b) TRLET. Y por otro lado la suspensión del contrato de trabajo por paternidad regulado en el artículo 48 bis, que fue introducido por la LOIMH en el TRLET. En estos

\footnotetext{
526 Artículo 48.4 octavo párrafo TRLET y artículo 49 b) cuarto párrafo EBEP.
} 
casos el trabajador tendrá derecho a la suspensión del contrato durante trece días ininterrumpidos, y no sólo en el caso de parto sino también cuando se trate de acogimiento o adopción. Esta suspensión es independiente del disfrute compartido de los periodos de descanso por maternidad. La Ley 9/2009 de 6 de octubre de ampliación de la duración del permiso de paternidad en los casos de nacimiento, adopción o acogida, y cuya entrada en vigor, prevista inicialmente para el 1 de enero de 2011, se va posponiendo sucesivamente año tras año ${ }^{527}$, ha modificado los artículos 48 bis del TRLET y el artículo 30.1 de la Ley 30/1984 de 2 de agosto, en el sentido de ampliar la duración del permiso de paternidad hasta las cuatro semanas ininterrumpidas. La Ley 22/2013 de 26 de diciembre de Presupuestos Generales del Estado para $2014^{528}$ ha pospuesto nuevamente, sin ninguna justificación, la ampliación del permiso por paternidad hasta un mes, y sin que haya demasiada confianza en su aplicación a partir del 1 de enero de 2015.

Una de las manifestaciones más graves de la desigualdad entre hombres y mujeres es la violencia de género. Las empleadas públicas víctimas de esta situación podrán hacer uso del permiso por razón de violencia de género contemplado en el artículo 49 d) EBEP. Este permiso puede consistir en considerar justificadas las

527 Primero por la Disposición Final octava del Real Decreto-Ley 20/2011 de 30 de diciembre de medidas urgentes en materia presupuestaria, tributaria y financiera para la corrección del déficit público, y después por la Ley 2/2012 de 29 de junio de Presupuestos Generales del Estado para 2012.

${ }^{528}$ Boletín Oficial del Estado núm. 309 de 26 de diciembre de 2013. 
faltas de asistencia por violencia de género o en la posibilidad de reducir la jornada o reordenar el tiempo de trabajo para hacer efectiva la protección o el derecho de asistencia integral de la funcionaria víctima de la violencia de género. Aunque es cierto que en la mayor parte de los casos la violencia se padece por las mujeres, sería deseable que este permiso fuera enunciado en términos neutros, de manera que pudiera ser utilizado también por los funcionarios que pudieran verse en esta situación.

La Ley 39/2010 de 22 de diciembre de Presupuestos Generales del Estado ${ }^{529}$ para 2011 introduce el permiso por cuidado de hijo menor afectado por cáncer u otra enfermedad grave en el EBEP. Este permiso dará derecho, siempre que ambos progenitores, adoptantes o acogedores de carácter preadoptivo o permanente trabajen, a una reducción de la jornada de trabajo de al menos la mitad de la duración de aquélla, sin dejar de percibir las retribuciones íntegras, para el cuidado, durante la hospitalización y tratamiento continuado, del hijo menor de edad afectado por cáncer o cualquier otra enfermedad grave que implique un ingreso hospitalario de larga duración y requiera la necesidad de su cuidado directo, continuo y permanente acreditado por los servicios médicos y, como máximo, hasta que el menor cumpla los 18 años.

${ }^{529}$ Boletín Oficial del Estado núm. 311 de 23 de diciembre de 2010. 
En el supuesto de que ambos presten servicios en el mismo órgano o entidad, ésta podrá limitar su ejercicio simultáneo por razones fundadas en el correcto funcionamiento del servicio.

Otras suspensiones y permisos son los previstos para la realización de exámenes prenatales y técnicas de preparación al parto en el artículo 48.1 e) EBEP, que resulta de aplicación a las funcionarias embarazadas y al personal laboral al servicio de la Administración Pública en virtud de lo dispuesto por el artículo 51 EBEP. En el artículo 37.3 f) TRLET, permite que el trabajador, previo aviso y justificación, pueda ausentarse del trabajo con derecho a remuneración, por el tiempo indispensable para la realización de exámenes prenatales y técnicas de preparación al parto que deban realizarse dentro de la jornada de trabajo. Se precisa la duración de este permiso, que se hace extensivo al personal laboral al servicio de la Administración Pública, salvo que en el convenio colectivo que resulte de aplicación se hubiera establecido una duración concreta. No obstante, como ya se ha tenido ocasión de poner de manifiesto, las mejoras que hubieran podido establecerse por convenio colectivo desaparecen como consecuencia de la reforma operada por el Real Decreto-ley 20/2012, de 13 de julio, de medidas para garantizar la estabilidad presupuestaria y de fomento de la competitividad.

Por último, el artículo 48.1 j) EBEP se refiere a los permisos por el tiempo indispensable para el cumplimiento de los deberes 
relacionados con la conciliación de la vida familiar y laboral. Este tipo de permisos no está previsto de manera genérica en el Estatuto de los Trabajadores, sin embargo se aplica también al personal laboral en virtud de lo establecido en el artículo 51 EBEP. Las solicitudes deberán presentarse con una antelación suficiente en función de la previsibilidad del hecho causante, para permitir su valoración y no infligir un daño desproporcionado a las exigencias funcionales y organizativas de la Administración ${ }^{530}$.

- Vacaciones.

El artículo 50 EBEP se refiere a las vacaciones del personal funcionario y será de aplicación al personal laboral al servicio de la Administración Pública en virtud de lo dispuesto en el artículo 51 EBEP. Sin que se haya establecido ninguna obligación legal en este sentido, la Administración Pública debería facilitar a sus empleados el disfrute de las mismas en aquellos periodos que coincidan con las vacaciones escolares para facilitar la conciliación de la vida familiar con la laboral.

El artículo 59 LOIMH ha dado un paso más al reconocer que "cuando el periodo de vacaciones coincida con una incapacidad temporal derivada del embarazo, parto o lactancia natural, o con el permiso de maternidad, o con su ampliación por lactancia, la empleada pública tendrá derecho a disfrutar las

530 Núñez-Cortés, 2008, págs. 237-238. 
vacaciones en fecha distinta, aunque haya terminado el año natural al que correspondan". Derecho que también asiste a los padres que estén disfrutando del permiso de paternidad.

- Situaciones administrativas que ¿facilitan la conciliación?

En el artículo 92 EBEP se establece que las situaciones del personal laboral se regirán por el Estatuto de los Trabajadores y por los Convenios Colectivos que les sean de aplicación. No obstante, los convenios colectivos podrán determinar la aplicación de la regulación de las situaciones administrativas de los funcionarios al personal laboral al servicio de las Administraciones Públicas en lo que resulte compatible con el Estatuto de los Trabajadores.

La excedencia es una situación administrativa que asegura el mantenimiento de una relación jurídica permanente con la Administración Pública, aunque provisionalmente no se esté desempeñando ninguna función pública concreta. En esta situación las partes quedan exoneradas de sus obligaciones recíprocas de trabajar y retribuir el trabajo, y el trabajador conserva durante un tiempo su derecho preferente al reingreso. En el artículo 46.3 del TRLET se regula la excedencia por cuidado de hijos como un derecho individual de los trabajadores, hombres o mujeres. El hecho causante puede ser tanto el nacimiento como la 
adopción, y el acogimiento tanto permanente como preadoptivo, aunque éstos sean provisionales, a contar desde la fecha de nacimiento o, en su caso, de la resolución judicial o administrativa que la reconozca. Por tanto, los supuestos son más amplios que para los funcionarios, puesto que se incluyen los casos de acogimiento provisional. No se requiere un tiempo determinado y anterior de prestación de servicios, aunque el acogimiento ha de durar al menos doce meses para posibilitar el derecho de excedencia ${ }^{531}$.

La duración de esta situación será de tres años, como máximo, a contar desde la fecha de nacimiento. Esto supone que si el permiso de maternidad es de dieciséis semanas ininterrumpidas y el de paternidad de quince días, la duración máxima de la excedencia nunca llegará a ser de tres años, porque a la madre o al padre le interesará agotar primero los permisos que no supongan una merma de sus retribuciones económicas. Además, no podrá disfrutarse de la excedencia una vez que el hijo o la hija hayan cumplido los tres años, y ello a pesar de que el TRLET permita, en el caso del personal laboral, que este plazo de tres años pueda disfrutarla de forma fraccionada ${ }^{532}$.

Los efectos consisten en reserva de puesto de trabajo durante un año, a diferencia de los funcionarios, que tal y como dispone el

\footnotetext{
531 Artículo 45.1 d) TRLET.

532 Párrafo tercero del número 3 del artículo 46 redactado por el apartado 9 de la Disposición adicional décimo primera de la LOIMH.
} 
artículo 89.4 párrafo $5^{\circ}$ EBEP tendrán derecho a la reserva durante dos años. Transcurrido este tiempo la reserva será a un puesto de trabajo del mismo grupo profesional o categoría equivalente sin que se haga la previsión en el artículo 46.3 TRLET, que sí se hace para los funcionarios, de que la reserva de puesto de trabajo sea en la misma localidad. Sería conveniente que el legislador, o legisladora, contemplara la reserva del puesto de trabajo durante los tres años que como máximo puede durar esta excedencia, o por lo menos que justifique por qué se reserva durante dos y no durante tres años el mismo puesto de trabajo.

La excedencia permite que tanto hombres y mujeres puedan ocuparse de sus responsabilidades familiares, si bien uno de ellos tendrá que renunciar a desempeñar una actividad profesional retribuida durante un periodo de tiempo. Aunque el tiempo que el trabajador permanezca en esta situación será computable a efectos de antigüedad, y aunque tenga derecho a participar en los cursos de formación que se convoquen, lo que en principio no perjudica a la promoción profesional de los empleados públicos que se encuentren en esta situación administrativa, lo cierto es que las excedencias no facilitan la conciliación entre trabajo y familia, no contribuyen a que hombres y mujeres se corresponsabilicen de las cuestiones domésticas y por tanto, no se consigue el cambio de mentalidad en los trabajadores ni en la propia Administración. Si además el solicitante de las excedencias suele ser "la solicitante", entonces se seguirá manteniendo la imagen de la mujer que 
antepone familia a trabajo, cuando no se trata de cuestiones antagónicas sino de dos aspectos de la vida que no hay por qué enfrentar. La solución pasa por incentivar el uso de estas situaciones por los hombres y en el caso de que dos empleados públicos, hombre y mujer, generen el derecho a disfrutarla por el mismo sujeto causante, si la Administración opta por limitar su ejercicio por razones justificadas relacionadas con el funcionamiento de los servicios, de preferencia al hombre antes que a la mujer en el disfrute de la excedencia.

Otro tipo de excedencia, la excedencia voluntaria por agrupación familiar del artículo 89.3 EBEP, no está regulada en el TRLET por lo que no será de aplicación al personal laboral de la Administración pública salvo que los convenios colectivos hayan contemplado esta posibilidad. Algunos convenios colectivos remiten a la legislación autonómica, así por ejemplo, la Ley 7/2005, de 24 de mayo, de la Función Pública de Castilla y León ${ }^{533}$ regula la excedencia voluntaria por agrupación familiar, y establece que podrá reconocerse a los funcionarios cuyo cónyuge resida en otro municipio por haber obtenido y estar desempeñando un puesto de carácter definitivo como funcionario de carrera o como laboral en cualquier Administración Pública, Organismo Autónomo, Entidad Gestora de la Seguridad Social así como en Órganos Constitucionales o del Poder Judicial. Esta excedencia permite que al menos uno de los cónyuges pueda ocuparse de las

533 Boletín Oficial del Estado núm. 162 de 8 de julio de 2005. 
responsabilidades familiares ${ }^{534}$. Sin embargo, además de los inconvenientes señalados anteriormente, en este supuesto no sólo se penaliza a los empleados públicos por su estado civil, ya que sólo se puede solicitar por los funcionarios que hayan contraído matrimonio, sino también se penaliza su promoción profesional, ya que el tiempo de permanencia en esta situación no será computable a efectos de ascensos, trienios y derechos en el régimen de Seguridad Social que les sea de aplicación.

b. Derechos retributivos.

Los derechos retributivos de los funcionarios y del personal laboral de la Administración Pública se estructuran de diferente manera. Así, en el artículo 22 EBEP se establece que las retribuciones de los funcionarios de carrera se clasifican en básicas y complementarias. Las retribuciones básicas, que se fijan en la Ley de Presupuestos Generales del Estado, están integradas por el sueldo asignado a cada Subgrupo o Grupo de clasificación profesional, en el supuesto de que éste no tenga Subgrupo, y por los trienios, que consisten en una cantidad determinada por cada tres años de servicio ${ }^{535}$. Las retribuciones complementarias de los funcionarios se establecerán por las correspondientes leyes de cada Administración Pública atendiendo a factores como la progresión alcanzada por el funcionario dentro del sistema de carrera

\footnotetext{
534 Artículo 91.3 de la Ley de Función Pública de Castilla y León.

535 Artículo 23 EBEP.
} 
administrativa; la especial dificultad técnica, responsabilidad, dedicación, incompatibilidad exigible para el desempeño de determinados puestos de trabajo o las condiciones en que se desarrolla el trabajo; el grado de interés, iniciativa o esfuerzo con que el funcionario desempeñe su trabajo y el rendimiento o resultados obtenidos; así como los servicios extraordinarios prestados fuera de la jornada normal de trabajo ${ }^{536}$.

Sin embargo, para el personal laboral, el artículo 27 EBEP establece que "se determinarán de acuerdo con la legislación laboral, el convenio colectivo que se aplicable y el contrato de trabajo, respetando en todo caso lo establecido en el artículo 21 del presente Estatuto", precepto este último que se refiere a los límites establecidos en la Ley de Presupuestos Generales del Estado para los empleados públicos.

En el artículo 26.3 TRLET se establece que "mediante la negociación colectiva o, en su defecto, el contrato individual, se determinará la estructura del salario, que deberá comprender el salario base, como retribución fijada por unidad de tiempo o de obra y, en su caso, complementos salariales fijados en función de circunstancias relativas a las condiciones personales del trabajador, al trabajo realizado o a la situación y resultados de la empresa, que se calcularán conforme a los criterios que a tal efecto se pacten (...)”. En el caso de la Administración Pública lo más frecuente es

536 Artículo 24 EBEP. 
que el convenio colectivo fije la estructura salarial del personal laboral en términos similares a la del personal funcionario. De acuerdo con lo previsto en el artículo 103.1 CE, las relaciones jurídicas mantenidas por la Administración Pública no se rigen por el principio de autonomía de la voluntad, sino que han de someterse al dictado de la Ley y al Derecho, por lo que la Administración Pública no goza del mismo grado de libertad que un empresario privado a la hora de fijar las retribuciones de sus trabajadores $^{537}$, exigiéndose en estos supuestos una estricta sujeción al artículo $14 \mathrm{CE}^{538}$.

Por este motivo en el EBEP no encontramos previsiones como la del artículo 28 TRLET, en el que se hace mención expresa a la igualdad de remuneración por razón de sexo. Según este precepto, “el empresario está obligado a pagar por la prestación de un trabajo de igual valor la misma retribución, satisfecha directa o indirectamente, y cualquiera que sea la naturaleza de la misma, salarial o extrasalarial, sin que pueda producirse discriminación alguna por razón de sexo en ninguno de los elementos o condiciones de aquélla". Sin embargo, aunque menos frecuentes que en el ámbito empresarial privado, las discriminaciones salariales en la Administración Pública pueden llegar a producirse en aquellos complementos salariales cuyos criterios de determinación adolecen, en algunos casos, de cierto subjetivismo.

\footnotetext{
${ }^{537}$ FJ 1 segundo párrafo de la STC 161/1991, de 18 de julio.

538 Romero Burillo, Ana Ma . Igualdad y Retribución. Tirant lo Blanch, Valencia, 2006, pág. 56.
} 
Así puede suceder con la productividad por ejemplo. Por este motivo el artículo 51. f) LOIMH hace referencia al deber de las Administraciones Públicas a establecer, en el ámbito de sus respectivas competencias, "medidas efectivas para eliminar cualquier discriminación retributiva, directa o indirecta, por razón de sexo”. En el caso de la productividad puede ser el desarrollo de un adecuado sistema de evaluación del desempeño, que de conformidad con el artículo 20.2 EBEP se adecuará a criterios de no discriminación, entre otros.

c. Derecho a la formación y a la promoción profesional.

En el artículo 14 g) EBEP se reconoce el derecho de todos los empleados públicos "a la formación continua y a la actualización permanente de sus conocimientos y capacidades profesionales, preferentemente en horario laboral". Esta última observación es trascendental para hacer compatible la formación con las responsabilidades familiares y domésticas. Además, no sólo hay un derecho a la formación sino también una obligación, ya que el artículo 54. 8 EBEP señala como principio de conducta de los empleados públicos mantener actualizada su formación.

Si tenemos en cuenta que una de las causas por las que el salario de las mujeres es menor es porque desempeñan puestos de trabajo para los que se requiere menor cualificación profesional, 
una de las cuestiones centrales sobre las que habrá que incidir es en su formación.

Es interesante fijarse en dos cuestiones relacionadas con la formación. En primer lugar las materias impartidas en los cursos realizados por hombres y mujeres. Es aconsejable incidir en la formación del personal en cuestiones de igualdad de trato y de oportunidades, y que en este tipo de cursos participen tanto hombres como mujeres. Se trata de influir en las ideas y concepciones sobre cada uno de los elementos del acceso al empleo público, así como de mentalizar y educar en la utilización de un lenguaje genérico. Así lo reconoce el artículo 51 c) LOIMH al establecer como criterio de actuación de las Administraciones Públicas la formación en igualdad, tanto en el acceso al empleo como a lo largo de la carrera profesional. En el artículo 61.2 LOIMH se hace referencia a la formación para la igualdad de trato y de oportunidades entre mujeres y hombres, y sobre prevención de violencia de género para todo el personal incluido en el ámbito de la Administración General del Estado.

En segundo lugar, el número de horas dedicadas a formación en ambos colectivos. En este punto se podría observar la diferencia entre las horas de cada curso que se realizan dentro del horario laboral y fuera del horario laboral. Si se trata de un curso de formación fuera del horario laboral, y son las mujeres las que asumen las responsabilidades domésticas y familiares, éstas 
tendrán mayores dificultades para poder participar en dichos cursos. Por eso habrá que procurar que los cursos de formación coincidan con el horario de trabajo, o bien hacer uso de las Tecnologías de la Información y las Comunicaciones, herramienta que permite promover las acciones formativas on line, lo que favorece el acceso a la formación tanto a hombres como a mujeres, al mismo tiempo que se facilita la conciliación de la vida personal, familiar y laboral, sin menoscabo de la promoción profesional $^{539}$.

La promoción de los empleados públicos está en gran parte condicionada por su formación, de tal forma que el acceso a la formación determinará las posibilidades de ascender de categorías inferiores a superiores o mejoras en las condiciones del propio trabajo. El esfuerzo formativo tiene que repercutir en la promoción profesional de la persona, puesto que en caso contrario, es un esfuerzo que acaba por desincentivar al personal. Por lo que hay que garantizar que la formación de los empleados públicos y sus niveles de promoción sean equilibrados desde el punto de vista de género.

El artículo 35 CE reconoce el derecho de los ciudadanos a la promoción en el trabajo sin discriminación por razón de sexo. Por ello, en el artículo 1.3 f) EBEP se establece como fundamento de actuación de las Administraciones Públicas la "igualdad, mérito 
y capacidad en la promoción profesional”, y en el artículo 14 c) EBEP se reconoce a todos los empleados públicos el derecho "a la progresión en la carrera profesional y promoción interna según principios constitucionales de igualdad, mérito y capacidad mediante la implantación de sistemas objetivos y transparentes de evaluación". Hubiera sido conveniente añadir, en aplicación del principio de transversalidad, que estos sistemas fueran neutros desde el punto de vista del género.

En el EBEP la promoción no es automática sino que se conecta con la evaluación periódica del desempeño como "procedimiento mediante el cual se mide y valora la conducta profesional y el rendimiento o el logro de resultados" ${ }^{240}$. Los sistemas de evaluación del desempeño se adecuarán a criterios de no discriminación ${ }^{541}$, sin menoscabo de los derechos de los empleados públicos como los derechos de conciliación de la vida personal, familiar y laboral. De este modo, las oportunidades de hacer carrera profesional se relacionan con la manera en que los empleados públicos realizan sus funciones, en atención a los objetivos de la organización, a su rendimiento y su actitud ante el servicio público, pudiéndose considerar como actitud positiva su interés por mantener actualizada su formación, y en particular su formación en cuestiones de igualdad de género.

\footnotetext{
540 Artículo 20.1 EBEP.

${ }^{541}$ Artículo 20.2 EBEP.
} 
Esto puede ser beneficioso para el cambio de mentalidad que se persigue en la Administración, en el que lo más importante no es tanto estar presente en el trabajo como conseguir los objetivos fijados inicialmente. De este modo se avanzará en la conciliación, pero de una manera diferente a como se ha hecho hasta ahora, vinculando este concepto, no al tiempo que se deja de trabajar, sino al tiempo que se trabaja, lo que hará posible compatibilizar verdaderamente trabajo y familia, sin conflictos y sin renuncias.

Según el artículo 19 EBEP la promoción profesional del personal laboral se hará efectiva, junto con la carrera profesional, "a través de los procedimientos previstos en el Estatuto de los Trabajadores o en los Convenios Colectivos". Por tanto se efectúa una remisión a los artículos 23 y 24 TRLET.

En el artículo 23.2 TRLET se establece que en la negociación colectiva se pactarán los términos del ejercicio de los derechos a la promoción y a la formación en el trabajo, "que se acomodarán a criterios y sistemas que garanticen la ausencia de discriminación directa o indirecta entre trabajadores de uno y otro sexo”. En la misma línea el artículo 24.2 TRLET señala que los ascensos y la promoción profesional se ajustarán a criterios y sistemas que garanticen la ausencia de discriminación directa o indirecta entre mujeres y hombres, pudiendo establecerse medidas de acción positiva dirigidas a eliminar o compensar situaciones de 
discriminación. Entre estas medidas el artículo 60.1 de la LOIMH permite otorgar "preferencia durante un año, en la adjudicación de plazas para participar en los cursos de formación a quienes se hayan incorporado al servicio activo procedentes del permiso de maternidad o paternidad, o hayan reingresado desde la situación de excedencia por razones de guarda legal (...)”.

d. Derecho a recibir protección eficaz en materia de seguridad y salud en el trabajo.

El artículo 40.2 de la Constitución Española establece que los poderes públicos "velarán por la seguridad e higiene en el trabajo". Para hacer efectivo este principio rector de la política social y económica es necesario implementar una política pública de protección de la salud de los trabajadores mediante la prevención de los riesgos derivados de su trabajo.

Paralelamente a esta actividad de los poderes públicos, el artículo 14 l) EBEP reconoce a todos los empleados públicos el derecho a recibir protección eficaz en materia de seguridad y salud en el trabajo, y el artículo 54.9 EBEP establece como principio de conducta correlativo, la observancia de las normas sobre seguridad y salud laboral.

La seguridad y la salud de los trabajadores se concreta en la Ley 31/95 de 8 de noviembre de Prevención de Riesgos 
Laborales $^{542}$. Tal y como se establece en el artículo 3.1 de esta Ley, la misma resulta de aplicación no sólo en el ámbito de las relaciones laborales reguladas por el TRLET, sino también en el ámbito de las relaciones de carácter administrativo o estatutario del personal al servicio de las Administraciones Públicas.

Esta Ley ha sido modificada por la Disposición adicional duodécima de la LOIMH, que introduce un nuevo apartado 4 en el artículo 5 en el que se establece la obligación de las Administraciones Públicas de "promover la efectividad del principio de igualdad entre mujeres y hombres, considerando las variables relacionadas con el sexo tanto en los sistemas de recogida y tratamiento de datos como en el estudio e investigación generales en materia de prevención de riesgos laborales, con el objetivo de detectar y prevenir situaciones en las que los daños derivados del trabajo puedan aparecer vinculados con el sexo de los trabajadores".

Así por ejemplo, el artículo 26 de la Ley 31/95 regula la protección de la maternidad, en el supuesto de que las condiciones de un puesto de trabajo pudieran influir negativamente en la salud de la trabajadora embarazada o del feto. En primer lugar hay que tratar de adaptar dichas condiciones o del tiempo de trabajo a la situación de la trabajadora afectada. Si ello no resulta posible, o si a pesar de dicha adaptación los Servicios Médicos del Instituto

\footnotetext{
542 Boletín Oficial del Estado núm. 269 de 10 de noviembre de 1995.
} 
Nacional de la Seguridad Social o de las Mutuas certifican, con el informe médico del Servicio Nacional de Salud que asista facultativamente a la trabajadora, que las mismas condiciones pueden influir negativamente en la salud de la trabajadora embarazada o del feto, ésta deberá desempeñar un puesto de trabajo o función diferente y compatible con su estado. Si no existiese puesto de trabajo o función compatible, la trabajadora podrá ser destinada a un puesto no correspondiente a su grupo o categoría, aunque conservará el derecho al conjunto de retribuciones de su puesto de origen. Lo dispuesto anteriormente también será de aplicación durante el periodo de lactancia natural ${ }^{543}$. Se trata de proteger la maternidad, aunque las condiciones laborales de la mujer trabajadora puedan verse perjudicadas si es destinada a un puesto que no corresponde a su categoría, bien porque sea un puesto de más responsabilidad y siga cobrando lo mismo, o bien porque sea un puesto de menos categoría y siga percibiendo las mismas retribuciones. El primer supuesto será el menos frecuente por no decir, impensable, pero el segundo penaliza el estatus profesional de la mujer mientras dure la situación de riesgo durante el embarazo.

En el caso de que el cambio de puesto no resultara técnica u objetivamente posible, o no pueda razonablemente exigirse por motivos justificados, podrá declararse el paso de la trabajadora afectada a la situación de suspensión del contrato por riesgo

543 Artículo 26.4 Ley 31/1995 de 8 de noviembre. 
durante el embarazo, así como, y esto es lo novedoso, por riesgo durante la lactancia natural de hijos menores de nueve meses ${ }^{544}$.

Conviene mencionar el Real Decreto 298/2009 de 6 de marzo por el que se modifica el Real Decreto 39/1997 de 17 de enero, por el que se aprueba el Reglamento de los Servicios de Prevención, en relación con la aplicación de medidas para promover la mejora de la seguridad y de la salud en el trabajo de la trabajadora embarazada, que haya dado a luz o en periodo de lactancia ${ }^{545}$. Se incluyen dos anexos, uno referido a la lista no exhaustiva de agentes, procedimientos y condiciones de trabajo que pueden influir negativamente en la salud de las trabajadoras embarazadas o en periodo de lactancia natural, del feto o del niño durante el periodo de lactancia natural; y otro en el que relacionan los agentes y condiciones de trabajo a los cuales no podrá haber riesgo de exposición por parte de trabajadoras embarazadas o en periodo de lactancia natural.

A la vista del contenido de estos Anexos parece poco probable que en el ámbito de la Administración Pública se pueda dar una situación como la amparada por el artículo 26 de la Ley de Prevención de Riesgos Laborales. De hecho, en el Capítulo V Título III EBEP no se regula ningún permiso por riesgo durante el embarazo o riesgo durante la lactancia natural. Aquí tenemos que

544 Artículo 26.3 y 26.4 Ley 31/1995 de 8 de noviembre.

545 Boletín Oficial del Estado núm. 57 de 7 de marzo de 2009. 
distinguir nuevamente entre personal funcionario y laboral al servicio de las Administraciones Públicas. En el caso de personal funcionario, la lista de permisos enumerados en el artículo 48.1 EBEP se establecía en defecto de previsión por parte de las Administraciones públicas. Es decir, que cada Administración Pública podía determinar otros supuestos de concesión de permisos a los funcionarios y funcionarias públicas, entre los que perfectamente se podría incluirse éste al que nos referimos. Sin embargo, el Real Decreto-ley 20/2012, de 13 de julio ha limitado el margen de maniobra de las Administraciones Públicas en este sentido. No obstante, como las previsiones de la Ley 31/95 se aplican a las Administraciones Públicas, y el artículo 58 LOIMH reconoce a las funcionarias que presten sus servicios en la Administración General del Estado licencia por riesgo durante el embarazo, para evitar agravios comparativos y en base al artículo $14 \mathrm{~m})$ EBEP, se debería seguir reconociendo la posibilidad de disfrutar de esta licencia a las empleadas públicas de todas las Administraciones. En el caso de personal laboral, en virtud del artículo 51 EBEP, podrán solicitar el disfrute de esta licencia prevista en el artículo 48.5 TRLET.

La protección en ambos supuestos, para todas las empleadas públicas, sería la misma. Se trata de situaciones en que las condiciones del puesto de trabajo pueden influir negativamente en la salud de la trabajadora embarazada o de su hijo o hija, y no es suficiente la adaptación de dichas condiciones para que 
desaparezca el riesgo. En estos casos la legislación laboral prevé la posibilidad de suspensión del contrato de trabajo, tratándose de contingencias cubiertas por las correspondientes prestaciones de Seguridad Social ${ }^{546}$. En el caso de las funcionarias se trata de supuestos de licencia, durante cuya duración se garantizan la plenitud de los derechos económicos de la funcionaria ${ }^{547}$, teniendo la misma consideración y efectos que la situación de incapacidad temporal. En este sentido nos referimos a la Disposición adicional vigésimo tercera de la LOIMH que modifica el artículo 22.1 de la Ley sobre Seguridad Social de los Funcionarios Civiles del Estado, aprobada por Real Decreto Legislativo 4/2000 de 23 de junio ${ }^{548}$ en el que se establece que "tendrá la misma consideración y efectos que la situación de incapacidad temporal la situación de la mujer funcionaria que haya obtenido licencia por riesgo durante el embarazo o riesgo durante la lactancia natural de hijos menores de nueve meses (...)". Asimismo, el artículo 135.1 del Texto Refundido de la Ley General de Seguridad Social" señala que "la prestación económica por riesgo durante el embarazo se concederá a la mujer trabajadora en los términos y condiciones establecidos en esta Ley para la prestación económica de incapacidad temporal derivada de contingencias profesionales (...)".

\footnotetext{
546 Artículo 45.1 d) TRLET. De conformidad con el artículo 45.2 TRLET "la suspensión exonera de las obligaciones recíprocas de trabajar y remunerar el trabajo".

547 Artículo 58 LOIMH titulado "licencia por riesgo durante el embarazo y lactancia".

548 Boletín Oficial del Estado núm. 154 de 28 de junio de 2000.

${ }^{549}$ Boletín Oficial del Estado núm. 154 de 29 de junio de 1994.
} 
La asimilación a la incapacidad temporal tiene una salvedad, y es que al tener reconocida la plenitud de derechos económicos mientras dure la situación protegida ${ }^{550}$, percibe la totalidad de sus retribuciones durante todo el tiempo, a diferencia de lo que ocurre con la incapacidad temporal ${ }^{551}$, que tras las modificaciones llevadas a cabo por el Real Decreto-Ley 20/2012 de 13 de julio, distingue entre contingencias comunes y contingencias profesionales, $\mathrm{y}$ limita el complemento retributivo según el caso, todo ello se supone que con el fin último de reducir el absentismo del personal al servicio de la Administración Pública.

Para determinar el alcance de las prestaciones en caso de situación de riesgo durante el embarazo de las funcionarias se distingue entre las funcionarias que están incluidas en el régimen general de la Seguridad Social y a las que resulta de aplicación el Real Decreto 295/2009 de 6 de marzo por el que se regulan las prestaciones económicas del sistema de Seguridad Social por maternidad, paternidad, riesgo durante el embarazo y riesgo durante la lactancia natural ${ }^{552}$, y las funcionarias adscritas a un régimen mutualista que se rigen por el Reglamento General del

\footnotetext{
550 Artículo 135. 3 del Texto Refundido de la Ley General de Seguridad Social en el que se pone de manifiesto que "la prestación económica consistirá en subsidio equivalente al 100\% de la base reguladora correspondiente".

551 Núñez-Cortés, 2008, págs. 236-237.

552 Boletín Oficial del Estado núm. 69 de 21 de marzo de 2009.
} 
Mutualismo Administrativo aprobado por Real Decreto 375/2003 de 28 de marzo $^{553}$.

Por otro lado, en relación con la obligación de los poderes públicos de velar por la seguridad e higiene en el trabajo, el artículo 27 LOIMH se refiere a la integración del principio de igualdad en la política de salud. Con este fin se han modificado la Ley 14/1986 de 25 de abril General de Sanidad ${ }^{554}$, y la Ley 16/2003 de 28 de mayo de Cohesión y Calidad del Sistema Nacional de Salud ${ }^{555}$. Son las Disposiciones adicionales octava y novena de la LOIMH las que regulan dichas modificaciones.

Así por ejemplo se incide en que las políticas, estrategias y programas de salud eviten que las diferencias físicas entre mujeres y hombres o los estereotipos sociales a ellas asociadas den lugar a discriminaciones entre ambos sexos en los objetivos y actuaciones sanitarias $^{556}$. Para ello las Administraciones Públicas sanitarias asegurarán la integración del principio de igualdad entre mujeres y hombres, garantizando su igual derecho a la salud ${ }^{557}$, y la prestación de servicios sanitarios en condiciones de igualdad efectiva y calidad ${ }^{558}$. Al mismo tiempo se incide en la importancia de diferenciar los riesgos, características y necesidades de mujeres y

\footnotetext{
553 Boletín Oficial del Estado núm. 87 de 11 de abril de 2003.

${ }^{554}$ Boletín Oficial del Estado núm. 102 de 29 de abril de 1986.

555 Boletín Oficial del Estado núm. 128 de 29 de mayo de 2003.

556 Artículo 3 apartado 4 de la LGS.

557 Artículo 6 apartado 2 LGS.

558 Artículo 2 letra a) de la Ley de Cohesión y Calidad del Sistema Nacional de Salud.
} 
hombres desde el punto de vista sanitario, lo cual se traduce en atenciones y servicios específicos para cada sexo ${ }^{559}$; en la inclusión de la perspectiva de género en las actuaciones formativas ${ }^{560}$; en el fomento de la investigación científica que atienda a las diferencias entre mujeres y hombres en relación con la protección de la $\operatorname{salud}^{561}$; y en el tratamiento desagregado por sexos de los datos contenidos en registros, encuestas, estadísticas u otros sistemas de información médica ${ }^{562}$. Por último, y para que todas las demás actuaciones señaladas anteriormente sean eficaces, una medida complementaria es hacer efectivo el principio de presencia equilibrada en el ámbito sanitario, impulsando la participación y el empoderamiento de las mujeres en los procesos de salud.

Por otra parte, la Disposición adicional vigésima segunda de la LOIMH modifica el artículo 59.3 de la Ley 55/2003 de 16 de diciembre del Estatuto Marco del personal estatutario de los servicios de salud. El artículo 59 de la Ley 55/2003 titulado "medidas especiales en materia de salud pública" permite que las disposiciones relativas a jornadas de trabajo y periodos de descanso puedan ser suspendidas de forma transitoria cuando las autoridades sanitarias adopten medidas excepcionales sobre el funcionamiento de los centros sanitarios conforme a lo previsto en

559 Artículo 12.2 letra f) de la Ley de Cohesión y Calidad del Sistema Nacional de Salud.

${ }^{560}$ Artículos 18.14 LGS y 34 letra e) de la Ley de Cohesión y Calidad del Sistema Nacional de Salud.

561 Artículo 18.15 LGS y artículo 44 f) de la Ley de Cohesión y Calidad del Sistema Nacional de Salud.

562 Artículo 18.17 LGS. 
el artículo 29.3 LGS $^{563}$, siempre que tales medidas así lo justifiquen y exclusivamente por el tiempo de su duración. Asimismo, también podrán ser suspendidas en un determinado centro, por el tiempo imprescindible y mediante resolución motivada adoptada previa consulta con los representantes del personal, cuando las circunstancias concretas que concurran en el centro imposibiliten el mantenimiento de la asistencia sanitaria a la población con los recursos disponibles. Estas medidas de suspensión del régimen de jornada y de descansos anteriormente descritos no se aplicarán al personal estatutario que disfrute del permiso por maternidad o de la licencia por riesgo durante el embarazo. La novedad de la LOIMH consiste en precisar que la suspensión de las normas generales sobre tiempo de trabajo tampoco puede afectar a las mujeres que se encuentren en situación de riesgo durante la lactancia natural.

También es destacable que el artículo 27.3 c) LOIMH haya incluido el acoso sexual y el acoso por razón de sexo dentro de la protección, promoción y mejora de la salud laboral. Además, en el artículo $14 \mathrm{~h}$ ) EBEP se reconoce como un derecho individual de los empleados públicos el respeto de su dignidad en el trabajo, “especialmente frente al acoso sexual y por razón de sexo, moral y laboral", y en el artículo 95.2 b) EBEP se califica con falta

\footnotetext{
563 Según este precepto, "cuando la defensa de la salud de la población lo requiera, las Administraciones sanitarias competentes podrán establecer regímenes temporales y excepcionales de funcionamiento de los establecimientos sanitarios".
} 
disciplinaria muy grave este tipo de conducta discriminatoria por razón de sexo. En este sentido el artículo 62 LOIMH se refiere a la negociación por parte de las Administraciones Públicas de un protocolo de actuación frente al acoso sexual y al acoso por razón de sexo, que ha sido aprobado por Resolución de 28 de julio de 2011 de la Secretaría de Estado para la Función Pública ${ }^{564}$.

En definitiva, la política seguida en materia de salud laboral y las actuaciones preventivas planificadas e implementadas tienen que tener un enfoque de género, con la finalidad de valorar si unas y otras atienden a las repercusiones que la actividad productiva puede generar diferencialmente sobre mujeres y hombres.

e. Igualdad y acción protectora de la Seguridad Social.

En el artículo 14 o) EBEP se reconoce el derecho de los empleados públicos a las prestaciones de la Seguridad Social correspondientes al régimen que les sea de aplicación.

Al hablar de la igualdad y la acción protectora de la Seguridad Social aplicable al personal al servicio de la Administración, pensamos en las prestaciones mientras dura el permiso por maternidad o paternidad. Durante este periodo la Administración tiene que cotizar a la Seguridad Social por la trabajadora mientras dure la suspensión del contrato de trabajo, a

${ }^{564}$ Boletín Oficial del Estado núm. 189 de 8 de agosto de 2011. 
pesar de que ésta no preste servicios. Lo mismo sucede con los padres que disfruten del permiso de paternidad, lo que contribuye a un necesario cambio de mentalidad en esta cuestión, haciendo ver a la Administración o al empresario que el cuidado de los hijos no es una responsabilidad de la madre exclusivamente. Sin embargo, hay que continuar avanzando y conseguir la supresión de la cotización empresarial a la Seguridad Social durante el periodo de maternidad y paternidad, haciendo que ese coste sea asumido por la sociedad en su conjunto y no solamente por el empleador. En el artículo 44 Uno 4 de la Ley 62/2003 de Medidas Fiscales, Administrativas y del Orden Social ${ }^{565}$ encontramos algún ejemplo de medidas de fomento del empleo que inciden favorablemente en esta idea, ya que aunque la obligación empresarial de cotizar a la Seguridad Social se mantiene durante la suspensión, se establece una bonificación del 100\% de la cuota empresarial a la Seguridad Social durante los doce meses siguientes a la reincorporación efectiva de la mujer al trabajo dentro de los dos años siguientes al periodo de suspensión o excedencia por cuidado de hijo ${ }^{566}$. En este programa se incluyen otras medidas para fomentar económicamente la contratación de las mujeres, como bonificaciones en las cuotas empresariales a la Seguridad Social de un $25 \%$ durante dos años si contratan a mujeres desempleadas entre 16 y 45 años, y del 100\% durante dos años si contratan mujeres desempleadas durante los 24 meses siguientes al parto.

\footnotetext{
565 Boletín Oficial del Estado núm. 313 de 31 de diciembre de 2003.

566 Sanguineti Raymond, 2004, pág. 37.
} 
La LOIMH también ha introducido importantes modificaciones en esta materia a través de sus disposiciones adicionales.

En primer lugar, en la Disposición adicional decimoquinta se modifica el Real Decreto Ley 11/98 de 4 de septiembre ${ }^{567}$ por el que se regulan las bonificaciones de cuotas a la Seguridad Social de los contratos de interinidad que se celebren con personas desempleadas para sustituir a trabajadores durante los periodos de descanso por maternidad, adopción o acogimiento. Los sujetos cuya contratación da lugar a las bonificaciones previstas en el Real Decreto Ley 11/98 son los mismos que antes de la aprobación de la LOIMH, las personas desempleadas. No será necesario acreditar un periodo determinado de permanencia en dicha situación, como tampoco ser titular en el momento de la contratación de una prestación por desempleo, de nivel contributivo o asistencial ${ }^{568}$. Esta bonificación opera con independencia de cuál haya sido la causa que haya llevado a dicha persona a la condición de desempleada, o de factores tales como su sexo, edad, capacidad u otras circunstancias especiales que puedan concurrir en ella (víctimas de violencia de género, excluidos sociales, etc.). Sin embargo, pese a hallarse desempleadas no podrán ostentar la

\footnotetext{
567 Boletín Oficial del Estado núm. 213 de 5 de septiembre de 1998.

568 Sánchez Trigueros, Carmen. Comentarios a la Ley Orgánica 3/2007 de 22 de marzo para la Igualdad Efectiva de Mujeres y Hombres. Aranzadi, Cizur Menor, 2008, pág. 882.
} 
condición de sustitutas, los familiares directos del empleador, las personas contratadas interinamente por Administraciones Públicas y sus organismos autónomos, y los trabajadores autónomos.

Las modificaciones introducidas por la LOIMH en el artículo 1 del Real Decreto Ley 11/1998 de 4 de septiembre consisten en ampliar el colectivo de personas susceptibles de ser sustituidas. Además de las trabajadoras que tengan suspendido su contrato de trabajo por riesgo durante el embarazo y durante los periodos de descanso por maternidad, adopción y acogimiento preadoptivo o permanente, se incluye a las trabajadoras que tengan suspendido su contrato de trabajo por riesgo durante la lactancia natural de un menor de nueve meses y a los trabajadores que tengan suspendido su contrato de trabajo por paternidad. Por lo que respecta a las trabajadoras y a los trabajadores autónomos, así como socios y socias de trabajo de las sociedades cooperativas, las novedades introducidas por la LOIMH son las mismas que las indicadas para los trabajadores y trabajadoras que no lo son.

Las cuotas a la Seguridad Social objeto de bonificación son las cuotas por contingencias comunes exclusivamente empresariales, cuotas por contingencias profesionales (accidentes de trabajo y enfermedades profesionales) y aportaciones empresariales de las cuotas de recaudación conjunta (desempleo, Fondo de Garantía Salarial y formación profesional). 
Tras la aprobación de la LOIMH la cuantía de la bonificación prevista sigue siendo la misma, esto es, el 100\% de las cuotas señaladas en el apartado anterior.

En segundo lugar, la Disposición adicional decimosexta modifica la Disposición adicional segunda de la Ley 12/2001 de 9 de julio de Medidas Urgentes de Reforma del Mercado de Trabajo para el incremento del empleo y la mejora de su calidad. Se reconoce por vez primera que a la cotización de los trabajadores por cuenta propia o autónomos -y no sólo a la de los trabajadores o de los socios trabajadores o socios de trabajo de las sociedades cooperativas-, sustituidos durante los periodos de descanso por maternidad, adopción, acogimiento, riesgo durante el embarazo pero también paternidad o riesgo durante la lactancia natural-, mediante los contratos de interinidad bonificados ${ }^{569}$, les será de aplicación una bonificación del $100 \%$ en las cuotas correspondientes, distinguiéndose los trabajadores encuadrados en un régimen de Seguridad Social propio de trabajadores por cuenta ajena, de los incluidos en un régimen de Seguridad Social propio de trabajadores autónomos. Además, sólo será de aplicación esta bonificación mientras coincidan en el tiempo la suspensión de actividad por dichas causas y el contrato de interinidad del

\footnotetext{
569 Real Decreto Ley 11/98 de 4 de septiembre por el que se regulan las bonificaciones de cuotas a la Seguridad Social de los contratos de interinidad que se celebren con personas desempleadas para sustituir a trabajadores durante los periodos de descanso por maternidad, adopción o acogimiento.
} 
sustituto, estableciéndose como límite máximo de aplicación de la bonificación el periodo de suspensión.

En tercer lugar, la Disposición adicional decimoctava modifica el Texto Refundido de la Ley General de la Seguridad Social aprobado por Real Decreto Legislativo 1/94 de 20 de junio, en adelante TRLGSS. Así, las situaciones de paternidad y riesgo durante la lactancia natural, se incluyen dentro del sistema de acción protectora de la Seguridad Social ${ }^{570}$, se tienen en cuenta a la hora de determinar la duración de la obligación de cotizar ${ }^{571}, y$ serán también computables a efectos de los distintos periodos previos de cotización exigidos para el derecho a las prestaciones ${ }^{572}$.

El artículo 124 TRLGSS regula las condiciones del derecho a las prestaciones, y la LOIMH añade un nuevo apartado $6^{\circ}$ a dicho precepto en el que se indica expresamente que "el periodo de maternidad o paternidad que subsista a la fecha de extinción del contrato de trabajo, o que se inicie durante la percepción de la prestación por desempleo, será considerado como periodo de cotización efectiva a efectos de las correspondientes prestaciones de la Seguridad Social por jubilación, incapacidad permanente, muerte y supervivencia, maternidad y paternidad". Por otro lado,

570 Artículo 38.1 c) TRLGSS.

571 Artículo 106.4 TRLGSS.

572 Artículo 124.3 TRLGSS. 
no se consideran situación asimilada a la de alta con cotización, los subsidios por riesgo durante la lactancia natural ${ }^{573}$.

La LOIMH también modifica el capítulo IV bis del Título II de la Ley General de la Seguridad Social. En primer lugar, a efectos de la prestación por maternidad se considera situación protegida el acogimiento simple de conformidad con el Código Civil o las leyes civiles de la Comunidades Autónomas que lo regulen, siempre que su duración no sea inferior a un año y aunque dichos acogimientos sean provisionales ${ }^{574}$. Para ser beneficiario de la prestación por maternidad, se suprime la referencia que el artículo 133 bis hacía a la necesidad de un periodo mínimo de cotización de ciento ochenta días dentro de los cinco años inmediatamente anteriores al parto, o a las fechas de la decisión administrativa o judicial de acogimiento o de la resolución judicial por la que se constituya la adopción. Actualmente se distinguen tres supuestos. Si el trabajador por cuenta ajena tiene menos de veintiún años, no se exige periodo mínimo de cotización. Si tiene cumplidos entre veintiuno y veintiséis años, el periodo mínimo de cotización exigido será de noventa días cotizados dentro de los siete años inmediatamente anteriores al momento de inicio del descanso, o alternativamente el trabajador acredita ciento ochenta días cotizados a lo largo de su vida laboral, con anterioridad a esta última fecha. Y en tercer lugar, si el trabajador es mayor de

573 Artículo 125.1 TRLGSS.

574 Artículo 133 bis TRLGSS. 
veintiséis años, el periodo mínimo de cotización exigido será de ciento ochenta días dentro de los siete años inmediatamente anteriores al momento de inicio del descanso, o alternativamente si el trabajador acredita trescientos sesenta días cotizados a lo largo de su vida laboral, con anterioridad a esta última fecha. No obstante, se introduce un supuesto especial en el que serán beneficiarias del subsidio por maternidad las trabajadoras por cuenta ajena que en caso de parto reúnan todos los requisitos establecidos para acceder a la prestación por maternidad, salvo el periodo mínimo de cotización al que nos hemos referido anteriormente $e^{575}$. La cuantía de la prestación será igual al 100\% del indicador público de renta de efectos múltiples (IPREM), y la duración de la prestación, que tendrá la consideración de no contributiva, será de cuarenta y dos días naturales a contar desde el $\operatorname{parto}^{576}$.

El actual capítulo IV ter del Título II pasa a ser el capítulo IV quater, introduciéndose en dicho título un nuevo capítulo IV ter rubricado "paternidad", que regula cuáles son las situaciones protegidas a efectos de la prestación por paternidad ${ }^{577}$, quienes resultan beneficiarios de la misma ${ }^{578}$ y en qué consiste la prestación económica por paternidad ${ }^{579}$.

575 Artículo 133 sexies TRLGSS.

576 Artículo 133 septies TRLGSS.

577 Artículo 133 octies TRLGSS.

578 Artículo 133 nonies TRLGSS.

579 Artículo 133 decies TRLGSS. 
En el capítulo IV quater se introducen las siguientes modificaciones. Se establece que la prestación correspondiente a la situación de riesgo durante el embarazo tendrá la naturaleza de prestación derivada de contingencias profesionales, desapareciendo la asimilación con la prestación económica de incapacidad temporal derivada de enfermedad común ${ }^{580}$. Además, la prestación económica consiste en un subsidio equivalente, no al $75 \%$ sino al 100\% de la base reguladora correspondiente ${ }^{581}$.

Por último, el nuevo capítulo IV quinquies regula la prestación económica por riesgo durante la lactancia natural, delimita cuál es la situación protegida ${ }^{582}$, quiénes son los beneficiarios y cuándo se produce la extinción de la misma ${ }^{583}$.

En el Capítulo VIII del mismo Título II novedosamente se incluyen, como sujetos que podrán causar derecho a las prestaciones de auxilio por defunción, pensión vitalicia por viudedad, pensión de orfandad, pensión vitalicia o, en su caso, subsidio temporal a favor de familiares $y$, en caso de muerte causada por accidente de trabajo o enfermedad profesional, además, indemnización a tanto alzado ${ }^{584}$, los perceptores de subsidios de paternidad o riesgo durante la lactancia natural ${ }^{585}$.

\footnotetext{
580 Artículos 134 último párrafo y 135.1 del TRLGSS.

581 Artículo 135.3 TRLGSS.

582 Artículo 135 bis TRLGSS.

583 Artículo 135 ter TRLGSS.

584 Artículo 171 TRLGSS.

585 Artículo 172.1 letra b) TRLGSS.
} 
El artículo 180 TRLGSS relativo a las prestaciones familiares en su modalidad contributiva también ha sido modificado, no sólo por la LOIMH sino también por la Ley 27/2011, de 1 de agosto, sobre actualización, adecuación y modernización del sistema de seguridad social ${ }^{586}$. En este sentido tendrá la consideración de periodo de cotización efectiva a efectos de las correspondientes prestaciones de la Seguridad Social por jubilación, incapacidad permanente, muerte y supervivencia, maternidad y paternidad, los tres primeros años del periodo de excedencia que los trabajadores disfruten en razón del cuidado de cada hijo o menor acogido, así como el primer año del periodo de excedencia que se solicite para el cuidado de otros familiares, hasta el segundo grado de consanguinidad o afinidad, que por razones de edad, accidente, enfermedad o discapacidad, no puedan valerse por sí mismos y no desempeñen una actividad retribuida.

Las cotizaciones realizadas durante los dos primeros años del periodo de reducción de jornada por cuidado de menor se computarán con un incremento de hasta el 100\% de la cuantía que hubiera correspondido si se hubiera mantenido sin dicha reducción ${ }^{587}$.

\footnotetext{
586 Boletín Oficial del Estado núm. 184 de 2 de agosto de 2011.

${ }^{587}$ Artículo 180. 3 TRLGSS.
} 
En el Título III del TRLGSS se regula la protección por desempleo, y en el artículo 211 del mismo, referido a la cuantía de la prestación por desempleo, la LOIMH ha añadido un nuevo apartado 5. Según este precepto, para el cálculo de la base reguladora de la prestación por desempleo, en los supuestos de reducción de jornada regulados en el artículo 37 apartados 4 bis, 5 y 7 del texto refundido de la Ley del Estatuto de los Trabajadores, para el cálculo de la base reguladora, las bases de cotización también se computarán incrementadas hasta el 100\% de la cuantía que hubiera correspondido si se hubiera mantenido sin reducción, el trabajo a tiempo completo o parcial $^{588}$.

En el artículo 222 TRLGSS titulado "Desempleo. Maternidad e incapacidad temporal", se ha introducido la referencia expresa a la situación de paternidad, y novedosamente se prevé que si el trabajador está percibiendo la prestación por desempleo total y pasa a la situación de maternidad o paternidad, percibirá la prestación por estas últimas en la cuantía que corresponda y se le suspenderá la prestación por desempleo y las cotizaciones a la Seguridad Social. Una vez extinguida la prestación por maternidad y paternidad, se reanudará la prestación por desempleo por la duración que restaba por percibir y la cuantía que correspondía en el momento de la suspensión ${ }^{589}$. El periodo de percepción de la prestación por desempleo no se ampliará por la circunstancia de

\footnotetext{
588 Artículo 211.5 TRLGSS.

589 Artículo 222.3 párrafos 3, 4 y 5 TRLGSS.
} 
que el trabajador pase a la situación de incapacidad temporal 0 maternidad, desapareciendo tras la reforma esta última referencia a la maternidad ${ }^{590}$.

Asimismo se modifica la disposición adicional sexta del TRLGSS, que pasa a denominarse "protección de los trabajadores contratados para la formación", estableciéndose que la acción protectora de este trabajador incluye la asistencia sanitaria en los casos de maternidad, las prestaciones económicas no sólo por maternidad sino también por paternidad, riesgo durante el embarazo y riesgo durante la lactancia natural, y las pensiones.

Por lo que respecta a las normas aplicables a los trabajadores contratados a tiempo parcial en relación con los periodos de cotización y las bases reguladoras ${ }^{591}$, en ellas se hace también referencia a las prestaciones por paternidad. Asimismo tendrán derecho a disfrutar de este tipo de prestaciones los trabajadores por cuenta ajena y por cuenta propia incluidos en los distintos Regímenes Especiales del sistema ${ }^{592}$.

Por último, destacamos la introducción de una nueva disposición adicional cuadragésima cuarta sobre "Periodos de cotización asimilados por parto", en la que se establece que a

\footnotetext{
${ }^{590}$ Artículo 222.3 párrafo 4 TRLGSS.

${ }^{591}$ Disposición adicional séptima apartado 1 regla segunda letra a) y regla tercera letra a) TRLGSS.

${ }^{592}$ Disposición adicional undécima bis TRLGSS.
} 
efectos de pensiones contributivas de jubilación y de incapacidad permanente de cualquier régimen de la Seguridad Social, se computarán a favor de la trabajadora solicitante de la pensión, un total de 112 días completos de cotización por cada parto de un solo hijo y de 14 días más por cada hijo a partir del segundo, salvo si por ser trabajadora o funcionaria en el momento del parto, se hubiera cotizado durante la totalidad de las dieciséis semanas o si el parto fuese múltiple, durante el tiempo que corresponda.

También relacionado con el tema que nos ocupa se encuentra la Disposición adicional vigésima tercera de la LOIMH, la cual modifica el Real Decreto Legislativo 4/2000 de 23 de junio por el que se aprueba el texto refundido de la Ley sobre Seguridad Social de los Funcionarios Civiles del Estado. En concreto, en el artículo 12 b) relativo a las prestaciones a que tienen derecho los mutualistas o sus beneficiarios, se añade junto al subsidio por incapacidad temporal, los subsidios por riesgo durante el embarazo o riesgo durante la lactancia natural.

Además, en el artículo 22 se establece como novedad que tendrán la misma consideración y efectos que la situación de incapacidad temporal, la situación de la mujer funcionaria que haya obtenido licencia por riesgo durante la lactancia natural de hijos menores de nueve meses. En este punto hacemos una referencia al Real Decreto 2/2010 de 8 de enero por el que se modifica el Reglamento General del Mutualismo Administrativo, aprobado 
por Real Decreto 375/2003 de 28 de marzo, en materia de incapacidad temporal y de riesgo durante el embarazo y durante la lactancia natural.

f. Igualdad en la extinción del contrato de trabajo.

En el artículo 63 EBEP se refiere a las causas de pérdida de la condición de funcionario de carrera, sin que quepa entender que las mismas causas son aplicables al personal laboral al servicio de la Administración Pública. No obstante, el régimen disciplinario es el mismo para todos los empleados públicos. En el artículo 93.4 EBEP se establece que "el régimen disciplinario del personal laboral se regirá, en lo no previsto en el presente Título (VII), por la legislación laboral". De hecho la extinción del contrato laboral suscrito con la Administración podría producirse en el supuesto de despido disciplinario del personal laboral por la comisión de faltas muy graves, aunque, de conformidad con el artículo 96.2 EBEP "procederá la readmisión del personal laboral fijo cuando sea declarado improcedente (...)", a diferencia de lo que sucede en la empresa privada en la que de acuerdo con el artículo 56 TRLET, el empresario podrá optar entre la readmisión del trabajador o el abono de una indemnización. La opción por la indemnización determinará la extinción del contrato de trabajo, que se entenderá producida en la fecha del cese efectivo en el trabajo. El artículo 96.2 EBEP impone, como consecuencia de la declaración de improcedencia de un despido disciplinario de personal laboral fijo, 
la readmisión automática, imposibilitando que la Administración Pública pueda disponer en esos casos de la relación laboral mediante el abono de la indemnización correspondiente. Se trata de un derecho de inamovilidad relativo o de menor intensidad que el reconocido para los funcionarios, puesto que sólo afecta al despido disciplinario.

Debido a las características que presiden el acceso a la función pública y las condiciones del empleo en la misma, así como la relación de faltas disciplinarias muy graves del artículo 95 EBEP que justificarían el despido disciplinario del personal laboral a su servicio, es poco probable que en la Administración se produzcan despidos motivados por alguna de las causas de discriminación prohibidas en la Constitución o en la Ley, o que se produzcan con violación de los derechos fundamentales y libertades públicas del trabajador. No obstante, sí pueden darse situaciones que si bien no tienen la consideración de despido propiamente dicho, en la práctica el efecto es el mismo. Pensemos por ejemplo en la no renovación de un contrato temporal. En la jurisprudencia del Tribunal de Justicia de la Unión Europea se ha declarado que "la falta de renovación de un contrato (...) no puede ser considerada un despido (...) no obstante, en la medida en que la falta de renovación (...) esté motivada por el embarazo de la trabajadora, constituye una discriminación directa por razón de sexo" ${ }^{\text {"593. }}$ Y es que tal y como ha puesto de manifiesto nuestro

${ }^{593}$ STJUE de 4 de octubre de 2001, C-438/99. 
Tribunal Constitucional, "la discriminación por razón de sexo no comprende sólo aquellos tratamientos peyorativos que encuentren su fundamento en la pura y simple constatación del sexo de la persona perjudicada. También comprende estos mismos tratamientos cuando se fundan en la concurrencia de condiciones o circunstancias que tengan con el sexo de la persona una relación directa e inequívoca. Tal sucede con el embarazo, elemento o factor diferencial que, por razones obvias, incide de forma exclusiva sobre las mujeres"594. En la Sentencia del Tribunal Constitucional número 173/1994 de 7 de junio encontramos una muestra de conducta discriminatoria reprobable por parte de la Administración Pública, quien se negó a renovar un contrato temporal en curso como consecuencia del embarazo de la trabajadora. La negativa a renovar un contrato o a contratar por parte del empresario, ha sido por un motivo discriminatorio probado y por tanto prohibido por el artículo $14 \mathrm{CE}$, que no puede ser valorada como un mero acto de libertad. Recientemente la Sentencia del Tribunal Constitucional número 17/2003 de 30 de enero, recuerda que en estos casos "la cuestión radicará en discernir si el cese constituyó realmente una extinción consensual (por vencimiento del término pactado) o si respondió a una vulneración del derecho fundamental aducido (aquí la prohibición de discriminación), (...) pues la libertad empresarial no alcanza a la producción de resultados inconstitucionales” ${ }^{\text {,595. }}$.

\footnotetext{
${ }^{594}$ FJ 2 de la STC 173/94, de 7 de junio.

${ }^{595}$ FJ 6 párrafo cuarto de la STC 17/03 de 30 de enero.
} 


\subsection{IGUALDAD DE OBLIGACIONES. CÓDIGO DE CONDUCTA.}

En el artículo 52 EBEP se menciona expresamente como principio de actuación de los empleados públicos "el de respeto a la igualdad entre mujeres y hombres". Este principio inspira su Código de Conducta configurado por los principios éticos y de conducta que se regulan en los artículos 53 y 54 EBEP. Entre los primeros destacamos por su relación con la materia que nos ocupa, el respeto a los derechos fundamentales y libertades públicas evitando toda actuación que pueda producir discriminación alguna por razón de género ${ }^{596}$. Por lo que respecta a los principios de conducta, se considera que tienen relación con el principio de igualdad de género y que pueden resultar eficaces para su realización efectiva, la obligación del empleado público de mantener actualizada su formación y cualificación ${ }^{597}$, o la observancia de las normas relacionadas con la seguridad y la salud laboral ${ }^{598}$, o la puesta en conocimiento de los órganos competentes de las propuestas que consideren adecuadas para mejorar el desarrollo de las funciones en las que estén destinados ${ }^{599}$, entre las que podrían destacarse aquellas relacionadas con la conciliación de la vida familiar y laboral, por ejemplo, la implantación progresiva del teletrabajo en aquellas unidades administrativas en las que sea

\footnotetext{
596 Artículo 53.4 EBEP.

597 Artículo 54.8 EBEP.

598 Artículo 54.9 EBEP.

599 Artículo 54.10 EBEP.
} 
posible, o el establecimiento de guarderías en el centro de trabajo al igual que se hace en algunas empresas privadas.

Por lo que respecta a los miembros del Gobierno y a los altos cargos de las entidades del sector público estatal, la reciente Ley 19/2013, de 9 de diciembre, de transparencia, acceso a la información pública y buen gobierno ${ }^{600}$, establece que asegurarán un trato igual y sin discriminaciones de ningún tipo en el ejercicio de sus funciones ${ }^{601}$, aunque es criticable que no se haya extendido a todos los altos cargos y autoridades de todas las Administraciones Públicas.

${ }^{600}$ Boletín Oficial del Estado núm. 295 de 10 de diciembre de 2013.

${ }^{601}$ Artículo 26 de la Ley 19/2013, de 9 de diciembre. 

VIII- LA NEGOCIACIÓN COLECTIVA AL SERVICIO DE LA IGUALDAD ENTRE HOMBRES Y MUJERES. MEDIDAS DE ACCIÓN POSITIVA Y PLANES DE IGUALDAD.

Hasta ahora se ha analizado la influencia de la normativa en el origen y desarrollo de la igualdad entre hombres y mujeres. Se ha visto cómo a partir del derecho a percibir el mismo salario por un trabajo de igual valor, se ha ido forjando el principio más amplio de igualdad de trato y de no discriminación por razón de sexo, bien sea directa o indirecta, así como el principio de igualdad de oportunidades para corregir las desigualdades de hecho que afectan a las mujeres. La jurisprudencia también ha contribuido a que la concepción meramente formal de la igualdad entre hombres y mujeres haya evolucionado hasta la asunción de una igualdad real o sustancial.

En nuestro ordenamiento jurídico, el artículo 14 de la Constitución Española reconoce un derecho individual a la igualdad y no discriminación, que se concreta en el mandato que el artículo 9.2 del texto constitucional traslada a los poderes públicos para que las condiciones de igualdad sean reales y efectivas. La igualdad formal, jurídica o "de iure" del artículo 14 CE se traduce en una igualdad en el trato dado por la ley y en la aplicación de la ley, así como en una prohibición de discriminación, que a su vez 
requiere una intervención pública, amparada por el artículo 9.2 CE, para alcanzar la igualdad material, de hecho o "de facto". Y ello porque el Estado social no sólo garantiza derechos individuales sino también derechos sociales, por lo que en este contexto los poderes públicos tienen que orientar su actividad hacia la búsqueda de una igualdad sustancial, entendida como igualdad de oportunidades.

Teniendo claro este esquema, para seguir avanzando en la consecución y consolidación de la igualdad material resulta fundamental aprovechar las oportunidades que ofrece la negociación colectiva, como ámbito especialmente idóneo para la regulación de esta temática por el valor añadido que otorga una regulación consensuada de los protagonistas de la relación de empleo público.

El diálogo social ha desempeñado un papel muy importante a la hora de tener en cuenta el principio de igualdad en la elaboración de los convenios colectivos. Fruto de ese diálogo social se han ido adoptando los Acuerdos Interconfederales para la Negociación Colectiva, en adelante ANC, los cuales tienen como objetivo inmediato definir las pautas generales que han de informar la práctica de la negociación colectiva durante su vigencia. No enuncian estipulación o pacto alguno del que pueda predicarse su aplicabilidad inmediata, ya que para ello sería precisa una verdadera negociación con capacidad para regular condiciones 
de trabajo, incluidas las que tienen una directa incidencia en el fomento de la igualdad. Los ANC sólo son recomendaciones que hacen las organizaciones sindicales y las asociaciones empresariales más representativas en el ámbito estatal, para que sean tenidas en cuenta a la hora de redactar un convenio colectivo.

El ANC de $2002^{602}$ es el primero en el que la igualdad de oportunidades entre hombres y mujeres es considerada como un objetivo a alcanzar en materia de empleo. Se trata de promocionar en los convenios colectivos actuaciones encaminadas a eliminar todo tipo de discriminaciones, directas e indirectas, motivadas por razones de género. Para ello habría que examinar las causas que originan las posibles diferencias, identificando los obstáculos y destacando las prácticas que pueden ser más adecuadas para fomentar la igualdad de oportunidades, entre las que se pueden incluir aquellas medidas que contribuyan a la diversidad profesional de las mujeres y su acceso a la formación, prácticas y contratación en ocupaciones y puestos tradicionalmente desempeñados por hombres. Más recientemente el ANC de $2005^{603}$ considera adecuado para su tratamiento por la negociación colectiva la inclusión de cláusulas de acción positiva para fomentar el acceso, en igualdad de condiciones, a sectores y ocupaciones en

${ }^{602}$ Aprobado por Resolución de 26 de diciembre de de 2001 de la Dirección General de Trabajo, publicada en el Boletín Oficial del Estado núm. 15 de 17 de enero de 2002.

603 Aprobado por Resolución de 7 de marzo de 2005 de la Dirección General de Trabajo, publicada en el Boletín Oficial del Estado núm. 64 de 16 de marzo de 2005. 
los que las mujeres se encuentren subrepresentadas; el establecimiento de sistemas de selección, clasificación, promoción y formación sobre la base de criterios técnicos, objetivos y neutros por razón de género; la implantación de sistemas de valoración de los puestos de trabajo a través de los que se evalúe periódicamente el encuadramiento profesional; el establecimiento de tiempos de trabajo y sistemas formativos que propicien la conciliación de la vida laboral, personal y familiar; y el seguimiento de los convenios colectivos desde la perspectiva de género. El último de los Acuerdos para el Empleo y la Negociación Colectiva ${ }^{604}$ aprobado es mucho menos extenso en cuanto a las propuestas para la consecución de la igualdad de oportunidades, aunque sigue refiriéndose a la misma como un objetivo a alcanzar en materia de empleo y ocupación.

Sería conveniente que el diálogo social no perdiera importancia como motor de la negociación colectiva en cuestiones de igualdad entre hombres y mujeres en el ámbito laboral. Es responsabilidad del Estado adoptar las medidas que considere más adecuadas para fomentar el diálogo entre los interlocutores sociales. Así lo ha puesto de manifiesto el artículo 8 ter de la Directiva 2002/73/CE del Parlamento Europeo y del Consejo de 23 de septiembre de $2002^{605}$, según la cual corresponde a los

\footnotetext{
604 Aprobado por Resolución de 30 de enero de 2012 de la Dirección General de Empleo, publicada en el Boletín Oficial del Estado núm. 31 de 6 de febrero de 2012.

${ }^{605}$ DOUE L 296/15 de 05.10.02.
} 
Estados miembros la tarea de alentar a dichos agentes sociales para que, sin renunciar al principio de autonomía que debe presidir su actuación, promuevan la igualdad entre hombres y mujeres y celebren, en el nivel adecuado, acuerdos y convenios colectivos que establezcan las normas antidiscriminatorias que sean necesarias.

En la regulación convencional de las cuestiones relacionadas con la igualdad y no discriminación por razón de sexo se pueden distinguir dos fases.

Una primera fase de toma de conciencia de la importancia de garantizar la vigencia del principio de igualdad de trato y no discriminación. Aquí se encuentran aquellos convenios que cabría caracterizar como de contenido pedagógico que incluyen cláusulas declarativas sobre la igualdad y no discriminación por razón de sexo en términos generales, o bien se remiten genéricamente a la legislación vigente o trasladan al convenio colectivo su contenido. El valor de estas cláusulas reside en dotar de una mayor visibilidad al derecho antidiscriminatorio de género, difundiéndolo entre el colectivo de personas incluido en el ámbito de aplicación del convenio. Sin embargo, la mera transposición al convenio no restablece las situaciones discriminatorias, por lo que en una fase posterior habrá que avanzar y pactar cláusulas verdaderamente eficaces para la consecución de la igualdad y no discriminación. 
En general, el tratamiento que se hace de las cuestiones relacionadas con la igualdad entre hombres y mujeres en esta primera fase destaca por su carácter fragmentario, en el sentido de que se suele identificar con aspectos concretos de la misma, generalmente temas vinculados con la maternidad y los permisos retribuidos. Esto puede ocasionar que en un mismo convenio coexistan cláusulas discriminatorias y cláusulas antidiscriminatorias, por lo que se debe adoptar un enfoque integral de la igualdad y no discriminación que abarque todos los aspectos tratados en la negociación ${ }^{606}$. Es decir, se trata de incorporar el principio de transversalidad de género en la negociación colectiva, de forma que se proyecte el principio de igualdad en todo el articulado del convenio.

Puesto que ya se ha analizado la legislación vigente en relación con cada uno de los elementos que conforman el concepto amplio de acceso al empleo público, no vamos a referirnos al posible contenido de las cláusulas declarativas de los convenios colectivos en relación con cada uno de dichos elementos, ya que esto supondría reiterar las observaciones hechas entonces. Por eso nos vamos a centrar en las posibilidades de la negociación colectiva en la siguiente fase, en la que los convenios colectivos incluyen cláusulas que mejoran la situación en la materia. Las mejoras más habituales consisten en superar los

${ }^{606}$ Informe 2/2003 del Consejo Económico y Social: La negociación colectiva como mecanismo de promoción de la igualdad entre hombres y mujeres, págs. 42-43. 
mínimos establecidos por la legislación vigente o en regular supuestos no previstos por la ley, sobre todo en materia de permisos no retribuidos, para erradicar definitivamente las discriminaciones en el empleo y lograr así que la igualdad entre hombres y mujeres sea real y efectiva. Sin embargo, la reciente reforma de la legislación laboral llevada a cabo en nuestro país refuerza el poder individual del empresario en la gestión de las condiciones de trabajo y erosiona el poder contractual colectivo de los trabajadores para mejorar las condiciones de empleo en materia de igualdad efectiva entre hombres y mujeres ${ }^{607}$.

Existen varios cauces formales a través de los cuales se concreta la contribución de la negociación colectiva en este propósito, entre los que destacamos, por su importancia, la adopción de medidas de igualdad y la aprobación de los planes de igualdad. Y aunque es cierto que el objetivo último de ambos es alcanzar la igualdad material, las primeras persiguen reparar y los segundos prevenir situaciones y conductas discriminatorias. Esto supone que junto a la tutela tradicional de la igualdad, basada en la tipificación de determinados actos como infracciones y la imposición de las correspondientes sanciones, aparece esta nueva tutela que debe pasar necesariamente por la negociación colectiva.

607 Las consecuencias negativas de la Ley 3/2012, de 6 de julio, sobre la negociación colectiva han sido puestas de manifiesto por Palomeque López, Manuel Carlos. El papel de la negociación colectiva en pro de la igualdad efectiva de la mujer trabajadora, a enjuiciamiento, en Figueruelo Burrieza, Ángela, directora y $\mathrm{M}^{\mathrm{a}}$ Luisa Martín Hernández, coordinadora. Perspectiva de género en la negociación colectiva: análisis por sectores feminizados y masculinizados. Bomarzo, Albacete, 2013. 
En relación con la regulación convencional de las cuestiones relacionadas con la igualdad entre hombres y mujeres en el empleo público laboral, habrá que tener en cuenta el artículo 32 EBEP, que establece que "la negociación colectiva, representación y participación de los empleados públicos con contrato laboral se regirá por la legislación laboral, sin perjuicio de los preceptos de este Capítulo que expresamente le son de aplicación". A ello se añaden las previsiones de la Disposición Adicional Octava EBEP, así como la Ley Orgánica para la Igualdad Efectiva de Mujeres y Hombres, normativa relativamente reciente que refuerza los mecanismos convencionales para el logro de la igualdad sustancial. Por lo que respecta a legislación laboral, regulan esta materia los artículos 3.1 b) y 3.2 TRLET en los que se concreta el sistema de fuentes de la relación laboral, y el Título III TRLET, que configura legalmente el derecho a la negociación colectiva garantizando su ejercicio en cumplimiento del artículo 37.1 CE. 


\section{LAS MEDIDAS DE IGUALDAD: ACCIONES POSITIVAS.}

Estas medidas se contemplan en la Disposición Adicional Octava del Estatuto Básico del Empleado Público, en cuyo apartado primero se establece que "las Administraciones Públicas están obligadas a respetar la igualdad de trato y de oportunidades en el ámbito laboral y, con esta finalidad, deberán adoptar medidas dirigidas a evitar cualquier tipo de discriminación laboral entre hombres y mujeres".

En primer lugar, esta disposición establece la obligación de las Administraciones Públicas de respetar la igualdad de trato y de oportunidades. Ya hemos señalado que la igualdad formal se traduce en la igualdad de trato y en la prohibición de discriminación, y que la igualdad material que persiguen los poderes públicos se entiende como una igualdad de oportunidades. Antes de seguir avanzando conviene hacer una serie de precisiones terminológicas para poder afrontar con claridad la cuestión de las acciones positivas. En sentido jurídico, la discriminación es una diferencia de trato arbitraria y por tanto no justificada, que se dispensa a una persona por su pertenencia a un colectivo que se encuentra en una posición sistemática de desigualdad, sin que exista necesariamente intención de discriminar 
por parte del sujeto activo de la relación. La acción positiva emplea el mismo mecanismo para conseguir el efecto contrario, por eso se le suele llamar también discriminación inversa o discriminación positiva, aunque en este caso la diferencia de trato no es arbitraria sino que estaría plenamente justificada en razón de la adscripción de un sujeto a un grupo social en esa posición de inferioridad, de sistemática de desigualdad. No obstante, estas denominaciones son criticadas por algunos autores como Álvarez del Cuvillo para quienes "ciertamente, la "acción positiva" constituye una especie de "reverso" de la discriminación que actúa en sentido positivo (...), pero, precisamente por eso mismo, no puede considerarse como un tipo de discriminación, en tanto esta palabra en el contexto del derecho antidiscriminatorio no se utiliza en su sentido original (separación, distinción, diferenciación) sino para calificar a determinadas diferencias de trato que reproducen las desigualdades estructurales entre grupos sociales"608. Lo cierto es que el término discriminación tiene connotaciones negativas, por lo que referirse a las acciones positivas como discriminación positiva o discriminación inversa puede empañar la finalidad legítima que persiguen, esto es, el respeto a la igualdad de trato y de oportunidades en el ámbito laboral. La legislación no ha tenido en cuenta este tipo de consecuencias, y así por ejemplo, cuando el artículo 61.1 EBEP subraya el carácter abierto de los procesos selectivos, establece que dicho carácter lo será sin perjuicio de las

608 Álvarez del Cuvillo, Antonio. Elementos para una valoración técnico-jurídica de las medidas de acción positiva. Revista de Relaciones Laborales, núm. 1, 2010, pág. 668. 
medidas de "discriminación positivas" previstas en dicho Estatuto. Por otro lado, a pesar de que este precepto abre la puerta a la adopción de medidas de acción positiva en el acceso al empleo público, el único colectivo al que se destinan de forma expresa es a las personas con discapacidad, a las que el artículo 59.1 EBEP reserva un cupo no inferior al cinco por ciento de las vacantes en las ofertas de empleo público que se aprueben.

Otra precisión conceptual al hilo de la primera parte de la Disposición Adicional Octava EBEP, es la distinción entre la igualdad de oportunidades y la igualdad de resultados. Esta distinción se ha utilizado por la jurisprudencia para establecer los límites a las acciones positivas. La igualdad de oportunidades o igualdad en el punto de partida, permite un tipo de acciones positivas como son los tratos preferenciales, por ejemplo, en las actividades de formación, de manera que todas las personas tengan idénticas posibilidades de alcanzar unos méritos determinados que las sitúen en el mismo nivel a la hora de acceder a un puesto de trabajo. La igualdad de resultados se refiere a otro tipo de acciones positivas que también entrañan un trato preferencial, aunque esta vez referido a la promoción a determinados puestos de trabajo. Así sucede con las denominadas cuotas de acción positiva establecidas para acabar con la segregación vertical existente en los puestos directivos en la Administración. A través de ellas se podrán reservar a las mujeres un determinado porcentaje de dichos puestos en las ofertas de empleo público, el porcentaje que se 
considere oportuno para evitar que la situación discriminatoria no se perpetúe durante más tiempo.

Sin embargo, esta distinción entre igualdad de oportunidades e igualdad de resultados no es absoluta, ya que la consecución de una cierta igualdad de oportunidades no se consigue sino a través de la igualación de resultados, de forma que como acertadamente señala Álvarez del Cuvillo "una medida de acción positiva destinada a favorecer la formación profesional de las mujeres incrementa la "igualdad de oportunidades" en el empleo, pero sólo a través de la imposición de la "igualdad de resultados" en el acceso a la formación" ${ }^{609}$. Lo que sucede es que la preferencia en el acceso a la formación está socialmente aceptada puesto que se vincula al criterio del mérito y capacidad de una persona, mientras que no sucede lo mismo con una preferencia en la contratación, que afecta a la distribución de los puestos de trabajo y que entraña un coste que repercute sobre una tercera persona, normalmente un varón, al que no puede atribuirse ninguna responsabilidad personal en el problema de la discriminación. Por tanto, para Álvarez del Cuvillo, los límites de las acciones positivas no hay que buscarlos en una distinción tajante entre la igualdad de oportunidades y la igualdad de resultados, sino que aceptando la estrecha relación que existe entre ambos conceptos, habrá que realizar caso por caso un juicio de proporcionalidad entre el fin social perseguido con la acción

${ }^{609}$ Álvarez del Cuvillo, 2010, pág. 664. 
positiva y sus efectos secundarios, es decir, los costes de la medida, procurando que los mismos los soporte la sociedad en su conjunto. Según este autor, la finalidad que se persigue con las acciones positivas no es privilegiar a las mujeres para hacer justicia histórica con ellas, tampoco se trata de protegerlas, sino de mejorar la cohesión social integrando en la sociedad a aquellas personas que se encuentran en una posición de desventaja por la mera pertenencia a un colectivo determinado.

En segundo lugar, la Disposición Adicional Octava EBEP establece la obligación de adoptar medidas dirigidas a evitar cualquier tipo de discriminación laboral entre hombres y mujeres, sin especificar cuáles son y entre las que sabemos que se pueden incluir las medidas de acción positiva. Sin embargo, a diferencia de lo que sucede en la legislación laboral, no establece el deber de negociarlas previamente, y ninguno de los preceptos del EBEP en los que se regula el derecho a la negociación colectiva se refiere a esta cuestión. Además, el legislador podría haber sido un poco más preciso y emplear, como ha hecho a lo largo del articulado del EBEP, el término "empleo público" o "empleado público" cuando quiere referirse a todo el personal al servicio de la Administración, en vez de utilizar la expresión "laboral", que puede inducir a confusión, y llevarnos a entender que dichas medidas sólo serán obligatorias en el caso del empleo público laboral. 
A diferencia del EBEP, en el artículo 45.1 LOIMH se establece que las medidas dirigidas a evitar cualquier tipo de discriminación laboral entre mujeres y hombres deberán ser negociadas y acordadas con los representantes de los trabajadores en la forma que se determine en la legislación laboral. Este deber deriva del artículo 4.2 c) TRLET, en el que se reconoce el derecho de los trabajadores a no ser discriminados directa o indirectamente para el empleo, o una vez empleados, por razones de sexo. Según la legislación laboral a que se refiere el artículo 45.1 LOIMH, concretamente el artículo 85.1 párrafo segundo TRLET, "sin perjuicio de la libertad de las partes para determinar el contenido de los convenios colectivos, en la negociación de los mismos existirá, en todo caso, el deber de negociar medidas dirigidas a promover la igualdad de trato y de oportunidades entre mujeres y hombres en el ámbito laboral o, en su caso planes de igualdad (...)". Se impone la obligación de negociar, lo que supone la modificación parcial del marco jurídico de la negociación colectiva. Sin embargo, la obligación de negociar no implica el deber de llegar a un acuerdo, de ahí que las medidas de igualdad no formen parte del contenido mínimo de los convenios colectivos previsto como obligatorio en el artículo 85.3 TRET. Una interpretación sistemática del deber de adoptar medidas y del deber de negociarlas regulados en los artículos 45.1 LOIMH y en el artículo 85.1 párrafo segundo TRLET, lleva a la conclusión de que se trata de deberes sucesivos, de manera que la adopción de tales medidas, entendidas en sentido amplio, requiere que se haya satisfecho 
previamente el deber de negociarlas. El fracaso de la negociación legitimaría al empresario al establecimiento de manera unilateral de las medidas destinadas a evitar cualquier tipo de discriminación. Conviene precisar que lo que el empresario podrá hacer de manera unilateral es adoptar medidas en favor de la igualdad de trato y no discriminación, sin que pueda en ningún caso adoptar de forma unilateral acciones positivas, ya que éstas suponen una excepción a lo previsto en el artículo $14 \mathrm{CE}$, y de conformidad con el artículo 8.12 del Texto Refundido de la Ley sobre Infracciones y Sanciones del Orden Social ${ }^{610}$ hacer lo contrario es constitutivo de infracción administrativa. Por lo que según un sector de la doctrina, el legislador debería haber contemplado una infracción administrativa específica si quería dotar de efectividad al deber de negociar ${ }^{611}$.

Además, a la luz del artículo 43 LOIMH las acciones positivas tienen un carácter voluntario, en el sentido de que la ley no puede imponerlas al empresario privado, aunque una vez que se pactan en el convenio pasan a ser de obligado cumplimiento, despejándose cualquier duda entorno a su legitimidad jurídica. Efectivamente, según este precepto "mediante la negociación colectiva se podrán establecer medidas de acción positiva para favorecer el acceso de las mujeres al empleo (...)".

\footnotetext{
${ }^{610}$ Boletín Oficial del Estado núm. 189 de 8 de agosto de 2000.

${ }^{611}$ Cordero González, Julio. Las medidas y los planes de igualdad: ¿Hacia un sistema de gestión de la igualdad efectiva de mujeres y hombres en la empresa?, en Reguero Celada, Justo y Ascensión García Trascasas, coordinadores. Hacia la igualdad efectiva entre hombres y mujeres (Estudios). Comares, Granada, 2008, págs. 259-261.
} 
La LOIMH ha establecido por primera vez en nuestro ordenamiento jurídico previsiones normativas en favor de adoptar medidas de acción positiva como forma de promover la igualdad sustancial entre hombres y mujeres, sobre todo en lo que al acceso al empleo se refiere. Así, el artículo 11.1 LOIMH reconoce de manera genérica la validez jurídica de las acciones positivas y permite a los poderes públicos la adopción de "medidas específicas en favor de las mujeres para corregir situaciones patentes de desigualdad de hecho respecto de los hombres”. Estas medidas son temporales, es decir, "serán aplicables en tanto subsistan dichas situaciones", y además "habrán de ser razonables y proporcionadas en relación con el objetivo perseguido en cada caso". Se considera que son razonables si su adopción responde a la eliminación de las condiciones de histórica desigualdad a la que tiene que enfrentarse el colectivo femenino. Es decir, que con las acciones positivas no se pretende acabar con un acto discriminatorio concreto de tipo individual, sino con la posición de inferioridad a la que durante siglos han estado sometidas las mujeres por el mero hecho de serlo y que se traduce en una serie de disfunciones en el funcionamiento de nuestra sociedad actual. Además, serán proporcionadas si permiten obtener como resultado la eliminación de los efectos de discriminaciones pasadas, y prevenir las presentes y futuras ${ }^{612}$. De todo esto se deduce la importancia de justificar, caso por caso, la adecuación e

${ }^{612}$ Fabregat Monfort, 2008, págs. 162-166. 
idoneidad de las medidas de acción positiva para eliminar tratos discriminatorios ante la ineficacia de otros mecanismos de tutela.

En relación con el empleo público, y sólo para la Administración General del Estado, el artículo 60 LOIMH contempla las medidas de acción positiva en las actividades de formación y de promoción a puestos directivos en la Administración General del Estado. Al amparo de la Disposición Adicional Octava apartado primero EBEP y del artículo 11.1 LOIMH, a través de la negociación colectiva se podrían ampliar los supuestos a los que se aplican las acciones positivas en todas las Administraciones Públicas. Sólo hace falta un compromiso real de los poderes públicos con los fines del Estado social para que la adopción de las medidas de acción positiva no se haga depender única y exclusivamente de los medios financieros existentes, ni se encuentren siempre condicionadas por debates políticos partidistas no siempre fructíferos en sentido positivo.

En todo caso, para que estas medidas puedan considerarse lícitas deben respetar los límites derivados de la jurisprudencia, tanto del Tribunal de Justicia de la Unión Europea, a la que se ha hecho referencia en el epígrafe VI de este trabajo, como de nuestro Tribunal Constitucional, destacando la sentencia de la sala segunda número 128/1987 de 16 de julio. En esta sentencia se parte de la existencia de un régimen de prestaciones en concepto de guardería aplicado por el Instituto Nacional de la Salud, en el 
que se establece una diferenciación en el tratamiento dispensado a los trabajadores según sean hombres o mujeres. De este modo, mientras que todas las trabajadoras con independencia de su estado civil y con hijos menores de seis años perciben una prestación por guardería, sólo los hombres viudos con hijos de esa edad perciben tal prestación. En este punto conviene señalar que "si bien la dirección de una empresa no está vinculada por un principio absoluto de igualdad de trato, ello no excluye la prohibición de distinciones basadas en factores que el ordenamiento catalogue como discriminatorias; prohibición que debe de operar de forma más intensa cuando se trata de un empleador de carácter público,613. Por ello el Tribunal Constitucional afirma que "la protección de la mujer por sí sola no es razón suficiente para justificar la diferenciación, ni es suficiente tampoco que el sujeto beneficiario de la protección sea la mujer, en cuanto tal mujer, pues ello en tales términos es evidentemente contrario al artículo 14 de la CE ${ }^{, 614}$. Así, la desigualdad de trato llevada a cabo por los poderes públicos tendrá su fundamento en la necesidad de remediar la situación de determinados grupos sociales definidos, entre otras características, por el sexo, y colocados en posiciones de desventaja en el ámbito laboral por razones que resultan de hábitos y tradiciones profundamente arraigados en la sociedad y que difícilmente se pueden eliminar por sí solos. En efecto, el tránsito de la igualdad "de iure" a la igualdad

\footnotetext{
${ }^{613}$ FJ 3 de la STC $128 / 87$, de 16 de julio.

${ }^{614}$ FJ 6 de la STC $128 / 87$, de 16 de julio.
} 
"de facto" supone permitir el establecimiento de un "derecho desigual igualatorio" y la adopción de medidas que reequilibren situaciones sociales discriminatorias preexistentes para asegurar el goce efectivo del derecho a la igualdad por parte de la mujer ${ }^{615}$.

El Tribunal Constitucional ha fallado en esta sentencia que el "hoy recurrente no se encuentra en la misma posición que el conjunto social que toma como punto de referencia y que el tratamiento desigual otorgado a éste no constituye una discriminación prohibida por el artículo 14 de la $\mathrm{CE}{ }^{\$ 616}$. Y es que "no pueden considerarse discriminatorias las medidas tendentes a favorecer el acceso al trabajo de un grupo en situación de clara desigualdad social, y que traten de evitar, mediante la concesión de ayudas económicas para el pago de guarderías, que una práctica social discriminatoria se traduzca en un apartamiento del trabajo de la mujer con hijos pequeños ${ }^{\text {\$17 }}$. Álvarez del Cuvillo ha puesto de manifiesto el efecto "boomerang" de este fallo, ya que el plus de guardería para "mujeres y hombres viudos" tiende a reproducir el estereotipo social de que la función de la mujer es el cuidado de los hijos y las hijas. Aunque tal observación sea acertada, esta es una de las medidas de acción positiva que menos perjudicarían al varón, si se compara por ejemplo con las cuotas en la promoción a puestos directivos. Además, si se consiguiera que los costes

\footnotetext{
615 Sánchez Trigueros, Carmen y Antonio V. Sempere Navarro. Comentarios a la Ley Orgánica 3/2007 de 22 de marzo para la Igualdad Efectiva de Mujeres y Hombres. Aranzadi, Cizur Menor, 2008, pág. 50.

${ }^{616} \mathrm{FJ} 11$ de la STC $128 / 87$, de 16 de julio.

${ }^{617}$ FJ 10 de la STC 128/87, de 16 de julio.
} 
económicos de esta medida los soportara no el empresario, sino toda la sociedad a través de impuestos establecidos específicamente con esta finalidad, esto contribuiría a tomar conciencia de que la maternidad y el cuidado de los hijos es una cuestión de la que todos los ciudadanos debemos hacernos responsables.

Antes de adoptar una medida concreta de acción positiva hay que realizar un estudio previo de los sectores en los que se pretende su aplicación. Para que la adopción de medidas de acción positiva no resulte contraria al artículo 14 de la Constitución Española debe constatarse que existe una situación de real desigualdad o infrarrepresentación de un colectivo en un ámbito concreto, en nuestro caso en el acceso al empleo público. No obstante, aunque es cierto que en la Administración Pública no se plantean, al menos de forma evidente y a juzgar por los datos objetivos consultados ${ }^{618}$, problemas de igualdad de oportunidades en el acceso al empleo, no ocurre lo mismo en materia de promoción profesional, siendo los hombres los que suelen alcanzar los puestos de mayor responsabilidad. Es pues en estos casos donde estaría justificada la aplicación de las medidas de acción positiva, y donde pueden ser un instrumento eficaz para la consecución de la igualdad real y efectiva. Todo ello sin perder de

618 Datos consultados en el Boletín Estadístico del personal al servicio de las Administraciones

Públicas: http://www.seap.minhap.gob.es/dms/es/publicaciones/centro_de_publicacion es_de_la_sgt/Periodicas/parrafo/Boletin_Estadis_Personal/Bol_estad_persener12-INTERNET.pdf. 
vista su carácter provisional al que ya se ha hecho referencia, por lo que se mantienen sólo mientras la situación de desigualdad persista. Así se desprende también de la lectura de la Convención sobre la eliminación de todas las formas de discriminación contra la mujer, por lo que de ningún modo entrañarán el mantenimiento de normas desiguales y cesarán cuando se hayan alcanzado los objetivos de igualdad de oportunidades y trato $^{619}$.

Asimismo, la preferencia en favor de las mujeres no puede ser absoluta, no pueden violar los principios de mérito y capacidad que se contemplan en el artículo 23.2 CE, sino que debe haber "igualdad de condiciones de idoneidad", tal y como se establece por el artículo 17.4 TRLET introducido por la Disposición adicional 11 de la LOIMH. Esta "igualdad de condiciones de idoneidad" debe entenderse referida a "méritos de igual valor" ya que resulta prácticamente imposible encontrar dos personas que reúnan exactamente los mismos méritos. $\mathrm{Y}$ es que la finalidad de estas medidas no es perjudicar a los hombres sino lograr una sociedad más democrática poniendo fin a la histórica discriminación a la que se han visto sometidas las mujeres, de tal manera que existiendo dos personas candidatas de distinto sexo con méritos de igual valor, la perjudicada, por no seleccionada, no sea la mujer.

\footnotetext{
${ }^{619}$ Artículo 4.1 de la Convención sobre la eliminación de todas las formas de discriminación contra la mujer adoptada por la Asamblea General de Naciones Unidas en su Resolución 34/180 de 18 de diciembre de 1979.
} 
Por último, a pesar de que las medidas de acción positiva respeten estos límites y de que puedan considerarse lícitas, ello no obsta para que siempre hayan sido duramente criticadas. Para paliar estas críticas, el artículo 17.4 segundo párrafo TRET contempla estas acciones desde una perspectiva neutra, es decir, admite la posibilidad de aplicarlas a los hombres siempre que éstos sean el sexo menos representado en la categoría o grupo profesional en la que se pretenda su establecimiento, y que podrán adoptar la forma de reservas o preferencias en los diferentes elementos que integran el concepto, amplio, de acceso al empleo, y que son las condiciones de contratación, de clasificación profesional, la promoción y formación.

El hecho de que vayan destinadas también a los hombres tiene el efecto positivo de terminar también con la segregación horizontal que caracteriza a determinadas funciones feminizadas y propiciar un sistema cultural diferente ${ }^{620}$, en el que la mujer deje de vincularse con empleos que reproducen en el ámbito público los roles que han desempeñado tradicionalmente en la esfera privada. Además, se evita que estas medidas se perciban de manera negativa, como ha sucedido hasta ahora, contribuyendo a degradar la valoración social del trabajo de las mujeres. Por otro lado, la existencia de una situación previa sistemática desigualdad en la

\footnotetext{
${ }^{620}$ Nevado Fernández, $\mathrm{M}^{\mathrm{a}}$ José. El derecho a la igualdad y no discriminación por género en las relaciones de trabajo, en Figueruelo Burrieza, Ángela, coordinadora. Las mujeres en la Constitución Europea: estudios multidisciplinares de género. Universidad de Salamanca, Salamanca, 2005, pág. 167.
} 
contratación en perjuicio de las mujeres y su permanencia se mantienen como criterios que fundamentan esta clase de medidas, pero éstas no operan en beneficio exclusivo de las mujeres sino también de los hombres. Por este motivo, para un sector de la doctrina los requisitos de infrarrepresentación y su permanencia, no deben comprobarse con carácter previo a la estipulación de las medidas de acción positiva, sino más bien a la hora de su aplicación comprobando que quien va a beneficiarse de ellas pertenece al "sexo menos representado" "21. Basta con verificar en el momento de su aplicación que en relación con un determinado puesto de trabajo, y en "igualdad de condiciones de idoneidad" las mujeres o los hombres son el género menos representado. No obstante, si lo que se persigue también es reducir la tasa de paro femenina, la perspectiva neutra quizás no sea lo más conveniente, por lo que podría valorarse su aplicación solamente en sectores con presencia mayoritaria de hombres, para que en sectores feminizados las mujeres no quedaran en desventaja, a partir de la necesidad prioritaria de reducir su tasa de paro $^{622}$.

\footnotetext{
${ }^{621}$ Sanguineti Raymond, 2011, pág. 52.

622 Bonino Covas, Carla y Jorge Aragón Medina. La negociación colectiva como instrumento para la igualdad laboral entre mujeres y hombres. Ministerio de Trabajo y Asuntos Sociales, Madrid, 2003, pág. 197.
} 



\section{LOS PLANES DE IGUALDAD.}

La Disposición Adicional Octava apartado segundo EBEP establece que, sin perjuicio de la obligación de las Administraciones Públicas de adoptar las medidas que sean necesarias para evitar cualquier tipo de discriminación laboral entre mujeres y hombres, éstas "deberán elaborar y aplicar un plan de igualdad a desarrollar en el convenio colectivo o acuerdo de condiciones de trabajo del personal funcionario que sea aplicable". El EBEP no hace distinción entre Administraciones Públicas en función del tamaño de las mismas, por lo que todas, incluso aquellas Administraciones Locales en las que sólo haya uno o dos empleados públicos, estarán obligadas a aprobar un Plan de Igualdad. El instrumento jurídico en el que se negociará el Plan de Igualdad será el convenio colectivo, si hablamos de personal laboral, y el acuerdo marco, si se trata de personal funcionario. Sin embargo, no encontramos en el texto del EBEP una definición de los planes de igualdad ni cómo llevar a cabo la elaboración de los mismos.

En el caso de la Administración General del Estado, el artículo 64 LOIMH ha sido un poco más preciso al establecer la obligación de elaborar un Plan de Igualdad que "será objeto de negociación, y en su caso acuerdo, con la representación legal de los empleados públicos en la forma en que se determine en la 
legislación sobre negociación colectiva en la Administración Pública (...)". A pesar de ello, entre las materias objeto de negociación del artículo $37 \mathrm{EBEP}$, no se incluye la elaboración de un Plan de Igualdad, ni se hace referencia a la forma concreta de negociarlo.

Por tanto, la legislación aplicable en el ámbito de la Administración Pública en relación con los Planes de Igualdad es prácticamente inexistente.

Fuera del ámbito de la Administración pública, las empresas también están obligadas a respetar la igualdad de trato y de oportunidades en el ámbito laboral y, con esta finalidad deberán negociar y en su caso acordar con los representantes de los trabajadores las medidas dirigidas a evitar cualquier tipo de discriminación laboral entre mujeres y hombres, que se concretan, según el artículo 45.2 LOIMH, en la elaboración y aplicación de un Plan de Igualdad. Será obligatoria su elaboración cuando se trate de empresas de más de doscientos cincuenta trabajadores, cuando así se establezca en el convenio colectivo o así lo haya dispuesto la autoridad laboral. Sin embargo surgen dudas sobre cómo articular la adopción de los planes de igualdad con el deber de negociarlos, ya que podría suceder que aún cumpliendo el deber de negociar no se llegue a un acuerdo. Como ya se ha hecho referencia anteriormente, esto no eximiría al empresario del deber de adoptar las medidas y planes de igualdad a que se refiere el 
artículo 45.1 LOIM, y ello porque las previsiones del artículo 45.1 LOIMH no tiene "un carácter meramente programático conectado de forma indisoluble a la obligación primaria constituida por el deber de negociar esas medidas" ${ }^{2023}$, sino que establecen un deber general que obliga al empresario a adoptar tales medidas. De manera que si ha habido negociación pero no se ha llegado a un acuerdo, esto le legitima para imponerlas unilateralmente, haciendo uso de su poder de dirección en beneficio de la igualdad entre hombres y mujeres en el empleo. Es decir, que el empresario tendrá que elaborar y aplicar un plan de igualdad aunque el proceso negociador finalice sin acuerdo. Aunque, como ya se ha puesto de manifiesto, lo que el empresario podrá hacer de manera unilateral es adoptar medidas en favor de la igualdad de trato y no discriminación, a excepción de las acciones positivas.

\subsection{Plan DE IgUaldad. Concepto y Fases DE ELABORACIÓN.}

Encontramos una definición de los Planes de Igualdad en el artículo 46.1 LOIMH, según el cual "los planes de igualdad de las empresas son un conjunto ordenado de medidas, adoptadas después de realizar un diagnóstico de la situación, tendentes a alcanzar en la empresa la igualdad de trato y de oportunidades entre hombres y mujeres y a eliminar la discriminación por razón de sexo". Este precepto continúa diciendo que "los planes de

${ }^{623}$ Cordero González, 2008, págs. 256. 
igualdad fijarán los concretos objetivos de igualdad a alcanzar, las estrategias y prácticas a adoptar para su consecución, así como el establecimiento de sistemas eficaces de seguimiento y evaluación de los objetivos fijados". Definición que puede extenderse a los planes de igualdad de la Administración Pública.

Si tenemos en cuenta el artículo 46.1 de la LOIMH, el Plan de Igualdad debe partir de una primera fase ineludible y básica que es la de la elaboración de un diagnóstico de la situación de la empresa o de la Administración pública en nuestro caso, en relación con la igualdad de oportunidades entre hombres y mujeres, durante la cual se realizan de forma sucesiva actividades de recogida de información y de análisis para finalmente, formular una serie de propuestas que puedan integrarse en el Plan de Igualdad. El diagnóstico no es un fin en sí mismo, sino que tiene un carácter instrumental, para identificar ámbitos específicos de actuación. En esta fase se analiza, desde una perspectiva de género, es decir, teniendo en cuenta los condicionantes sociales asignados a cada sexo, una serie de materias que coinciden con cada uno de los elementos que integran el concepto amplio de acceso al empleo público. En esta primera fase lo más correcto sería referirnos a los planes como Planes "para" la igualdad, mientras que una vez puesto en marcha y en fase de analizar los resultados, se podría 
utilizar mejor la preposición "de", es decir, que "el uso de la preposición cambia cuando el plan da resultado" ${ }^{24}$.

En el artículo 46.2 LOIMH hace una enumeración que no es taxativa sobre las posibles áreas de intervención de los planes de igualdad, y que también pueden ser de aplicación a la hora de elaborar un plan de igualdad en la Administración Pública. Estas materias son el "acceso al empleo, la clasificación profesional, promoción y formación, retribuciones, ordenación del tiempo de trabajo para favorecer, en términos de igualdad entre mujeres y hombres, la conciliación laboral, personal y familiar, y prevención del acoso sexual y del acoso por razón de sexo". Es decir, se trata de conocer y comprender por qué se producen desigualdades en cada uno de los elementos que conforman el concepto amplio de acceso al empleo público, así como de dar soluciones concretas a las posibles conductas discriminatorias ligadas a esos elementos. Y además, que esas soluciones se pongan en práctica y sean efectivas para erradicar discriminaciones.

Adicionalmente se analiza también desde la perspectiva de género la política de gestión de personal de la Administración Pública, el interés en la cuestión de la igualdad de trato y de oportunidades por parte de las autoridades y personal al servicio

${ }^{624}$ Nevado Fernández, Ma José. La igualdad a través de los planes: de los planes "para" la igualdad a los planes "de", en Figueruelo Burrieza, Ángela, directora y $\mathrm{M}^{\mathrm{a}}$ Luisa Martín Hernández, coordinadora. Perspectiva de género en la negociación colectiva: análisis por sectores feminizados y masculinizados. Bomarzo, Albacete, 2013, pág. 295. 
de las Administraciones públicas que ocupen puestos directivos y por tanto, con capacidad para tomar decisiones favorables en este sentido, la composición de los órganos de representación del personal y su implicación en la consecución de la igualdad de oportunidades, así como el lenguaje empleado en la Administración.

Además, de conformidad con el artículo 48.1 LOIMH habrán de incorporarse medidas específicas para "promover condiciones de trabajo que evite el acoso sexual y el acoso por razón de sexo y arbitrar procedimientos específicos para su prevención y para dar cauce a las denuncias y reclamaciones" por estos motivos.

Tras la evaluación de la realidad realizada en el diagnóstico y en atención a los concretos resultados que ésta arroje, se redactará un informe en el que se reflejarán las propuestas de medidas para corregir las situaciones discriminatorias detectadas, si las hubiese, y las causas que las provoquen, según se desprende de los datos obtenidos ${ }^{625}$. Toda esta información servirá para el diseño del borrador de Plan de Igualdad, que en cumplimiento del principio de transparencia al que alude expresamente el artículo 47 LOIMH, será accesible a la representación legal de los trabajadores.

\footnotetext{
${ }^{625}$ Núñez-Cortés Contreras, Pilar. Nociones básicas sobre igualdad en las relaciones laborales. Guía para la empresa y Administraciones Públicas. Tecnos, Madrid, 2009, págs. 43-45.
} 
En el Plan ya elaborado se distinguen los objetivos que se propone alcanzar, que deben ser realistas y concretos; las prácticas y estrategias necesarias para lograr los objetivos señalados y un sistema eficaz de seguimiento y evaluación de los objetivos ${ }^{626}$.

La siguiente fase es la de la implantación del Plan de Igualdad y que consiste en poner en marcha aquellas estrategias y prácticas previstas en el mismo. El Plan de Igualdad no es una mera declaración formal de la igualdad, sino que supone la plasmación específica del conjunto de medidas que se requieren para garantizar la igualdad real ante unas circunstancias concretas. Y finalmente la fase de control y aplicación del Plan que deberá apoyarse en los sistemas de seguimiento y evaluación de los objetivos previstos inicialmente.

\subsection{Plan ESTRATÉGico DE IGUALDAD DE OPORTUNIDADES.}

Junto a estos planes de igualdad que debe elaborar la Administración Pública para garantizar la igualdad de trato y de oportunidades en el interior de su organización, encontramos otro tipo de planes, que son elaborados a instancia de la propia Administración en ejercicio de su actividad de fomento de la igualdad, y que irían dirigidos al exterior de su propia organización, como un conjunto de propuestas que pueden ser adoptadas en 
diferentes ámbitos de la sociedad para superar la brecha aún existente entre la igualdad legal y la igualdad real.

La Ley Orgánica 3/2007, de 22 de marzo, establece el fundamento jurídico para avanzar hacia la efectiva igualdad en todos los ámbitos de la vida social, económica, cultural y política. $\mathrm{Su}$ aplicación requiere de un Plan Estratégico que concrete los objetivos, ámbitos y medidas de actuación en los que los poderes públicos han de centrar sus acciones. La coordinación entre los distintos niveles de Administraciones Públicas y los distintos estamentos sociales hace necesario la elaboración de dicho Plan Estratégico. Así, el artículo 17 LOIMH establece que "el Gobierno, en las materias que sean de la competencia del Estado, aprobará periódicamente un Plan Estratégico de Igualdad de Oportunidades, que incluirá medidas para alcanzar el objetivo de igualdad entre mujeres y hombres y eliminar la discriminación por razón de sexo". De este modo, el 17 de diciembre de 2007 el Consejo de Ministros aprobó el Plan Estratégico de Igualdad de Oportunidades para el periodo $2008-2011^{627}$.

El Plan Estratégico de Igualdad de Oportunidades se inspira en los principios básicos de igualdad y no discriminación, y en cuatro principios rectores relacionados entre sí, como son el de ciudadanía, empoderamiento, transversalidad e innovación.

${ }^{627}$ El texto del Plan Estratégico puede consultarse en la siguiente dirección http://www.csd.gob.es/csd/estaticos/myd/PlanEstrategico2008-2011.pdf. 
En primer lugar se lleva a cabo una redefinición del modelo de ciudadanía en concordancia con la igualdad de género, que entiende la igualdad más allá de la equiparación de lo femenino con lo masculino y considera lo femenino como riqueza, es decir, que lo que la mujer tiene de propio es algo bueno y que debe ser valorado positivamente. El concepto de ciudadanía no se limita a la participación en el poder político, sino que se extiende al disfrute de los derechos civiles y sociales. Esto significa que el mero reconocimiento de los derechos no es suficiente. Es necesario un claro compromiso para erradicar la discriminación indirecta, lo que implica trabajar por la representación de las mujeres para que puedan optar a ser elegidas en todas las estructuras y a todos los niveles, en igualdad de condiciones ${ }^{628}$.

En segundo lugar el concepto de empoderamiento de las mujeres, el cual se refiere a su capacidad para acceder a aquellos puestos en los que se toman decisiones, así como a la revalorización de la aportación de las mujeres. Este concepto, al igual que el de ciudadanía, se vincula directamente con el de autonomía, es decir, con el reconocimiento por parte de la sociedad en su conjunto de la capacidad de las mujeres para adoptar sus propias decisiones, y con el de corresponsabilidad, el cual va más allá del de conciliación. La idea de corresponsabilidad social es una pieza clave en el desarrollo del contenido del Plan

${ }^{628}$ Plan Estratégico de Igualdad de Oportunidades, 2008-2011, pág. 6. 
Estratégico de Igualdad de Oportunidades. Si la conciliación se entiende como la posibilidad de que las mujeres compatibilicen la esfera privada y la pública, el concepto de corresponsabilidad se refiere a la necesidad de que hombres y mujeres, titulares de los mismos derechos, se erijan, al mismo tiempo, en responsables de similares deberes y obligaciones en los escenarios público y privado, en el mercado laboral, en las responsabilidades familiares y en la toma de decisiones ${ }^{629}$. Se trata de aumentar no sólo la implicación de los hombres en la realización efectiva de la igualdad de género, sino también la de los agentes sociales e instancias públicas y privadas, de manera que se establezca un nuevo modelo de relaciones sociales que no implique la subordinación de las mujeres. El objetivo es promover el desarrollo de un modelo de convivencia familiar y social más igualitaria, incorporando el principio de igualdad de oportunidades a las relaciones afectivas y de convivencia doméstica, y sobre todo sensibilizando a los hombres para que hagan uso de sus derechos de paternidad, de excedencia por cuidado de hijos y personas dependientes, o del derecho a la jornada de trabajo a tiempo parcial.

En tercer lugar, la transversalidad de la perspectiva de género. La transversalidad alude a la necesidad de que los poderes públicos se impliquen de forma integral para incorporar la dimensión de género en todas sus actuaciones, de tal forma que la adopción de toda decisión sea normativa o ejecutiva, necesitará de un estudio

${ }^{629}$ Plan Estratégico, 2008-2011, pág. 7. 
previo sobre su impacto diferencial en mujeres y hombres, así como de la reestructuración de los sistemas de toma de decisiones para que acepten la perspectiva de las diferencias de género ${ }^{630}$.

Por último, la innovación científica y tecnológica entendida como una de las principales fuerzas de cambio social. Y es que para superar el dominio masculino del sistema ciencia-tecnología, del diseño y funciones de sus productos, es esencial el acceso de las mujeres al núcleo duro de la práctica científica, tecnológica y de usuaria, para que la remodelen, introduciendo la perspectiva y las necesidades de las mujeres ${ }^{631}$.

Estos cuatro principios inspiradores ordenan y articulan el contenido del Plan Estratégico de Igualdad de Oportunidades, el cual comprende diferentes ámbitos como la participación política y social, la participación económica, la corresponsabilidad, la educación, innovación y conocimiento, la salud, la imagen, la atención a la diversidad e inclusión social, violencia, política exterior y de cooperación para el desarrollo y la tutela del derecho a la igualdad.

Algunos de estos ámbitos ya han sido objeto de estudio por su relación directa con el acceso al empleo público, por eso en este momento sólo nos detenemos en uno de ellos, concretamente en

\footnotetext{
${ }^{630}$ Plan Estratégico, 2008-2011, pág. 7 y 8.

631 Plan Estratégico, 2008-2011, pág. 8.
} 
el sistema educativo, por su importancia para superar las limitaciones estereotipadas de los roles, permitiendo un desarrollo más equilibrado y libre de la personalidad y el acceso a las mismas oportunidades, ayudando a construir relaciones entre los sexos basadas en el respeto y la corresponsabilidad e impulsando la participación de hombres y mujeres en todos los espacios de la sociedad $^{632}$.

En el artículo 23 LOIMH se hace referencia expresamente a la educación para la igualdad de mujeres y hombres, en el artículo 24 LOIMH a la integración del principio de igualdad en la política de educación. Entre las diversas actuaciones que pueden llevarse a cabo en este campo podemos destacar la edición del material educativo en el que se incluya la perspectiva de género, se haga un uso no sexista del lenguaje y de las imágenes, y se incorpore el saber de las mujeres y su contribución social e histórica al desarrollo de la humanidad; la garantía de una educación para la igualdad y desde la igualdad entre hombres y mujeres; y el fomento del diseño y la realización de programas de orientación al estudio no sexista, que promuevan la elección de estudios de forma no discriminatoria $^{633}$.

El artículo 25 de la LOIMH también regula la igualdad en el ámbito de la educación superior mediante la promoción por las

\footnotetext{
632 Plan Estratégico, 2008-2011, pág. 39.

633 Plan Estratégico, 2008-2011, pág. 44.
} 
Administraciones Públicas de estudios e investigaciones especializadas en la materia ${ }^{634}$.

La vigencia de este Plan Estratégico ya ha finalizado, por lo que es necesario proceder a su evaluación y poner en marcha lo más rápido posible la elaboración del un nuevo plan, que incluya nuevas propuestas para seguir avanzando en la igualdad entre hombres y mujeres. La Coordinadora de Organizaciones de Mujeres para la Participación y la Igualdad (COMPI) ha realizado una evaluación del Plan Estratégico 2008-2011 y formulado propuestas para un nuevo plan ${ }^{635}$, que desafortunadamente a día de hoy todavía no se ha aprobado. Sin embargo, el 29 de mayo de 2013, la ministra de Sanidad, Servicios Sociales e Igualdad ha presentado, durante su comparecencia en la Comisión de Igualdad del Congreso de los Diputados, el nuevo Plan Estratégico para el periodo 2013-2016 sin que todavía se tenga acceso al texto íntegro del mismo. La crisis económica no puede ser el pretexto ni la excusa para frenar el avance de la sociedad hacia la igualdad. La igualdad, como ya hemos visto en la primera parte de este trabajo, es un valor superior del ordenamiento jurídico, es un principio, es un derecho fundamental, y por lo tanto no es una cuestión residual que sólo afecta a las mujeres.

\footnotetext{
${ }^{634}$ Cabero Morán, Enrique, Ascensión García Trascasas y Justo Reguero Celada. Consideración especial del impacto de la Ley Orgánica 3/2007 en el sistema normativo e institucional del Espacio Europeo de Educación Superior en España, en Palomeque López, Manuel Carlos, director. Igualdad efectiva de mujeres y hombres. Ratio Legis, 2011, págs. 167-190.

635 http://www.compi.org/evaluacion_peiomh.pdf
} 


\subsection{Plan DE IgUALDAD DE OPORTUNidAdes ENTRE HOMBRES Y MUJERES DE CASTILLA Y LEÓN.}

A nivel autonómico se ha aprobado por Decreto 1/2007 de 12 de enero el IV Plan de Igualdad de Oportunidades entre Mujeres y Hombres en Castilla y León ${ }^{636}$, el cual es expresión de la voluntad política regional dirigida a la consecución de una igualdad real y efectiva entre mujeres y hombres, considerado como una herramienta para producir cambios sociales positivos en esta materia.

Este Plan se estructura en siete áreas de intervención que son el área de transversalidad, imprescindible para afianzar la igualdad de género en las políticas generales de la Junta de Castilla y León; el área de empleo y formación, para lograr la igualdad entre mujeres y hombres en el acceso, permanencia y promoción en el trabajo, así como en el control de los recursos económicos; el área de salud y calidad de vida; el área de sensibilización, educación y medios de comunicación para afianzar valores educativos y culturales para la igualdad de mujeres y hombres; el área de participación y acceso al poder; y un área específica para la mujer en el medio rural y otra para la mujer con problemática específica.

\footnotetext{
${ }^{636}$ Boletín Oficial de la Junta de Castilla y León núm. 12 de 17 de enero de 2007.
} 
Recientemente, por Acuerdo 35/2013 de 16 de mayo se ha aprobado el I Plan Autonómico para la Igualdad de Oportunidades entre Mujeres y Hombres y contra la Violencia de Género en Castilla y León con un periodo de vigencia de 2013 hasta $2018^{637}$. Uno de los principios rectores de este Plan es el de unidad, según el cual se presenta un plan único en el que se aborda la desigualdad entre mujeres y hombres y la violencia de género de forma conjunta, puesto que se considera que la violencia de género es la máxima expresión de desigualdad entre mujeres y hombres. Otros principios que han inspirado la elaboración de este plan son los de enfoque integral, por el que se abordan todos los ámbitos donde se puedan manifestar la desigualdad y la violencia de género; el de transversalidad de la perspectiva de género, superando el enfoque basado en acciones específicas en favor de las mujeres; el principio de empoderamiento de las mujeres, dirigido a valorar y fortalecer la autonomía de las mujeres, la forma de ejercer el poder $y$ de relacionarse, incorporando sus perspectivas, necesidades e intereses, facilitando el ejercicio activo de sus derechos y su acceso a la toma de decisiones; el refuerzo del diálogo social para contribuir al logro de la igualdad real y efectiva; participación de toda la sociedad en la consecución de la igualdad y atención a la diversidad, puesto que hay mujeres que por su origen racial, por ser discapacitadas, por tener menos recursos económicos, etc., sufren una doble discriminación.

637 Boletín Oficial de la Junta de Castilla y León núm. 94 de 20 de mayo de 2013. 
Las áreas de intervención de este nuevo plan son seis, desapareciendo el área de conciliación de la vida laboral, personal y familiar que aunque sigue considerándose como un ámbito de actuación de gran importancia para la igualdad de oportunidades no se aborda específicamente en este Plan, sin que los motivos alegados sean suficientes, desde mi punto de vista, para justificar su exclusión ${ }^{638}$. La facilidad para conciliar la vida laboral, personal y familiar sigue siendo un elemento básico para la igualdad de oportunidades. La escasez de medidas de conciliación o el temor a las consecuencias negativas que para la carrera profesional pueden derivarse del ejercicio de estos derechos, sigue suponiendo una dificultad especial para las mujeres, que aumenta el riesgo de discriminaciones indirectas por motivos de género.

Entre las Áreas que se incluyen en el plan nos referimos, en primer lugar, al Área de política institucional de género, cuyo objetivo estratégico consiste en tener en cuenta el impacto diferencial de género que la implantación de las políticas públicas tiene en la vida de la ciudadanía. Persigue garantizar la integración de la perspectiva de género en el funcionamiento de la Administración, insistiendo en la formación en esta materia y promoviendo la cooperación entre Administraciones. Asimismo se

\footnotetext{
${ }^{638}$ En la página 14 del Acuerdo 35/2013 de 16 de mayo dice textualmente que "esto es así porque se ha optado por un modelo de planificación separada e independiente de cada uno de esos dos ámbitos", sin que se diga por qué motivo ha sido así.
} 
considera prioritario difundir entre la sociedad las diferentes manifestaciones y consecuencias de la desigualdad y la violencia de género con el fin de sensibilizar, modificar actitudes e impulsar su rechazo social.

En segundo lugar destaca el Área de participación y empoderamiento, según la cual la plena ciudadanía equivale a la igualdad de oportunidades para participar en todos los niveles de toma de decisiones de la vida pública. Entre los objetivos de este área destacan la toma de conciencia del poder que individual y colectivamente ostentan las mujeres y que tiene que ver con la recuperación de la propia dignidad de las mujeres como personas; el fomento del asociacionismo; la promoción de la participación de toda la sociedad en las políticas de igualdad y contra la violencia de género; y la difusión de la perspectiva de género entre la población juvenil.

En tercer lugar, sigue siendo fundamental el Área de educación, cultura y deporte para eliminar prejuicios y estereotipos que pueden llevar a la desigualdad, destacando el papel de los centros educativos como transmisores de valores igualitarios.

En cuarto lugar, el Área de economía y empleo que promociona la igualdad entre mujeres y hombres en el acceso, la permanencia y promoción en el trabajo, con especial atención a las mujeres con mayores dificultades de inserción. Entre los objetivos 
que se propone este área destacan el desarrollo de actuaciones que incentiven y favorezcan la elaboración de planes de igualdad en las pequeñas y medianas empresas de la región, así como la promoción en los procesos de negociación colectiva de medidas de acción positiva dirigidas a disminuir las desigualdades de género, o también el fomento de la responsabilidad social de las empresas en materia de igualdad de oportunidades y contra la violencia de género.

Por último tenemos el Área de salud y calidad de vida, centrada en mejorar las condiciones de vida de las mujeres a lo largo de todo su ciclo vital, destacando el papel de los servicios sociales y sanitarios en la prevención y atención de la violencia de género; y el Área de atención integral a las víctimas de violencia de género, capaz de dar una respuesta adecuada a las necesidades de las víctimas de la violencia de género mediante una red de servicios de calidad, que les permita alcanzar su autonomía personal y desarrollar un nuevo proyecto de vida.

En el Anexo II de este Plan se evalúa el IV Plan de Igualdad de Oportunidades entre Mujeres y Hombres de Castilla y León (2007-20011) y el II Plan contra la Violencia de Género en Castilla y León (2007-2011). Se detectan los avances producidos a partir de la evolución de los indicadores más representativos sobre la situación real y las condiciones sociales en las que viven las mujeres. Se evalúan los cambios producidos, las realizaciones y los 
resultados de ambos planes, se determinan los principales logros alcanzados identificando los casos de buenas prácticas, así como las posibles amenazas aún existentes para la igualdad.

2.4. Planes De igUALDAD EN LA ADMINISTRACiÓN LOCAL. EL PLAN DE IGUALDAD DE LA DIPUTACIÓN DE SALAMANCA.

La Ley 7/1985 de 2 de abril Reguladora de las Bases del Régimen Local, establece en su artículo 25.1 que "el Municipio, para la gestión de sus intereses y en el ámbito de sus competencias, puede promover toda clase de actividades y prestar cuantos servicios contribuyan a satisfacer las necesidades y aspiraciones de la comunidad vecinal". Por otra parte, el artículo 27.3 c) de la misma Ley, recientemente modificada por la Ley 27/2013, de 27 de diciembre, de racionalización y sostenibilidad de la Administración local $^{639}$, permite que el Estado o las Comunidades Autónomas puedan delegar en las Entidades Locales algunas competencias, entre ellas "la prestación de servicios sociales, promoción de igualdad de oportunidades y la prevención de la violencia contra la mujer", con el objeto de evitar duplicidades administrativas, mejorar la transparencia de los servicios públicos y el servicio a la ciudadanía, y en general, contribuir a los procesos de racionalización administrativa.

${ }^{639}$ Boletín Oficial del Estado núm. 312 de 30 de diciembre de 2013. 
En este sentido, la Ley 1/1998 de 4 de junio, de Régimen Local de Castilla y León ${ }^{640}$, establece en su artículo 20.1 letra n) que los municipios de Castilla y León ejercerán competencias en materia de promoción de la igualdad de la mujer en los términos que establezca la legislación del Estado y de las Comunidades Autónomas. Por su parte, la sección $2^{\mathrm{a}}$ del Capítulo II del Título I de la Ley 1/2003 de 3 de marzo de Igualdad de Oportunidades entre mujeres y hombres en Castilla y León se refiere a las competencias de las Corporaciones Locales en materia de promoción de la igualdad y asistencia a la mujer. En todo caso, serán competencias de las Diputaciones Provinciales y de los Ayuntamientos con más de 20.000 habitantes la adopción de medidas necesarias para el fomento de acciones positivas en favor de las mujeres de su ámbito territorial; la aprobación y ejecución en su respectivo ámbito, de Planes de Igualdad de Oportunidades entre Mujeres y Hombres, velando por la coordinación con las acciones, programas y servicios de la Junta de Castilla y León destinados a las mujeres, así como por la coherencia y complementariedad con los Planes Generales de la Comunidad; y el fomento de la participación y presencia de las mujeres en la vida política, social, económica y cultural en sus respectivos ámbitos de competencia $^{641}$.

\footnotetext{
${ }^{640}$ Boletín Oficial del Estado núm. 197 de 18 de agosto de 1998.

${ }^{641}$ Artículo 11 de la Ley 1/2003 de 3 de marzo de Igualdad de Oportunidades entre mujeres y hombres en Castilla y León.
} 
En la provincia de Salamanca, la Diputación de Salamanca por acuerdo de Pleno en sesión ordinaria de fecha 25 de mayo de 2006, aprobó el II Plan de Igualdad de Oportunidades que ha estado vigente durante el periodo 2007-2011 ${ }^{642}$. Este Plan se basa en ideas claves como el reconocimiento de que la igualdad es un derecho y una cuestión de justicia con las mujeres, y que si se quiere construir una sociedad más justa y democrática es imprescindible trabajar por una plena incorporación de las mujeres a todos los ámbitos de la sociedad. Se parte de la constatación de que un marco jurídico igualitario no implica la consecución de una igualdad real, por lo que el uso de acciones positivas constituye uno de los instrumentos más efectivos para corregir las situaciones de mayor desventaja. Además, al igual que sucede en los ámbitos estatal y autonómico, las actuales políticas de igualdad trasladan el centro de atención de la mujer al concepto de género, tratando de superar la construcción social que asigna, desde su nacimiento, diferentes y jerarquizados roles a hombres y mujeres. Finalmente, en todas las políticas públicas se velará para la incorporación de la perspectiva de género en la toma de decisiones, así como en la planificación, la puesta en marcha y la evaluación de las mismas.

Las áreas de intervención del Plan de Igualdad de Oportunidades de la Provincia de Salamanca serán estudiadas a continuación.

${ }^{642}$ Boletín Oficial de la Provincia de Salamanca núm. 190 de 3 de octubre de 2006. 
En primer lugar nos encontramos con el área de igualdad en la actividad económica, cuyo objetivo general es la promoción de la igualdad entre hombres y mujeres en la vida económica, especialmente en el empleo. En este sentido se promoverá el autoempleo de las mujeres apoyando sus iniciativas empresariales; se favorecerá la diversificación de opciones profesionales entre mujeres y hombres sin sesgo de género, para lo cual se prevé expresamente la promoción de proyectos innovadores de formación dirigidos a mujeres como puede ser el teletrabajo; se combatirá la discriminación de la mujer en el empleo por ejemplo mediante el conocimiento de los derechos laborales de las empleadas de hogar y mujeres migrantes; y se garantizará el acceso de la mujer a las nuevas tecnologías de la información y la comunicación a través de cursos de alfabetización informática ${ }^{643}$. En el caso de la Diputación de Salamanca destacan las subvenciones a asociaciones de mujeres de la provincia para favorecer el empoderamiento y la autonomía de las mujeres, como por ejemplo la realización de talleres para iniciarse o afianzarse en el uso de las nuevas tecnologías, o para promover la igualdad a través de cursos que sensibilicen a la sociedad sobre la necesidad de la igualdad, como por ejemplo aquellos que en los que se reflexiona y se aprenden técnicas para hacer que la

${ }^{643}$ II Plan de Igualdad de la provincia de Salamanca, págs. 25-28. 
corresponsabilidad en la tareas domésticas y en los cuidados de los hijos e hijas y personas dependientes, sea una realidad ${ }^{644}$.

En segundo lugar, el área de participación y representación tiene como objetivo fomentar una igual participación $\mathrm{y}$ representación de hombres y mujeres en los ámbitos de toma de decisiones. Como ya se ha puesto de manifiesto, una democracia plena exige la presencia equilibrada de mujeres y hombres en todos los ámbitos de toma de decisiones. Para ello se establecen como objetivos específicos una mejora del equilibrio entre hombres y mujeres en los niveles de responsabilidad, órganos de decisión y representación, para lo cual se adoptarán medidas como la formación de las mujeres en habilidades directivas, o la sensibilización a la sociedad de los beneficios de la participación equilibrada de hombres y mujeres ${ }^{645}$. Sin embargo, en el caso de la Diputación de Salamanca no hay una composición equilibrada del gobierno provincial. Esto puede ser debido a que el requisito establecido por el artículo 44 bis de la Ley Orgánica 5/1985 de 19 de junio del Régimen Electoral General (LOREG), introducido por la Disposición adicional segunda de la LOIMH, no resulta de aplicación en los pequeños municipios. Según dicho precepto, la composición de mujeres y hombres en las candidaturas que se presenten para las elecciones estatales y autonómicas deberá ser equilibrada, sin embargo, el artículo 187.2 LOREG señala que esto

\footnotetext{
${ }^{644}$ Estas subvenciones pueden consultarse en el Boletín Oficial de la Provincia de Salamanca núm. 104 de 3 de junio de 2013.

${ }^{645}$ II Plan de Igualdad de la provincia de Salamanca, págs. 29-31.
} 
no será exigible en las candidaturas que se presenten en los municipios con un número de residentes igual o inferior a 3.000 habitantes. Por lo tanto, puesto que la elección de los diputados provinciales depende de las elecciones municipales, y si los municipios de la provincia se caracterizan por su escasa población, las previsiones del artículo 44 bis serán de aplicación en muy pocos supuestos, de manera que difícilmente se alcanzará la composición equilibrada en el gobierno provincial, al menos a corto plazo.

También se crea un área específica para la conciliación de la vida personal, familiar y laboral con el objeto de promover la igualdad de acceso y el pleno disfrute de los derechos sociales para las mujeres y los hombres. Esto requiere implicar al empresario en la conciliación mediante la promoción de acuerdos de flexibilización de jornadas de trabajo; o hacer efectiva la corresponsabilidad en la realización de las obligaciones familiares $^{646}$.

Destaca el área de prevención social y atención a las situaciones de violencia con el objeto de promover la igualdad en la vida civil a través del pleno disfrute de los derechos humanos y las libertades fundamentales por parte de los hombres y mujeres. En este sentido, el Plan de Igualdad ha previsto la necesidad de atender de forma integral a las mujeres víctimas de violencia de

${ }^{646}$ II Plan de Igualdad de la provincia de Salamanca, págs. 33-35. 
género a través de medidas concretas como el acceso a las plazas de la guardería Guillermo Arce a los hijos e hijas de las víctimas de violencia de género; asimismo se incide en la necesidad de prevenir la violencia hacia las mujeres mediante campañas de sensibilización dirigidas a la sociedad ${ }^{647}$. El programa "Aprendiendo la Igualdad" que ha puesto en marcha el Área de Bienestar Social de la Diputación de Salamanca se destina a promover un modelo alternativo de relación entre las personas jóvenes basado en la igualdad de género y el respeto a las diferencias por razón de sexo, a detectar e intervenir ante situaciones de desigualdad y a prevenir la violencia.

En quinto lugar, el área de transmisión de valores y actitudes igualitarias promueve el cambio de roles y estereotipos establecidos en función del género. Los objetivos específicos de esta área son muy variados pudiendo destacar la promoción del uso no sexista del lenguaje, o la realización de proyectos de sensibilización de la población de la provincia de Salamanca en relación a la igualdad, mediante la celebración de actos en el día 8 de marzo reconocido internacionalmente como Día Internacional de la Mujer y el 25 de noviembre como Día Internacional contra la Violencia de Género ${ }^{648}$.

\footnotetext{
647 II Plan de Igualdad de la provincia de Salamanca, págs. 37-39.

${ }^{648}$ II Plan de Igualdad de la provincia de Salamanca, págs. 41-44.
} 
Por último, se incluye un área específica de igualdad en el ámbito local con el objeto de promover la implicación de las entidades locales de la provincia en el desarrollo del principio de igualdad. Para ello se llevarán a cabo programas de formación de cargos electos y personal al servicio de las administraciones locales para la adquisición de conocimientos y herramientas para la elaboración e implementación de políticas municipales de igualdad; se avanzará en la integración sistemática de la perspectiva de género en las políticas provinciales mediante la creación de una Comisión de igualdad integrada por personas responsables de la aplicación del principio de igualdad en las diferentes áreas de la Diputación; y se apoyará la planificación y ejecución de políticas de igualdad por parte de las Corporaciones Locales, a través de subvenciones para la realización de proyectos de igualdad municipales, la prestación de asesoramiento y asistencia técnica a las entidades locales en la elaboración de planes, programas y proyectos de igualdad, o de programas que sensibilicen en materia de género a todas las personas vinculadas a las Administraciones locales de la provincia ${ }^{649}$. Nuevamente el Área de Bienestar Social de la Diputación de Salamanca tiene un mayor protagonismo al impulsar programas como "Foros para la igualdad" y especialmente el programa "Igualdad en la Vida Local" que engloba todas las medidas de asistencia y cooperación económica y técnica para el desarrollo desde los Ayuntamientos de la provincia,

${ }^{649}$ II Plan de Igualdad de la provincia de Salamanca, págs. 45-46. 
de proyectos de igualdad destinados a la población de uno o varios municipios.

De este modo se observa como las Entidades Locales integran el derecho de igualdad en el ejercicio de sus competencias en los términos del artículo 21. 2 LOIMH. 



\section{OTROS INSTRUMENTOS.}

Cada vez va cobrando más fuerza la concepción del convenio colectivo como plataforma difusora de los valores de igualdad y no discriminación en el ámbito laboral y de empleo. Esta tarea de promoción de la igualdad de trato puede llevarse a cabo principalmente a través de los convenios colectivos, pero no sólo ni exclusivamente. Junto a los convenios colectivos cabe destacar los códigos de conducta, las buenas prácticas, el seguimiento de las prácticas desarrolladas en el lugar de trabajo, y la investigación y el intercambio de experiencias. Entre los instrumentos específicos de seguimiento destacan las Comisiones de Igualdad, que suponen el paso a la acción en la detección de discriminaciones y en el diseño e implementación de mecanismos correctores.

Además, la mayor exigencia del principio de igualdad en la negociación colectiva, no sólo pasa por incorporar reglas igualitarias en los contenidos de los convenios colectivos, sino también a través de la mayor exigencia de este principio por parte de la Administración al ejercer el control de legalidad de los convenios ex art. 90.5 ET, es decir, efectuando un examen de los mismos desde la perspectiva de género, incidiendo en la formación específica en materia de igualdad entre hombres y mujeres por parte de los negociadores y el incremento de la presencia y 
participación femenina en la composición de las mesas de negociación y en todo el proceso negociador ${ }^{650}$.

Por último, en relación con el ámbito local, resulta muy interesante la previsión del artículo 22 LOIMH en el que se hace referencia a acciones de planificación equitativa de los tiempos llevadas a cabo por las corporaciones locales con el fin de avanzar en hacia un reparto equitativo de los tiempos entre mujeres y hombres.

\footnotetext{
${ }^{650}$ Montoya Melgar, Alfredo. El derecho del trabajo como instrumento de igualdad de mujeres y hombres, en Sánchez Trigueros, Carmen, directora. La Presencia Femenina en el Mundo Laboral: Metas y Realidades. Aranzadi, Cizur Menor, 2006, pág. 46.
} 


IX- RETOS Y PERSPECTIVAS DE FUTURO: EL TRABAJO A DISTANCIA.

\section{CAMBIOS TECNOLÓGICOS E IGUALDAD DE GÉNERO.}

Hay dos aspectos biológicamente muy arraigados del sexo que tradicionalmente han afectado a la división sexual del trabajo y que son, la superior fuerza física masculina y la función reproductora de la mujer. Cualquier cambio tecnológico que sea capaz de alterar la exigencia de fuerza, la necesidad de movilidad prolongada y rápida, así como el periodo de atención necesario en el ámbito laboral, tiene en potencia capacidad para cambiar la composición sexual de los roles de trabajo y poder facilitar el acceso de las mujeres al trabajo remunerado ${ }^{651}$. Así como la revolución agraria sustituyó la horticultura femenina por la agricultura masculina como estructura económica principal, la revolución industrial beneficia a las mujeres puesto que las exigencias de fuerza en el trabajo no doméstico disminuyeron de manera considerable. Sin embargo, los lugares de trabajo y vivienda se separaron espacialmente, lo que dificultaba combinar la maternidad con el trabajo fuera de casa. Además el periodo de atención al trabajo fuera del ámbito doméstico en las sociedades industrializadas era mucho mayor, con largos horarios de trabajo que excluían la

651 Saltzman, 1992, págs. 165. 
posibilidad de cuidar simultáneamente de los hijos pequeños. Esto exigía, si las mujeres deseaban participar en tareas productivas, no sólo reproductivas, o bien una reducción del tamaño de la familia, es decir, un cambio demográfico que se traduce en un descenso de la natalidad en las sociedades industrializadas, o bien la puesta en marcha de políticas públicas orientadas a la creación de formas alternativas de cuidado de $\operatorname{los}$ hijos $^{652}$. Es en este periodo cuando se generaliza el trabajo a domicilio, antecedente del trabajo a distancia, y que se presenta como una forma de ahorrar costes al empresario y de hacer compatible el cuidado de los hijos con el trabajo remunerado.

En la actualidad, la realidad sociológica para la que surgió el trabajo a domicilio ha cambiado. Nos encontramos ante una nueva era que el profesor Manuel Castells ha definido como la Era de la Información ${ }^{653}$. La revolución que supone la difusión de las Tecnologías de la Información y las Comunicaciones ha influido en la concepción y características del trabajo a domicilio. Se ha pasado del trabajo manufacturero a tareas de tipo informático o aquellas que conllevan un trabajo de tipo intelectual, y su regulación legal es mucho más avanzada como se verá posteriormente.

${ }^{652}$ Saltzman, 1992, págs. 166.

${ }^{653}$ Castells, Manuel. La Era de la Información. Volumen I. La Sociedad Red. Alianza, Madrid, 1997. 
En este apartado se hará una breve referencia a la importancia de las Tecnologías de la Información y las Comunicaciones para la Administración Pública, y en concreto para su funcionamiento interno, potenciando nuevas formas de organización del trabajo, como el trabajo a distancia o teletrabajo, que contribuyen a su modernización, a una mayor productividad y a abrir nuevas vías para avanzar en la igualdad de género.

Las TIC han transformado la Administración Pública, tanto su actividad administrativa interna como su forma de relacionarse con los ciudadanos, dando lugar a un conjunto de actuaciones jurídicas y materiales para las que se ha acuñado el término de Administración electrónica o en inglés eGovernment. La Sociedad de la Información es el punto de partida de la Administración electrónica y la futura consolidación de este modo de administrar, junto con la evolución tecnológica propia de la sociedad civil, determinará el advenimiento de un nuevo modelo social denominado Sociedad del Conocimiento. Con la implantación de la Administración electrónica se quiere mejorar el funcionamiento interno y externo de la Administración.

Por lo que respecta a la mejora del funcionamiento externo, la Administración electrónica aspira a facilitar las gestiones a los ciudadanos, ayudándoles a resolver aspectos prácticos tanto en lo personal como en lo laboral, agilizar la tramitación de los expedientes administrativos, ahorrar costes, 
suprimir las barreras territoriales y potenciar la igualdad, pues conecta directamente a los ciudadanos con la Administración independientemente de su ubicación geográfica, de su nivel económico, de su edad y de su género. Sin embargo, existen amplias extensiones del territorio, como por ejemplo las zonas rurales, que se incorporan más lentamente al fenómeno, y sobre todo de grupos de población que carecen de acceso a las TIC, lo que ha dado lugar a lo que se conoce con el nombre de brecha digital y que puede agravar las desigualdades sociales ${ }^{654}$. Cuando la brecha digital se refiere a las diferencias que hay entre hombres y mujeres según su capacidad o posibilidad de utilizar las TIC de forma eficaz, se habla de brecha digital de género. Las Administraciones Públicas son responsables de impulsar políticas y programas destinados a reducirla trabajando para mejorar la motivación y la formación TIC de las mujeres. El objetivo es que las mujeres no sean sólo usuarias de nivel primario, sino que se las incorpore como protagonistas, integrando su visión en los procesos de diseño, producción y gestión de ámbitos científicos y tecnológicos. Se trata de favorecer la expansión de los proyectos de las mujeres como diseñadoras de sitios Web, gestoras de redes o consultoras de servicios TIC, de forma que Internet se establezca como una herramienta para cambiar los estereotipos y las relaciones de género.

654 Gamero Casado, Eduardo y Martínez Gutiérrez, Rubén. El Derecho Administrativo ante la Era de la Información, en Gamero Casado, Eduardo y Julián Valero Torrijos, coordinadores. La Ley de Administración Electrónica. Comentario sistemático a la Ley 11/2007 de 22 de junio, de acceso electrónico de los ciudadanos a los servicios públicos. Aranzadi, Cizur Menor, 2009, págs. 29-35. 
Para conseguir estos objetivos es imprescindible invertir económicamente en ellos, de este modo, en la Disposición adicional décima de la LOIMH se establece que se constituirá un fondo especial para promover la plena incorporación de las mujeres en la Sociedad de la Información, que se dotará con 3 millones de euros en cada uno de los ejercicios presupuestarios de 2007, 2008 y 2009. Sin embargo, esta inversión no ha continuado en ejercicios posteriores, por lo que deducimos que el objetivo ya se ha cumplido, es decir, que las mujeres ya están plenamente incorporadas en la Sociedad de la Información, o bien que, dada la actual coyuntura económica, ya no se considera como un asunto prioritario.

El Plan Estratégico de Igualdad de Oportunidades elaborado por el Gobierno para el periodo 2008-2011 también puso de manifiesto que la innovación es una de las principales fuerzas de cambio social, siendo esencial incrementar la participación de las mujeres en la innovación y su acceso en igualdad a las tecnologías, no sólo como usuarias, sino también como generadoras y creadoras. Prueba de ello es que los artículos 28 y 30.5 de la LOIMH reconocen la necesidad de incorporar el principio de igualdad de oportunidades entre mujeres y hombres en el ámbito de la Sociedad de la Información e instan a los poderes públicos a promover la plena incorporación de las mujeres en este sector mediante "el desarrollo de programas específicos, en 
especial, en materia de acceso y formación en tecnologías de la información y de las comunicaciones", y promoviendo "el uso de políticas y actividades dirigidas a la mujer rural, y la aplicación de soluciones alternativas tecnológicas, allá donde la extensión de estas tecnologías no sea posible”.

Así por ejemplo, en el marco del Plan Avanza, se ha puesto en marcha un Plan de Acción para la Igualdad de Oportunidades entre Mujeres y Hombres en la Sociedad de la Información ${ }^{65}$, en el que se ha previsto la implantación de mecanismos que incentiven la igualdad, como la inclusión de criterios de género en las convocatorias de ayudas, y la inclusión del género como eje transversal de las evaluaciones de los resultados de las políticas para impulsar el desarrollo tecnológico y la Sociedad de la Información ${ }^{656}$. La disposición adicional cuarta apartado noveno de la Ley 56/07 de 28 de diciembre de Medidas de Impulso de la Sociedad de la Información ${ }^{657}$, se refiere específicamente a este hecho al establecer que la elaboración de las estadísticas públicas relativas a personas físicas ofrecerán sus datos desagregados por sexo para facilitar la evaluación del impacto de género en materia de Telecomunicaciones y la Sociedad de la Información. Se trata de ampliar el conocimiento actualmente disponible sobre la participación femenina en los entornos de la ciencia y la tecnología, así como acerca de la brecha digital de género, a fin de

\footnotetext{
655 http://e-igualdad.net/sites/default/files/plan_accion_SI.pdf

${ }_{656}$ Plan Estratégico de Igualdad de Oportunidades, 2008-2011, pág. 53.

${ }^{657}$ Boletín Oficial del Estado núm. 312 de 29 de diciembre de 2007.
} 
alimentar las estrategias innovadoras para alcanzar la igualdad también en estos ámbitos.

Por lo que respecta a la mejora del funcionamiento interno y por tanto, a la mejora de la organización administrativa gracias a las Tecnologías de la Información, hay que referirse de forma especial al trabajo a distancia o tradicionalmente conocido como teletrabajo, que debe promoverse como una forma de lograr mayor eficiencia y eficacia en la actuación de la Administración al mismo tiempo que facilita la conciliación de la vida familiar y laboral de sus empleados. De este modo se mejora la calidad de vida de los trabajadores, lo que redunda en beneficio de los servicios que son prestados. Seguidamente se analizarán los aspectos más importantes relacionados con esta forma de prestar los servicios públicos. 

2. DEL TRABAJO A DOMICILIO AL TRABAJO A DISTANCLA. EVOLUCIÓN Y RÉGIMEN JURÍDICO.

Aunque el origen del trabajo a domicilio ha sido estudiado en profundidad por el profesor Luis Enrique de la Villa Gil ${ }^{658}$, en este epígrafe se ha considerado oportuno hacer una breve referencia a esta forma de organización del trabajo por su vinculación estrecha al trabajo de las mujeres y por ser considerado como el antecedente del trabajo a distancia, y por tanto, del teletrabajo.

La aparición del trabajo a domicilio está vinculada a la transformación de las condiciones económicas operantes en el tránsito del artesanado al salariado. Al aumentar los encargos como consecuencia del desarrollo comercial, ciertos artesanos se convierten en comerciantes respecto del trabajo de otros, los artesanos más humildes, que pasan a desempeñar el papel de trabajadores a domicilio suministrando productos manufacturados ${ }^{659}$.

El proceso expansivo del trabajo a domicilio se debe a los avances de la técnica y al liberalismo económico. El desarrollo industrial provoca la desaparición de aquellos talleres artesanos

${ }^{658}$ De la Villa Gil, Luis Enrique. El Trabajo a domicilio. Aranzadi, Cizur Menor, 1996.

${ }^{659}$ Guilbert, Madeleine et Viviane Isambert-Jamati. Travail féminin et travail à domicile. Centre National de la Recherche Scientifique, Paris, 1956, pág. 9. 
con menos recursos económicos para tecnificar su producción. Estos artesanos que no pueden trabajar ya por cuenta propia se convirtieron en trabajadores a domicilio. Por lo que, en contra de lo que pudiera pensarse, la revolución industrial no termina con el trabajo a domicilio. Esto se debe a que pese a los progresos técnicos, no era posible alcanzar de pronto una producción con la misma calidad que el trabajo manual, las máquinas no eran capaces de realizar todas las tareas que se ejecutaban manualmente y el precio también era más bajo en la producción manual que en la tecnificada. Por eso el trabajo a domicilio subsiste a costa de seguir aceptando las paupérrimas condiciones en las que siempre se había desarrollado, y no sólo para suministrar productos manufacturados, sino que se va a convertir en una prolongación de las fábricas complementando el trabajo desarrollado en las $\operatorname{mismas}^{660}$.

En nuestro país, el trabajo a domicilio se consolida como forma productiva debido al desarrollo de la industria textil y algodonera a partir de la segunda mitad del siglo XIX. Las características propias del trabajo a domicilio se traducen en una serie de ventajas e inconvenientes para las personas que lo desempeñan. Algunas de estas ventajas son las que hacen que sean las mujeres quienes asuman generalmente esta forma de trabajar. Así por ejemplo, una de esas ventajas era y es la de ser un trabajo que puede realizarse en el hogar familiar, lo que hace que se

${ }^{660}$ De la Villa, 1996, págs. 34-35. 
considere como una forma doméstica de participar en el proceso productivo, y como todo lo que lleva aparejado el calificativo de doméstico no está valorado como se merece. Por tanto, uno de los motivos que explican que el trabajo a domicilio estuviera tan mal remunerado es porque no se concebía como una forma de obtener ingresos suficientes para vivir de manera independiente, sino como un medio de complementar los ingresos familiares.

Los inconvenientes asociados a las primeras manifestaciones del trabajo a domicilio derivan de las condiciones infrahumanas en las que se desarrollaba, en locales antihigiénicos, con salarios exiguos y jornadas agotadoras, baste con recordar que el trabajo a domicilio también era llamado de la explotación del sudor o sweating system. Esto puso de manifiesto la necesidad de protegerlo, para que todas las ventajas que justificaban su utilización no se vieran empañadas por la angustiosa situación laboral de las personas que lo desempeñaban, en su mayoría mujeres y menores de edad. Para ello es necesario no sólo que se proteja jurídicamente a estos trabajadores, sino que se les proteja igual que a todos los demás. El problema residía en el hecho de que los trabajadores a domicilio no eran considerados ni trabajadores por cuenta propia ni trabajadores por cuenta ajena, sino una categoría intermedia deficientemente delimitada ${ }^{661}$. Junto a esta ausencia de regulación jurídica, otro motivo de indefensión era que las personas que trabajaban a domicilio no tenían relación

${ }^{661}$ De la Villa, 1996, pág. 44. 
alguna entre sí, por lo que les faltaba el mínimo de unión y solidaridad entre ellos para crear una institución capaz de representar y defender sus intereses ${ }^{662}$. El trabajador a domicilio aparece en sus orígenes como un trabajador aislado y sin conciencia colectiva, rasgos que podrían explicar sus peores condiciones laborales y su inferioridad en el conjunto de la sociedad.

Las primeras leyes que se interesan por las condiciones laborales de los trabajadores son la "Ley de 30 de enero de 1900 regulando las responsabilidades por accidentes de trabajo"663; la "Ley de 13 de marzo de 1900 regulando el trabajo de las mujeres y de los niños" ${ }^{664}$, que prohibía el trabajo en domingo y días festivos a los obreros que son objeto de esta ley, y estableció las primeras normas protectoras de la maternidad al no permitir el trabajo a las mujeres durante las tres semanas posteriores al alumbramiento; el "Real decreto de 13 de noviembre de 1900 aprobando el reglamento para la aplicación de la ley de 13 de marzo de 1900 acerca del trabajo de las mujeres"665; el "Real decreto de 26 de junio de 1902 disponiendo que la jornada de trabajo no podrá exceder de once horas" "666; la "Ley de 3 de marzo de 1904 regulando el descanso dominical" "667 y su Reglamento de 19 de

\footnotetext{
662 De la Villa, 1996, pág. 64.

663 Colección Legislativa de España, Tomo V, Vol. I, 1900, págs. 144-149.

${ }^{664}$ Colección Legislativa de España, Tomo V, Vol. I, 1900, págs. 276-280.

${ }^{665}$ Colección Legislativa de España, Tomo VII, Vol. III, 1900, págs. 723-729.

${ }^{666}$ Colección Legislativa de España, Tomo XII, Vol. II, 1902, págs. 352-353.

${ }^{667}$ Colección Legislativa de España, Tomo XVII, Vol. I, 1904, págs. 490-492.
} 
abril de $1905^{668}$; el "Real Decreto de 24 de agosto de 1913 fijando la jornada máxima ordinaria de trabajo efectivo de los obreros de ambos sexos en la industria textil" ${ }^{\prime 669}$. Sin embargo, estas leyes no dan lugar a la creación de un cuerpo legal regulador de las relaciones laborales, persiguiendo cada una de ellas por separado, el logro de resultados concretos, de carácter policial ${ }^{670}$. Además sólo se aplican a los obreros, es decir, a aquellos trabajadores que ejecutaban habitualmente y por cuenta ajena trabajo manual fuera del domicilio, de manera que los trabajadores a domicilio no podían beneficiarse de la protección incipiente de los derechos laborales que ofrecían estas leyes.

La regulación jurídica del trabajo a domicilio quedaba enmarcada en sus orígenes en el ámbito del derecho civil común, y más precisamente en el contrato de arrendamiento de servicios. Hubo que esperar hasta principios del siglo XX para que este tipo de trabajo abandonara su configuración como contrato de arrendamiento de servicios y tuviera una reglamentación en sentido propio.

El Real Decreto-ley de 26 de julio de $1926^{671}$ regula por primera vez con carácter general el trabajo a domicilio y al año siguiente se aprueba su Reglamento por Real Decreto Ley de 20 de

\footnotetext{
${ }^{668}$ Colección Legislativa de España, Tomo XXI, Vol. I, 1905, págs. 696-704.

${ }^{669}$ Colección Legislativa de España, Tomo XLIX, Vol. III, 1913, págs. 102-107.

${ }^{670}$ De la Villa, 1996, pág. 96.

${ }^{671}$ Colección Legislativa de España, Tomo XCIX, Vol. IV, 1926, págs. 303-312.
} 
octubre de $1927^{672}$. Ambos Reales Decretos segregaron del ordenamiento civil al trabajo a domicilio incorporándolo al Derecho del trabajo y, en consecuencia, los derechos y garantías que él establece. La técnica de incorporación no fue la de integrar a los trabajadores a domicilio en el concepto de trabajador, sino la de asimilarlos a él ${ }^{673}$. Estos Reales Decretos Leyes permanecieron en vigor hasta la aprobación de la Ley de Contrato de Trabajo de 26 de enero de 1944, que pasa a considerar al contrato de trabajo a domicilio como un contrato de naturaleza especial. Con esta Ley el trabajo a domicilio se extiende a cualquier prestación que se desarrolle fuera de las dependencias de la empresa, siempre que se trate de un lugar libremente elegido por el trabajador con independencia de que sea su domicilio o cualquier otro. A ello había que sumarle además el dato de que la prestación se realice sin el control o vigilancia por el empresario o su representante.

Siguiendo la línea de la evolución normativa hay que destacar otros dos momentos, uno es el de la Ley 16/1976 de 8 de abril de Relaciones Laborales ${ }^{674}$ y la aprobación del Estatuto de los Trabajadores. En la sistematización realizada por el ET el trabajo a domicilio deja de considerarse como un contrato especial. A pesar de que este trabajo posee unos rasgos particulares, el legislador consideró oportuno llevar a cabo la integración total del trabajo a

\footnotetext{
${ }^{672}$ Colección Legislativa de España, CVI, Vol. V, 1927, págs. 160-168.

673 Gallardo Moya, Rosario. El viejo y el nuevo trabajo a domicilio. De la máquina de bilar al ordenador. Ibidem, Madrid, 1998, pág. 19.

${ }^{674}$ Boletín Oficial del Estado núm. 96 de 21 de abril de 1976.
} 
domicilio en el ordenamiento jurídico laboral, sin que hoy quepan dudas de su carácter laboral común. A continuación analizaremos la regulación actual del trabajo a domicilio, que pasa a denominarse trabajo a distancia, siendo una de sus principales modalidades el teletrabajo. 

3. CONCEPTO Y CARACTERÍSTICAS DEL TRABAJO A DISTANCLA.

En el Capítulo II de la Resolución de 30 de enero de 2012 de la Dirección General de Empleo, por la que se registra y publica el II Acuerdo para el Empleo y la Negociación Colectiva 2012, 2013 y $2014^{675}$, se establece que el objetivo prioritario de la negociación colectiva debe ser el mantenimiento y recuperación del empleo, sin olvidar otros objetivos fundamentales como el cumplimiento del principio de igualdad de trato y no discriminación en el empleo y en las condiciones de trabajo, así como la promoción de la igualdad de oportunidades entre mujeres y hombres, o la incidencia de las TIC en el desarrollo productivo general y en las relaciones laborales. Para ello se deben articular instrumentos que permitan un adecuado equilibrio entre flexibilidad para las empresas y seguridad para los trabajadores. Por lo que ahora nos interesa, este Acuerdo se refiere al teletrabajo como una de las formas innovadoras de organización y ejecución de la prestación laboral derivada del propio avance de las TIC, que permite la realización de la actividad laboral fuera de las instalaciones de la empresa, o en nuestro caso, de la Administración. Los convenios colectivos son el lugar más adecuado para regularlo observando algunos criterios como la voluntariedad y el carácter reversible del mismo, la igualdad de derechos y obligaciones de todos los

${ }^{675}$ Boletín Oficial del Estado núm. 31 de 6 de febrero de 2012. 
trabajadores, y la necesidad de que aspectos como la privacidad, la confidencialidad o la prevención de riesgos laborales, estén convenientemente regulados.

De la redacción del artículo 13 TRLET por la Ley 3/2012 de 6 de julio de medidas urgentes para la reforma del mercado de trabajo $^{676}$, extraemos los siguientes elementos del trabajo a distancia que a su vez nos proporcionan un concepto del mismo y definen sus principales características.

\subsection{ELEMENTO ESPACIAL.}

El trabajo a distancia o teletrabajo se caracteriza porque la actividad laboral se deslocaliza, es decir, se presta en un lugar distinto al de los centros de trabajo tradicionales.

Hasta la reforma laboral de 2012, la única figura legal que guardaba cierta analogía con el teletrabajo era la relativa al trabajo a domicilio previsto en el artículo 13 TRLET. Sin embargo, los elementos definitorios del tradicional trabajo a domicilio, en especial, la falta de vigilancia empresarial, dificultaban la integración de algunas manifestaciones del teletrabajo en esta regulación legal.

${ }^{676}$ Boletín Oficial del Estado núm. 162 de 7 de julio de 2012. 
El punto III del Preámbulo de la Ley 3/2012, hace constar su deseo de dar cabida al teletrabajo como "una particular forma de organización del trabajo que encaja perfectamente en el modelo productivo y económico que se persigue, al favorecer la flexibilidad de las empresas en la organización del trabajo, incrementar las oportunidades de empleo y optimizar la relación entre tiempo de trabajo y vida personal y familiar". Y aunque el Preámbulo alude a la modificación del tradicional trabajo a domicilio para dar acogida al "trabajo a distancia basado en el uso intensivo de las nuevas tecnologías”, el nuevo artículo 13.1 TRLET omite cualquier referencia a las mismas, por lo que no se pueden excluir de esta noción aquellos supuestos de trabajo a distancia en los que no estén presentes las nuevas tecnologías ${ }^{677}$.

Como consecuencia de esta reforma legal, el trabajo a domicilio pasa a denominarse trabajo a distancia, que según la nueva redacción del artículo 13 TRLET es "aquel en el que la prestación de la actividad laboral se realice de manera preponderante en el domicilio del trabajador o en el lugar libremente elegido por éste, de modo alternativo a su desarrollo presencial en el centro de trabajo de la empresa". Lo determinante es la libre elección del lugar de la prestación que se externaliza, siendo el supuesto normal el domicilio del trabajador, pero no el único. Por lo tanto, si la libre elección del lugar de la prestación es

677 Sempere Navarro, Antonio V. y Rodrigo Martín Jiménez. Claves de la Reforma Laboral de 2012. Estudio de la Ley 3/2012, de 6 de julio y del Real Decreto-Ley 20/2012 de 13 de julio. Aranzadi, Cizur Menor, 2012, pág. 207. 
un elemento definitorio del trabajo a distancia, y el teletrabajo es trabajo a distancia, la conclusión es que la libre elección del lugar de la prestación también es un elemento definitorio del teletrabajo. A pesar de ello ¿podrían darse en la práctica supuestos de teletrabajo en los que la elección del lugar de la prestación fuera el resultado de un acuerdo entre ambas partes o incluso fruto de la imposición unilateral del empresario? Si esto fuera así, nos encontraríamos nuevamente con supuestos de teletrabajo excluidos del Derecho del Trabajo, lo que por el momento aconseja excluir esta posibilidad. Sólo se considera teletrabajo si el lugar de realización de la prestación ha sido elegido libremente por la persona que teletrabaja.

El lugar concreto en el que se desarrolla la actividad laboral da lugar a las diferentes modalidades de trabajo a distancia, siendo la más común que la prestación se efectúe en el domicilio del trabajador. Sin embargo, el concepto de trabajo a distancia es mucho más amplio y abarca también aquellas actividades laborales que se realizan desde un centro de recursos compartidos - espacios físicos al servicio de terceros para su uso compartido, también llamados telecentros, dotados de unas instalaciones, infraestructuras y servicios informáticos y de telecomunicación del más alto nivel; aquellas que se ejecutan desde un centro satélite lugar distinto al centro de trabajo donde la empresa desarrolla la actividad económica principal, en el que se sitúa una fase diferenciada de dicha actividad; o también aquellas que se prestan 
desde una estación de trabajo móvil - en el que el teletrabajador dispone de unos equipamientos informáticos que, por ser portátiles y estar dotados del software y del hardware informáticos y de comunicación adecuados, le permiten teletrabajar en cualquier lugar, encontrarse localizable en todo momento y poder acceder a cualquier información de la oficina central o recibirla de ella, e incluso transmitirla de su parte.

En estrecha relación con este elemento espacial está la cuestión de la jornada de trabajo, ya que es uno de los aspectos que pueden verse más afectados por la práctica del teletrabajo. Una vez que se opta por el teletrabajo, ¿toda la jornada de trabajo debe realizarse a distancia, o por el contrario, sólo una parte de ella? Y ¿cómo se ve afectada la jornada de trabajo por el hecho de teletrabajar? En respuesta a la primera pregunta, frente a la anterior redacción del artículo 13 TRLET, que parecía presuponer que la totalidad de la actividad laboral se llevara a cabo fuera de la empresa, el actual artículo 13 TRLET permite que se lleve a cabo "de manera preponderante" en un lugar distinto a las instalaciones de la empresa, lugar que como ya se ha señalado puede ser el domicilio de la persona trabajadora, pero no sólo ni exclusivamente. En respuesta a la segunda pregunta, una de las principales características del teletrabajo es que flexibiliza la gestión del tiempo de trabajo. Sin embargo, el lugar en el que se lleva a cabo la prestación puede condicionar dicha autonomía para organizar y desarrollar el trabajo. La modalidad más flexible sería 
aquella en la que la prestación se realiza en el propio domicilio, al poderse ejecutar en cualquier momento del día. Por el contrario, cuando se trabaja en un telecentro o de forma itinerante, la flexibilidad es menor y los condicionantes provienen de los horarios de apertura y cierre del telecentro, o de las demandas de los propios clientes. Sin embargo, a mayor flexibilidad, más se difumina la distinción entre tiempo de trabajo y tiempo libre, por lo que sí que es conveniente establecer ciertos límites temporales a la jornada de teletrabajo ${ }^{678}$.

La falta de previsiones específicas en nuestro ordenamiento, no permiten sin más la pura y simple aplicación de las reglas generales contenidas en el TRLET, por lo que la negociación colectiva desempeñará un papel esencial en la precisión de estas peculiaridades. La negociación colectiva debería ocuparse de las cuestiones relativas al tiempo de teletrabajo y que inciden en la igualdad de género, como por ejemplo hasta qué punto está justificada la utilización de los permisos retribuidos por enfermedad de familiar o las reducciones de jornada por razones de guarda legal, cuando se teletrabaja en el domicilio y se dispone de gran autonomía para elegir libremente la distribución de la jornada diaria. Sin embargo, las soluciones de la negociación colectiva no pueden suponer un retroceso en la cuestión de igualdad entre hombres y mujeres en el acceso al empleo y en las

678 García Romero, Belén. El Teletrabajo. Aranzadi, Cizur Menor, 2012, págs. 106-107. 
condiciones de trabajo, ni privar al teletrabajo de uno de sus fines últimos como es aumentar la corresponsabilidad de toda la sociedad en esta cuestión.

\subsection{ELEMENTO INSTRUMENTAL. LAS TECNOLOGÍAS DE LA INFORMACIÓN Y LAS COMUNICACIONES.}

Además de todo lo anterior, es imprescindible que la deslocalización se produzca o resulte favorecida por la utilización de medios informáticos y de comunicación tecnológicamente avanzados, es decir, aquellos que permitan mantener en conexión el ordenador central de la empresa o de la Administración en nuestro caso, con el videoterminal externo del trabajador para ejecutar la actividad laboral contratada, reconociéndose que dicha conexión tenga el carácter de imprescindible para trabajar. El teletrabajo se caracteriza por la telemática aplicada, no por la mera utilización de la informática. Es decir, que la deslocalización y la utilización de los medios tecnológicos avanzados son indisociables a la vista del teletrabajo ${ }^{679}$.

Como consecuencia de la utilización de las Tecnologías de la Información y las Comunicaciones la mayor parte de los supuestos de teletrabajo se realizan con vigilancia del empresario. En la anterior redacción del artículo 13 TRLET, uno de los rasgos

679 Sellas i Benvingut, Ramón. El Régimen Jurídico del Teletrabajo en España. Aranzadi, Cizur Menor, 2001, págs. 34-35. 
definitorios del trabajo a domicilio era la falta de vigilancia empresarial. Sin embargo, esa falta de vigilancia no era un elemento presente en todos los tipos de teletrabajo posibles. Lo que se pretende con esta reforma que suprime el requisito de la falta de vigilancia, es eliminar aquellos obstáculos que impedían la aplicación de la normativa laboral a todos los supuestos de teletrabajo. Y ello porque en el teletrabajo la condición de falta de vigilancia no tiene por qué darse siempre. En el teletrabajo puede no haber una supervisión física del trabajo, pero sí puede haberla tecnológica, por ejemplo, cuando el teletrabajo se realiza on line, es decir, cuando el teletrabajador hace uso de las telecomunicaciones para recoger las especificaciones del trabajo, para realizarlo o para enviar el resultado del mismo. Asimismo, hay que tener en cuenta que, incluso cuando la prestación se realiza off line, es decir, cuando el teletrabajador, tras recibir unas instrucciones iniciales, desarrolla su actividad desconectado, sin enlace informático directo con la computadora central de la empresa, es posible un control posterior si el ordenador tiene incorporados ciertos dispositivos que permiten un control total del proceso productivo, control que puede ser incluso mayor que el que se realiza en los locales de la empresa. Estos dispositivos son lo que se denomina software accounting, a través del cual se puede registrar la hora de encendido y apagado del ordenador, interrupciones, errores, número de operaciones realizadas, el tiempo empleado en cada uno o la memoria utilizada ${ }^{680}$. Ahora bien, estos sistemas de control

${ }^{680}$ García Romero, 2012, págs. 92-93. 
deberán ser proporcionados a su finalidad, será necesario cohonestar y conciliar el derecho a controlar la actividad laboral con el derecho del trabajador a proteger su intimidad personal y familiar y su domicilio, sin que el control telemático permita cualquier intromisión ilegítima injustificada o desproporcionada en las vidas de los teletrabajadores ${ }^{681}$.

Por tanto, con la nueva normativa, se puede calificar como teletrabajo tanto aquellos supuestos en los que se realice con vigilancia empresarial como sin ella, a diferencia de lo que sucedía en el tradicional trabajo a domicilio, que sólo requería la entrega de la tarea encomendada y la posible calidad de la misma.

El tipo de conexión con la Administración también puede condicionar la autonomía para organizar y desarrollar el trabajo, y por tanto la flexibilidad de la jornada de trabajo que permite mejorar el equilibrio entre la vida personal, familiar y laboral. Así, si se teletrabaja on line el control ejercido por el empresario comporta la necesidad de cumplir con los horarios de trabajo de la empresa, mientras que si se desarrolla desconectado es más evidente la ductilidad y la libre distribución de la jornada y descansos. El control del empresario debe limitarse al cumplimiento de la prestación por parte del trabajador, lo que como se verá a continuación comporta un cambio en la forma de trabajar en la Administración.

${ }^{681} \mathrm{FJ}$ sexto SAN 42/2004, de 31 de mayo. 


\subsection{ELEMENTO ORGANIZATIVO.}

Otro de los presupuestos necesarios para la implantación de un sistema de teletrabajo es la progresiva sustitución de la organización funcional vertical por una organización orientada a la gestión horizontal de procesos y equipos de trabajo, con implantación de una metodología de dirección por objetivos, y de evaluación en función de los resultados obtenidos. De este modo, dejará de tener tanta importancia la presencia física en el centro de trabajo, la visibilidad en el mismo, como criterio a tener en cuenta en la valoración del trabajo desempeñado. Esto a su vez hará desaparecer progresivamente el temor a ver mermadas las posibilidades de crecimiento profesional como consecuencia de teletrabajar, aumentando la demanda de esta forma de desarrollar la prestación laboral. Por tanto, teletrabajar no es sólo trabajar a distancia utilizando las telecomunicaciones y la informática, teletrabajar es servirse de estos elementos para trabajar de un modo diferente, escapando del modelo tradicional de organización del trabajo ${ }^{682}$.

La utilización del teletrabajo supone una transformación interna de la Administración Pública, ya que la dificultad en el desarrollo de modelos de trabajo más flexibles como este no sólo

682 Thibault Aranda, Javier. El Teletrabajo. Análisis jurídico-laboral. Consejo Económico y Social, Madrid, 2001, pág. 29. 
está en el grado de desarrollo tecnológico de un país, sino en su cultura organizacional. En nuestro país se suele vincular el grado de compromiso con el trabajo con las horas de permanencia en el puesto de trabajo. Sin embargo, el teletrabajo supone un grado de individualismo que es difícil de aceptar en determinadas organizaciones, como puede ser el caso de la Administración Pública. Por eso el teletrabajo lleva aparejado un cambio de mentalidad que consiste en controlar los resultados del trabajo ${ }^{683}$. Ahora bien, se trata de ejercer un control técnico del cumplimiento de los objetivos por parte del trabajador, que no tenga en cuenta a la persona, evitando en todo momento servirse de las Tecnologías de la Información para invadir y enjuiciar la esfera privada del trabajador protegida por el artículo 20.3 TRLET. Cualquier intento de controlar la prestación con el objetivo de acumular datos para reconstruir el perfil ideológico y político de la persona que teletrabaja, debe ser considerado ilícito $^{684}$.

También es importante que se establezcan prácticas de dirección participativa en el que se puedan delegar responsabilidades, lo que permitirá que el acceso a dichos puestos directivos resulte más fácil a aquellas personas que

\footnotetext{
683 Pérez Pérez, Manuela. El teletrabajo: efectos en la conciliación de la vida familiar y laboral. Fundear, Zaragoza, 2008, pág. 24.

684 Pérez de los Cobos Orihuela, Francisco. Nuevas tecnologías y relación de trabajo. Tirant lo Blanch, Valencia, 1990, págs. 91-92.
} 
tradicionalmente se han hecho más responsables de las cuestiones familiares, es decir, las mujeres.

Hace falta que los empleados públicos perciban como algo real el compromiso formal de la organización a la que pertenecen, en nuestro caso la Administración Pública, con las políticas que les permitan compaginar su vida personal y familiar. La Administración Pública, sus dirigentes políticos, y los propios compañeros y compañeras de trabajo deben ser sensibles a esta problemática y no crear sentimiento de culpabilidad en la persona trabajadora que hace uso no sólo de este sino de todos los instrumentos que le permiten flexibilizar su forma de trabajar. 
4. VENTAJAS E INCONVENIENTES DEL TRABAJO A DISTANCLA.

Estos cambios en la mentalidad organizativa y la implantación de esta forma de desarrollar el trabajo traen consigo una serie de ventajas e inconvenientes tanto para la Administración como para las personas que ocupen estos puestos de trabajo.

Ya se ha indicado que una de las principales ventajas del teletrabajo es la flexibilidad para conseguir un equilibrio entre la vida personal, familiar y laboral. La flexibilidad horaria permite a los empleados públicos compaginar su trabajo con sus responsabilidades familiares y con los horarios fijos del resto de miembros de la familia, como la hora de entrada o de salida del colegio de sus hijos. Se supone que a mayor flexibilidad mayor posibilidad de armonizar las responsabilidades familiares y laborales, de conciliar la vida personal o familiar con la profesional, y por tanto de tener una mayor calidad de vida. Sin embargo, hay una serie de variables que pueden alterar este supuesto idílico como son las características de la persona que teletrabaja, del entorno laboral, o de la propia familia. 


\subsection{CARACTERÍsticAs DE LA PERSONA QUE TRABAJA A DISTANCIA.}

El teletrabajo conlleva una pérdida de integración en la organización administrativa y un riesgo de aislamiento personal o social, que podrá ser mayor o menor dependiendo del lugar elegido para realizar la prestación, y de qué porcentaje de la jornada de trabajo se desarrolle a distancia. Por eso, debe cuidarse especialmente el proceso de selección y reclutamiento de los teletrabajadores, los cuales deben reunir una serie de cualidades que son fundamentales para que a pesar de ese riesgo, el teletrabajo pueda ser realizado con éxito.

En primer lugar es necesario tener una alta capacidad de comunicación, porque aunque el superior jerárquico tiene la obligación de informar de todos los proyectos que se pongan en marcha en el centro de trabajo, es indudable que el teletrabajador deberá mostrar idéntico interés por el desarrollo y consecución de los objetivos de la organización igual que si estuviera físicamente en la sede de la Administración a la que pertenece, y es esa capacidad de comunicación y ese interés en su trabajo lo que le ayudará, a pesar de trabajar a distancia, a realizar sus tareas con la misma motivación y el mismo rendimiento que si se encontrara en un despacho situado en las dependencias administrativas. Las fórmulas de teletrabajo intermedias, es decir, aquellas en las que el trabajo se realiza en parte a distancia y en parte en un centro de 
trabajo de la propia Administración, son las que permiten un tiempo mínimo de estancia en ese centro de trabajo para favorecer la idea de pertenencia real a la organización así como el ejercicio de los derechos colectivos que le correspondan ${ }^{685}$.

También es fundamental que se trate de una persona con autodisciplina, que sepa organizar y gestionar bien su tiempo, y con facultades para saber priorizar lo que debe hacer en cada momento, bien atender las necesidades de la familia o bien ejecutar las tareas de su trabajo. Estas cualidades harán más fácil el hecho de tener que seguir un horario y evitar los dos extremos, tanto aumentar el tiempo dedicado al trabajo en detrimento de la familia, - es decir, una sobreexplotación que derive en adicción al trabajo y que puede ser frecuente cuando los teletrabajadores prestan sus servicios exclusivamente con carácter móvil-, como un aumento de las responsabilidades domésticas haciendo dejación de sus funciones en el trabajo, - lo que puede suceder si se trabaja sólo desde el domicilio. Por ello se desarrollan estrategias de gestión de los límites en el teletrabajo, pudiendo distinguirse entre aquellas que se orientan a la integración de la familia y el trabajo, y aquellas que se orientan a la segmentación. Las primeras son las que permiten una mayor flexibilidad, mientras que las segundas requieren hacer un esfuerzo emocional por mantener separadas ambas esferas, la vida personal y familiar, y la laboral.

${ }^{685}$ García Romero, 2012, pág. 25. 
Además la persona que teletrabaja deberá tener buenos conocimientos de informática, ya que la mayor parte de los problemas técnicos tendrá que solucionarlos por sí mismo, por lo que la Administración tendrá que incidir en la formación en Tecnologías de la Información con carácter previo a la implantación de programas piloto de teletrabajo.

\subsection{CARACTERÍSTICAS DEL ENTORNO LABORAL.}

Las características del entorno laboral también influyen en el adecuado desarrollo del teletrabajo. Es imprescindible contar con el apoyo del superior jerárquico y la aceptación del resto de personal. El apoyo del superior jerárquico está muy relacionado con el tipo de control ejercido por el mismo. Considero que si el teletrabajo se pone en marcha como una herramienta más al servicio de la igualdad de género, el control del superior jerárquico debería limitarse al cumplimiento, dentro del plazo que se considere adecuado y razonable, de los objetivos fijados al trabajador, permitiendo que el trabajo se ejecute de forma desconectada y con libre distribución de jornada y descansos. Si por el contrario el teletrabajo se piensa únicamente con una forma de ahorrar costes a la Administración, probablemente se buscará ejercer un control más intenso a través de un enlace informático con la Administración de tipo interactivo, con la consiguiente obligación de cumplir los horarios de trabajo y por tanto con 
menor autonomía y flexibilidad en la gestión del trabajo por parte del teletrabajador. Cuando la persona que teletrabaja puede controlar la implementación de las tareas y además tiene la capacidad de ajustar la planificación de las mismas a las necesidades de la familia o sus deseos personales, habrá mayores posibilidades de armonizar la vida laboral y familiar, y una mayor satisfacción con el trabajo. Por tanto es aconsejable otorgar mayor libertad e independencia a los empleados públicos que teletrabajen. Programar el trabajo con entera libertad permite trabajar cuando la persona se siente más productiva, así como poder adaptarse mejor a las responsabilidades familiares de manera que se evite trabajar en aquellos momentos en los que las distracciones $O$ responsabilidades familiares sean mayores ${ }^{686}$.

En relación con el entorno laboral y cuando el lugar elegido para trabajar a distancia sea el domicilio de la persona, es destacable la repercusión que puede tener la disponibilidad de una zona de trabajo en el hogar. Cuando se teletrabaja se produce una intrusión del trabajo en el espacio familiar, de manera que o bien se lleva a cabo una reorganización de la vivienda o bien se van utilizando de modo alternativo los espacios comunes de la familia, lo que puede difuminar los límites entre familia y trabajo. El número de horas de trabajo o la frecuencia de interrupciones en casa podrán controlarse mejor si se dispone de un espacio apropiado para trabajar en el domicilio.

${ }^{686}$ Pérez Pérez, 2008, págs. 41-42. 
Para la Administración el teletrabajo se traduce en un incremento de la productividad como consecuencia del ahorro de tiempo no productivo. Esto se debe a que en la oficina tradicional las personas son más propensas a interrupciones debido a la proximidad y a los encuentros fortuitos con el resto de personal, en cambio, cuando teletrabajan estas personas pueden disponer de un mayor grado de control sobre estas interacciones ${ }^{687}$. Habrá menos interrupciones en el trabajo, aunque sólo en el caso de que el teletrabajador haya optado por un modelo en el que los límites entre trabajo y familia estén bien separados, es decir, esté presente en el domicilio, pero al mismo tiempo ausente del mismo para cualquier incidencia que se plantee durante sus horas de teletrabajo. No obstante, esta separación tajante también tiene el inconveniente de ser menos flexible y de privar al teletrabajo de uno de sus fines, el que debería ser más importante para aquellas personas que quieren teletrabajar, que es dar un giro a las rígidas exigencias derivadas de la forma tradicional de trabajar. No obstante, algunas empresas mundialmente conocidas han utilizado recientemente este argumento para revocar sus políticas de teletrabajo, indicando que es precisamente en estos encuentros fortuitos entre los trabajadores cuando surgen algunas de las ideas más brillantes y novedosas.

${ }^{687}$ Pérez Pérez, 2008, pág. 31. 
Otra de las ventajas que tiene el teletrabajo para la Administración es que se ahorran los costes derivados del mantenimiento de un espacio para el trabajo en la sede de la organización. Sin embargo la persona que teletrabaja tendrá que asumir costes que antes no soportaba, como equipamiento, incremento de las facturas de luz, teléfono, calefacción entre otros. Además, en ausencia de regulación laboral, el trabajador puede encontrarse desprotegido ante problemas como accidentes laborales, contratos o planes de jubilación. Por este motivo los convenios colectivos deben adaptarse y regular aquellos aspectos del teletrabajo que no estén previstos en el TRLET.

\subsection{LAS CARACTERÍSTICAS DEL ENTORNO FAMILIAR.}

Por último, las particularidades de la familia, el sexo de la persona que teletrabaja, el número de hijos que viven en el hogar familiar y sus edades, así como la presencia de otra persona que cuide de los mismos, también son factores que influyen en el teletrabajo. Asimismo, el compromiso o la corresponsabilidad de la pareja hacia la familia es un elemento clave para que el teletrabajo consiga realmente una mayor conciliación de la vida laboral y familiar, y disminuyan el conflicto trabajo-familia. Por lo que respecta a la influencia del sexo, las mujeres suelen ser reacias a adoptar el teletrabajo porque consideran que contribuye a reafirmar la responsabilidad sobre las tareas domésticas al estar más tiempo en el hogar, hecho que no suele suceder cuando realizan su jornada 
laboral fuera del domicilio ${ }^{688}$. Por lo que si es cierto que el teletrabajo puede llegar a empeorar la injusta división de tareas domésticas para las mujeres, podría potenciarse el teletrabajo masculino en la Administración, de manera que así los hombres lleguen a dedicar más tiempo al hogar y se consiga mayor equilibrio en este sentido.

Para la Administración el teletrabajo se traduce en una reducción del absentismo provocado por determinados acontecimientos familiares imprevisibles de los que el trabajador tiene que ocuparse. Asimismo, la mayor facilidad para contratar personal cualificado con independencia de su residencia y la menor contaminación ambiental pueden ser determinantes para potenciar la implantación de esta forma de trabajar.

688 Pérez Pérez, 2008, págs. 32-33. 


\section{OTRAS CUESTIONES RELACIONADAS CON EL TRABAJO A DISTANCIA.}

En el nuevo artículo 13 TRLET se establece que "el acuerdo por el que se establezca el trabajo a distancia se formalizará por escrito". Además se deberá entregar al teletrabajador las informaciones escritas acerca de las condiciones aplicables al contrato de trabajo o a la relación laboral conforme a la Directiva 91/533/CEE del Consejo de 14 de octubre de $1991^{689}$.

En el apartado tercero del mismo artículo 13 TRLET se establece que "los trabajadores a distancia tendrán los mismos derechos que los que prestan sus servicios en el centro de trabajo de la empresa". De este modo tendrán plena vigencia el derecho al descanso por maternidad y paternidad, o el derecho a disfrutar de una excedencia por cuidado de hijos, aunque en relación con este último existe una tendencia creciente a configurar el teletrabajo como una alternativa a esta suspensión de la relación laboral ${ }^{690}$.

El precepto legal sienta como principio la equiparación en derechos de los trabajadores a distancia, pero no contiene prescripción alguna sobre el contenido mínimo del acuerdo de

\footnotetext{
${ }^{689}$ DOUE L 288/33 de 18.10.91.

${ }^{690}$ García Romero, 2012, pág. 135.
} 
teletrabajo. Razones de seguridad jurídica justifican que la persona que teletrabaje pueda conocer previamente el contenido de la prestación laboral, aunque no presente peculiaridades puesto que las mismas funciones pueden realizarse en el centro tradicional de la empresa o en el propio del teletrabajo; cómo se ejercerán los poderes organizativos del empresario; cómo se controlará el tiempo de trabajo; qué tipo de conexión, on line/off line, habrá con la empresa; cómo se garantizarán ciertos derechos del teletrabajador, como el derecho a la seguridad y salud en el trabajo, o el derecho a la intimidad, cuestiones que deberán ser reguladas a través de los correspondientes convenios colectivos ${ }^{691}$.

En relación con los derechos de las personas que teletrabajan, el párrafo segundo del artículo 13 TRLET prevé que “el empresario deberá establecer los medios necesarios para asegurar el acceso efectivo de estos trabajadores a la formación profesional para el empleo, a fin de favorecer su formación profesional", y deberá informarles "de la existencia de puestos de trabajo vacantes para su desarrollo presencial en el centro de trabajo". Estas medidas garantizan que el teletrabajo no perjudique profesionalmente a las personas que, no olvidemos nunca, de manera voluntaria, accedan a esta forma de realizar la prestación laboral, ya que el teletrabajo modifica únicamente la manera en que se efectúa el trabajo, sin que pueda perjudicar al estatus laboral del trabajador o trabajadora.

${ }^{691}$ García Romero, 2012, págs. 102-103. 
En el apartado cuarto del artículo 13 TRLET se reconoce el derecho a una "adecuada protección en materia de seguridad y salud" y en el quinto se les permite el ejercicio de "los derechos de representación colectiva" para lo cual estos trabajadores "tienen que estar adscritos a un centro de trabajo concreto de la empresa".

Por lo que respecta a la protección en materia de seguridad y salud, sería conveniente que la negociación colectiva incluyera las cláusulas específicas al respecto, que concreten la frecuencia e intensidad de las comprobaciones que la Administración está obligada a llevar a cabo en relación con cada una de las modalidades de teletrabajo que pueden presentarse. Además, cuando la prestación se realiza en régimen de teletrabajo existen unos riesgos genéricos derivados del uso de las nuevas tecnologías, ya que el trabajo continuo ante pantallas de ordenador ha hecho aparecer una serie patologías como dolencias posturales, visuales, etc., que hacen necesario establecer mecanismos de protección. Junto a ellos existen otros riesgos específicos que afectan de forma especial al teletrabajo a domicilio, motivados por la posible falta de adecuación del lugar de la prestación, como mala iluminación o falta de ventilación, o relacionados con el aislamiento físico o psíquico que puede afectar a la persona que teletrabaja.

La normativa aplicable es la Ley 31/1995 de 8 de noviembre de Prevención de Riesgos Laborales y con carácter 
específico, el Real Decreto 488/97 de 14 de abril ${ }^{692}$, que fija las disposiciones mínimas de seguridad y salud relativas al trabajo con equipos que incluyen pantallas de visualización, trasponiendo al derecho interno la Directiva 90/270 CEE de 29 de mayo ${ }^{693}$, sobre la misma materia. La cuestión más polémica es la de las consecuencias de las radiaciones emitidas por el videoterminal sobre la salud de los trabajadores, y especialmente de las trabajadoras embarazadas. Los niveles de radiación emitidos por los videoterminales han sido considerados generalmente inocuos para la salud de los trabajadores, aunque estudios recientes afirman la existencia de relación entre el trabajo continuado ante el videoterminal y la existencia de abortos espontáneos o embarazos con dificultades ${ }^{694}$. La relación no se ha demostrado claramente y se ignoran los efectos a largo plazo de la exposición continuada a este tipo de radiaciones, precisamente por este motivo es comprensible la inquietud de las mujeres embarazadas, ya que si un médico no puede certificar ese riesgo para el embarazo difícilmente se podrá hacer valer su derecho a la salud y la protección de la maternidad previsto en el artículo 26 de la Ley $31 / 95$ de 8 de noviembre.

La Administración es responsable de la salud y seguridad de sus empleados públicos, incluidos los que teletrabajan. Por ello deberá garantizar que los teletrabajadores reciben información y

\footnotetext{
${ }^{692}$ Boletín Oficial del Estado núm. 97 de 23 de abril de 1997.

${ }^{693}$ Diario Oficial de la Unión Europea, DO L 156 de 21.6.1990.

${ }^{694}$ Pérez de los Cobos, 1990, pág. 54.
} 
formación adecuadas sobre los riesgos derivados de la utilización de los equipos informáticos, así como tras una evaluación inicial de las condiciones de seguridad y salud, determinar las medidas de prevención que deben ser adoptadas. Para verificar la correcta aplicación de las normas en materia de salud y seguridad será competente la Inspección de Trabajo, que tendrá acceso al lugar del teletrabajo. Si es el domicilio, según el artículo 5.1 de la ley 42/97 de 14 de noviembre ordenadora de la Inspección de Trabajo y Seguridad Social ${ }^{695}$, este acceso está sometido a previa notificación y consentimiento previo del interesado. No obstante, también es posible que el teletrabajador compruebe por sí mismo su puesto de trabajo, para lo cual deberá recibir la formación adecuada mediante un curso realizado por el Servicio de Prevención Ajeno contratado por la Administración.

En relación con los derechos colectivos, los teletrabajadores tienen los mismos derechos que el resto de trabajadores. Están sometidos a las mismas condiciones de participación y elegibilidad, y están incluidos en el cálculo determinante de los umbrales necesarios para las instancias de representación de los trabajadores. Los representantes de los trabajadores serán informados y consultados sobre la introducción del teletrabajo. Sea cual sea el modelo de articulación del teletrabajo, es imprescindible la inclusión de los teletrabajadores en el Convenio colectivo si es personal laboral o en el Acuerdo Marco

${ }^{695}$ Boletín Oficial del Estado núm. 274 de 15 de noviembre de 1997. 
si es personal funcionario, para evitar que sus condiciones de trabajo sean más precarias que las del resto de empleados públicos. 
6. EJEMPLO DE PROYECTO PILOTO DE TELETRABAJO EN LA ADMINISTRACIÓN LOCAL.

El Acuerdo Marco Europeo sobre teletrabajo ${ }^{696}$, firmado el 16 de julio de 2002 en Bruselas, invita a los interlocutores sociales a negociar acuerdos de trabajo flexible para modernizar la organización del trabajo con el objetivo de mejorar la productividad y la competitividad de las empresas y lograr el equilibrio necesario entre flexibilidad y seguridad. Se trata de introducir en los ordenamientos jurídicos de los Estados miembros y en el entorno laboral y social de los trabajadores, soluciones tecnológicas innovadoras al desempeño del servicio público, que pueden contribuir de forma muy positiva a la mejora de la calidad de vida personal y laboral de los trabajadores sin menoscabo de su productividad.

En este sentido, la Disposición final sexta de la LOIMH, habilita al Ministerio de Administraciones Públicas, actual Ministerio de Política Territorial, para regular antes del 1 de marzo de 2008 las condiciones del teletrabajo en la Administración General del Estado. Así, la Orden APU/1981/2006 de 21 de

\footnotetext{
${ }^{696} \mathrm{http}$ // / europa.eu/legislation_summaries/employment_and_social_policy/em ployment_rights_and_work_organisation/c10131_es.htm
} 
junio $^{697}$, ha sido la primera norma que, en línea con el Acuerdo Marco sobre teletrabajo firmado en Bruselas, ha abierto las puertas a la posibilidad de teletrabajo en la Administración General del Estado.

En la Administración de la Comunidad Autónoma de Castilla y León, la Orden ADM/2154/2009 de 17 de noviembre, sobre el Programa Experimental de Teletrabajo «Trabaja desde casa» ${ }^{698}$, señala que el teletrabajo consiste en utilizar las tecnologías de la información para independizar al trabajador del lugar físico en el que se encuentra. Se define como toda modalidad de prestación de servicios en la que se desarrolla una parte de la jornada laboral de forma no presencial y desde un puesto de trabajo ubicado fuera de las dependencias de la Administración ${ }^{699}$. Constituye así una forma de organización que permite establecer modalidades de prestación de servicios diferentes a la presencial y con ello favorecer la conciliación de la vida personal y familiar con la laboral. Quedan excluidos de la participación en este programa los empleados públicos que ocupen puestos de trabajo en oficinas de registro, atención e información al público, así como todos aquellos que presten servicios presenciales y los que ocupen puestos de libre designación ${ }^{700}$. De tal forma que los únicos puestos susceptibles de ser desempeñados en esta modalidad de

\footnotetext{
${ }^{697}$ Boletín Oficial del Estado núm. 149 de 23 de junio de 2006.

${ }^{698}$ Boletín Oficial de la Junta de Castilla y León núm. 223 de 20 de noviembre de 2009.

${ }^{699}$ Artículo 2 Orden ADM/2154/2009 de 17 de noviembre.

700 Artículo 3.2 Orden ADM/2154/2009 de 17 de noviembre.
} 
teletrabajo son los relacionados con las funciones de estudio y análisis de proyectos, elaboración de informes, asesoría, redacción, corrección y tratamiento de documentos, inspección, mantenimiento de sistemas de información y tratamiento de información ${ }^{701}$.

Por lo que respecta a la Administración local, la implantación de proyectos piloto de teletrabajo puede guiarse por las experiencias desarrolladas por la Administración General del Estado y la Administración Autonómica. En el caso del Ayuntamiento de Salamanca el II Plan de Igualdad entre hombres y mujeres de Salamanca para el periodo 2009-2013, ha previsto como líneas estratégicas de actuación la celebración de jornadas de debate sobre el teletrabajo, por lo que se deduce, que se trata de una medida de carácter promocional, y por tanto, pendiente de desarrollo concreto. En otras ocasiones podemos encontrar algunas muestras de interés por el teletrabajo en ordenanzas, por ejemplo, en la Ordenanza de Administración Electrónica de la Diputación de Salamanca ${ }^{702}$ se hace una mención al teletrabajo en la Disposición Final quinta como una medida de conciliación de la vida personal y laboral de los trabajadores, aunque sea fuera de su articulado. Sin embargo, se echa en falta que en el Acuerdo Marco para el personal funcionario y en el Convenio colectivo para el personal laboral de la Diputación ${ }^{703}$ no se haya regulado todavía.

\footnotetext{
701 Artículo 6 Orden ADM/2154/2009 de 17 de noviembre.

702 Boletín Oficial de la Provincia de Salamanca núm. 86 de 8 de mayo de 2012.

703 Boletín Oficial de la Provincia de Salamanca núm. 99 de 25 de mayo de 2005.
} 
Aquí proponemos el desarrollo de un proyecto de teletrabajo en la Administración Local tomando como referencia el Manual para la implantación de Programas piloto de teletrabajo en la Administración General del Estado elaborado por el anterior Ministerio de Administraciones Públicas ${ }^{704}$, así como los resultados de las primeras jornadas sobre teletrabajo organizadas por la fundación telefónica, ya que aunque estas últimas se refieren a la empresa privada, considero que son de gran interés a la hora de inspirar este tipo de proyectos en la Administración Pública ${ }^{705}$.

Desde un punto de vista administrativo deberán observarse las disposiciones generales sobre los procedimientos administrativos previstas en los artículos 68 y siguientes de la Ley 30/1992 de 26 de noviembre de Régimen Jurídico de las Administraciones Públicas y del Procedimiento Administrativo Común ${ }^{706}$. Según esta Ley, el procedimiento para la implantación de un proyecto piloto de teletrabajo se iniciará de oficio por acuerdo del órgano competente, en este caso el Presidente de la Diputación, en virtud de las funciones de dirección del gobierno y la administración de la Provincia que le atribuye el artículo 34.1 letra a) de la Ley 7/1985 de 2 de abril, Reguladora de las Bases del

\footnotetext{
${ }_{704}$ Dicho Manual puede ser consultado en la siguiente dirección electrónica http://www.seap.minhap.gob.es/dms/es/areas/funcion_publica/iniciativas/m ejora_de_la_administracion_general_del_estado/funcion_publica/concilia/med idas/teletrabajo/Manual-Teletrabajo.

${ }^{705} \mathrm{http}$ // / sociedadinformacion.fundacion.telefonica.com/docs/repositorio//es _ES//TelefonicaySI/Publicaciones/teletrabajo.pdf

706 Boletín Oficial del Estado núm. 285 de 27 de noviembre de 1992.
} 
Régimen Local $^{707}$. Con anterioridad al acuerdo de iniciación, sería conveniente abrir un periodo de información previa ${ }^{708}$ con el fin de estudiar las necesidades de flexibilidad de los empleados públicos para conciliar su vida personal y familiar con la profesional, y la percepción que éstos tienen hacia el teletrabajo como herramienta para alcanzar dicha flexibilidad. Esto permitirá determinar la conveniencia o no de iniciar el procedimiento para la implantación del proyecto piloto de teletrabajo.

Una vez constatada la necesidad de mayor flexibilidad en la prestación laboral y el interés de los trabajadores en participar de manera voluntaria en el proyecto piloto de teletrabajo, hay que planificar adecuadamente las actuaciones necesarias para su puesta en marcha. Para ello habrá que redactar un programa en el que se definan su contenido y ámbito de aplicación. También se deberán justificar las razones por las cuales a esa Administración le interesa introducir el teletrabajo como forma de prestar los servicios públicos, reflejar los objetivos perseguidos, la duración del proyecto piloto con indicación de las fases y los tiempos necesarios para su implantación, la metodología aplicable, las áreas que se considera más adecuadas para participar en el proyecto, así como los puestos de trabajo que se verán afectados dentro de la misma, el número de personas implicadas y los criterios de selección de cada una de ellas, el modelo de teletrabajo a seguir

\footnotetext{
707 Boletín Oficial del Estado núm. 80 de 3 de abril de 1985.

708 Artículo 69.2 de la Ley 30/92 de 26 de noviembre.
} 
especificando la distribución de la jornada de trabajo, el equipamiento necesario, las necesidades formativas de los participantes, así como un análisis de los costes y de los beneficios derivados de la modificación sustancial en los conceptos tradicionales de tiempo y espacio laboral que el teletrabajo lleva aparejados.

Redactado el documento de planificación del proyecto de teletrabajo, y una vez que se cuenta no sólo con el interés de los trabajadores sino también con el compromiso del personal funcionario o laboral que ocupe puestos directivos y de la autoridad pública responsable con capacidad de decisión en la materia, se presentará la propuesta que permitirá la iniciación formal del procedimiento.

Tras ello comienza la fase de instrucción que comprende los actos necesarios para la determinación, conocimiento y comprobación de los datos en virtud de los cuales debe pronunciarse la resolución que apruebe la implantación del teletrabajo en la Administración. Nos referimos a la emisión de los informes jurídico y técnico, en los que se estudie la viabilidad del proyecto desde el punto de vista legislativo, económico y técnico, que se juzguen necesarios para resolver. En esta fase se creará un equipo de trabajo que dinamice y supervise el proyecto piloto, involucrando a los representantes de los trabajadores, dándoles audiencia como parte interesada en el procedimiento. Este equipo 
contribuirá a solucionar los problemas que puedan surgir en la implantación y desarrollo del programa, realizando un seguimiento del mismo y evaluando continuamente sus resultados.

La fase final es la resolución motivada del procedimiento y su puesta en marcha dentro del Área elegida de entre todas las que integran la Corporación. Para ello se informará al personal y a las distintas Áreas del Organismo por medios que garanticen su difusión a todo el personal, se llevará a cabo la selección de los trabajadores con arreglo a los criterios definidos en el programa piloto, se designará al supervisor del programa, que normalmente coincidirá con el superior jerárquico de la persona que teletrabaje, y que ocupará de la coordinación del trabajo de los teletrabajadores, de la planificación de los objetivos a alcanzar en el trabajo, definiendo las herramientas internas a utilizar y los tiempos óptimos para la realización de las tareas, facilitando la resolución de dudas, conflictos y evaluando la consecución de los objetivos planificados inicialmente.

Concluido el Programa, debe realizar la evaluación de sus resultados de acuerdo con los sistemas que se hayan aprobado en la propuesta del Programa Piloto. Los factores de satisfacción deberán regularse en el documento inicial y pueden ser los relacionados con el incremento de la productividad, la mejora de la satisfacción en el trabajo, mejora del equilibrio entre tiempo de trabajo y tiempo libre, reducción de costes y gastos generales, entre 
otros. Serán evaluados tanto los aspectos subjetivos, mediante encuestas de satisfacción que permitan extraer conclusiones sobre cómo ha facilitado el teletrabajo la conciliación de la vida laboral y la familiar, como los objetivos, referidos a la cantidad y calidad del trabajo por parte de los supervisores. Los supervisores deberán evaluar cualitativamente la incidencia del teletrabajo sobre cómo ha afectado al funcionamiento del Organismo que corresponda. Finalizada la experiencia piloto y si los resultados han sido positivos, se estaría en condiciones de planificar el ajuste y extensión del programa a otras Áreas de la Administración, siguiéndose los mismos trámites, y completando su regulación a través de la negociación colectiva.

Los puestos directivos tienen una gran responsabilidad a la hora de promover el teletrabajo y favorecer así el cambio de mentalidad organizativa de la Administración, contribuyendo a su modernización sin perder de vista que siempre tiene que actuar movida por el interés general. La imposibilidad de supervisión directa del trabajo desarrollado por los teletrabajadores, las posibles dificultades iniciales en la implantación del teletrabajo como las deficiencias en el intercambio de información o retrasos en la toma de decisiones, o el problema de mantener la confidencialidad de los procedimientos e información de la entidad, no son obstáculos insalvables. Con directivos públicos con capacidad para motivar a los trabajadores a distancia y hacerles partícipes de los objetivos de la entidad, sin que se produzca una 
pérdida de la atmósfera del trabajo en equipo, el teletrabajo es una vía muy interesante para conseguir ese cambio que los dirigentes políticos persiguen en el funcionamiento de la Administración, ya que permite establecer sistemas de evaluación del trabajo relacionados con el desempeño de las tareas, tal y como contempla el artículo $20 \mathrm{EBEP}^{709}$. También es muy importante potenciar la comprensión de la Ley Orgánica 15/99 de 13 de diciembre de Protección de Datos de Carácter Personal ${ }^{710}$, ya que su desconocimiento hace que se vean problemas de falta de confidencialidad donde realmente no los hay si se implementa una adecuada política de protección de datos ${ }^{711}$.

709 Sierra Benítez, Esperanza Macarena. El contenido de la relación laboral en el teletrabajo. Consejo Económico y Social de Andalucía. Sevilla, 2011, pág. 128.

${ }^{710}$ Boletín Oficial del Estado núm. 298 de 14 de septiembre de 1999.

${ }^{711}$ El artículo 9 y el 10 de la Ley Orgánica 15/99 se refieren a la seguridad de los datos y al deber de secreto profesional respecto de los datos de carácter personal. 



\section{$\mathrm{X}$ - CONCLUSIONES.}

Históricamente la mujer ha ocupado una posición en la sociedad de inferioridad con respecto al hombre. Salvo contadas excepciones, el sexo ha implicado una vida económica, política, legal y moral, distinta y subordinada para ellas. La experiencia y reflexión personal de las mujeres sobre su situación, supone un despertar de las conciencias individuales y colectivas y alienta el espíritu de las primeras reivindicaciones feministas. Con el paso del tiempo, gracias al trabajo desarrollado desde la Filosofía, la Sociología o el Derecho, la mejora de la condición de la mujer como miembro independiente de la sociedad es una realidad evidente. Sin embargo, las discriminaciones se seguirán produciendo mientras no cambie el sistema de género por el que nos regimos de manera más o menos voluntaria, que sigue amparando estereotipos sexuales perjudiciales para la igualdad real y efectiva entre mujeres y hombres. Para ello resulta crucial incidir en la relación entre los sexos en el ámbito doméstico, a través de políticas públicas que fomenten una mayor participación y asunción de responsabilidades en este terreno por parte de los hombres y promocionando el ejercicio de los derechos que permiten conciliar la vida familiar con la laboral por su parte. Asimismo, es imprescindible avanzar en un cambio real y no sólo teórico, en la mentalidad organizativa dentro la Administración, fomentando las relaciones entre los empleados públicos basadas 
en la cooperación y desarrollando, de una vez por todas, formas de prestación de los servicios públicos centradas en la consecución eficiente de los objetivos propuestos, más que en la insana competitividad y en la presencia improductiva en el centro de trabajo.

La igualdad como valor superior del ordenamiento jurídico es el fundamento filosófico de aquellas normas aprobadas con el objetivo de equilibrar la relación entre hombres y mujeres. El estudio de esta vertiente de la igualdad refleja la moral que subyace en la actividad legislativa de los poderes públicos y que está sometida a constante evolución histórica. Es la forma de enlazar la perspectiva histórica-filosófica y la sociológica-cultural con uno de los posibles conceptos de igualdad de nuestro ordenamiento jurídico. Asimismo la igualdad aparece como un principio general del derecho que limita la acción de los poderes públicos y de los ciudadanos; y finalmente como un derecho fundamental a no ser discriminado por razón de sexo.

El planteamiento del derecho a la igualdad está condicionado por el modelo de Estado. En el Estado liberal la igualdad conlleva la abolición de privilegios. En el Estado social el derecho fundamental a la igualdad no se limita a una mera exigencia de igualdad formal de trato, sino que aparece como un derecho a la prohibición de la discriminación, es decir, un derecho a ser tratado de manera desigual para conseguir ser materialmente 
igual. La exigencia de razonabilidad en el trato diferenciado, la de la proporcionalidad de las medidas en la diferenciación legal, y el término de comparación de las situaciones de igualdad han contribuido a delimitar el concepto y el contenido del derecho de igualdad.

Particularmente la igualdad de género no sería posible sin el Estado social, en el que la igualdad formal se complementa con la igualdad material, que implica una desigualdad de derecho para llegar a la igualdad de hecho. El ejemplo más claro de esta forma de proceder son las acciones positivas, consideradas como un medio válido y amparado por el ordenamiento jurídico para avanzar en la igualdad entre hombres y mujeres de manera real y efectiva. A pesar de las críticas, las acciones positivas mejoran la cohesión social integrando en la sociedad a aquellas personas que se encuentran en una posición de desventaja por la mera pertenencia a un colectivo determinado. En relación con el sexo, es preciso aplicarlas de manera neutral, no solo para disminuir el rechazo hacia las mismas y hacia las mujeres que se benefician de ellas, sino también para aumentar el uso que puede hacerse de ellas. Es decir, que en aquellos ámbitos en los que la presencia masculina sea menor, aplicar acciones positivas, y no sólo cuando la infrarrepresentación sea femenina.

Para que la igualdad sea realmente tal y no un concepto carente de eficacia es preciso forjarlo en normas jurídicas. El 
derecho a la igualdad reconocido en el artículo 14 CE, ocupa una posición central en el conjunto de los derechos fundamentales regulados en la Constitución. Tanto la jurisprudencia de los Tribunales Europeos como las Directivas Comunitarias, y la propia normativa de los Tratados, ha contribuido de manera importante al desarrollo legislativo del artículo $14 \mathrm{CE}$ y a la inserción de determinados grupos de población e integración en el Estado de Derecho. De todos esos grupos es el género, en relación con el artículo $14 \mathrm{CE}$, el que ha producido una mayor legislación de desarrollo de esta norma, así como resoluciones jurisprudenciales. El papel del Tribunal Constitucional ha sido trascendental en el avance de los derechos de igualdad entre hombres y mujeres, validando cada una de las leyes que han configurado el derecho a la igualdad.

La legislación que se ha producido en materia de género, conlleva un cambio radical en nuestra forma de vida y representa uno de los mayores avances históricos en esta materia. Ese cambio se produce gradualmente, a medida que las normas estatales y autonómicas vayan desarrollándose y se pongan en práctica a través de las correspondientes políticas públicas. Es necesaria una acción decidida por parte de los poderes públicos encaminada a acabar con una serie de estereotipos que continúan vigentes, roles sociales asumidos por las mujeres desde tiempos inmemoriales y que van más allá de las desigualdades basadas únicamente en el sexo. La Administración Pública, como paradigma de lo público y 
como ente cuyo fin último es servir con objetividad los intereses generales, tiene que asumir la iniciativa de poner en marcha esas políticas públicas de forma transversal, de manera que todas las decisiones políticas incluyan la perspectiva de género y tengan en cuenta el impacto que estas puedan tener para ambos sexos.

La situación en la que se encuentran hombres y mujeres en el empleo público ha mejorado considerablemente desde el Estatuto de López Ballesteros. El análisis del concepto de acceso al empleo público permite identificar aquellos aspectos en los que las carencias en materia de igualdad pasan aún inadvertidas, y que representan un nuevo marco de actuación por parte de la Administración para avanzar hacia la igualdad real y efectiva. Las diferencias entre el régimen jurídico en materia de igualdad aplicable al personal funcionario y laboral que presta sus servicios en la Administración, son prácticamente inexistentes. No sucede lo mismo cuando se trata de personal laboral no perteneciente a la Administración, cuyo acceso al empleo está condicionado por el principio de libertad de empresa.

Los derechos de los empleados y empleadas públicas relacionados con la conciliación de la vida personal y familiar, se centran sobre todo en el tiempo que se deja de trabajar para poder compaginar el trabajo con la vida personal y el cuidado de la familia. Los retos consisten en implicar a los hombres en el ejercicio de estos derechos y en el desarrollo de mecanismos que 
permitan conciliar sin dejar de trabajar, hacer definitivamente compatible trabajo y familia, ya sea mediante propuestas como el teletrabajo, fomentar un servicio de guarderías dentro del centro de trabajo, o hacer compatibles los horarios laborales con los escolares. 




\section{BIBLIOGRAFÍA}

- Agripa, Enrique Cornelio. De la nobleza y preexcelencia del sexo femenino. Índigo, Barcelona, 1999.

- Alexy, Robert. Teoría de los derechos fundamentales. Centro de Estudios Políticos y Constitucionales, Madrid, 2007.

- Álvarez del Cuvillo, Antonio. Elementos para una valoración técnico-jurídica de las medidas de acción positiva. Revista de Relaciones Laborales, núm. 1, 2010.

- Amorós, Celia. Teoría Feminista: de la Ilustración a la Globalización. Minerva, Madrid, 2005.

- Anderson, Bonnie S. y Judith P. Zinsser. Historia de las mujeres. Una historia propia. Crítica, Barcelona, 1991.

- Astelarra, Judith. Veinte años de políticas de igualdad. Cátedra, Madrid, 2009.

- Balaguer Callejón, M $\mathrm{M}^{\mathrm{a}}$ Luisa. Igualdad y Constitución Española. Tecnos, Madrid, 2010.

- Ballester Pastor, $\mathrm{M}^{\mathrm{a}}$ Amparo. La transposición del principio antidiscriminatorio comunitario al ordenamiento jurídico laboral español. Tirant lo Blanch, Valencia, 2010.

- Boccaccio, Giovanni. Mujeres preclaras. Cátedra, Madrid, 2010.

- Bock, Gisela. La mujer en la historia de Europa. Crítica, Barcelona, 2001. 
- Bonino Covas, Carla y Jorge Aragón Medina. La negociación colectiva como instrumento para la igualdad laboral entre mujeres $y$ hombres. Ministerio de Trabajo y Asuntos Sociales, Madrid, 2003.

- Bourdieu, Pierre. La dominación masculina. Anagrama, Barcelona, 2000.

— Bourdieu, Pierre. Cuestiones de sociología. Istmo, Madrid, 2003.

- Butler, Judith. El género en disputa. El feminismo y la subversión de la identidad. Paidós, Barcelona, 2001.

- Cabero Morán, Enrique. Relaciones laborales e igualdad efectiva de mujeres y hombres, en Figueruelo Burrieza, Ángela, $\mathrm{M}^{\mathrm{a}}$ Luisa Ibáñez Martínez y Rosa Ma Merino Hernández, coordinadoras. Igualdad ¿para qué? A propósito de la Ley Orgánica de Igualdad Efectiva de Mujeres y Hombres. Comares, Granada, 2007.

- Cabero Morán, Enrique, Ascensión García Trascasas y Justo Reguero Celada. Consideración especial del impacto de la Ley Orgánica 3/2007 en el sistema normativo e institucional del Espacio Europeo de Educación Superior en España, en Palomeque López, Manuel Carlos, director. Igualdad efectiva de mujeres y hombres. Un estudio sobre el impacto institucional de la aplicación de la Ley Orgánica 3/2007, de 22 de marzo, para la igualdad efectiva de mujeres y hombres, en el sistema español de relaciones laborales y de protección social (20082009). Ratio Legis, Salamanca, 2011.

- Carrasco Canals, Carlos. La burocracia en la España del siglo XIX. Instituto de Estudios de Administración Local, Madrid, 1975. 
- Castells, Manuel. La Era de la Información. Volumen I. La Sociedad Red. Alianza, Madrid, 1997.

- Castells Oliván, Manuel y Marina Subirats Martori. Mujeres y hombres ¿un amor imposible? Alianza, Madrid, 2007.

- Corte Heredero, Nieves. Breviario de Jurisprudencia Constitucional en Materia Laboral: El Derecho a la Igualdad (art. 14 CE), y la Garantía de Indemnidad (art. 24.1 CE). Aranzadi, Cizur Menor, 2011.

- Crampe-Casnabet, Michelle. Las mujeres en las obras filosóficas del siglo XVIII, en Duby, Georges y Michelle Perrot, directores. Historia de las mujeres en Occidente. Volumen III: Del Renacimiento a la Edad Moderna. Taurus, Madrid, 2003.

- Cruz Villalón, Jesús. La Igualdad de Trato en el Derecho Comunitario Laboral. Aranzadi, Cizur Menor, 1997.

- Dalarun, Jacques. La mijer a ojos de los clérigos, en Duby, Georges y Michelle Perrot, directores. Historia de las mujeres en Occidente. Volumen II: La Edad Media. Taurus, Madrid, 2003.

- Davara Rodríguez, Miguel Ángel. Acceso electrónico de los ciudadanos a los servicios públicos. El Consultor de los Ayuntamientos (La Ley), Madrid, 2010.

- De la Barre, Poullain. De l'excellence des hommes contre l'égalité des sexes. Jean du Puis, Paris, 1675.

— De Beauvoir, Simone. El segundo sexo. Cátedra, Madrid, 2011. 
- De Condorcet, Nicolas. Sobre las admisión de las mujeres al derecho de ciudadanía, en Puleo, Alicia. La Ilustración olvidada. La polémica de los sexos en el siglo XVIII. Anthropos, Madrid, 1993.

- De Gouges, Olympe. Declaración de los derechos de la mujer y de la ciudadana, en Puleo, Alicia. La Ilustración olvidada. La polémica de los sexos en el siglo XVIII. Anthropos, Madrid, 1993.

- De Luna, Álvaro. Libro de las virtuosas e claras mugeres. Cátedra, Madrid, 2009.

- De Madariaga, Salvador. Mujeres españolas. Espasa-Calpe, Madrid, 1972.

- De Pizán, Cristina. La Ciudad de las Damas. Siruela, Madrid, 2000.

- Descartes, René. Discurso del método. Ediciones Orbis, Barcelona, 1983.

- Díaz Revorio, Francisco Javier. Valores superiores e interpretación constitucional. Centro de Estudios Políticos y Constitucionales, Madrid, 1997.

- Druesne, Gérard. Droit et Politiques de la Communauté et de l'Union Européennes. Presses Universitaires de France, París, 1998.

- Duby, Georges y Michelle Perrot. Historia de las mujeres en Occidente. Taurus, Madrid, 2003.

- Durkheim, Émile. Las reglas del método sociológico. Morata, Madrid, 1993.

- Fabregat Monfort, Gemma. La discriminación de género en el acceso al mercado de trabajo. La posibilidad de una nueva tutela a la luz de la 
Ley Orgánica 3/2007 de 22 de marzo para la igualdad efectiva de mujeres y hombres. Tirant lo Blanch, Valencia, 2008.

- Feijoo, Benito. Teatro crítico universal. Joaquín Ibarra, Madrid, 1778.

- Fernández Domínguez, Juan José y Susana Rodríguez Escanciano. La Negociación Colectiva de los Funcionarios Públicos. Centro de Estudios de Derecho, Economía y Ciencias Sociales, Barcelona, 1996.

- Fernández Domínguez, Juan José y Susana Rodríguez Escanciano. Hacia un nuevo régimen jurídico del personal al servicio de las administraciones públicas. Instituto Andaluz de Administración Pública, Sevilla, 2006.

- Fernández Domínguez, Juan José y Susana Rodríguez Escanciano. El acceso al empleo público. Centro de Estudios Financieros, Madrid, 2005.

- Fernández Villanueva, Concepción. Feminismos, masculinismos e individualismos: el futuro de la igualdad de género, en Quintero Soto, María Luisa y Carlos Fonseca Hernández, coordinadores. Investigaciones sobre el género. Aspectos conceptuales y metodológicos. Porrúa, México D.F., 2008.

- Folguera Crespo, Pilar. Revolución y Restauración. La emergencia de los primeros ideales emancipadores (1868-1931), en Garrido González, Elisa, directora. Historia de las mujeres en España. Síntesis, Madrid, 1997. 
- Folguera Crespo, Pilar. La II República. Entre lo privado y lo público (1931-1939), en Garrido González, Elisa, directora. Historia de las mujeres en España. Síntesis, Madrid, 1997.

- Foucault, Michel. Historie de la sexualité. Gallimard, Paris, 1976.

- Fraisse, Geneviève. Del destino social al destino personal. Historia filosófica de la diferencia de los sexos, en Duby Georges y Michelle Perrot, directores. Historia de las mujeres en Occidente. Volumen IV: El siglo XIX. Taurus, Madrid, 2003.

- Gallardo Moya, Rosario. El viejo y el nuevo trabajo a domicilio. De la máquina de hilar al ordenador. Ediciones Ibidem, Madrid, 1998.

- García de Enterría, Eduardo y Tomás Ramón Fernández. Curso de Derecho Administrativo I. Aranzadi, Cizur Menor, 2011.

- García-Perrote Escartín, Ignacio y Jesús R. Mercader Uguina. Ley de Igualdad: consecuencias prácticas en las relaciones laborales y en la empresa. Lex Nova, Valladolid, 2007.

- García Romero, Belén. El Teletrabajo. Aranzadi, Cizur Menor, 2012.

- Giddens, Anthony. Las nuevas reglas del método sociológico. Crítica positiva de las sociologías comprensivas. Amorrortu, Buenos Aires, 2011.

— Giddens, Anthony. Sociología. Alianza, Madrid, 2012.

- Godino Reyes, Martín. El contrato de trabajo en la Administración Pública. Cívitas, Madrid, 1996.

- Goffman, Erving. La presentación de la persona en la vida cotidiana. Amorrortu, Buenos Aires, 1997. 
- González Antón, Ricardo. Estatutos Históricos de los funcionarios de la Administración Civil del Estado. Ministerio de Administraciones Públicas, Madrid, 1996.

— Goñi Sein, José Luis. Ponencias XIX Congreso Nacional de Derecho del Trabajo y de la Seguridad Social "El Estatuto Básico del Empleado Público". Ponencia temática primera "Ámbito subjetivo de aplicación del Estatuto. Concepto y clases de empleado público. Adquisición y pérdida de la relación de servicio”. Laborum, Murcia, 2008.

- Guilbert, Madeleine y Viviane Isambert-Jamati. Travail féminin et travail à domicile. Centre National de la Recherche Scientifique, Paris, 1956.

- Harris, Marvin. Introducción a la antropología general. Alianza, Madrid, 2013.

- Jagoe, Catherine. La mujer en los discursos de género: textos y contextos en el siglo XIX. Icaria, Barcelona, 1998.

- Jimenez Asensio, Rafael. Politicas de selección de la función pública española (1808-1978). Instituto Nacional de Administración Pública, Madrid, 1989.

- Jimena Quesada, Luis. La Europa social y democrática de Derecho. Dykinson, Madrid, 1997.

- Lalinde Abadía, Jesús. Los medios personales de gestión del poder público en la historia española. Estudios de Historia de la Administración. Instituto de Estudios Administrativos, Madrid, 1970. 
- Larraña, Enrique. La construcción de los movimientos sociales. Alianza, Madrid, 1999.

- López Gómez, José Manuel. La relación laboral especial de empleo público. Estudio de su régimen jurídico tras el Estatuto Básico del Empleado Público. Aranzadi, Cizur Menor, 2009.

- López-Romero González, Mª Piedad. El largo camino hacia la igualdad en la clasificación y promoción profesionales, en Wilfredo Sanguineti Raymond, director y $\mathrm{M}^{\mathrm{a}}$ Luisa Martín Hernández, coordinadora. Propuestas para la igualdad de género en la negociación colectiva. Estudio a partir de la negociación colectiva en Castilla y León. Bomarzo, Albacete, 2011.

- Loraux, Nicole. ¿Qué es una diosa?, en Duby, Georges y Michelle Perrot, directores. Historia de las mujeres en Occidente. Taurus, Madrid, 2003.

- Lousada Arochena, José Fernando. Ley de Igualdad y Contrato de Trabajo: modificaciones del Estatuto de los Trabajadores, Seguridad Social, infracciones y sanciones, prevención de riesgos y procedimiento laboral. Francis Lefebvre, Madrid, 2007.

- Llamas Cascón, Ángel. Los valores jurídicos como ordenamiento material. Universidad Carlos III y Boletín Oficial del Estado, Madrid, 1993.

- Martin, Georges. Berenguela de Castilla (1214-1246): en el espejo de la historiografía y su época, en Morant, Isabel. Historia de las mujeres en España. Cátedra, Madrid, 2005.

- Martin, Georges. Mujeres y poderes en la España medieval. Centro de Estudios Cervantinos, Alcalá de Henares, 2011. 
- Mercader Uguina, Jesús R. Esquemas de Derecho Social de la Unión Europea. Tirant lo Blanch, Valencia, 2010.

- Mill, John Stuart. El sometimiento de las mujeres. Edaf, Madrid, 2005.

— Mill, John Stuart y Harriet Taylor Mill. Ensayos sobre la igualdad sexual. Antonio Machado Libros, Madrid, 2000.

— Molière. Les Précieuses ridicules. Gallimard, Paris, 1998.

- Montoya Melgar, Alfredo. El derecho del trabajo como instrumento de igualdad de mujeres y hombres, en Sánchez Trigueros, Carmen, directora. La Presencia Femenina en el Mundo Laboral: Metas y Realidades. Aranzadi, Cizur Menor, 2006.

- Moore, Henrietta L. Antropología y feminismo. Cátedra, Madrid, 2009.

- Mora Ruiz, Manuela. Formación y objeto del Derecho antidiscriminatorio de género: perspectiva sistemática de la igualdad desde el Derecho público. Editorial Atelier, Barcelona, 2010.

- Morant, Isabel. Historia de las mujeres en España. Cátedra, Madrid, 2005.

- Nevado Fernández, M ${ }^{\mathrm{a}}$ José. El derecho a la igualdad y no discriminación por género en las relaciones de trabajo, en Figueruelo Burrieza, Ángela, coordinadora. Las mujeres en la Constitución Europea: estudios multidisciplinares de género. Universidad de Salamanca, Salamanca, 2005.

- Nevado Fernández, Ma José. La igualdad a través de los planes: de los planes "para" la igualdad a los planes "de", en Figueruelo 
Burrieza, Ángela, directora y $\mathrm{M}^{\mathrm{a}}$ Luisa Martín Hernández, coordinadora. Perspectiva de género en la negociación colectiva: análisis por sectores feminizados y masculinizados. Bomarzo, Albacete, 2013.

- Nevado Fernández, María José. Tiempo de trabajo y género, en Escudero Rodríguez, Ricardo José, coordinador. Observatorio de la negociación colectiva: empleo público, igualdad, nuevas tecnologías y globalización. Cinca, Madrid, 2010.

- Nevado Fernández, María José. La protección de la trabajadora victima de violencia de género. Relaciones laborales: Revista crítica de teoría y práctica, ISSN 0213-0556, Nº 2, 2009.

- Nevado Fernández, María José. El cuidado legal de personas a cargo de trabajadores (maternidad y parentalidad en las relaciones de trabajo y de seguridad social). Civitas. Revista española de derecho del trabajo, ISSN 0212-6095, No 106, 2001.

- Nevado Fernández, María José. El cuidado legal de personas a cargo de trabajadores (Maternidad y parentalidad en las relaciones de trabajo y de seguridad social) (1). Civitas. Revista española de derecho del trabajo, ISSN 0212-6095, No 105, 2001.

- Nieto, Alejandro. Estudios históricos sobre Administración y Derecho Administrativo. Instituto Nacional de Administración Pública, Madrid, 1986.

- Nieto, Alejandro. La retribución de los funcionarios en España. Ediciones de la Revista de Occidente, Madrid, 1967.

- Núñez-Cortés Contreras, Pilar. Nociones básicas sobre igualdad en las relaciones laborales. Guía para la empresa y Administraciones Públicas. Tecnos, Madrid 2009. 
- Núñez-Cortés Contreras, Pilar, Teresa Velasco Portero y Amparo Garrigues Jiméne. Igualdad y conciliación de vida personal y laboral en la empresa y administraciones públicas (tras las modificaciones introducidas por la Ley 3/2007, para la Igualdad Efectiva de Mujeresy Hombres y la Ley 7/2007, del Estatuto Básico del Empleado Público. Dykinson, Madrid, 2008.

— Ortega López, Margarita. Siglo XVIII: La Ilustración, en Garrido González, Elisa, directora. Historia de las mujeres en España. Síntesis, Madrid, 1997.

- Palomeque López, Manuel Carlos. Los derechos laborales en la Constitución Española. Centro de Estudios Constitucionales, Madrid, 1991.

- Palomeque López, Manuel Carlos. Derechos fundamentales generales y relación laboral: los derechos laborales inespecíficos, en Sempere Navarro, Antonio, director. El modelo social en la Constitución Española de 1978. Ministerio de Trabajo y Asuntos Sociales, Madrid, 2003.

- Palomeque López, Manuel Carlos. El derecho constitucional de igualdad y no discriminación y su contenido esencial en el sistema de relaciones de trabajo y de protección social, en Palomeque López, Manuel Carlos, director. Igualdad efectiva de mujeres y hombres. Un estudio sobre el impacto institucional de la aplicación de la Ley Orgánica 3/2007, de 22 de marzo, para la igualdad efectiva de mujeres y hombres, en el sistema español de relaciones laborales y de protección social (20082009). Ratio Legis, Salamanca, 2011. 
- Palomeque López, Manuel Carlos. La construcción jurídica del contrato de trabajo, en Rojas Rivero, Gloria, coordinadora. Orígenes del contrato de trabajo y nacimiento del Sistema de Protección Social. Bomarzo, Albacete, 2012.

- Palomeque López, Manuel Carlos y Manuel Álvarez de la Rosa. Derecho del Trabajo. Editorial Universitaria Ramón Areces, Madrid, 2013.

- Palomeque López, Manuel Carlos. El papel de la negociación colectiva en pro de la igualdad efectiva de la mujer trabajadora, a enjuiciamiento, en Figueruelo Burrieza, Ángela, directora y $\mathrm{M}^{\mathrm{a}}$ Luisa Martín Hernández, coordinadora. Perspectiva de género en la negociación colectiva: análisis por sectores feminizados y masculinizados. Bomarzo, Albacete, 2013.

- Parsons, Talcott y Robert F. Bales. Family, Socialization and Interaction Process. Routledge and Kegan Paul Ltd., Londres, 1956.

- Peces Barba, Gregorio. Los valores superiores. Colección Temas clave de la Constitución Española. Tecnos. Madrid, 1984.

- Pérez de los Cobos Orihuela, Francisco. Nuevas tecnologías y relación de trabajo. Tirant lo Blanch, Valencia, 1990.

- Pérez Luño, Antonio Enrique. Dimensiones de la Igualdad. Editorial Dykinson, Madrid, 2007.

- Pérez Pérez, Manuela. El teletrabajo: efectos en la conciliación de la vida familiar y laboral. Fundear, Zaragoza, 2008. 
- Pérez del Río, Teresa. Mujer e Igualdad: estudio en materia social y laboral. Instituto Andaluz de la Mujer, Sevilla, 1999.

- Pérez Royo, Javier. Curso de Derecho Constitucional. Marcial Pons Ediciones Jurídicas, Madrid, 1994.

- Posada, Adolfo. Feminismo. Librería de Fernando Fé, Madrid, 1899.

- Puñet Gómez, Pilar. Las medidas para la promoción de la igualdad efectiva en la función pública, en Sala Franco, Tomás, coordinador. Comentarios a la Ley Orgánica 3/2007 de 22 de marzo para la Igualdad Efectiva de Mujeres y Hombres. La Ley, Madrid, 2008.

- Rawls, John. Teoría de la justicia. Fondo de Cultura Económica, México D.F., 2010.

- Redondo García, Ana Mª Algunas consideraciones en torno a la anunciada Reforma Constitucional. Parlamento y Constitución. Anuario, ISSN 1139-0026, No 8, 2004.

- Redondo García, Ana Ma. Igualdad en la Ley y juicio de constitucionalidad, en Pérez Tremps, Pablo, coordinador. La Reforma del Tribunal Constitucional. Actas del $V$ Congreso de la Asociación de Constitucionalistas de España. Tirant lo Blanch, Valencia, 2007.

- Régnier-Bohler, Danielle. Voces literarias, voces místicas, en Duby, Georges y Michelle Perrot, directores. Historia de las mujeres en Occidente. Volumen II: La Edad Media. Taurus, Madrid, 2003. 
- Reguero Celada, Justo y Ascensión García Trascasas. Hacia la Igualdad Efectiva entre Hombres y Mujeres (Estudios). Comares, Granada, 2008.

- Rey Martínez, Fernando. El derecho fundamental a no ser discriminado por razón de sexo. Mc Graw-Hill, Madrid, 1995.

- Rodríguez Escanciano, Susana. Parto múltiple y acumulación del permiso de lactancia tras la Ley 3/2007, de 22 de maryo, de igualdad efectiva entre hombres y mujeres. Aranzadi Social: Revista Doctrinal, ISSN 1889-1209, Vol. 1, N. 19 (Mar), 2009.

- Rodríguez Escanciano, Susana. La excedencia por razones familiares : una realidad jurídica necesitada de mayor protección social. Anuario da Facultade de Dereito da Universidade da Coruña, ISSN 1138-039X, No 11, 2007.

- Rodríguez Escanciano, Susana. La protección de la funcionaria victima de violencia de género. Tribuna social: Revista de seguridad social y laboral, ISSN 1130-7331, Nº 185, 2006.

- Rodríguez Escanciano, Susana. El permiso por lactancia: dificultades para el disfrute paterno (Comentario a la STSJ Canarias / Las Palmas, de 22 de septiembre de 2003). Estudios financieros. Revista de trabajo y seguridad social: Comentarios, casos prácticos : recursos humanos, ISSN 1138-9532, No. 255, 2004.

- Rodríguez Escanciano, Susana. La conciliación de la vida laboral y familiar en Castilla y León. Revista de investigación económica y social de Castilla y León, ISSN 1575-5835, Nº 7, 2004.

- Rodríguez Escanciano, Susana. La suspensión del contrato de trabajo por maternidad y supuestos asimilados: breves consideraciones tras 
la promulgación del Real Decreto 1251/2001, de 16 de noviembre. Estudios financieros. Revista de trabajo y seguridad social: Comentarios, casos prácticos : recursos humanos, ISSN 11389532, No. 227, 2002.

- Rodríguez Escanciano, Susana. La protección jurídico-laboral de la mujer: luces y sombras. Cedecs, 2002.

- Rodríguez Piñero, Miguel y Mª Fernanda, Fernández López. Igualdad y discriminación. Tecnos, Madrid, 1986.

- Rojas Rivero, Gloria, coordinadora. Orígenes del contrato de trabajo y nacimiento del Sistema de Protección Social. Bomarzo, Albacete, 2012.

- Romeo Mateo, María Cruz. Destinos de mujer: esfera pública y politicos liberales, en Morant, Isabel, directora. Historia de las mujeres en España y América Latina. Volumen III: Del siglo XIX a los umbrales del siglo XX. Cátedra, Madrid, 2008.

- Romero Burillo, Ana Ma Igualdad y Retribución. Tirant lo Blanch, Valencia, 2006.

- Rousseau, Jean Jacques. El contrato social. RBA, Barcelona, 2004.

- Rousseau, Jean Jacques. Discurso sobre el origen y los fundamentos de la desigualdad entre los hombres y otros escritos. Tecnos, Madrid, 2010.

- Rousseau, Jean Jacques. Emilio o De la educación. Alianza, Madrid, 2007. 
- Rubio Llorente, Francisco. Derechos fundamentales y principios constitucionales (Doctrina jurisprudencial). Ariel, Barcelona, 1995.

- Sala Franco, Tomás. Incidencia de la legislación laboral en el marco de la función pública. Instituto Nacional de Administración Pública, Madrid, 1989.

- Sala Franco, Tomás y Ma Amparo Ballester Pastor. Reducción y adaptación de jornada por conciliación. Tirant lo Blanch, Valencia, 2009.

- Saltzman, Janet. Equidad y género: una teoría integrada de estabilidad y cambio. Cátedra, Madrid, 1992.

- Sánchez Morón, Miguel. Derecho de la Función Pública. Tecnos, Madrid, 1997.

- Sánchez Trigueros, Carmen y Antonio V. Sempere Navarro. Comentarios a la Ley Orgánica 3/2007 de 22 de marzo para la Igualdad Efectiva de Mujeres y Hombres. Aranzadi, Cizur Menor, 2008.

- Sanguineti Raymond, Wilfredo. Mecanismos legales de lucha contra la discriminación de la mujer en el trabajo: una revisión crítica, en Martínez Gallego, Eva $M^{\mathrm{a}}$ y Justo Reguero Celada, coordinadores. Mujer y Empleo. Una estrategia para la igualdad. Comares, Granada, 2004.

- Sanguineti Raymond, Wilfredo. La negociación colectiva sobre acceso al empleo de la mujer: el lento avance de la igualdad, en Sanguineti Raymond, Wilfredo, director y $\mathrm{M}^{\mathrm{a}}$ Luisa Martín Hernández, coordinadora. Propuestas para la igualdad de género en la negociación 
colectiva. Estudio a partir de la negociación colectiva en Castilla y León. Bomarzo, Albacete, 2011.

- Santamaría Pastor, Juan Alfonso. Sobre la génesis del Derecho Administrativo Español en el siglo XIX (1812-1845). Instituto García Oviedo. Universidad de Sevilla, Sevilla, 1973.

- Sellas i Benvingut, Ramón. El Régimen Jurídico del Teletrabajo en España. Aranzadi, Cizur Menor, 2001.

- Sempere Navarro, Antonio V. y Rodrigo Martín Jiménez. Claves de la Reforma Laboral de 2012. Estudio de la Ley 3/2012, de 6 de julio y del Real Decreto-Ley 20/2012 de 13 de julio. Aranzadi, Cizur Menor, 2012.

- Sierra Benítez, Esperanza Macarena. El contenido de la relación laboral en el teletrabajo. Consejo Económico y Social de Andalucía, Sevilla, 2011.

- Sissa, Giulia. Filosofías del género: Platón, Aristóteles y la diferencia sexual, en Duby, Georges y Michelle Perrot, directores. Historia de las mujeres en Occidente. Volumen I: La Antigüedad. Taurus, Madrid, 2003.

- Sledziewski, Elisabeth G. Revolución Francesa. El giro, en Duby, Georges y Michelle Perrot, directores. Historia de las mujeres en Occidente. Volumen IV: El siglo XIX. Taurus, Madrid, 2003.

- Tamames, Laura y Ramón Tamames. Introducción a la Constitución Española. Alianza, Madrid, 2003.

- Tierno Galván, Enrique. Leyes Políticas Españolas Fundamentales (1808-1978). Tecnos, Madrid, 1984. 
- Thibault Aranda, Javier. El Teletrabajo. Análisis jurídico-laboral. Consejo Económico y Social, Madrid, 2001.

- Thomas, Yan. La división de los sexos en el derecho romano, en Duby, Georges y Michelle Perrot, directores. Historia de las mujeres en Occidente. Volumen I: La Antigüedad. Taurus, Madrid, 2003.

- Thomasset, Claude. La naturaleza de la mujer, en Duby, Georges y Michelle Perrot, directores. Historia de las mujeres en Occidente. Volumen II: La Edad Media. Taurus, Madrid, 2003.

- Thomson, William y Anna Wheeler. La demanda de la mitad de la raza bumana, las mujeres, contra la pretensión de la otra mitad, los hombres, de mantenerlas en la esclavitud politica, y en consecuencia civil y doméstica. Comares, Granada, 2000.

- Tobío, Constanza. La familia y el empleo: prácticas y discursos de las mujeres, en Radl Philipp, Rita, directora. Cuestiones actuales de sociología del género. Centro de Investigaciones Sociológicas, Madrid, 2001.

- Vélez Sainz, Julio. "De amor, de honor e de donas" Mujer e ideales corteses en la Castilla de Juan II (1406-1454). Editorial Complutense, Madrid, 2013.

- Vivero Serrano, Juan Bautista. El acceso al empleo público en régimen laboral. Tirant lo Blanch, Valencia, 2009.

- Wollstonecraft, Mary. Vindicación de los derechos de la mujer. Cátedra, Madrid, 1994. 
- Wollstonecraft, Mary. La Educación de las Hijas. El Desvelo Ediciones, Santander, 2010.

- Woolf, Virginia. Una babitación propia. Seix Barral, Barcelona, 2011. 


\section{COLECCIONES Y REVISTAS}

- Decretos del Rey nuestro Señor Don Fernando VII. Imprenta Real, Madrid.

- Colección Legislativa de España. Imprenta de la Revista de Legislación, Madrid.

— Revista de Relaciones Laborales. 


\section{JURISPRUDENCIA}

- STC 22/1981 de 2 de julio.

- STC 49/1982 de 14 de julio.

- STC 8/1983 de 18 de febrero.

- STC 75/1983 de 3 de agosto.

- STC 76/1983 de 5 de agosto.

- STC 31/1984 de 7 de marzo.

- STC 83/1984 de 24 de julio.

- STC 14/1985 de 1 de febrero.

- STC 142/1985 de 23 de octubre.

— STC 53/1985 de 11 de abril.

- STC 166/1986 de 19 de diciembre.

- STC 39/1986 de 31 de marzo.

— STC 50/1986 de 23 de abril.

- STC 20/1987 de 19 de febrero.

- STC 19/1987 de 17 de febrero.

- STC 119/1987 de 9 de julio.

- STC 30/1987 de 11 de marzo.

— STC 26/1987 de 27 de febrero.

- STC 99/1987 de 11 de junio.

- STC 128/1987 de 16 de julio. 
- STC 108/1988 de 8 de junio.

- STC 184/1990 de 15 de noviembre.

- STC 30/1991 de 14 de febrero.

— STC 161/1991 de 18 de julio.

- STC 21/1992 de 14 de febrero.

- STC 281/1993 de 27 de septiembre.

- STC 269/1994 de 3 de octubre.

- STC 58/1994 de 28 de febrero.

— STC 173/1994 de 7 de junio.

- STC 88/2001 de 2 de abril.

— STC 214/2006 de 3 de julio.

- STC 181/2012 de 15 de octubre.

— STS de 20 de julio de 1990 (RJ/1990/6141).

— STS de 20 de enero de 1998 (RJ/1998/1000).

— STS de 8 de mayo de 1998 (RJ/1998/4586).

— STS de 4 de mayo de 2000 (RJ/2000/4266).

— STS de 15 de junio de 2005 (RJ/2005/6256).

— STS de 30 de septiembre de 2009 (RJ/2009/7357).

— STSJ de Castilla y León 523/06 de 14 de marzo.

— STSJ, Burgos (Sala de lo Social Sección 1ª) no 523/2012 de 12 de julio.

- SAN 42/2004 de 31 de mayo.

- STJUE de 25 de mayo de 1970, C-80/70.

— STJUE de 8 de abril de 1976, C-43/75. 
— STJUE de 15 de junio de 1978, C-149/77.

— STJUE de 17 de mayo de 1990, C-262/88.

— STJUE de 15 de mayo de 1986, C- 224/84.

— STJUE de 17 de octubre de 1989, C-109/88.

— STJUE de 1 de julio de 1986, C-237/85.

— STJUE de 3 de octubre de 2006, C-17/05.

— STJUE de 17 de octubre de 1995, C-450/93.

- STJUE de 11 de noviembre de 1997, C-409/95.

— STJUE de 28 de marzo de 2000, C-158/97.

- STJUE de 12 de julio de 1984, C-184/83.

— STJUE de 13 de diciembre de 1994, C-297/93.

- STJUE de 1 de febrero de 2005, C-203/03 (Comisión/Austria).

— STJUE de 26 de junio de 2001, C-381/99 (Brunnhofer).

- STJUE de 31 de mayo de 1995, C-400/93 (Royal Copenhaguen).

— STJUE de 22 de abril de 1997, C-18/95 (Nils Draehmpaehl).

- STJUE de 30 de junio de 1988, C-318/86 (Comisión/República francesa).

- STJUE de 22 de noviembre de 2012, el asunto Ebal Moreno (C-385/11).

- STJUE de 4 de octubre de 2001, C-438/99 (caso Jiménez Melgar c. Ayuntamiento de Los Barrios).

- STEDH de 12 de enero de 2006. 